TRANSNATIONALISM FROM BELOW:

AN EXPLORATION OF TRANSNATIONAL ENGAGEMENT BEHAVIOR OF NICARAGUAN IMMIGRANT ENTREPRENEURS

\author{
A Dissertation \\ presented to \\ the Faculty of the Graduate School \\ at the University of Missouri-Columbia \\ In Partial Fulfillment \\ of the Requirements for the Degree \\ Doctor of Philosophy \\ by \\ Andrea Tappmeyer \\ Dr. Stephen Jeanetta, Dissertation Supervisor \\ December 2018
}


The undersigned, appointed by the Associate Vice Chancellor of the Graduate School, have examined the dissertation entitled TRANSNATIONALISM FROM BELOW: AN EXPLORATION OF TRANSNATIONAL ENGAGEMENT BEHAVIOR OF NICARAGUAN IMMIGRANT ENTREPRENEURS

presented by Andrea Tappmeyer, a candidate for the degree of doctor of philosophy and hereby certify that, in their opinion, it is worthy of acceptance.

Professor Stephen Jeanetta

Professor Corinne Valdivia

Professor Hua Qin

Professor David O'Brien 


\section{ACKNOWLEDGEMENTS}

This project would not have been possible without the support, guidance, and encouragement of my family, friends, mentors, and colleagues. I feel incredibly grateful for the network that has guided me through this research as well as those that have helped me manage and balance my professional and personal obligations during this journey.

My husband Yasser has endured over three years of split attention and increased stress levels in our household. He has been an empathetic sounding board and provided me the stability and strength to continue on this path when I doubted myself. Although he has been the compassionate soul I needed, I know he enthusiastically awaited the end of this process so that he could have his wife's presence back on a daily basis. My daughter Sasha, came into our lives at the end of this process. She was born January 23, 2018 and allowed me the health during my pregnancy to work full steam on my research and provided short windows of peace after her birth so that I could garner the last motivation needed to finish this huge project. Her presence drove me to complete my dissertation in order to become a role model to her as she grows into a strong and courageous young woman. I am fortunate to have parents that continuously support and motivate me in the challenges that I take on. My mother encouraged me to pursue this PhD while working full-time when I doubted my ability. She sees me in a light that makes me constantly believe I can do more, follow my passions, and challenges the boundaries that I have placed for myself. My father is a coach and a true motivator. His steadfast loyalty and confidence in my abilities became a foundation for everything I have achieved.

This project would not have been possible without the guidance and instruction from my committee members and professors. I owe a great deal of gratitude to my chair, Dr. Stephen Jeanetta. Dr. Jeanetta dedicated countless hours to helping me hone my 
ideas and later reading through hundreds of pages of my drafts and offering valuable feedback. He guides with a positivity that helped me take the small steps along the way that eventually led to the culmination of this project. I also would like to acknowledge my committee members for their persistence, direction, and patience throughout this process. I was fortunate to have been enrolled in coursework with Dr. Hua Qin and Dr. David O’Brien. Our interactions during these initial courses guided my thought process throughout my dissertation research. They were always available to discuss my research and challenged many assumptions that I brought with me. Dr. Corrine Valdivia provided an outside vantage point that added depth to my proposal and broadened my perspectives. She is kind and gracious and an overall pleasure to work with. I would also like to extend my deep gratitude to all of the individuals that have been part of my academic journey. Throughout my primary and secondary education, my undergraduate studies, through my master's degree and now my PhD, I have had the pleasure to have worked with many inspirational, knowledgeable, and motivating individuals that have forever impacted my worldview and life trajectory.

I would like to offer my heartfelt appreciation to the participants in this study and to the community of Villa Sandino, Nicaragua. I had the pleasure to live in the beautiful town of Villa Sandino for two years and consider this community to be my second home. The individuals that have immigrated to the United States and took the time to provide me insights into their journey were the core to my study. Our candid conversations about the challenges they have faced as well as their unique perspectives regarding their ability to maintain engagement with the community of Villa Sandino were eye opening. They directed the focus of my research and continue to inspire me in my professional endeavors. I am fortunate to be a part of this extended community and appreciative of the friendships that have evolved over the years. 


\section{TABLE OF CONTENTS}

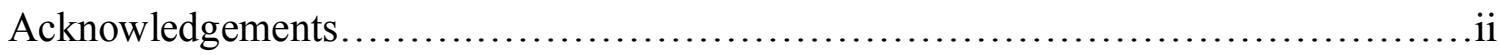

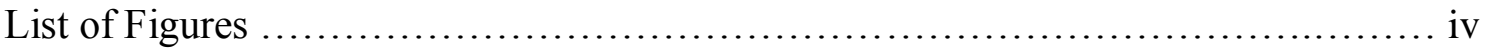

List of Tables.........................................................................

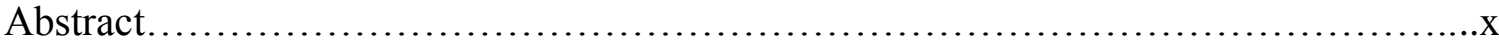

Chapter 1 - Introduction and Significance ...................................................................1

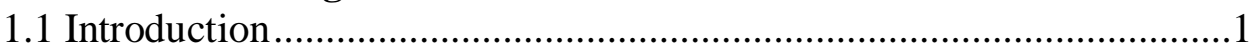

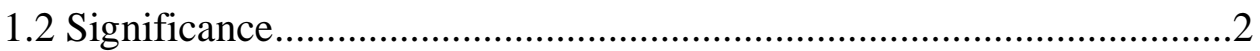

1.2.1 Central America and Mexico Immigration .............. 3

1.2.2 Brain Drain.......................................................... 5

1.2.3 Beyond Financial Remittances …………………....

1.2.4 Transnationalism from Below...................................

Chapter 2 -Literature Review .....................................................................................................11

2.1 Migration and Development ................................................................11

2.1.1 Migration as a Livelihood Strategy .........................18

2.1.2 Migration and Community......................................22

2.2 Transnationalism..........................................................................29

2.3 The Transnational Experience …………………………......................35

2.3.1 Transnational Immigrants ........................................35

2.3.2 Sending Country/Community ...................................43

2.3.2.1 Engagement Strategy .......................47

2.3.3 Receiving Country/Community ..............................51

2.3.3.1 Engagement Strategy ......................52

2.3.4 The Transnational Space .........................................54

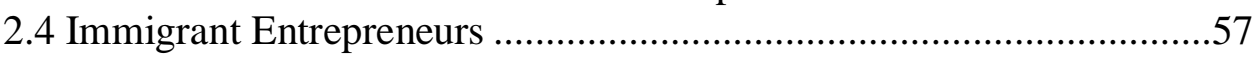

2.4.1 General overview …………………………......57

2.4.2 Latino Entrepreneurs...............................................66

2.5 Transnational Case Study Review - Central America \& Mexico .......69

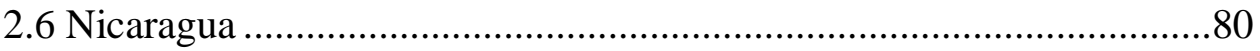

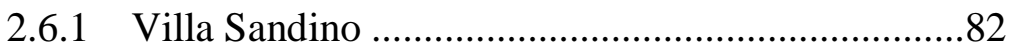

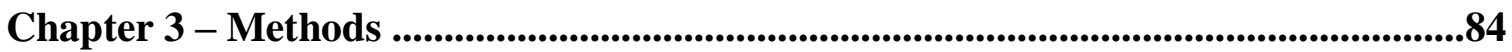

3.1 Purpose and Objectives..................................................................84

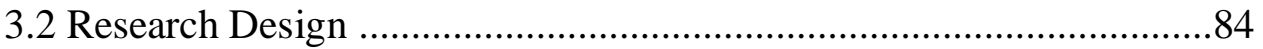

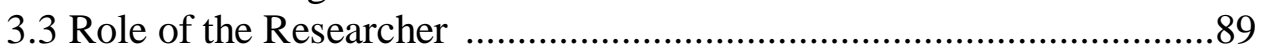

3.4 Population and Sample .................................................................94

3.5 Data Collection ………………………………….......................96

3.6 Data Processing and Analysis ..........................................................98

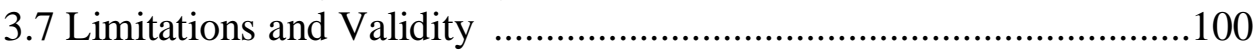


Chapter 4 - With-In Case Study Analysis...........................................................................102

4.1 Case Study Interviews I (Immigrant Entrepreneurs) .........................102

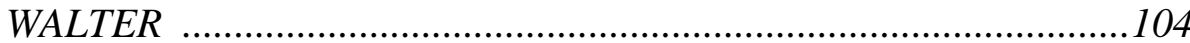

Lack of cultural connections leads to expanded social network.. 105

Leveraging stability to create opportunity ..................................107

Supporting individuals to foster financial sustainability .............110

Focusing on interests .............................................................111

Transition from informal to formal ............................................113

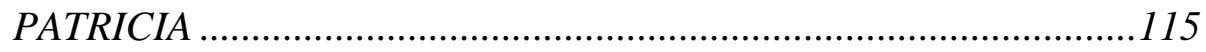

Integration into parallel culture …………………...................116

Familiarity as security .............................................................118

Familiarity as incubation............................................................ 121

Cultural translation of resources and ideas ................................124

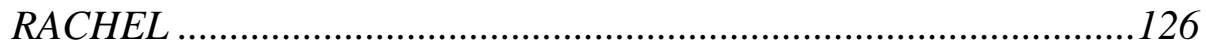

Becoming engaged and finding community ................................127

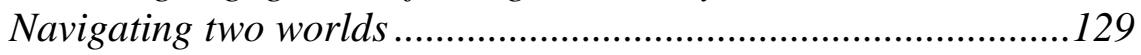

Problem-solving and development of an entrepreneurial spirit..131

Partnership to overcome weaknesses .........................................132

'Out-of-the-box thinking' '..............................................................133

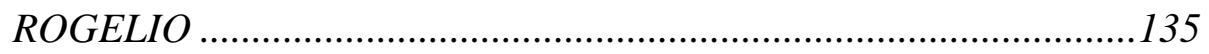

Delayed gratification and resilience...........................................136

Ability to 'pivot' and adopt changes ........................................139

Connecting through religion .......................................................142

Self-reliance above trust in others ................................................. 144

Establishing relationships built on respect and quality................146

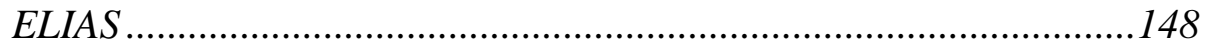

Change as growth ...............................................................149

Legacy and family tradition .....................................................150

Connecting struggle with success ............................................152

The importance of mentorship and guidance ...............................154

Information as power ...............................................................156

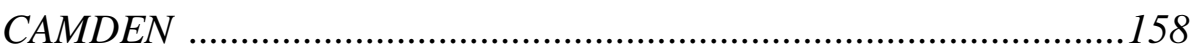

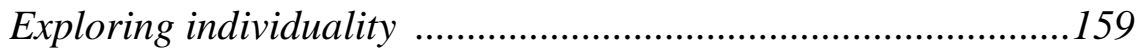

Systematic evolution ……………………………....................161

Transparency and equity .........................................................163

Power and control.................................................................164

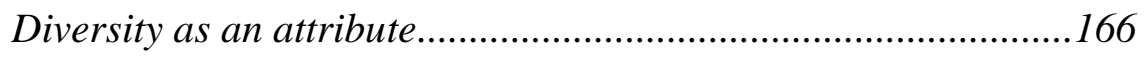

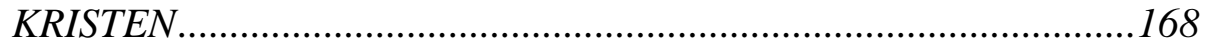

The role of structure and organization ……………...............169

Finding voice and communication ............................................171 
Creating value through personalization and differentiation ......173

Establishing connections and strengthening linkages ...............174

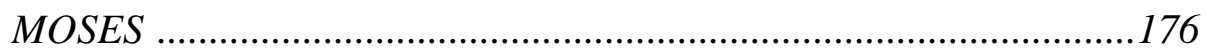

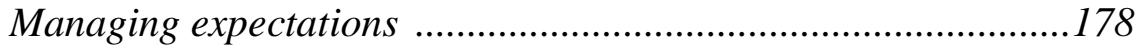

Determination, perseverance and self-reliance ........................180

Expanding influence through relationship building ....................183

Functional capacity building through hands-on experience .......185

Self-advocacy ........................................................................ 186

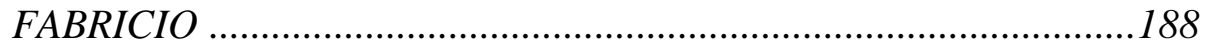

Gaining exposure through diverse connections .........................190

Focus on opportunity identification ...........................................192

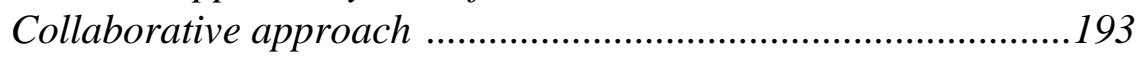

Sustainable and diversified investing practices .........................195

Vision and foresight as strategies for personal realization .........196

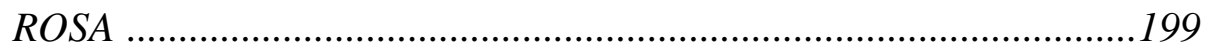

Building on cultural capital ......................................................197

Faith and preparedness as complementary qualities ................200

Shifting perspectives .............................................................202

Progress through a participatory and forward-looking approach................................................204

Authenticity and value-based decision making ..........................206

4.2 Case Study Interviews II (Leadership Group of Villa Sandino) .......207

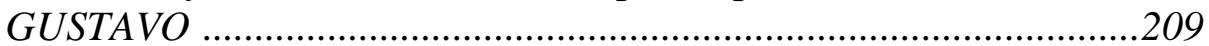

Community Overview ..........................................................2 210

Community Development .........................................................213

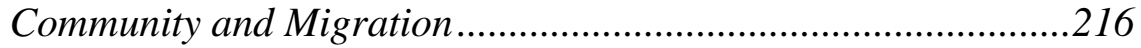

Emigrant engagement in Community of Origin .........................218

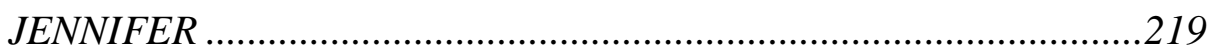

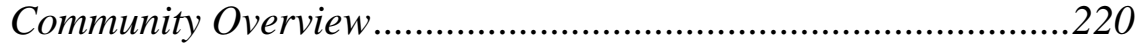

Community Development ......................................................221

Community and Migration ........................................................226

Emigrant engagement in Community of Origin..........................228

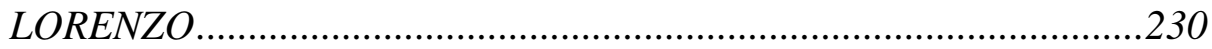

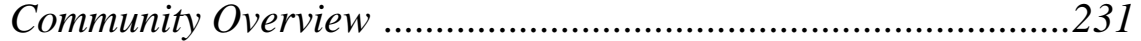

Community Development .......................................................2233

Community and Migration ........................................................236

Emigrant engagement in Community of Origin..........................238

Chapter 5 - CROSS CASE ANALYSIS ................................................................243

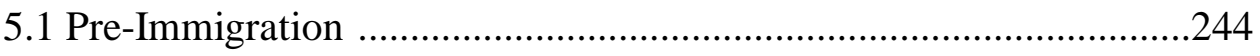




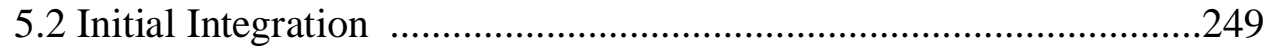

5.3 Pre-Entrepreneurial Endeavor .......................................................259

5.4 Entrepreneurship Start-Up to Present ........................................269

Chapter 6 - TRANSNATIONALISM FROM BELOW .........................................281

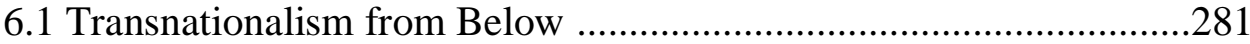

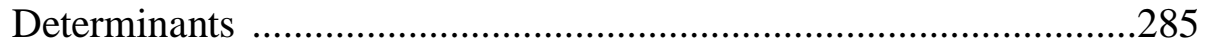

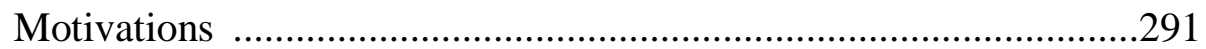

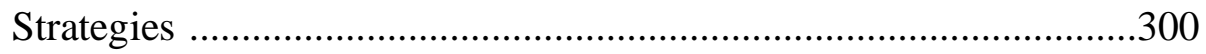

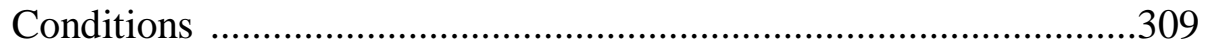

Transnationalism from Below Analysis ..........................................317

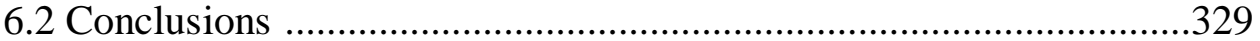

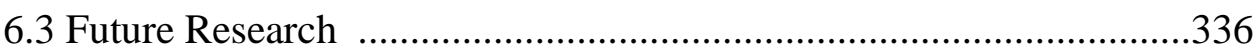

References .............................................................................................................................................338

Appendix A - Interview Guide (Immigrant Entrepreneurs) ................................353

Appendix B - Interview Guide (Community Leaders - Villa Sandino) ...................355

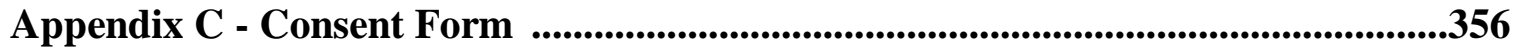

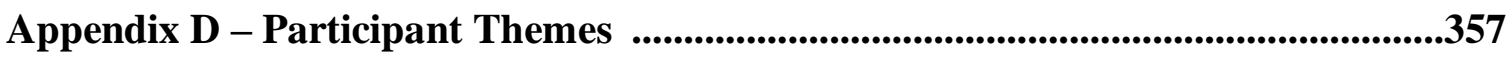

Appendix E - Grouped Themes Determinants/Strategies/Motivations/Conditions 359

Vita.............................................................................................360 


\section{List of Figures}

Figures

Page

Figure 1: Migration-Development Cycle: Neo-Classical Economic Perspective..............13

Figure 2: Migration-Development Cycle: Historical-Structural Perspective ....................13

Figure 3: Conceptual Framework of the Pessimistic Perspectives of Migration

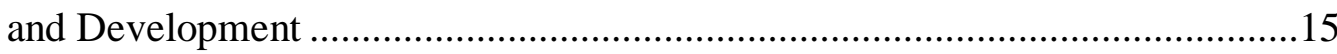

Figure 4: A State-Centric interaction pattern vs. Transnational interactions and interstate politics .30

Figure 5: Diaspora Engagement Strategies and Policies ...........................................47

Figure 6: Representation of Hispanics in workforce (Age 25-64) ...............................66

Figure 7: Representation of Hispanics in the workforce and Hispanic and non-Hispanic self-employment rates, 2000-2010 .67

Figure 8: Representation of Hispanic immigrants and natives ...................................68

Figure 9: Nicaraguan-Origin Population in the U.S., 1990-2013 .................................82

Figure 10: Data Analysis in Qualitative Research ......................................................99

Figure 11: Figure 11: Transnationalism from Below Latino Immigrant Entrepreneurs (Villa Sandino, Nicaragua) .283 


\section{List of Tables}

\section{Tables}

\section{Pages}

Table 1: Remittances - From United States to Central America and Mexico ...................4

Table 2: Opposing Views on Migration and Development .........................................17

Table 3: Typology of Transnational Practices in Different Spheres of Social Life...........34

Table 4: Transnationalism - Types and Level of Institutionalization .............................35

Table 5: Spheres of integration and transnationalism for an individual migrant...............37

Table 6: Typology of interactions between integration and transnationalism .................40

Table 7: Broad Level Diasporic Engagement Categories ...........................................49

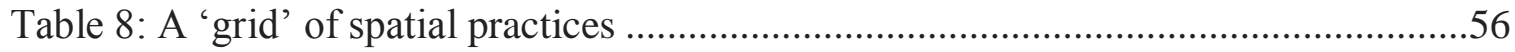

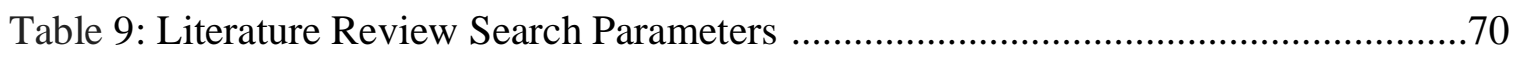

Table 10: Selected Articles for Literature Review .................................................... 71

Table 11: Matrix of Inclusion Level of Selected Variables ............................................73

Table 12: Description of Diaspora Activity Identified in Reviewed Literature ................75

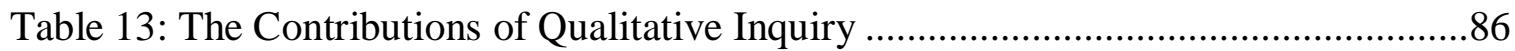

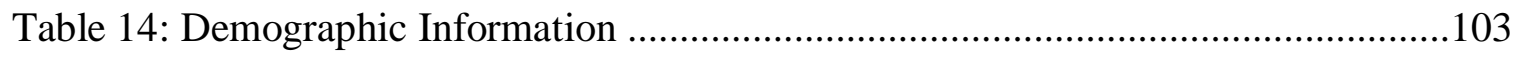

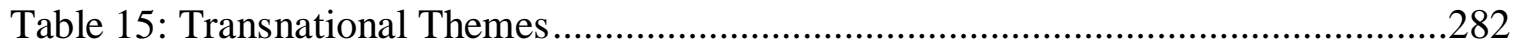




\title{
TRANSNATIONALISM FROM BELOW: AN EXPLORATION OF TRANSNATIONAL ENGAGEMENT BEHAVIOR OF NICARAGUAN IMMIGRANT ENTREPRENEURS
}

\author{
Andrea Tappmeyer \\ Dr. Stephen Jeanetta, Dissertation Supervisor
}

\begin{abstract}
This study explores the concept of transnationalism through individual experiences of migrants from the community of Villa Sandino, Nicaragua that have become entrepreneurs as immigrants in the United States. Through semi-structured interviews, their unique entrepreneurial journeys and transnational engagement are examined using qualitative research methods. Both with-in and temporal cross case analyses were utilized to present a comprehensive investigation. Specifically, the determinants, motivations and strategies of these immigrant Latino entrepreneurs that participate in transnational engagement are observed. Also, the experiences of the immigrant entrepreneurs are explored to understand the local ecosystem and institutions that supports these individuals' entrepreneurial success in their receiving communities of San Francisco and Miami as well as investigate the concept of transnationalism from below.
\end{abstract}




\section{Chapter 1: Introduction and Significance}

\subsection{Introduction}

High levels of immigration continue to present challenges as well as opportunities in this dynamic and complex globalized environment. Migration has the potential to expand social capital (Flora, 1998), develop human capital, and increase economic activity (Rudel, 2006) of individuals and households in sending countries. On the other hand, migration activities have also been linked to negative outcomes; including brain drain and the intensification of wealth inequality (Zamora, 2005). However, there has been a recent paradigmatic shift from the basic notion of brain drain, focused on loss of human capital, to the potential gains that exist in the realm of social capital, coined brain gain. Brain gain offers the complementary view of brain drain by focusing on the potential that immigrants offer and their unique ability to become development agents for their countries of origin (Ite, 2002).

Entrepreneurship represents a type of brain gain that has the potential to add value simultaneously to both the receiving and sending communities of Latino immigrant groups. Immigrants are twice as likely to engage in entrepreneurial activities as nativeborn Americans (Weins, 2010). Immigrant entrepreneurs have attracted attention as potentially powerful agents in the migration-development nexus. Policy-makers, NGOs, donors, and other development institutions are realizing the potential impact this group can have on poverty reduction and development in their countries of origin (Naude, Siegel, and Marchand, 2015). However, it is important to understand the unique position and characteristics of Latino immigrant entrepreneurs to realize the opportunities and 
barriers that exist in creating constructive transnational spaces.

This study explores the determinants and motivations of Latino immigrant entrepreneurs who are actively involved in transnational engagement activities as well as the strategies utilized by this group to maintain relationships and provide development assistance to their country of origin. In order to create a focused approach, the study will concentrate on exploring transnationalism within a group of immigrant entrepreneurs that have immigrated to the United States from the town of Villa Sandino, Nicaragua. Understanding transnationalism from the perspective of Latino immigrant entrepreneurs will influence program development and policy reform in both the business and migration fields. This specified group will illustrate the barriers and opportunities of Nicaraguan immigrant entrepreneurs and the transnational relationships that are fostered by the town of Villa Sandino. Apart from providing insights regarding individuals and interactions for this specific community, this study will also be able to illustrate transnationalism from below for Latinos in general and may provide a basis and framework for expanded studies into other Latino populations and communities. Recognizing the nature of transnational engagement of these individuals can also guide both the receiving and sending communities to develop more supportive and beneficial migrant engagement strategies.

\subsection{Significance}

Research in the realm of migration and development has recently converged, highlighting the importance of viewing these complex concepts in an interconnected manner. Development researchers are increasingly incorporating migration into their work and similarly migration researchers are devoting more attention to the area of 
development ("Migration and Development", 2015). Development conditions are a primary factor that drive people to leave their home countries, depleting human capital and reducing opportunities to leverage some of the most capable community members to become agents of change and improvement. However, diaspora populations often maintain a relationship with their homeland through social, financial, and political channels (Brinkerhoff, 2008). Understanding the relationship between migrant and country of origin, as well as the barriers and challenges that exist, is crucial to developing a supportive atmosphere that promotes transnational spaces that can have positive impacts on household, community, and national levels.

\subsubsection{Central America and Mexico Immigration}

It is assumed that migration will benefit countries of origins by increasing incoming financial flows and expanding social networks. According to the World Bank (2016), worldwide remittance flows to developing countries is forecasted to reach 493 billion dollars by the year 2018. Central America and Mexico received over 40 billion dollars in incoming remittance flows for the year 2015 (Orozco, Porras, \& Yansura, 2016). Over half of the U.S. foreign-born population originates from the Central America and Mexico region, and it is estimated that the over $75 \%$ of remittances to this region come from within the United States (O’Neil, 2003). In fact, the economic flow from remittances from within the United States surpasses the combined level of foreign direct investment and development assistance (World Bank, 2016). For Nicaragua specifically, remittances reached $\$ 1.19$ Billion in 2015. Remittances have continued to become increasingly important to Nicaragua, growing by $4.8 \%$ between 2015 and 2016 
and making up almost 10\% of the annual GDP. The interconnectedness between the United States and Central America and Mexico is evident and provides an important opportunity to incorporate a dialogue around the concepts of engaging migrants from these areas into future joint efforts with policy makers and development practitioners.

\section{Table 1: Remittances - From United States to Central America and Mexico}

\begin{tabular}{|l|l|l|l|}
\hline COUNTRY & Annual & Growth \% 2014- & Remittances as \% of \\
Remittances US\$ & $\mathbf{2 0 1 5}$ & GDP \\
\hline BELIllions 2015 & 156 & $0.0 \%$ & 4.7 \\
\hline COSTA RICA & 527 & $-5.6 \%$ & 1.2 \\
\hline EL SALVADOR & 4,280 & $3.0 \%$ & 16.8 \\
\hline GUATEMALA & 6,285 & $15.2 \%$ & 1.1 \\
\hline HONDURAS & 3,719 & $10.9 \%$ & 17.4 \\
\hline MEXICO & 24,771 & $4.8 \%$ & 1.9 \\
\hline NICARAGUA & 1,190 & $4.8 \%$ & 9.7 \\
\hline PANAMA & 645 & $-1.1 \%$ & 1.6
\end{tabular}

Note: Adapted from World Bank. Systems \& Remittances. (2016). Retrieved March 19, 2016, from http://www.worldbank.org/en/topic/paymentsystemsremittances

Diasporas play key roles in foreign direct investment (FDI), tourism, political advocacy and support, philanthropy, knowledge transfer, technological advances, and creating diplomatic and cultural bridges. However, the research of these activities and their effects is limited and generally low in quality and relevant content (Ambrosius \& Cuecuecha, 2016). Academic contributions in this realm are lacking and there is no 
adequate systematic approach to explore the connectedness. It has been noted that research regarding the link between diasporas and development is necessary to build knowledge, develop theory, and hone appropriate methods to understand the complexity of these relationships and create actionable recommendations for future endeavors (Brinkerhoff, 2008).

The vast majority of research on transnational engagement focuses on Mexican diaspora groups, which is understandable as immigration between Mexico and the United States greatly surpasses that of the other countries, and a large number of Mexican diaspora communities exist throughout the United States (Garip, 2012). The literature does note that Mexican diasporic engagement strategies are often emulated by other countries in the region (Flores-Yeffal \& Aysa-Lastra, 2011), which provides a beneficial framework in which supporting institutions and policies can be adopted by countries interested in engaging their diaspora. However, this focus on Mexico is also limiting due to the fact that most of the countries in the region differ substantially in terms of the level of immigration as well as operate on a different geographic level with distinctive political and economic structures (Zamora, 2005). Further research performed in the Central American region would be beneficial to provide more relevant best practices for these diverse countries. Therefore, this study will focus on the country of Nicaragua and will pinpoint one community to further investigate the transnational phenomenon in a contained and practical context.

\subsubsection{Brain Drain}

A critical sociological issue related to immigration is the concept of brain drain. The term "brain drain" began to appear in the international development literature in the 
mid-1960s, to explain the phenomenon of the depletion of community resources as the result people moving to another country and essentially removing the human capital embedded in that individual from their home country. This physical movement results in the parallel transfer of skills, knowledge, abilities, and future potential from sending to receiving country (Meyer, 2001). This reality creates challenges for communities in developing countries that are continually losing some of the most educated and talented population to developed nations with advanced economies and more opportunities. However, there have been more recent developments with this concept that suggest that the simplistic notion of brain drain ignores the reality that individuals often leave communities that do not have supporting institutions and networks to develop their talents and take advantage of the economic and social gains of their capabilities. In other words, these individuals would not have been able to reach their highest potential within the bounds of their home community. This reality poses a paradigmatic shift from the basic notion of brain drain, focused on loss of human capital, to the potential gains that exist in the realm of social capital, coined "brain gain". (Meyer, 2001). Brain gain offers a contrasting view of brain drain by focusing on the potential that immigrants offer in the realm of financial flow from rich to poor countries, building diplomatic and knowledge bridges, technology transfers, and returning human capital (Ite, 2002).

\subsubsection{Beyond Financial Remittances}

Transnational activities of immigrants tend to focus on economically based endeavors undertaken, particularly remittances. Remittances refers to financial transfers from migrants to households in their country of origin. Typically, these are recurring transfers between an immigrant living abroad for a year or longer and their family 
members residing in their home country ("Remittance Data", 2014). The use of financial remittances is prevalent among immigrant groups, especially among those migrating from less advanced economies than the United States. These remittances are important sources of income for many families of migrants and have been cited as having significant potential for poverty reduction. Further, remittances are often a stable source of income, resistant to economic recessions, that offer a sense of security and consistency to households in developing nations (Orozco, 2009).

It is clear that financial remittances have a positive household level impact, however damaging community level outcomes have also been found (Clemens, Özden \& Rapoport, 2015). One common issue with the initial impact of remittances is the creation of an inequality in wealth. These financial remittances are typically channeled to the poor, but seldom reach the poorest of the poor and often only provide temporary relief without leading to permanent financial security (Brinkerhoff, 2008). Often, remittances received at the household level are spent outside of the community because there are limited institutions and businesses in existence to absorb this influx of financial capital. These fragmented economic interactions tend to lead to short-term benefits and do not offer considerable advancement towards sustainable community development. Even when remittances are distributed in a more collective manner, or businesses are established to provide community wide employment, the wealth tends to concentrate amongst the wealthier and middle class community members. It is important to note that this wealth disparity is observed to decline overtime, especially when migration continues to increase (Garip, 2012). 
Financial remittances will most likely continue to be an important and powerful form of migrant transnational engagement, however there is a need to understand the full impact of these transfers as well as to explore and cultivate other beneficial types of transnational activities. One particularly dynamic and potentially impactful type of transnational activity is illustrated in the idea of social remittances. Social remittances are the transfer of know-how, practice, skills, and ideas between migrants and their home community. Through continuous contact and communication, migrants influence the views and norms of households of origin. Perspectives on gender, democracy, healthcare, education, and innovation are directly impacted and this shift in outlook and attitude creates opportunity for meaningful community level, bottom-up development (Levitt \& Lamba-Nieves, 2010). This study will examine the diverse types of transnational engagement undertaken by Latino immigrant entrepreneurs as well as explore the potential for developing new and innovative transnational activities that can have community level impact. By understanding how to leverage and incentivize the unique skills and social capital of this particular group, migrant entrepreneurs will be able to play an increasingly involved role in community level sustainable development.

\subsubsection{Transnationalism from Below}

Transnationalism, in broad terms, can be defined as "multiple ties and interactions linking people or institutions across the borders of nation states" (Vertovec, 1999, p.447). As the transnational field has developed, it has become delineated into the concepts of 'transnationalism from above' and 'transnationalism from below'. 'Transnationalism from above' refers multinational corporations, international institutions, mainstream media, and other elite factions (Faist, n.d.). Multilateral organizations such as the 
International Monetary Fund (IMF) the United Nations (UN), the World Bank, as well as large international non-governmental organizations (NGOs) engage in, and monitor, the transnational spaces on a global, multi-dimensional level are examples of this type of 'transnationalism from above' (Smith \& Guarnizo, 1998). These relationships are fundamental to diplomacy, development, and national security efforts. These types of engagement provide the traditional view of transnationalism in a globalized society. This focus can be characterized as "transnationalism from above" as the actors are working on a high-level and are elite in nature.

This study will take a different approach by exploring transnational spaces from the perspective of immigrant entrepreneurs with limited resources, power, and influence. By focusing on individual relationships across the border and the potential that exists to leverage the unique skills and social networks developed by these entrepreneurs, an understanding of 'transnationalism from below' will emerge. Transnationalism from below encompasses grassroots transnational enterprises, migrant networks, social movements, and the basic relationships maintained between individual migrants and country of origin. Immigrant entrepreneurs have distinct skills and social networks that allow them to reach across borders to spread business knowledge and inject the entrepreneurial spirit to their community of origin. Direct investments in businesses or collaborations in start-up initiatives is an example of 'transnationalism from below'. This type of transnationalism is interconnected with 'transnationalism from above' and often challenges the traditional power structures and institutions and provides agency to individuals typically excluded in the social field (Faist, n.d.). 
This type of engagement can have dramatic effects on community level development and has the possibility of reconfiguring traditional power structures to create social and economic change in a manner that can complement and supplement the activities of higher level institutions. A greater focus on research regarding "transnationalism from below" will add a more comprehensive understanding on how to create a collective gain from migrant groups, while empowering individuals that are often disregarded and overlooked in the development field. Latino immigrant entrepreneurs are a particularly interesting subject for this analysis as they have developed a unique set of skills and social capital and have the potential to create innovative transnational spaces. 


\section{Chapter 2: Literature Review}

This literature review will focus on developing a basis of understanding regarding transnationalism and its potential as a framework for understanding the roles of immigrant entrepreneurs in both their home and host country. First, the historical relationship between migration and development will be discussed to lend context to the various, and often opposing, perspectives that have emerged relating to the effects of immigration on cross-border advancements. Then, the concept of transnationalism will be explored in depth to offer an overview of the current research in the field as well as provide contextual examples transnationalism from both a sending and receiving country context. The review will then delve into discerning the unique attributes and characteristics of immigrant entrepreneurs, specifically Latino entrepreneurs, to afford a preliminary exploration on the challenges and unique support systems of the individuals identified as a key participant in this study. Nicaragua and the community of Villa Sandino will also be examined to provide specific contextual understanding for the specific sample group of this study. Finally, a case study review is undertaken on 23 articles relating to transnationalism in Central American countries. This case study review synthesizes the findings of relevant research in the field to find patterns and insights that will provide a strong basis for further exploration into the transnational space.

\subsection{Migration and Development}

Discourse relating to the relationship between migration and development dates back to the 1950s, with academic and political debates vacillating from optimistic to pessimistic outlooks and back again (Haas, 2010). In the 1950s-1960s the discourse 
focused on views of development economists on labor migration as a critical element of modernization. This focus was rooted in neo-classical economic theory (Castles \& Ranis, 2008). According to neo-classical economic theory, there are macro and micro assumptions that underlie the explanation of labor migration as it pertains to economic development. These assumptions posit that wage differences between sending and receiving countries are the main cause for labor migration and thus the elimination of wage differences would ultimately eliminate labor based migration (Harris \& Todaro, 1970). Further, the theory focused on the individual as a rational being that relies on information to weigh the costs and benefits of migrating versus staying in their home country and the individual will choose to emigrate when the net return from moving outweighs that of staying (Borjas, 1990). Government regulations and policies in both sending and receiving countries can also have a large influence on the control of flow and frequency of labor migration (Massey, 2005). This model suggests economic disparities between countries generates the flow of migrants attempting to maximize financial returns and these flows should eventually equalize conditions and wages between underdeveloped and developed areas, creating an economic equilibrium (Castles \& Ranis, 2008). Remittances from migrants were attributed to stimulating economic growth and return migrants were seen as development agents by bringing back capital, as well as knowledge, ideas, and entrepreneurial attitudes. Migrants were seen as potential development agents that had the ability to accelerate diffusion of modernization through spatial boundaries (Haas, 2010). This outlook created an overall optimistic view of the association between migration and development (see Figure 1). 


\section{Figure 1 : Migration-Development Cycle: Neo-Classical Economic Perspective}

Beginnings of development in underdeveloped country
Migration

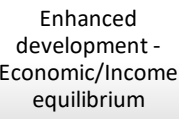

Source: Adapted from (Castles \& Ranis, 2008)

The perspective on the migration-development nexus shifted to a more pessimistic outlook dominated by historical-structural theory during the 1970s, and into the 1980s (Castles \& Ranis, 2008). This era represented a paradigm shift from the virtues of migration to the portrayal of the linkages between development and migration as a vicious cycle. The insights of this perspective are drawn from Marx's historical materialism, focusing on class structure and social relations of production (Wood, 1982). Migration is highlighted as a means for mobilizing cheap labor for more politically and economically powerful countries, perpetuating underdevelopment and exploiting resources to make rich countries richer and deepen chronic poverty, dependency, and outmigration in poor countries (see Figure 2) (Castles \& Ranis, 2008).

\section{Figure 2: Migration-Development Cycle: Historical-Structural Perspective}

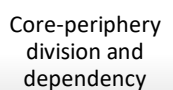

division and
dependency

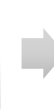

Migration

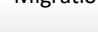

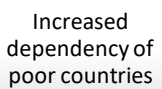

poor countries

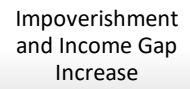

and Income Gap

Third world labor freely available

for capital in core

Source: Adapted from (Castles \& Ranis, 2008) 
This skeptical perspective also aligns with the cumulative causation theory, developed by Swedish economist Gunnar Myrdal in 1956. The principles of this theory focused on a multi-causal approach that delineated institutional change as successive and circular and often times persisted in a negative manner causing differential growth patterns. This differential growth does not occur all of a sudden in a chaotic fashion but is gradual, leading to lack of awareness or responsiveness to negative externalities (Massey et al, 1993). Once differential growth has transpired, inequalities in spatial welfare will deepen and economies of scale will perpetuate the dichotomized characteristics of the cycle of poverty and dependency. This will, in essence, drain underdeveloped regional and national economies of their most valuable human capital, increase asymmetric growth, encourage more out-migration, and deepen dependency (Haas, 2010).

This model is associated with the concepts of dependency theory, which gained popularity in the late 1960s, by suggesting that the world capitalist system is made up of poor peripheral countries and rich core countries and over time the marginalized peripheral regions will be exploited by the core regions. This view rejected the popularity of the previously accepted modernization and development philosophies by positing that the unique structures and history of a country, along with the embedded integration into the world economy as a weak member, prohibited a nation from moving along an imagined path from a primitive version of a developed country to an advanced economy. Thus, peripheral countries would not be accelerated along a path to development but would rather be caught in a cycle of dependence. Migration would perpetuate this problem and become increasingly necessary as the cycle developed and exploitation worsened (Wood, 1982). By the late 1970s a more comprehensive, world systems 
theory, had developed to further articulate the ideas of the incorporation of peripheral nationals into the world economy. This theory focused on the nation state as the unit of analysis and conceived that the introduction of multi-national corporations into underdeveloped economies accelerated rural transformations, causing displaced workers, expansion of informal economies, rapid urbanization, and overarching poverty (Castles \& Ranis, 2008). A visual overview of the pessimistic perspectives on the relationship between migration and development can be found in Figure 3.

Figure 3: Conceptual Framework of the Pessimistic Perspectives of Migration and

\section{Development}

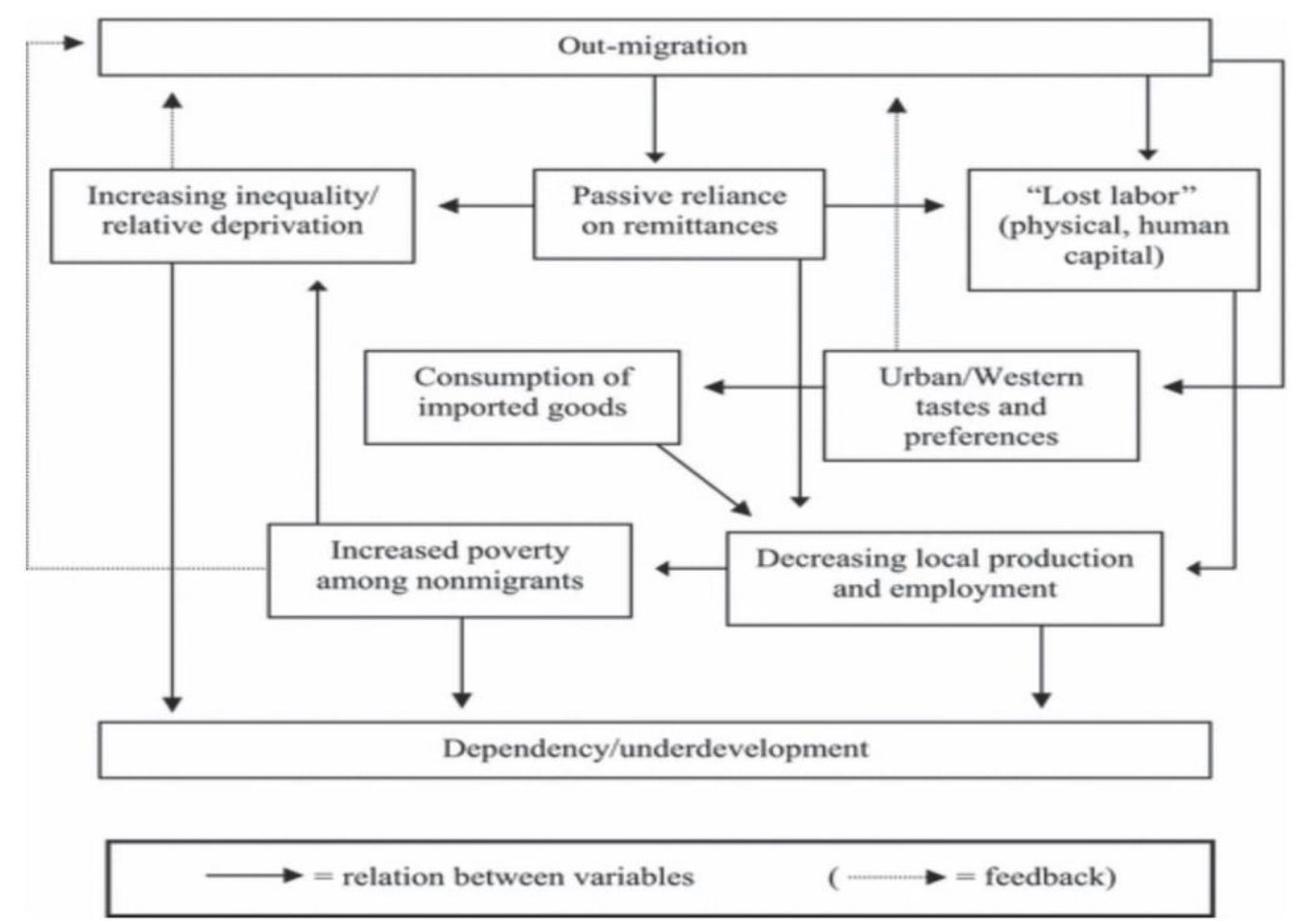

Source: Haas, 2010

Criticisms regarding the deterministic and circular nature of these pessimistic views arose in the 1980s. The validity of this perspective was questioned due to the lack 
of consideration of the heterogeneous nature of the context and localized impact of diverse immigrant groups. Further, the assumption that the positive spread effects, like remittances, do not outweigh the negative backwash effects was not supported by empirical evidence. Lastly, the hypothesis of the infinite nature of the core and periphery country relationship was deemed as unrealistic because at some point peripheral countries would become too impoverished for individuals to be able to migrate (Haas, 2010). Therefore, the discourse has further evolved to include various models that attempt to provide a more holistic understanding of the diverse and heterogeneous relationship between migration and development (Castles \& Ranis, 2008). These theories provide a more positive, yet more diversified, outlook of this nexus. The evolving theoretical perspectives relating to migration and development attempted to include the role of structure, relating to the political, economic, social, and cultural barriers and opportunities, as well as agency, relating to the ability of an individual to overcome and reshape structural constraints (Haas, 2010). Some of the prominent theories that have emerged include the new economics of labor migration (NELM), dual or segmented labor market theory, migration networks theory, and transnational theory. 


\section{Table 2 : Opposing Views on Migration and Development}

\begin{tabular}{ll} 
Opposing Views on Migration AND DEVElopmen \\
\hline Migration optimists & Migration pessimists \\
\hline Functionalist & $\leftrightarrow$ Structuralist \\
Neo-classical & $\leftrightarrow$ Neo-Marxist \\
Modernization & $\leftrightarrow$ Disintegration \\
Net North-South transfer & $\leftrightarrow$ Net South-North transfer \\
Brain gain & $\leftrightarrow$ Brain drain \\
More equality & $\leftrightarrow$ More inequality \\
Remittance investment & $\leftrightarrow$ Consumption \\
Development & $\leftrightarrow$ Dependency \\
Less migration & $\leftrightarrow$ More migration
\end{tabular}

Source: Haas, 2010

The expansion of new economics theories and livelihood models align with the relatively recent introduction of the multi-directional theoretical perspective of transnationalism. Transnational theory provides an approach that recognizes the possibility for migrants to create transnational spaces and adopt transnational identities (Guarnizo, Portes, and Haller, 2003). This approach also highlights the effect of the collective nature of migration and development and reduces the focus on individual actors by adopting the unit of analysis of groups or networks of related people. The exploration of transnationalism and transnational spaces is becoming an increasingly important approach to understanding the dynamic, heterogeneous nature of the diverse actors and structures that are integral to the migration and development nexus (Faist, 2004). 


\subsubsection{Migration as a Livelihood Strategy}

Migration is prevalent in many rural communities and is often undertaken as part of an overall livelihood strategy. This movement of people creates opportunities and pressures on sending households and communities and has the potential to impact the sustainable development of an area. A livelihood encompasses people, their abilities and skills, and their means of living, including assets, income, food, and other intangible resources (Chambers \& Conway, 1991). A livelihood can be deemed sustainable if it adequately satisfies basic needs and is resilient against shock and stresses. Social inclusion is central to the concept of sustainable development (De Haan, 2000). Also, an important attribute of a sustainable livelihood is that it will continue to provide opportunities and sustainable livelihood outcomes to future generations, contributing to sustainability at a local and global level (Chambers \& Conway, 1991).

While sustainable development is often viewed at a community level, sustainable livelihoods are typically examined at the household level. The sustainable livelihoods framework is comprised of the context of vulnerability; livelihood assets; transformational processes and structures, which include legislation, policies, and institutions; and livelihood strategies and outcomes (Sagynbekova, 2016). Assets within the livelihood framework are constructed of social capital, human capital, natural capital, financial capital, and physical capital (De Haan, 2010). Livelihood strategies are the activities and tactics used to achieve livelihood outcomes. Outcomes can include a heightened sense of well-being, increased income, decreased vulnerability, more resilient food security, and more sustainable utilization of natural resources (Ellis, 1998). Within this framework individuals and households work through the context of vulnerability to 
best capitalize on the available assets in order to increase resiliency and decrease susceptibility to current and future detrimental circumstances. Prevailing institutional and social structures and the unique local contexts influence the livelihood strategies available for people to construct their most beneficial livelihood strategy and outcome (Sagynbekova, 2016).

Livelihood strategies for mitigating stress and disturbances are varied and can be used simultaneously or successively to create the most resilient and enduring outcomes. These strategies include, reducing consumption, accumulation and storage of assets (including food), preservation of assets base for use during reestablishment and recovery after shock has dissipated, depleting food and asset stockpile, diversification, appealing to goodwill of individuals and organizations, collecting outstanding debts and favors, and migration (Chambers \& Conway, 1991).

Migration as a livelihood strategy has many implications for short-term and longterm maintenance and development at the household level. Individuals and households migrate for various reasons including; family reunification, to secure better employment opportunities, persecution, natural disasters, or in search of an overall better quality of life. Migration can be temporary or long-term and can be internal (within the country boundaries) or external (across national borders) (Castles \& Ranis, 2008). Although migration is itself a livelihood strategy, it is also interweaved with other strategies noted above. Migration can be part of a diversification strategy as social and kin networks are central to creating diversified income portfolio and may mitigate risk of relying on all family members working within a local agriculture sector (Ellis, 1998). Utilizing migration as a diversification strategy will provide a secondary, or possibly primary, 
income stream that is not susceptible to the same local economic, political, and social vulnerabilities. Financial remittances from migrant household members is a substantial source of income for many households, especially throughout the developing world. The use of financial remittances is prevalent among immigrant groups, especially among those migrating from less advanced economies than the United States. These remittances are important sources of income for many families of migrants and have been cited as having significant potential for poverty reduction. One particular advantage of remittances as a diversification strategy is that they are often a stable source of income, resistant to economic recessions. Remittances can offer a sense of security and consistency to households in developing nations (Orozco, 2009).

Migration is also interconnected with the strategies of appealing to goodwill of individuals and organizations and collecting outstanding debts and favors. When community households' social networks expand due to family, friends, and community members that migrate to more urban or advanced economies, it provides increased opportunities for soliciting outside assistance (Chambers \& Conway, 1991). Even when the migrant is not providing consistent remittances to the household, or is being solicited from an outside household, in times of desperation or increased vulnerability these households have the opportunity to implore assistance from individuals that have a community tie and may have succeeded in gaining increased economic security through migration (Castels \& Ranis, 2008).

The concept of transnationalism is a valuable lens to further delve into the areas of livelihood strategies and sustainable development. Transnationalism, in broad terms, can be defined as "multiple ties and interactions linking people or institutions across the 
borders of nation states" (Vertovec, 1999, p.447). As migrants leave their home country and emigrate internationally, they often maintain strong ties with their households and community of origin. This reality creates the opportunity for these individuals to become transnational migrants, participating in both their home and receiving communities.

The creation of a transnational space and conveyance of social remittances is potentially impactful for sustainability and household livelihood strategies of communities of origin, however various challenges do exist. At a community level, transnational activities may reinforce power structures and increase wealth disparity. It is important to reiterate that livelihood strategies are influenced by the unique context of a household's economic, social, and ecological environment. Individuals and households that have higher levels of assets and social networks have more choices when developing their livelihood strategies, which may include education and migration. Often, the poorest of the poor are not able to utilize these more sustainable strategies and are driven by desperation with fewer options (Chambers \& Conway, 1991). This may have community level implications, increase risk, and lead to increases in wealth disparity, affecting the overall well-being and development of an area. Transnationalism from below that is focused on household level connections alone, may create fragmentation within a community. This negative outcome can be mitigated through a community field approach, focusing on development of the community through collective action and social inclusion rather than solely development of social fields within the community (Flora \& Flora, 2008). 


\subsubsection{Migration and Community}

The idea of community has many implications to the social, individual, and ecological well-being of individuals within society. In order to explore the relationship between migration and transboundary communities, it is important to first understand the meaning of the concept of community. Community is a widely-used concept that carries many meanings and is often ill-defined by those who attempt to operationalize its significance. Community can be viewed in various ways and can have diverse meanings, but a focus on groups of people is central in the discipline of Sociology. Three primary areas of emphasis include; viewing community through locality and place, focusing on social systems and organizations in which groups of people's needs are met, and concentration on a shared sense of identity within a distinct group (Flora \& Flora, 2008). When defining community, Wilkinson (1991) emphasizes "interpersonal bonds, such as a shared territory, a common life, collective actions, and mutual identity" and highlights the importance of social interaction (p. 11).

The perception of community has shifted over time. Historically, there was not a clear division between the ideas of society and community, however in the modern-day context these two concepts have become distinct. Ferdinand Tonnies viewed "community as a product of 'natural wills', while society is the creation of 'rational wills' which leave little room for the former" (Delanty, 2003, pg. 34). The expressions of community as Gemeinschaft and society as Gesellschaft are utilized to define key differences and construct a bidirectional relationship that is increasingly noticeable. Tonnies regarded these two concepts as types of associative life, however they were typically used in a polarizing manner (Wilkinson, 1991). However, it does appear that 
these ideas do not necessarily have to exist at opposite sides of a spectrum, but instead can be represented as cyclical in nature where each is constantly adapting and affecting the other, both positively and negatively. Emile Durkheim expanded on the discourse of community and society by introducing the concepts of mechanical and organic solidarity. Mechanical solidarity is based in a 'collective conscience' that is grounded in common values and beliefs of individuals and low levels of autonomy. Organic solidarity, on the other hand, is more prevalent in modern society and is based on interdependence of individuals in advanced societies due to increasingly specialized work (Delany, 2003). Durkheim has argued that the connections created by organic solidarity are actually a more cohesive 'social glue' because of the dependence on one another and lack of selfsufficiency (Durkheim, 1964).

Much of the current discourse centers around the nostalgic idea of community as something that has been lost and focuses on the revitalization of recovering this sense of shared life (Delanty, 2003). Some believe that community has been lost to modernity, however it is more realistic to recognize that the idea of community must be transformed and reestablished to fit within the modern-day context while retaining some of the traditional values and bonds of the past. Place-based communities are significant, everyone is tied to at least one location and shares vulnerability with others that reside in that place. However, with the growth of global interconnectivity and the increase of mobility and migration of individuals, we can no longer rely solely on place-based definitions of community. Communities of choice are becoming more prevalent and it is therefore important to appreciate the unique characteristic of these formed groups (Delanty, 2003). The traditional definition of community as a singular, place-based group 
of individuals can be expanded to include a differentiated framing that is inclusive of a group of individuals bonded by some sense of commonality. The idea of commonality can be defined as a perception by members of a group that they share common characteristics with each other, enabling them to empathize and to gain a sense of selfreassurance. Defining community through commonality in the age of technology also expresses the reality that individuals are now able to be selective of communities they take part in and connect to individuals regardless of location, space, and time (Willson, 2006).

Paul Morris offers a simple 'assent' and 'descent' dichotomy to differentiate community types on a basic level. The community of descent represents the place based grouping, where members are tied to a locale and incorporate into the identity, values and culture of that community. Communities of 'assent' epitomize a category of choice (Willson, 2006). It appears that individuals are increasingly creating a community relationship based on technologically-aided access to other individuals that express similar common interests. While the location based relationships are seen more in a societal context, individuals interacting through abstract social forms often have the primary goal of furthering individual needs. This concept is also meaningful for the discussion of migration and community (Barajas, 2009). Migrants are able to choose to maintain consistent communication with friends, family members, and other community members through various communication platforms that are inexpensive, or free, and reliable. Although this community tie begins as a community of 'descent' based on locality, it is transformed to a community of 'assent' when the migrant chooses to maintain community relationships while physically living in another area. 
By expanding the definition of community to include groups beyond locally bounded entities, we are able to move the discussion of community in a direction that considers the effects of migration and allows for the exploration of transboundary and transnational communities. There are many types of migration, and each creates a unique relationship with the development of transboundary communities. Migration can be internal (within country border) or external (change of residence across national borders), temporary or long-term, forced or voluntary (Castles \& Ranis, 2008). The underlying reasons for migration are also expansive but can be classified within the categories of economic, social, political, and environmental migration. Some specific examples of these reasons are family reunification, the search for employment opportunities, the need to flee from persecution, natural disasters, or other difficult conditions, or generally moving in search for an overall better quality of life (Schiller, \& Faist, 2012). Regardless of the reason or type of migration, community organization and structures affect, and are affected by, migration, and community dynamics in both origin and destination regions are altered by this movement of people (Qin \& Flint, 2012).

The impact of migration on community, and specifically its influence on community development, is central to the understanding of the negative and positive relationships that exist in this nexus. Migration has a cause and effect relationship with the community of origin. Migration can be viewed as a cause of community issues, driving individuals outside of the locality in search for better opportunities or escape from unfavorable realities (Schiller, \& Faist, 2012). The development of transnational communities creates a platform that can mitigate brain drain and develop a bidirectional flow of knowledge, skills, and resources to capitalize on the notion of brain gain. 
Out-migration can also have significant impacts on community cohesion and involvement of migrant households in origin community activities and organizations. This may happen because of an increased external social network and a decreased reliance on community resources, and may result in households of migrants becoming detached from their community over time (Qin \& Flint, 2012). However, migration can also be seen as a broadening of the community when social ties are able to be maintained and social networks transformed between sending and receiving areas, generating positive, local community development in areas of origin (Flora 2008). The transnational view allows migrants to maintain inclusion in a transnational, or transboundary, community where they are able to integrate into their receiving community while maintaining active participation within their community of origin.

Although transboundary communities offer great potential for community development, there are various challenges that arise when developing the transboundary or transnational arena. In these cross-border transactions, migrants are tasked with the stressful role of integrating into their receiving communities while maintaining relationships with their community of origin. The concept of transnational to successfully navigate this space. Understanding the ability to establish, balance, and maintain structural and socio-cultural ties in two countries simultaneously is complex and multifaceted but central to the development of the transnational space.

To address some of the potential negative impacts of migration on community and navigate the complexity of developing successful transboundary communities, it is important to separate the ideas of development within a community and development of a community (Flora 1998). Wilkinson (1991) offers the succinct definition of community 
development as "a process of developing the community field" (p. 87). The community field is comprised of the whole community and consists of the ability of individuals, families, government agencies, and other organizations and institutions to act purposefully and collectively towards the advancement or change of the community (Flora \& Flora, 2008). While migrant involvement in home communities often is aimed at the development 'within a community', by directing financial remittances directly at a household, increasing educational opportunities of select individuals, creating or investing in a single business, they often do not achieve 'development of the community' and promotion of inclusive collective action.

A unifying construct that highlights the distinct position of communities, regardless size and location, and provides for a valuable lens to view potential transboundary community development is the community capitals framework (Flora, 2004). This model illustrates the unique resource combination that can be examined and operationalized to explore the sustainable development impacts on any community level. Sustainable development is presented as the balance of the economy, environment, and social equity. Flora's framework organizes community capital into the categories of built, financial, political, social, human, cultural, and natural (Flora and Flora, 2008). Each community must understand their resources and attempt to create a balance that creates a healthy ecosystem and economy while fostering social inclusion. This framework correlates with the typologies of transnational activities, which are, political, economic, and sociocultural practices, that have emerged through case study research and are typically utilized to identify migrants' transnational behavior patterns (Guarnizo, 2003; Portes, 1996; Portes, Guarnizo \& Haller, 2002; Faist, 2000). As the community 
understands their unique resources and works collectively to build a productive and healthy ecosystem, the transnational community can also approach the community in a parallel manner, creating an integrated approach that involves both migrant and nonmigrant community members in a socially inclusive way.

At the community level, the relationship gained through diasporas multiplies the social capital available to members of the home community, as well as allowing migrants to stay engaged in their culture while building bridges between receiving and home communities (Clemens, Özden \& Rapoport, 2014). As migration has created the opportunity to build extended social networks and create communities that transcend geographic borders, it is evident that the community-to-community relationship may benefit from structural organization that supports community level objectives.

Migration and community have a cyclical relationship and the creation of a connective, transnational space, creates an opportunity for the positive impacts of migration to be harnessed while avoiding many of the negative consequences historically experienced. Because an emphasis is shifting from the individual level development to community level development, it is beneficial for a holistic and inclusive approach to understanding community-to-community relationships through transnational community development and support. This type of engagement can have dramatic effects on community level development and has the possibility of reconfiguring traditional power structures to create social and economic change in a manner that can complement and supplement the activities of higher level institutions. 


\subsection{Transnationalism}

A 'transnational turn' in migration and development studies emerged in the early 1990s (Faist, 2004; Glick Schiller, Basch, and Blanc-Szanton, 1991). Transnationalism had appeared in some earlier works but had not gained momentum and popularity until recent years. Randolph Bourne is often credited for introducing the concept of transnationalism in his article Trans-national America published in 1916, where he argued for integration of immigrants into American society instead of forced assimilation. Bourne's concepts were later defined as multiculturalism (Nichols, 2009; Garrett, 2011). Discussions regarding the model of transnationalism reemerged in the article, Transnational relations and world politics, published in 1972 by Joseph Nye and Robert Keohane (Schiller \& Faist, 2012). This examination focused on the effect of transnational agents and organizations on interstate politics. The term transnational relations was used as a shorthand for the broader 'transnational interactions and organizations'. The discussion of transnational relations was cautionary and presented the concept as a potential threat to the State and national values. Five effects of transnational relations were presented including; "1.) attitude changes, 2.) international pluralism, 3) increases in constraints on states through dependence and interdependence, 4) increases in the ability of certain governments to influence others, and 5) the emergence of autonomous actors with private foreign policies that may deliberately oppose or impinge on state policies.” (Nye \& Keohane, 1972, p. 337). This early discourse approached the idea of transnationalism as "contracts, coalitions, and interactions across state boundaries that are not controlled by the central foreign policy organs of governments" (p. 329). Nye and Keohane (1972) contributed a model of complex interdependence that illustrated the 
emerging connectivity between domestic agents on an international platform and the ability for individuals and organizations to engage in discourse and activities that circumnavigate government control (See Figure 4).

Figure 4: A State-Centric interaction pattern vs. Transnational interactions and interstate politics
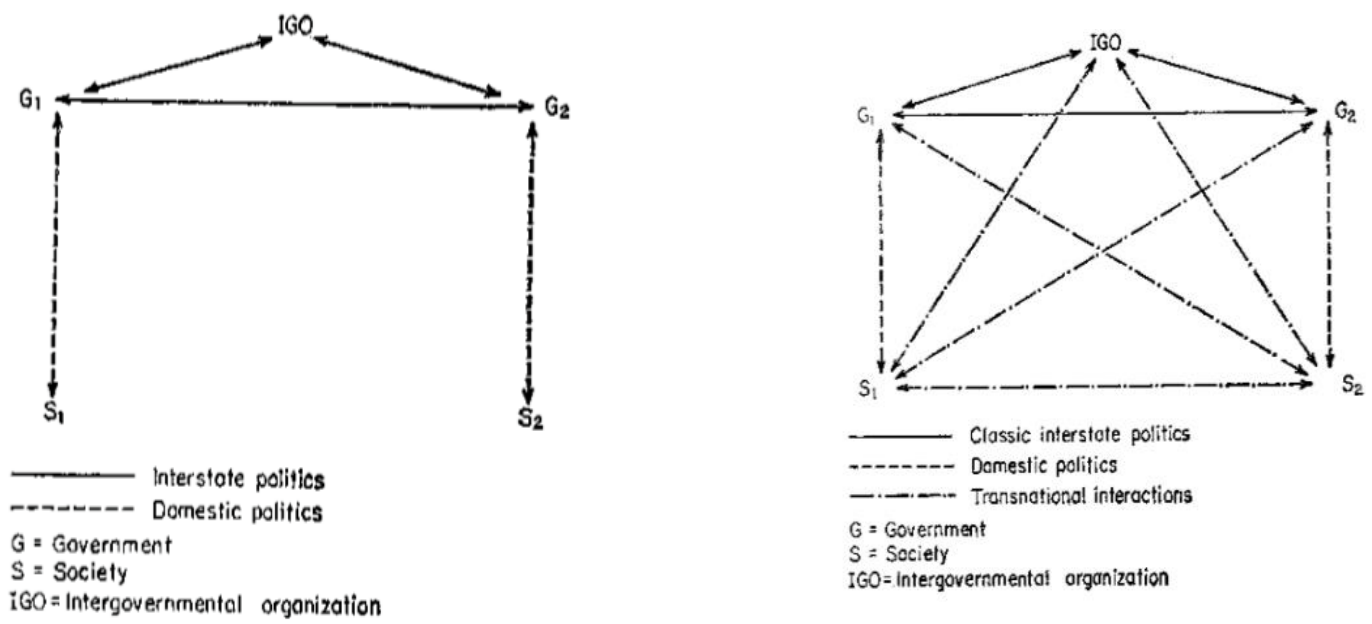

Source: Nye \& Keohane 1972, p. 337

Transnationalism gained momentum in the 1990s when it was popularized by American sociologists Linda Basch, Nina Glick Schiller and Cristina Szanton Blanc (Schiller, Basch, \& Blanc, 1992a, 1992b, 1995). Transnationalism was introduced as “a new analytic framework for understanding migration" in the early 1990s (Glick Schiller, Basch, and Blanc-Szanton, 1991). The concept was later expanded upon and empirically explored by various scholars. Alejandro Portes, a Cuban-American sociologist, has contributed significantly to the area of transnationalism through various studies and collaborations focused on transnational organizations, the relationship between adaptation and transnational engagement, transnational communities, and transnational entrepreneurs (Portes, Guarnizo, \& Landolt, 1999; Portes, \& Radford, 2002, Portes, 
Guarnizo, Haller, 2002). The concept of 'transnationalism from below' was introduced and explored by Luis Eduardo Guarnizo and Michael Peter Smith (Smith, \& Guarnizo, 2003). Jose Itzigsohn (2000), Patricial Landolt (1999), and Haller (2002) have also made interesting contributions to transnationalism through the lens of incorporation, gender, and immigrant economic adaptation. The research of Steven Vertovec (1999) offers insights into transnational social formations, ethnic diasporas, and international migration and Peter Kivisto has explored the changing nature of citizenship and identity as well as engaging in an overall discourse into emerging ideas related to transnationalism and assimilation (Kivisto \& Faist 2008). Lastly, Thomas Faist (2004) a professor of Transnational, Development and Migration Studies at the University of Bielefeld has published widely in the field of transnationlization, international migration, and transnational social spaces.

Recent debate on the subject has taken a positive, but disjointed, direction. The tone of the conversations present the transnational space as an underdeveloped resource, but the nature of the concept and the underlying theory remain vague (Schiller, Basch, \& Blanc, 1995, Haas, 2010; Smith \& Guarnizo, 2003; Faist, 2004). The prior theoretical perspectives regarding migration and development provided critical and optimistic perspectives of the role of migrants in the ever-globalizing world, however the complexity of the activities and attitudes that cross social fields and geographical boundaries necessitates a multifaceted and inclusive approach to fully understand the nuances of this phenomenon. Migrants are increasingly living a dual life, speaking two languages, having homes in receiving and sending countries, maintaining regular contact across borders, and creating transnational spaces that allow for a bidirectional flow of 
information and culture (Portes, Guarnizo, \& Landolt, 1999). Transnationalism offers a framework to understand the reality of migrants' evolving cross border relationships and aligns with the current era of globalization (Al-Ali and Koser 2002).

One of the challenges of this field is there is no clear and agreed upon conceptual framework and varying definitions of the term exist (Portes, Guarnizo \& Landolt, 1999; Faist, 2004; Smith\& Guarnizo, 2003; Haas, 2010). A broad and encompassing description of transnationalism is defined as "a process of movement and settlement across international borders in which individuals maintain or build multiple networks of connection to their country of origin while at the same time settling in a new country" (Fouron \& Glick-Schiller, 2001, p. 60). Basch et al. (1994) suggests transnationalism is simply defined as "a process by which migrants, through their daily life activities create social fields that cross national boundaries": (p. 7). While Vertovec (1999) proposes that it is best expressed as "multiple ties or interactions linking people or institutions across the borders of nation-states" (p. 447). Vertovec also provides six themes through which transnationalism is expressed; "as a social morphology, as a type of consciousness, as a mode of cultural reproduction, as and avenue of capital, as a site of political engagement, and as a reconstruction of 'place' or locality" (p. 447). These definitions share the overarching evidence of linkages that transcend borders, but approach the subject from different lenses.

Portes et al. (1999) argues that to establish and ground this novel area of investigation, it is preferable to delimit the concept to activities and occupations which necessitate consistent and continued cross border contact and physical presence over time for successful implementation (p. 219). This lens provides a solid and well-defined 
conceptual grounding with which to approach transnational research. However, this narrow focus discounts alternative transnational experiences and the dynamic nature of the cross-border relationships of migrants (Schiller \& Faist, 2012) as well as opportunities emerging due to the evolving nature of technology and modern communication systems (Willson, 2006). Therefore, this framework has subsequently been redefined to incorporate these realities and better describe the milieu of the modern migrant experience. One manner that has evolved to counter the narrow definition of transnationalism is the necessity of physical presence. As technologies have expanded to allow individuals to maintain consistent and meaningful relationships regardless of location, the ideas of community and culture are able to be viewed separately from locality and, as a result, lack of physical presence and distance are no longer impediments to the maintenance of communal relationships. (Kennedy and Roudometof, 2002). This in fact opens the doors for the exploration of the phenomenon of transnational communities, existing in an in-between space (Barajas, 2009; Guarnizo, Portes, \& Haller, 2003).

Thematic fields have developed to segment this field into economic (Guarnizo, 2003; Portes, 1996, Portes, Guarnizo \& Haller, 2002), political (Ostergaard-Nielsen, 2002; Guarnizo, Portes, \& Haller, 2003; Nye \& Keohane 1972), and sociocultural (Faist, 2000; Vertovec, 2003; Levitt \& Glick Schiller, 2004, Koundoura, 2012,) typologies (see Table 3). These typologies allow for the examination of the specific mix of transnational activities undertaken by immigrants and migrant networks and provides an avenue for linking activities to development outcomes in the host country (Bowling, 2009). Defining the different spheres of transnational practices also creates a comparable analytic method for research in this realm because the use of political, economic, and sociocultural 
typologies can be utilized across disciplines and is relatively uniform in case studies and research regarding transnationalism. Although the broad categories can be used universally, it is important to explore the distinct manners in which migrants create value within each sphere within their unique home/host country context (Bauböck \& Faist, 2010).

Table 3: Typology of Transnational Practices in Different Spheres of Social Life

\begin{tabular}{|c|c|c|c|}
\hline & \multicolumn{3}{|c|}{ Transnational practices } \\
\hline & Strong & Moderate & Weak \\
\hline $\begin{array}{l}\text { Political } \\
\text { practices }\end{array}$ & $\begin{array}{l}\text { Membership and } \\
\text { participation in the } \\
\text { non-resident country } \\
\text { or transnational } \\
\text { political } \\
\text { organisations; Extra- } \\
\text { territorial voting }\end{array}$ & $\begin{array}{l}\text { Cooperation with } \\
\text { parties or organisations } \\
\text { abroad as a member of } \\
\text { resident country-based } \\
\text { (migrant) organisations }\end{array}$ & $\begin{array}{l}\text { Interest in the } \\
\text { politics and policies } \\
\text { of other countries } \\
\text { or transnational } \\
\text { political actors and } \\
\text { institutions }\end{array}$ \\
\hline $\begin{array}{l}\text { Economic } \\
\text { practices }\end{array}$ & $\begin{array}{l}\text { Transnational } \\
\text { entrepreneurship or } \\
\text { occupational } \\
\text { functions based on } \\
\text { cross-border } \\
\text { exchange of goods, } \\
\text { capital, services, } \\
\text { knowledge or labour }\end{array}$ & $\begin{array}{l}\text { Occasional } \\
\text { occupational } \\
\text { involvement in cross- } \\
\text { border exchange of } \\
\text { goods, capital, services, } \\
\text { knowledge or labour }\end{array}$ & $\begin{array}{l}\text { Use of certain } \\
\text { transnational skills } \\
\text { or resources for } \\
\text { occupational } \\
\text { activities }\end{array}$ \\
\hline $\begin{array}{c}\text { Sociocultural } \\
\text { practices }\end{array}$ & $\begin{array}{l}\text { Membership and } \\
\text { participation in non- } \\
\text { resident country or } \\
\text { transnational } \\
\text { networks or } \\
\text { organisations; } \\
\text { Continuous } \\
\text { participation in } \\
\text { organised forms of } \\
\text { cross-border help and } \\
\text { support }\end{array}$ & $\begin{array}{l}\text { Occasional } \\
\text { participation in } \\
\text { organisations abroad or } \\
\text { transnational networks; } \\
\text { Continuous informal } \\
\text { cross-border help and } \\
\text { support activities } \\
\text { (including transnational } \\
\text { family care) }\end{array}$ & $\begin{array}{l}\text { Participation in } \\
\text { migrant } \\
\text { organisations which } \\
\text { occasionally } \\
\text { cooperate with } \\
\text { organisations in } \\
\text { other countries; } \\
\text { Sporadic informal } \\
\text { cross-border help } \\
\text { and support } \\
\text { activities (including } \\
\text { transnational family } \\
\text { care) }\end{array}$ \\
\hline
\end{tabular}

Source: Reisenauer \& Gerdes (2012).

The evolution of approaches to the issue of transnationality has also led to the delineation of 'transnationalism from above' and 'transnationalism from below' - based on initiation points and level of institutionalization (See Table 4) (Smith \& Guarnizo, 1998). 'Transnationalism from above' refers institutional transnational actors such as, multinational corporations, international institutions, mainstream media, and other elite 
factions (Faist, n.d.). 'Transnationalism from above' is described as a homogenizing force that takes place on a macro-level that transcends two or more states, and includes processes that are projected in an unequal manner by elites that seek, but don't necessarily obtain, dominance in the political, economic and social domains (Smith \& Guarinzo, 1998). Transnationalism from below encompasses grassroots transnational enterprises, migrant networks, social movements, and the basic relationships maintained between individual migrants and country of origin. This type of transnationalism is interconnected with 'transnationalism from above' and often challenges the traditional power structures and institutions and provides agency to individuals typically excluded in the social field (Faist, n.d.).

Table 4: Transnationalism - Types and Level of Institutionalization

\begin{tabular}{|c|c|c|c|c|}
\hline \multicolumn{5}{|c|}{ Sector } \\
\hline & & Economic & Political & Socio-cultural \\
\hline \multirow[t]{2}{*}{$\begin{array}{l}\text { Level } \\
\text { of } \\
\text { institutionalization }\end{array}$} & Low & $\begin{array}{l}\text {-Informal cross-country traders } \\
\text {-Small businesses created by } \\
\text { returned immigrants in home } \\
\text { country } \\
\text { - Long-distance circular labour } \\
\text { migration }\end{array}$ & $\begin{array}{l}\text { - Home town civic com mittees } \\
\text { created by immigrants } \\
\text { - Alliances of immigrant } \\
\text { committee with home country } \\
\text { political associations } \\
\text { - Fund raisers for home country } \\
\text { electoral candidates }\end{array}$ & $\begin{array}{l}\text {-A mateur cross-country sport } \\
\text { matches } \\
\text {-Folk music groups making } \\
\text { presentations in immigrant centres } \\
\text {-Priests from home town visit and } \\
\text { organize their parishioners abroad }\end{array}$ \\
\hline & High & $\begin{array}{l}\text {-Multinational investments in } \\
\text { Third World countries } \\
\text { - Development for tourist } \\
\text { market of locations abroad } \\
\text {-Agencies of home country } \\
\text { banks in immigrant centres }\end{array}$ & $\begin{array}{l}\text {-Consular officials and } \\
\text { representatives of national } \\
\text { political parties abroad } \\
\text {-Dual nationality granted by } \\
\text { home country governments } \\
\text {-Immigrants elected to home } \\
\text { country legislat ures }\end{array}$ & $\begin{array}{l}\text {-International expositions of } \\
\text { national arts } \\
\text { - Home country major artists } \\
\text { perform abroad } \\
\text { - Regular cultural events organized } \\
\text { by foreign embassies }\end{array}$ \\
\hline
\end{tabular}

Source: Portes et al. 1999

\subsection{The Transnational Experience}

\subsubsection{Transnational Immigrants}

Immigrants are in a unique position of attempting to integrate into their new environment while maintaining ties to their home communities. It is often thought that as 
immigrants move away from their home community, they become hyper individualistic and quickly attempt to integrate into the American culture (Barajas, 2009). However, the development of transnational identities increases competing social relationships and heightens the risk for fragmenting communities. Racial, gender, and class inequalities remain across borders and immigrants are often not able to fully assimilate into their new communities (Brown \& Bean, 2006). Often immigrants experience a sense of "inbetweeness", meaning that although there is often an increased sense of home in both places, there was also a sense that these migrants no longer fully belong to either place. They are "in-betweeners", enjoying benefits but also confronting challenges on both sides of the border (Barajas, 2009).

Perspectives on immigrant integration are continually evolving in the increasingly globalized environment. In fact, globalization and integration are associated processes that are essentially connected through transnationalism (Portes \& Zhou 1993). Immigrant integration and transnationalism occur on both a structural and socio-cultural level (See table 5). Socio-cultural integration refers to a sense of belonging while structural integration refers to the ability to incorporate into the major institutions and associations of a society (Erdal, \& Oeppen, 2013). Immigrants experience varying levels of belonging to both home and host country as well as differing levels of access to structural institutions. Understanding the ability to establish, balance, and maintain structural and socio-cultural ties in two countries simultaneously is complex and multifaceted. 


\section{Table 5: Spheres of integration and transnationalism for an individual migrant}

\begin{tabular}{|c|c|c|c|}
\hline & & Integration & Transnationalism \\
\hline \multirow[t]{3}{*}{ Socio-cultural } & Emotional & Degree of belonging & Degree of belonging \\
\hline & $\begin{array}{l}\text { Cultural and } \\
\text { religious }\end{array}$ & $\begin{array}{l}\text { Possible to practice culture } \\
\text { and religion }\end{array}$ & $\begin{array}{l}\text { Possible to maintain cultural } \\
\text { and religious connections }\end{array}$ \\
\hline & Social & $\begin{array}{l}\text { Ability to develop new social } \\
\text { networks/capital }\end{array}$ & $\begin{array}{l}\text { Ability to maintain social } \\
\text { networks/capital }\end{array}$ \\
\hline \multirow[t]{4}{*}{ Structural } & Economic & $\begin{array}{l}\text { Access to appropriate } \\
\text { employment/income }\end{array}$ & $\begin{array}{l}\text { Access to financial resources } \\
\text { and opportunity to transfer } \\
\text { and invest internationally }\end{array}$ \\
\hline & Political & $\begin{array}{l}\text { Opportunities for political } \\
\text { participation }\end{array}$ & $\begin{array}{l}\text { Opportunities for political } \\
\text { participation }\end{array}$ \\
\hline & Legal & $\begin{array}{l}\text { Possibility of (dual) } \\
\text { citizenship and regularised } \\
\text { status }\end{array}$ & $\begin{array}{l}\text { Possibility of (dual) } \\
\text { citizenship and regularised } \\
\text { mobility }\end{array}$ \\
\hline & & $\begin{array}{l}\text { Perceived measures taken } \\
\text { against discrimination }\end{array}$ & \\
\hline
\end{tabular}

Source: (Erdal \& Oeppen, 2013)

Differing perspectives exist regarding the relationship between transnational engagement and the integration of immigrants into a receiving community. Early assimilation theories concentrated on the complete transition of an immigrant from their origin culture to that of their receiving community, the end product being an immigrant that was indistinguishable from other members of the host society (Waters and Jimenez, 2005). This approached immigration from a convergence perspective, theorizing the values, norms, characteristics, and behaviors of immigrants would become increasingly similar over time and second generation immigrants would be homogeneous with their native counterparts (Brown \& Bean, 2006). Over time, the theories developed to embrace the unique culture, language, and background of an immigrant by approaching their reception in a more integrative manner while considering the barriers that exist in the incorporation process.

Portes and Zhou (1993) introduced the theory of segmented assimilation, which recognized the relevance of the classic assimilation model but incorporated the effects of macro-level social conditions on micro-level integration experiences. The segmented 
assimilation model illustrates the structural barriers that exist for many immigrant populations and can stagnate growth, leading to divergent paths of assimilation. In this model, it is argued that there are different factions with which new immigrants may assimilate depending on their social, human and cultural capital, creating divergent assimilation patterns. These assimilation paths include "straight-line" or conventional upward assimilation, downward assimilation, and 'selective acculturation" (Xie \& Greenman, 2005).

Multiculturalism is a popular lens, that takes many different forms, in which to view incorporation efforts of distinct ethnic groups. Traditional multiculturalism acknowledged and accepted the diversity of immigrant populations but was based on the division of the social and the cultural and aimed at managing cultural diversity as "a means of protecting the established society from the new cultural communities" (Delanty, 2003, p. 93). Although this perspective departs from the goal of homogenization, unequal power-dynamics are apparent and the heterogeneity within immigrant groups is not considered (Lefebvre, 1991), creating an atmosphere that consolidates individuals into predetermined enclaves without consideration of their unique abilities and capacity. This reality necessitates an evolving understanding of multiculturalism and compels rural and urban areas to capitalize on this increased diversity and successfully integrate new members instead of isolating or diminishing their differences. One multicultural strategy to promote the positive aspects that arise from the melding of individuals from different areas of the world is interculturalism. This approach encourages cultural awareness and tolerance and views cultural differences as a positive attribute to community well-being. 
Transnational multiculturalism is also an emerging model that focuses on increased flexibility of citizenship that transcends borders (Delanty, 2003).

From a transnational perspective, the relationship between successful incorporation and maintained connections with home country entities is particularly significant. Initially, it was assumed that as an immigrant assimilated into the receiving country their cultural identity and allegiance would shift, dissolving homeland ties and associations (Waters and Jimenez, 2005). Conversely, if an immigrant was not successfully incorporated into society, they must rely on ethnic enclaves for support and their relationships with their country of origin strengthened as they became more isolated from the host country social structure. An overall negative association between integration and transnational engagement was presupposed, creating tension for an immigrant living in-between two cultures (Erdal, \& Oeppen, 2013). However, more recent investigations have found that successful economic and cultural integration can actually support transnational activities of migrant groups by broadening an immigrant's social network and increasing their resources. Integration assists immigrants with development of social and human capital which can then be extended across borders through investments, the development of advocacy and knowledge networks, and linkages of diverse social networks (Kushnirovich, 2015).

Erdal \& Oeppen (2013) provided a typology of the relationship between integration and transnationalism, defining the association as additive, synergistic, or antagonistic (See table 6). Additive relationships represent an immigrant that is able to establish and maintain strong ties to both home and host country. Conversely, antagonistic relationships refer to a negative correlation between integration and 
transnational engagement, where connections to one place result in a feeling of displacement in the other on a socio-cultural level, and demands in one country limit one's ability to engage in the other on a structural level. Lastly, the synergistic interaction presented as the possibility of positive experiences in one country being able to be leveraged to create a multiplier effect of benefits for the other. It is clear the relationship between integration and transnationalism is not simple or straightforward, however this dual connection presents a valuable opportunity to create constructive outcomes for both sending and receiving communities as well as having a notable influence on the welfare and overall happiness of the individual immigrant. Beyond solely focusing on integration effects on immigrants it is also important to note that integration is actually a two-way process where immigrants are also changing and reshaping mainstream society through the social resources they bring into their receiving communities (Üçok, 2011). Integration and incorporation strategies are therefore an important tool in the development of overarching transnational engagement plans.

Table 6: Typology of interactions between integration and transnationalism

\begin{tabular}{clll}
\hline & \multicolumn{1}{c}{ Type of interaction } & \\
\cline { 2 - 4 } & \multicolumn{1}{c}{ Additive } & \multicolumn{1}{c}{ Synergistic } & \multicolumn{1}{c}{ Antagonistic } \\
\hline $\begin{array}{c}\text { Socio-cultural } \\
\text { integration and } \\
\text { transnationalism }\end{array}$ & $\begin{array}{l}\text { Feeling of belonging and } \\
\text { socio-cultural } \\
\text { connections in country } \\
\text { of origin and of } \\
\text { settlement }\end{array}$ & $\begin{array}{l}\text { Feeling of belonging } \\
\text { and connections in one } \\
\text { place give confidence to } \\
\text { further develop } \\
\text { connections in other }\end{array}$ & $\begin{array}{l}\text { Feeling of belonging and } \\
\text { socio-cultural } \\
\text { displace feelings of } \\
\text { belonging in other }\end{array}$ \\
$\begin{array}{l}\text { Structural } \\
\text { integration and } \\
\text { transnationalism }\end{array}$ & $\begin{array}{l}\text { Economically active in } \\
\text { country of origin and of } \\
\text { settlement } \\
\text { (Dual) citizenship }+ \\
\text { regularised mobility }\end{array}$ & $\begin{array}{l}\text { Resources gained in one } \\
\text { place are invested to } \\
\text { develop further } \\
\text { resources in the other }\end{array}$ & $\begin{array}{l}\text { Demand for resources in } \\
\text { one place limits ability } \\
\text { to meet demands in } \\
\text { other }\end{array}$ \\
\hline
\end{tabular}

Source: (Erdal \& Oeppen, 2013) 
Cultural identity is closely related to the concept of integration and is a complex topic in the transnational space. New assimilation theories recognize that the effect of ethnic identity on integration is not necessarily a disadvantage but can provide added value to both the migrant as well as the receiving society (Üçok, 2011). However, there is a tension in transnational literature between conceptualizing identity as a free-floating and malleable process of self-identification versus the more empirical view of identity embedded in socially and politically structured processes of collective action and group formation (Smith \& Guarnizo, 2003). As noted earlier, the sense of "in-betweeness" many migrants experience creates a reality where one's identity is not grounded or stable and often causes tension for the immigrant trying to reconcile their place in two diverse worlds. Identity can be thought of in two manners. First, the traditional view consists of a shared, collective history based on ethnicity and fixed or stable in nature. The second, emergent perspective, is metamorphic and evolving, characterized by similarities as well as differences (Hall, 1990). This position recognizes that "as well as the many points of similarity, there are also critical points of deep and significant difference which constitute 'what we really are'; or rather - since history has intervened- 'what we have become'." (Braziel \& Mannur, 2008, pg. 236).

Consumption also plays a significant role in the construction of identities of immigrants. Acquisition of possessions may strengthen consumer integration of an immigrant in the receiving community. At the same time, consumption behavior is also renegotiated at the home country level. Immigrants are often able to express higher levels of consumption during return visits as well as demonstrate material achievement through social media and other connective technology (Üçok, 2011). As a result, 
immigrants may "culture swap" as they use goods to navigate between their cultural identities and renegotiate relationships between home and host country. This creates a fluidity of identity and has the potential to result in an ambiguity of individual integrity and a diminished sense of overall belonging (Smith \& Guarnizo, 2003)

As a possible means to bridge some of the individual identity challenges experienced by transmigrants, there has been the emergence of diaspora groups organizing and pursing collective endeavors, creating a sense of collective identity. These organized migrant groups include charitable organizations, hometown associations, political affiliates, humanitarian organizations, professional associations, NGOs and other development-focused initiatives, cultural clubs, virtual networks, transnational media initiatives, and other federated associations (O'Neil, 2003). These expanded activities and connections are further examined through the concept of social capital. Social capital theories traditionally focused on the individuals' ability to gain benefits through membership in a social network or other type of social structure (Lin, 1999). However, this research has expanded to include the exploration of social capital as a community level approach. According to Bourdieu (1986) community social capital is “...the aggregate of the actual or potential resources which are linked to possession of a durable network or more or less institutionalized relationships of mutual acquaintance and recognition - or in other words, membership in a group - which provides each of its members with the backing of the collectivity-owned capital, a "credential' which entitles them to credit, in various senses of the word" (p. 21). The emergence of collectivity amongst immigrant groups represents another facet of transnationalism and creates a 
space for immigrants to maintain strong homeland connections while providing greater local level social capital and integration opportunities.

\subsubsection{Sending Country/Community}

Countries with high levels of out migration have a vested interest in maintaining fruitful relationships with diaspora populations. It is important to understand the levels of social order to truly grasp the intricacies of transmigrant engagement by the sending country. Social order can be categorized by the master mechanisms of community, market, and state (Streeck \& Schmitter, 1985). The principle of community refers to the duties and rights attached to members of a collective. Communities are grounded in the values reciprocity, solidarity and trust and bounded by obligations and rights of the included members. Shared knowledge and beliefs, common institutions, and kinship linkages are also characteristics of the community level of social order. The purpose of the state authority is to serve the common good and tasked with widespread development through hierarchical control. Whereas the community distinguishes boundaries of 'us' and 'others', the state is bounded by territorial borders and is tasked with the authority to utilize power and legitimacy to implement country level decisions in political communities. In contrast, the market is not bounded by geographic borders and operates through a dispersed competition that is driven by the interest and acquisition of individual goods by human agents. The market does not take into consideration, or have control over, the impact its pursuits and the subsequent acquisitive activities may have on the future selves of individuals (Faist, 2007). These three mechanisms all have distinct, yet integrated, relationships with the transnational field and potential for valuable transnational interactions. 
Out-migration creates the potential for both positive and negative effects on sending countries and communities. On one hand, high levels of migration often leave a country vulnerable to losing their best and the brightest individuals, reducing human capital. Also, emigrants that maintain relationships with their home country often question state power and may be seen as an antagonistic force (Weeks \& Weeks, 2013). Migrants may cause a "deterritorializeing” effect on nation-states by blurring boundaries, which may ultimately challenge their authority (Basch, Schiller, \& Szanton-Blanc, 1994). One reason for this is transmigrants usually have more established social power than their counterparts still residing in the sending country. By maintaining transnational relationships, especially with disadvantaged groups, these connections can weaken state control because these marginalized factions have new channels of association and are not as dependent on state controls and mandates (Spoonley, Bedford, \& Macpherson, 2003). This reality can weaken political culture. For instance, emigration has traditionally been viewed by the Mexican government as a political threat and a glaring example its failure to generate prosperity. (Weeks \& Weeks, 2013).

However, countries are increasingly realizing the potential benefits of engaging with their diasporas abroad and with the mass movement of people. It is a topic that most governments cannot afford to ignore (Weeks \& Weeks, 2013). There is a mutual benefit to engaging with diaspora emigrant networks at the state level,. The infusion to the economy due to increased remittances is one of the most recognized benefits. However, sending governments are realizing that other synergistic opportunities exist. Governments are identifying diaspora groups abroad as potential liaisons that can be leveraged to lobby in the receiving countries political arena and create diplomatic and development bridges 
(Clemens, Özden \& Rapoport, 2014). The development of state-emigrant relationship has generated a renewed interest and intensified level of communication and cooperation in many policy arenas. In Latin America, governments in the region have intensified their focus and interest on United States immigration policy which has led to discussions and opened up dialogues within the region and with the U.S. that would not have prevailed absent the large emigrant networks (Weeks \& Weeks, 2013).

An emerging advantage that is garnering more interest is the concept of social remittances (Levitt and Nyberg-Sørensen, 2004). Social Remittances encompasses the flow of ideas, knowledge, and 'good' practices such as gender equity, human rights, and democracy (Faist, 2007). Social remittances represent a transnational channel that has the potential to create shifts in the social and human capital of a country. Paired with economic and political reciprocities, may lead to sustainable development at the community and country level (Levitt \& Lamba-Nieves, 2010).

Sustainable development is a term that is has differing connotations throughout disciplines and is associated with unique temporal and spatial dimensions. However, the concept is based in the interconnectedness of three main concepts, the environment, economy, and society (Rudel, 2006). Sustainable community development also encapsulates these three dimensions but reduces the geographic scope by placing focus on a local, tangible level. This concept is captured by the idea that "definitions of sustainable community development stress the importance of striking a balance between environmental concerns and development objectives while simultaneously enhancing local social relationships (Bridger \& Luloff, 1999). 
At the community level, the relationship gained through diasporas multiplies the social capital available to members of the home community, as well as allowing migrants to stay engaged in their culture while building bridges between receiving and home communities (Clemens, Özden \& Rapoport, 2014). This increased social capital has been associated with increased economic returns to sending communities. Economic exchanges have been linked to both positive and negative community level outcomes. These financial remittances are typically channeled to the poor, but seldom reach the poorest of the poor and often only provide temporary relief without leading to permanent financial security (Brinkerhoff, 2008). These fragmented economic interactions tend to lead to short-term benefits and do not offer considerable advancement towards sustainable community development. It is important to examine this unique relationship between migrants and sustainable community development to develop an understanding of how these groups can engage with home communities in a comprehensive and systematic manner that encompasses environmental, economic and societal attributes while minimizing possible negative externalities.

Multilateral agencies and donor governments have also begun to shift focus to the potential influence diasporas can have in the development arena and to the overall reduction of poverty in origin countries (Newland \& Patrick, 2004). There are, in fact, many avenues of influence between the diaspora and home communities that should be acknowledged and explored in relation to sustainable community development. Because an emphasis on diasporas shifts focus from individual level development to community level development, it is beneficial for a holistic and inclusive approach to understanding community-to-community relationships. 


\subsubsection{Engagement Strategy}

In order to harness the value of the diaspora while avoiding undesirable outcomes, sending countries are developing outreach and engagement strategies aimed at building fruitful relationships with their emigrant populations. Diaspora engagement strategies and policies are not stagnant and unitary but instead represent a nuanced arrangement of legislative and institutional and arrangements and programs that fluctuate across timescales and spatial dimensions (Gamlen, 2006). It is essential to consider whether the diasporic engagement strategies should be coordinated as a specific strategy to be developed in addition to the countries existing agendas or integrated into established policies and strategies as a supporting endeavor (Clemens, Özden \& Rapoport, 2014). There are various manners and scales in which sending countries can develop a transnational approach (See Figure 5), it is in a countries interest to develop a comprehensive, integrated, and strategic plan that fits to the unique nature of the diasporic and country level characteristics.

\section{Figure 5: DIASPORA ENGAGEMENT STRATEGIES AND POLICIES}
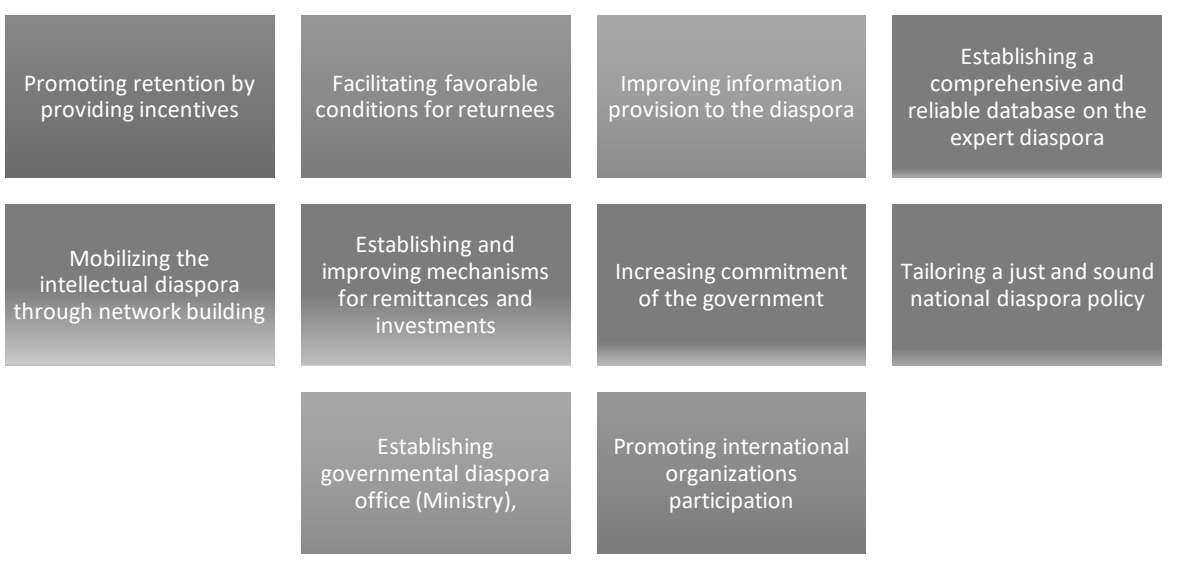

Promoting international

organizations

participation

Source: Adapted from (Woldetensae, 2007) 
In order to successfully navigate this transnational agenda, sending governments must be able to build trust and exercise power in an efficient and responsive manner. According to Foucault (1982) this capacity involves three types of relationships: relations concerning power, communication relationships, and finalized activities. This highlights the importance of understanding underlying power dynamics and establishing a dialogic approach when developing engagement strategies. Three broad levels of engagement can be identified to operationalize this transnationalization of government: policies aimed at capacity building and generating a discursive, state-centric 'transnational national society', the extension of rights to emigrant populations, and the extraction of obligations from the diaspora (Gamlen, 2006). Capacity building refers to the dual roles of institution building and symbolic nation building which establishes an objective capacity and relationship of communication in which transnational objectives can be transmitted and received (Foucault, 1982). Diaspora networks often include diverse and diffuse identities. At the same time, there is frequently a lack of coordination and cohesion between emigration focused actors within the state system. This creates a difficult atmosphere to coordinate transnational activities. By building capacity at the institution level to increase the state's ability to govern diaspora populations while simultaneously creating the engaging in symbolic nation-building to produce a homogenous or cohesive national diaspora the transnational space is more receptive for additional value driven transnational activities and relationships (Gamlen, 2006).

While capacity building initiatives aim to create a relationship of communication, extending rights and extraction of obligations represents the finalized actions of power exercised by the state. Incentivizing emigrant membership in home-society through 
political incorporation and other rights transfers, generates goodwill and entices steady flows of investments and remittances from the diaspora (Itzigsohn, 2000; Goldring, 1998). States sometimes feel threatened by the extension of social and civil rights to their emigrants. However, it is an important component in order to leverage the shared national identity to garner returns. The final action in this engagement process is to take advantage of the mutual trust and institutional structures developed to support the transnational space and to implement programs that can channel social and financial remittances as well as develop other beneficial networks and return value from the diaspora (Gamlen, 2006).

Table 7: Broad Level Diasporic Engagement Categories

Capacityuiding
-Symbolic nation-
building
-Conferences \&
conventions
-Shaping media \& PR
-Cultural promotions \&
induction
-Inclusive rhetoric \&
symbols
- Institution building
-Consular and
consultative bodies
-Building transnational
networks
- Monitoring efforts
-Dedicated bureaucracy
- Ministerial level agency

Extendingights
-Political incorporation
- Can run for office
- Parliamentary
representation
- Indefinite,
unconditional vote
- Postal voting
- Embassy voting
- Must return to vote
-Dual nationality
-Special membership
concessions
- Civil and social rights
-Welfare protection
- Tourism services

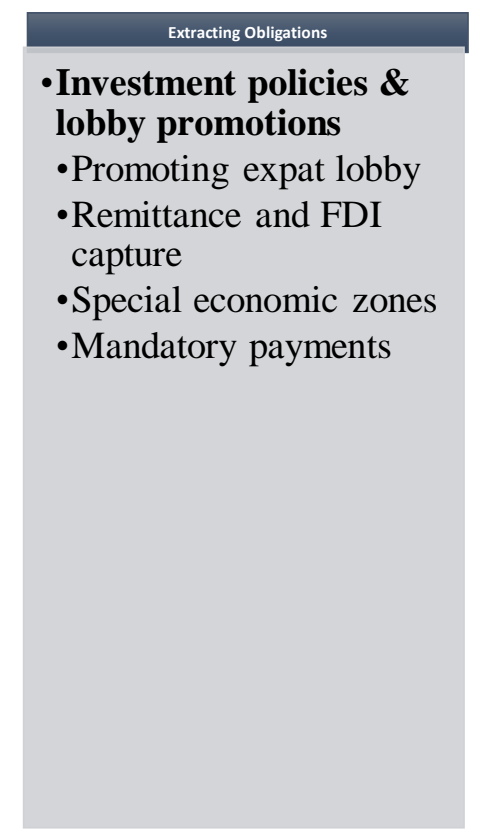

Source: Adapted from (Gamlen, 2006) 
Transnational engagement of immigrant populations is incorporated into government strategies to differing degrees. The Mexican government has established a comprehensive diaspora engagement plan that includes active outreach to diaspora communities and the extension of continued rights and privileges (Flores-Yeffal \& AysaLastra, 2011). The same level of national level policy development is not found throughout the rest of the region. Some countries, including El Salvador and Guatemala, have attempted to establish similar engagement strategies although these programs are at a smaller scale and still in nascent stages (Sandoval, 2013) (Portes, Guarnizo, \& Haller, 2002). Allowing emigrants to maintain voting rights is an engagement strategy that serves the dual purpose of influencing local policy while maintaining civic relationships with individuals that have left the country but still demonstrate a level of concern for the wellbeing of their home country and community (Lafleur, 2015). Similarly, extending citizenship rights to emigrants residing abroad is another manner sending governments utilize to maintain a bidirectional relationship with emigrants that are permanently living abroad. The phenomenon of dual citizenship embodies the concept of transnationalism by illustrating the manner in which individuals are formally linked to more than one country (Weeks \& Weeks, 2013). The majority of Latin American countries extend dual citizenship rights to their citizens. Before the passage of the Immigration Reform and Control Act (IRCA) of 1986, El Salvador, Peru, Panama, and Uruguay granted this right. Subsequently, in the early 1990s, eight more countries (Mexico ,Brazil, Costa Rica , Colombia, Dominican Republic, , Guatemala, Ecuador, and Venezuela) followed suit by passing laws to provide for this right. Honduras, Bolivia, and Chile joined in 2003-2004, 
following increasingly restrictive immigration policies following the September 11, 2001 attacks (Weeks \& Weeks, 2013).

A non-governmental strategy that has aided in linking these two groups is the development of communication channels and media publications that connect the interests within these networks (Mercado, 2013). This creates a bidirectional flow of ideas, concerns, and current events, allowing immigrants to directly connect with their home country while also receiving information directly from members of the sending community. This produces an ongoing conversation, increases real time understanding, broadens knowledge bases, and serves as a historical artifact of the interactions within the network. Other transnational networks are engaged in activities focused on technology and business as well as advocacy. It is noted that even when local policy is weak and local movements are non-existent, advocacy networks focused on women's human rights generate high levels of impact on a community level (O'Brien, 2015).

\subsubsection{Receiving Country/Community}

To construct a productive transnational space, it is imperative that all stakeholders reap benefits, otherwise the significant investment of time and resources required will not be considered worthwhile. The benefits for migrants and the country of origin have already been discussed. However, the role of the receiving country is often overlooked or diminished in this discussion. One perspective is that transnationalism of immigrants threatens the solidarity and cultural integrity of the receiving society (Portes, 1999). Conversely, successfully receiving and incorporating immigrant populations into a society generates a dynamic population, increases innovative opportunities, and develops diplomatic and economic bridges across the globe. Diminishing downward assimilation 
of immigrants lessens strains on government funded welfare and support programs while developing productive and contributive citizens (Erdal \& Oeppen, 2013).

The manner in which governments of nations, regions, and cities approach immigrant reception has a drastic effect on the reaction and loyalty of the migrant towards the receiving community as well as their approach to transnational engagement (Portes, 1999). An example of the effects of unreceptive reactions to arriving immigrants is illustrated by a case study undertaken with a focus on second-generation Mexican adolescents in a region of California. The state adopted hostile measures aimed at reducing benefits available to immigrants and diminishing the use of foreign language usage among the Spanish speaking population. In response to these mandates, community members began to identify more strongly with their Mexican heritage and their loyalty and identification with the United States diminished. In fact, prior to these changes, 17 percent of this community identified as Mexican while 90 percent identified as American or Hispanic. After the measures were enacted the ethnic identification dramatically shifted with a remarkable 40 percent identifying as Mexican (Portes \& Macleod, 1996).

Developing engagement strategies that balance the successful integration of immigrants into the structural and socio-cultural dimensions of the receiving country, while respecting the ethnic identities of immigrants is a complex, but necessary, task for countries with high levels of immigration.

\subsubsection{Engagement Strategy}

Government agencies and development organizations in the United States are realizing the potential contributions of diaspora populations. For example, the United 
States Agency for International Development (USAID) has launched a comprehensive diaspora partnership initiative to collaborate with immigrant populations which are "uniquely positioned to amplify and sustain global growth" (USAID, n.d.). The program focuses on leveraging diaspora engagement through the channels of entrepreneurship and investment, post-disaster response, market linkages and business networks, as well as skills and knowledge transfer networks. Through this initiative, USAID has developed the African Diaspora Marketplace, India Investment Initiatives, Raices, and MicroMentor. These diaspora driven initiatives focus on linking diasporas with home communities to provide entrepreneurial mentorship, funding for investment in small business development, as well as technical assistance for development and growth of diaspora-run businesses (USAID, n.d.).

USAID has also partnered with the U.S. Department of State to launch the International diaspora Engagement Alliance (IdEA). This alliance focuses on three core pillars of diaspora engagement; entrepreneurship, innovation and philanthropy and volunteerism. IdEA recognizes diasporas are "informal ambassadors for the United States in their countries of origin, and the diplomatic and developmental influence of global diaspora communities has been largely overlooked" (International diaspora Engagement Alliance. n.d.). An annual Global Diaspora Week (GDW) is organized by this partnership to create awareness of diaspora contributions and stimulate interaction and crossfertilization of ideas among diaspora groups (Global Diaspora n.d.). The IdEA also supports business platforms that promote the entrepreneurial spirits through business competitions conducted throughout the Caribbean and Latin America (LaIdea, n.d.; Compete Caribbean, n.d.) 
Community level program objectives and local policy shift from supporting transnational engagement to solely promoting integration efforts. English language classes and citizenship preparation assistance are among the most widely offered programs. Training programs, small-business development support and funding opportunities are also prominent local level tools to aid in the economic integration of immigrants (Portes, 1998). The institutions providing these services do not typically utilize strategies that create a parallel objective of encouraging immigrants to leverage their new skills in the transnational space. Although, the development of skills, financial resources, and social capital contribute to the development of immigrants and can translate into increased constructive transnational activities, there are often constraints and obstacles that obstruct the ability to mobilize this increased human and social capital in the transnational arena. Adjusting local level policy and programmatic perspectives to shift towards a dual integration/transnational approach may provide an advantageous platform for immigrants to prosper locally while making significant contributions to their country of origin (Brown \& Bean 2006).

\subsubsection{The Transnational Space}

The increasing focus on transnationalism has created the necessity to understand the relationships of migrants that transcend borders and connect disparate entities. Space is a central concept to the transnational field and the fluidity of cross-border engagement presents a fundamental challenge to methodological nationalism (Faist, 2000).

Methodological nationalism is underpinned by the assumption that equates country to the unit of analysis and conflates the national state institutions to the main social context influencing and affecting migration and immigrant issues. Transnationalism moves 
beyond this structure by recognizing that cross-border social ties and relationships maintained by migrant groups compel transnational researchers to approach investigations with a relationally organized spatial framework (Faist, 2012). The concept of transnational space provides an expanded lens to view the totality of the networks constructed by migrants that span the borders of at least two territories (Jackson, Craig, \& Dwyer, 2004).

Mountz and Wright (1996) present the idea of transnational space as "the medium through which migrants organize their lives" (pg. 415). Additionally, transnational fields may be understood "not as spatial metaphors but as systems of social relations composed of networks of networks that may be locally situated" (Schiller \& Çağlar 2009, pg. 180). Transnational space is socially constructed (Collyer \& King, 2015) and emphasizes the individual agency of immigrants, regardless of level of power and influence, to exert strategic influence on its production (Conradson \& Latham, 2005). Faist (2004a) posits that transnational space is ultimately a combination of structural controls and individual agency, involving "processes that signify a transformation in the spatial organization of social and symbolic relations" (pg. 3). In this realm, a distinction is drawn between material geographic spaces, symbolic spaces, and imaginative spaces (Jackson, Craig \& Dwyer, 2004). Lefebvre (1991) criticized the notion of 'absolute space' because of the involvedness and different planes ranging from physical to perceived and imagined. Building on Lefebvre's insights, Harvey (1990) developed a comprehensive "grid of spatial practices" encompassing 'material space' (experience), representations of space' (perception) and 'spaces of representation' (imagination) (See table 8). These three dimensions illustrate the interrelated aspects related to social 
practice and how it is related to space. 'Material space' explains the material and physical flows across space and the concrete way in which space is experienced. 'Representation of space' refers to the symbolic and normative manners in which space is perceived and provides the underlying knowledge and codes that allows the other dimensions to be understood and communicated. The third dimension, 'spaces of representation' represents the ability and draw to create alternate visions of space. This dimension creates new meanings and may challenge the first two dimensions. Viewed together, the three dimensions not only offer a framework for understanding space, but also a transformative approach to spatial practices (Harvey, 1990).

\section{Table 8: A 'grid' of spatial practices}

\begin{tabular}{|c|c|c|c|c|}
\hline & $\begin{array}{c}\text { Accessibility and } \\
\text { Distanciation }\end{array}$ & $\begin{array}{c}\text { Appropriation } \\
\text { and Use of Space }\end{array}$ & $\begin{array}{l}\text { Domination and } \\
\text { Control of Space }\end{array}$ & $\begin{array}{c}\text { Production of } \\
\text { Space }\end{array}$ \\
\hline $\begin{array}{c}\text { Material Spatial } \\
\text { Practices } \\
\text { (experience) }\end{array}$ & $\begin{array}{l}\text { flows of goods, money, } \\
\text { people, labor power, } \\
\text { information, etc.; transport and } \\
\text { communications systems; } \\
\text { market and urban hierarchies; } \\
\text { agglomeration }\end{array}$ & $\begin{array}{l}\text { land uses and built } \\
\text { environments; social spaces } \\
\text { and other 'turf' designations; } \\
\text { social networks of } \\
\text { communication and mutual aid }\end{array}$ & $\begin{array}{l}\text { private property in land; state } \\
\text { and administrative divisions } \\
\text { of space; exclusive } \\
\text { communities and } \\
\text { neighborhoods; exclusionary } \\
\text { zoning and other forms of } \\
\text { social control (policing and } \\
\text { surveillance) }\end{array}$ & $\begin{array}{l}\text { production of physical } \\
\text { infrastructures (transport and } \\
\text { communications; built } \\
\text { environments; land clearance, } \\
\text { etc.); territorial organization } \\
\text { of social infrastructures } \\
\text { (formal and informal) }\end{array}$ \\
\hline $\begin{array}{c}\text { Representations } \\
\text { of Space } \\
\text { (perception) }\end{array}$ & $\begin{array}{l}\text { social, psychological and } \\
\text { physical measures of distance; } \\
\text { map-making; theories of the } \\
\text { 'friction of distance' (principles } \\
\text { of least effort, social physics, } \\
\text { range of a good, central place } \\
\text { and other forms of location } \\
\text { theory) }\end{array}$ & $\begin{array}{l}\text { personal space; mental maps of } \\
\text { occupied space; spatial } \\
\text { hierarchies; symbolic } \\
\text { representation of spaces; } \\
\text { spatial 'discourses' }\end{array}$ & $\begin{array}{l}\text { forbidden spaces; 'territorial } \\
\text { imperatives'; community; } \\
\text { regional culture; nationalism; } \\
\text { geopolitics; hierarchies }\end{array}$ & $\begin{array}{l}\text { new systems of mapping, } \\
\text { visual representation, } \\
\text { communication, etc.; new } \\
\text { artistic and architectural } \\
\text { 'discourses'; semiotics }\end{array}$ \\
\hline $\begin{array}{c}\text { Spaces of } \\
\text { Representation } \\
\text { (imagination) }\end{array}$ & $\begin{array}{l}\text { attraction/repulsion; } \\
\text { distance/desire; access/denial; } \\
\text { transcendence; 'medium is the } \\
\text { message' }\end{array}$ & $\begin{array}{l}\text { Familiarity; hearth and home; } \\
\text { open places; places of popular } \\
\text { spectacle (streets, squares, } \\
\text { markets); iconography and } \\
\text { graffiti, advertising }\end{array}$ & $\begin{array}{l}\text { Unfamiliarity; spaces of fear; } \\
\text { property and possession; } \\
\text { monumentality and } \\
\text { constructed spaces of ritual; } \\
\text { symbolic barriers and } \\
\text { symbolic capital; construction } \\
\text { of 'tradition'; spaces of } \\
\text { repression }\end{array}$ & $\begin{array}{l}\text { utopian plans; imaginary } \\
\text { landscapes; science fiction } \\
\text { ontologies and space; artists' } \\
\text { sketches; mythologies of } \\
\text { space and place; poetics of } \\
\text { space; spaces of desire }\end{array}$ \\
\hline
\end{tabular}

Source: (Harvey, 1990, pg. 220-221)

A popular method for understanding transnational space is the triadic approach. This approach arose due to the perceived inadequacy of the utilization of binary opposites in reflecting the complexity of the relationships that develop across borders (Collyer \& King, 2015). This approach simultaneously "links transmigrants, the localities to which 
they migrate, and their locality of origin"(Smith \& Guarnizo, 2003, pg. 13). However, the triadic approach has been challenged because it "puts migrants in the air" (Pries, 2001, pg. 21), outside of the localities in which they move between. A return to a duality approach allows for the integration of geographic and social space and places migrants as a fluid actor, embedded in the structure (Collyer \& King, 2015).

\subsection{Immigrant Entrepreneurs}

\subsubsection{General overview}

Immigrants engaging in entrepreneurial activities have been identified as a particularly impactful group that have the potential to significantly contribute to the development of both their home and host communities (Kushnirovich, 2015). Entrepreneurship is often deemed a critical activity to increase stability and drive economic opportunity in developing countries. However, the vast majority of entrepreneurial related research has been conducted in advanced economies and is not transferrable to developing nations with vastly different political, cultural, and economic ecosystems. More recent research expands on earlier theories by recognizing that entrepreneurship is a mechanism to capitalize on knowledge spillovers to stimulate economic growth (Audretsch ,2004). These theories emphasize the role entrepreneurship plays in multiplying the intrinsic knowledge of the individual by acting as a catalyst for other actors to start new enterprises. There are two kinds of knowledge spillovers: internal and external. External knowledge spillovers refer to the positive impact that entrepreneurial activity has on the surrounding community, region, or nation. The concept of internal knowledge spillovers illustrates the meaningful contribution that can be taken advantage of in a collective entrepreneurial environment. Internal knowledge 
spillovers occur when there is a positive impact of knowledge between individual of a group or organization. It illustrates how the growth and creation of innovative ideas can be multiplied when a group can build upon each other's perspectives, intrinsic knowledge, and social connections. (Carlino, 2001).

Integration patterns of immigrants attempting to engage in entrepreneurial activities is critical to the success of business initiatives as well as their ability to engage in transnational activities (Kushnirovich, 2015). There are a diverse range of transnational engagement strategies and activities that exist between immigrants and their home community and country. Traditionally, remittances have been the dominant focus for examining the relationships of migrants between destination and origin countries. This type of activity will most likely remain strong, as it is a direct link to sending households and an important family tie. However, this sole focus on economic indicators creates an imbalanced view of how migration affects overall community well-being. Immigrant entrepreneurs have the potential to capitalize on expanded social networks to create more community level impacts and institutional development within home countries (Stewart, 2012). Immigrant entrepreneurs have the potential to capitalize on their unique set of skills and knowledge to transfer entrepreneurial competencies to members of their home communities. This knowledge and resource transfer can create a sustainable impact and deter the dependence on monthly remittances to sustain households (Waldinger, 2014). Heightened entrepreneurial capabilities paired with investment and resource transfers empowers individuals in developing nations to create opportunities for their communities and direct the development initiatives (Phillips, 2009). 
Various conceptual frameworks have been developed to account for the trends of immigrant entrepreneurship. Ivan light (Light, 1973) presented the notion that hostile environments within receiving communities may propel immigrants to pursue selfemployment opportunities. Immigrants that experience high levels of frustration and hardships when attempting to integrate into the economic society often pursue opportunities outside of the traditional economy, pursuing self-employment opportunities and creating stronger social bonds within their local ethnic population. This connection to the ethnic community subsequently supports the immigrant's ability to compete in broader markets by creating information networks, support for the initial business with a loyal customer base, access to co-ethnic labor, and access to favorable sources of credit (Light \& Bonacich, 1991).

Another explanation focused on the investigation of catalysts of immigrant entrepreneurship centers around the concept of 'middleman minorities'. This concept posits that certain groups are more disposed to entering into entrepreneurial endeavors based on traditional social positions and traditional economic activities of the immigrant populations. This concept grew out of observations that a high level of ethnic businesses were started by groups that were historically trading populaces of minority status (Bonacich, 1973). This argument presumes individuals are predisposed to entrepreneurship, and the intrinsic attitudes and economic cultures of a group is predictive of immigrant entrepreneurial behavior. The businesses of these immigrant groups are not tied to co-ethnic support and are not geographically clustered around ethnic settlements. Rather, these businesses tend to target low-income groups in inner cities. It is suggested that the middleman minorities have a sojourning orientation that 
intensifies their place as an intermediary with the ability to bridge social networks, enhancing their business practices. The migration of middleman minorities is often economically driven and the groups typically are focused on amassing capital, maintaining ties with colleagues in both host and origin countries, but remain detached from the host society (Verdaguer, 2009).

This concept remains relevant but cannot be viewed as a comprehensive model as many examples of groups without traditional economic backgrounds have succeeded in creating and maintaining businesses in receiving countries, as an example Greek fishermen, with no traditional business experience, successfully became restauranteurs in the U.S. This culturalist explanation, arguing attitudes, beliefs, and patterns of behavior are the most important underlying factor in entrepreneurial pursuits of immigrants is no longer considered broadly illustrative of immigrant entrepreneurship (Portes, 1998). Because the notion that groups pursue entrepreneurial endeavors because they are entrepreneurial by nature has been expanded to include other factors, the programmatic and policy discussions of how to promote and support entrepreneurship throughout all immigrant populations can be seen as valuable for both receiving and sending countries, as well as the for the well-being of immigrant populations.

To further explore the social and economic context of immigrant entrepreneurs a labor market incorporation analysis was introduced in the late 1970s and further expanded upon in the 1980s. This model suggested that a two-tiered labor market exists for both migrants and non-migrants. This market is comprised of a primary and secondary segment. The primary segment is characterized by credential-based selection criteria, rules and regulations governing performance and wages, and formal career 
advancement channels. Conversely, the secondary market is illustrated by relatively low pay and productivity, limited advancement opportunities, and an atmosphere where ethnicity status was an important selection criteria (Piore, 1980). Within this model, immigrants were consistently located in the secondary labor market, and because the permeability between primary and secondary markets was relatively low, immigrants had fewer opportunities to achieve socio-economic advancement. This model was expanded on by Portes and Bach (1985) to add flexibility by illustrating that immigrants often have the opportunity to create economic alternatives that are unavailable to the native-born labor market. This idea was coined the 'ethnic enclave' model. This model focused on exploring immigrant communities and how they were often able to incubate and accelerate ethnic businesses (Portes \& Rumbaut, 2014). Portes and Bach illustrated this concept through a study of Cuban refugees in the Miami region that successfully revitalized the area where the ethnic enclave settled and saw a rise in Cuban owned businesses from 8 to 21 percent within a 6-year period. This study expanded on earlier concepts by positing that Cuban immigrants not only settled in the United States with predetermined entrepreneurial attributes but also created an atmosphere that stimulated the creation of these qualities (Portes \& Bach, 1985).

Waldinger (1986) provided a model, referred to as the 'interactive approach', that integrates both the host country's opportunity structure and the immigrant groups' social structure. Later, it was suggested that each immigrant group has unique characteristics and circumstances that allow for the exploitation of non-ethnic opportunities within the immigrant community. Once the ethnic community becomes well-established, and internal entrepreneurial success is supported, individuals will utilize familial, personal, 
professional, and community networks in an integrated fashion to create tailored business strategies. Three categories were presented to explore variations in immigrant entrepreneurship patters, including; pre-migration circumstances, the context of migration, and post-migration characteristics. This model, although more broadly focused on external and internal factors, is limited because an underlying assumption is that ethnic resources are available to the ethnic group in an equal and comprehensive manner and it excludes the internal deviations of class, gender, religion, and other factors that create diversity within immigrant populations (Verdaguer, 2009).

When exploring the success of immigrant populations, it is evident that each group has unique social, economic, and cultural circumstances that create distinct paths to success or barriers to entry. Often the immigrant group fits into different patterns and contexts that include a mix of the frameworks presented above. For instance, the Jewish and Chinese populations are often suggested as examples of successful 'middleman minorities', although there is likely a combination of factors underlying the accomplishments of these groups. These immigrant populations are considered to be culturally predisposed to entrepreneurial tendencies, as they were often positioned between producer and consumer in roles as traders and money lenders within their countries of origin. However, it appears that this predisposition was frequently paired with blocked or limited access to opportunity structures and hostile receptions in receiving communities. For instance, segregation laws in the United States hampered Chinese immigrants from learning English, diminishing the opportunity for effective integration and propelling them into self-employment arrangements.

The first major wave of Jewish immigrants to the United States were from 
Germany and were largely educated. This group was able to establish success within a couple of generations. However, the second large group of Jewish immigrants came from Russia and Eastern Europe and were considerably less educated as their counterparts. However, the established Jewish population was able to provide high levels of support to this group through food, shelter, jobs, and increased social capital. They had a vested interest in incubating this group to ensure ethnic survival and advancement. This unified group integrated into their receiving society at a minimal level, only to the extent necessary to prosper in the economic arena (Bonacich, 1973). The immigrant group continued to grow due to the creation of a valuable business network, informal lines of credit, and protected access to employment opportunities. As this groups' coethnic economic success heightened, external hostility from American society increased because of a perceived lack of integration. This example, shows attributes of "middleman minority' entrepreneurs but also refers to the strength of ethnic enclaves and ethnic community incubation as well as hostile reception contexts. Many connecting factors led to the overall entrepreneurial success of this immigrant population (Verdaguer, 2009).

The Korean immigrant population is an interesting example of the use of transnational entrepreneurship and the ability to expand beyond circumscribed co-ethnic markets. Korean immigrants have been able to capitalize on local demands for ethnic products and create transnational bridges that allow for financial flows to their country of origin and the acquisition of products that had a distinct demand in their communities of origin (Portes, 1998). In the 1960s, the Korean population began businesses based on the increased demand for wigs and hair treatments, influenced by European and African style, within their ethnic enclaves. These individuals became importers and business 
owners. Once established, as illustrated in the 'interactive approach', these groups were able to successfully expand outside of their ethnic markets into African American neighborhoods. In these external communities, the Korean entrepreneurs expanded their beauty businesses to incorporate retail options. They benefited from cheap rent in their new business communities and advantageous credit terms within their co-ethnic import relationships (Light, Bonacich, 1991). This is an illustration of how external opportunity structure and intrinsic social structure and relationships are able to be integrated and exploited to create successful entrepreneurial endeavors outside of traditions ethnic enclaves.

Mexican immigrant groups have seen substantially lower levels of entrepreneurship when compared to other immigrant populations. Many possible reasons for this have been posited, including barriers to financial capital and lower levels of human capital acquisition. However, this alone would not explain the low levels of selfemployment, as other examples suggest lack of employment opportunities with adequate wages often drives individuals to entrepreneurial activities, such as in the Cuban groups in Miami. One notable difference between the Cubans and Mexicans, is the context of migration. Much of the Cuban population arrived as refugees and this status created a social cohesion that promoted the production of efficient ethnic enclaves. The Mexican population has not had the same migration experience and may not experience the same level of social cohesion (Portes, 1998).

Also, an interesting temporal comparative can be drawn between Japanese and Mexican groups. The Japanese, similar to Mexican immigrants, experienced high level of hostility and discrimination upon initial arrival and had similar levels of human capital, 
however the Japanese engaged in entrepreneurial endeavors at a much higher rate than their Mexican counterparts. A primary reason for the difference between these groups can be viewed through temporal expectations. The proximity of Mexican immigrants to their country of origin allowed for the alternative to return home, and many Mexicans planned for eventual return migration to their home community after they had sufficiently supported their family or had accumulated enough assets to retire back home (Portes, 1998). The Japanese, on the other hand, had little opportunity to return home because of the distance and resources required. The Japanese immigrants intended on staying in the United States and built their life in a manner that provided for a prosperous economic future. The Japanese also, benefited from high levels of social solidarity that supported their initial success. However, it was found that in second and subsequent generations this social solidarity diminished, as many Japanese transitioned to professional employment arenas, indicating that this solidarity may be temporal and situational in nature (Ujimoto, Bonacich, \& Modell, 1982).

Through exploring the underlying characteristics of these immigrant entrepreneurial models and reviewing cases of immigrant groups that have been able to achieve success, a better understanding of the unique mix of extrinsic and intrinsic entrepreneurial characteristics of the Nicaraguan immigrant entrepreneurs can be investigated. Further this groups circumstances will be evaluated to understand the unique barriers as well as opportunities that exist for this specific population. 


\subsubsection{Latino Entrepreneurs}

Latino immigrant entrepreneurs have the potential to bolster the U.S. economy, however they are often overshadowed by other immigrant entrepreneur groups such as Indian, Taiwanese, and Chinese. It is essential to understand the distinct characteristics of Latino entrepreneurs in order to appreciate the unique challenges and recognize the potential of this group in the transnational space. In 2010, one out of every six people living in the United States was Hispanic. This is an increase from one out of eight in 2000 (U.S. Census Bureau, 2000; 2010). The Survey of Business Owners (SBO) (U.S. Census Bureau, 2012) reports that this group engages in entrepreneurial activities at an elevated rate compared to overall workforce. Engagement rose from 8.2 percent to 13 percent between 2000 and 2010 (see figure 6). In fact, the entrepreneurial spirit of the Latino population has strengthened and continually increased while the self-employment rates of the overall population has shown an overall decrease over this 10-year span (See figure 7).

Figure 6: Representation of Hispanics in workforce (Age 25-64)

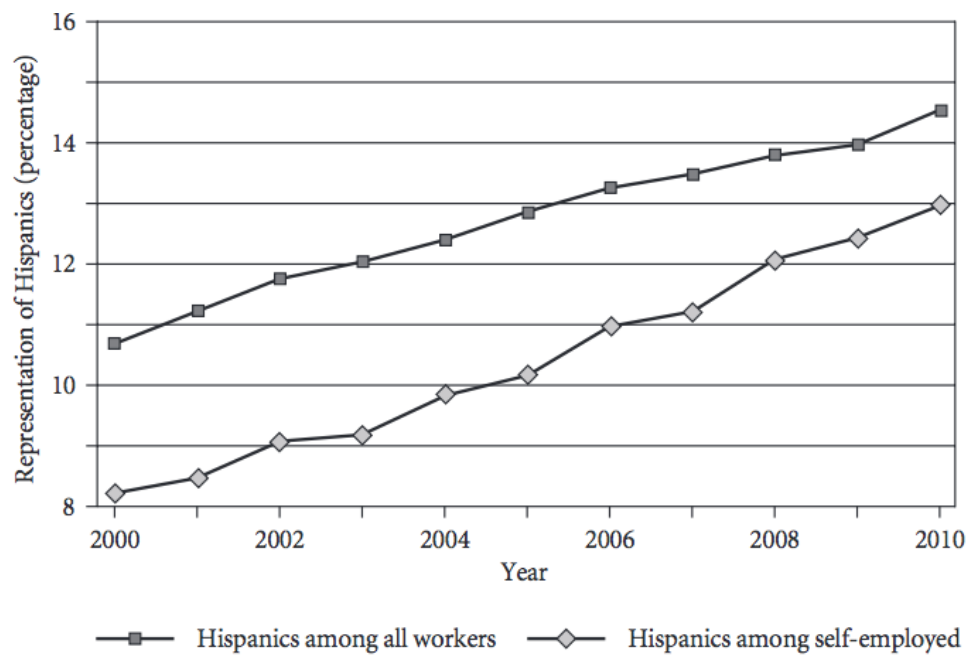

Source: (Davila \& Mora, 2013, pg. 2) 
Figure 7: Representation of Hispanics in the workforce and Hispanic and nonHispanic self-employment rates, 2000-2010

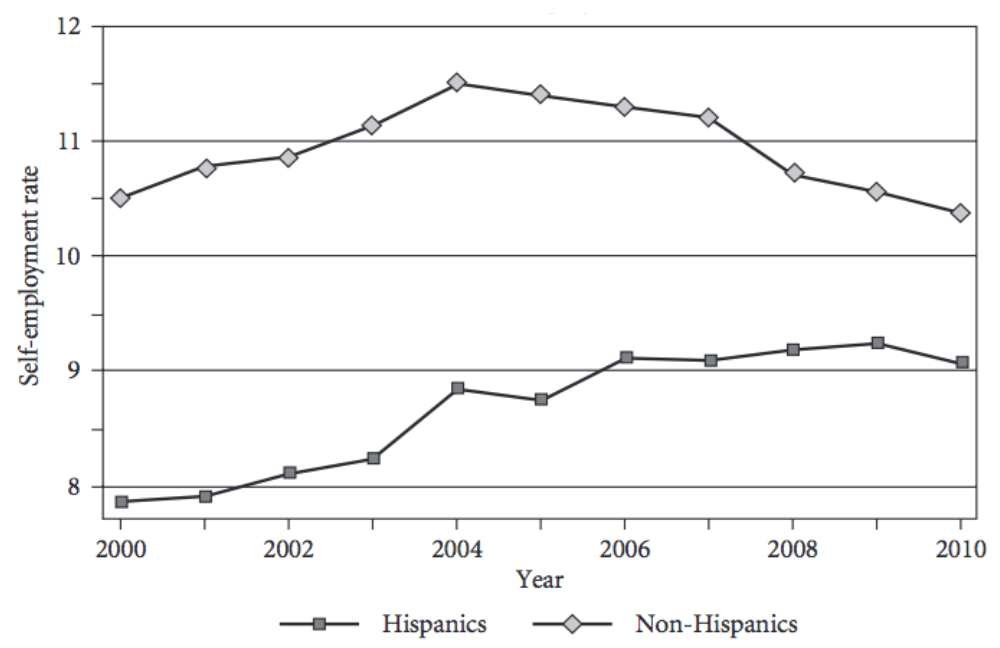

Source: (Davila \& Mora, 2013,pg. 2)

Further, the Latino immigrant population is particularly active in the entrepreneurial arena. It is estimated immigrants own over 50 percent of the Hispanicowned businesses and the immigrant share of self-employed businesses has steadily grown on a yearly basis, including during 2007-2009, a period known as the Great Recession (See figure 8) (Davila \& Mora, 2013). Since the Latino population represents a large portion of the U.S. population and entrepreneurship is particularly prevalent within immigrant Latinos, further investigation into the motivations and strategies of this group will prove to be valuable to capture and enhance domestic economic contributions while promoting transnational engagement among these business owners. 
Figure 8: Representation of Hispanic immigrants and natives

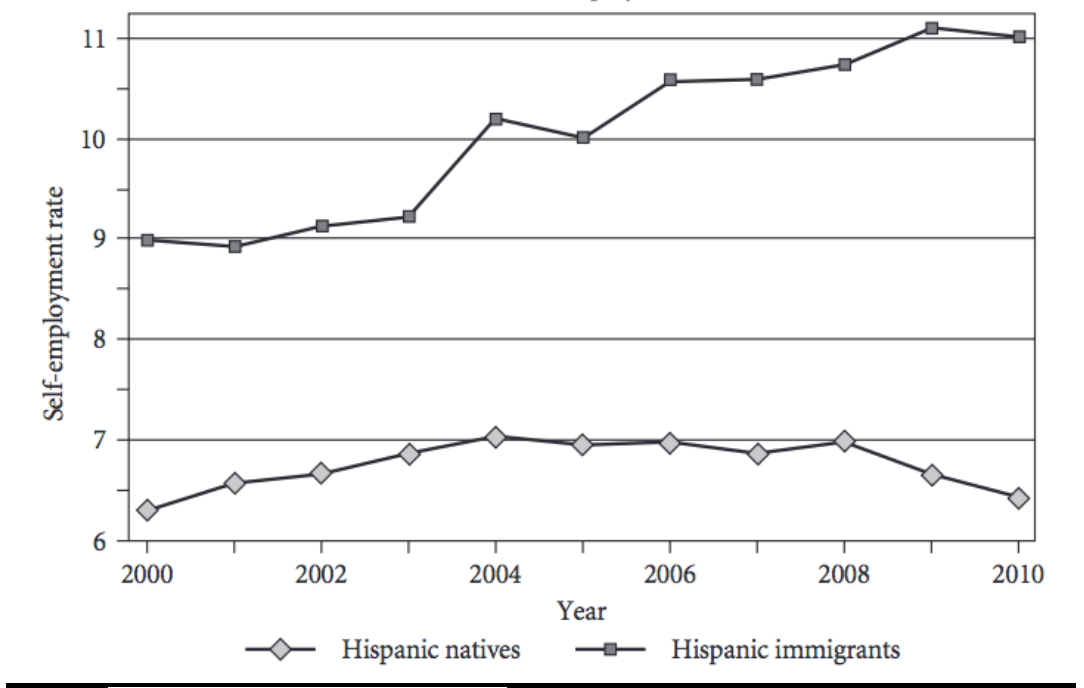

Source: (Davila \& Mora, 2013, pg. 4)

Latinos face many obstacles including high failure rates, lack of assets, and a higher propensity of being working poor despite their entrepreneurial efforts and the high growth rate of Latino entrepreneurs. According to a Kauffman study, although immigrants pursue entrepreneurial activities at nearly double the rate of native-born Americans, nine out of ten immigrant entrepreneurs are categorized as low-income earners (Fetsch, 2015). Latinos demonstrate a heightened entrepreneurial spirit but there are important distinctions to make between this group and traditional entrepreneurial perspectives. Entrepreneurship is often associated with high-growth businesses, innovation, and opportunity driven motives. However, the Latino population often pursues entrepreneurial endeavors from a necessity-driven perspective (Portes, 1998). Latinos are frequently driven to self-employment options because of lack of opportunities in the local workforce and relatively low entry level wages. For example, the average income of Latino entrepreneurs in Missouri is significantly higher than for Latino wage laborers. In 2000, the average wage laborer earned an income of $\$ 19,799$ compared to the average entrepreneur's income of \$30,346 (MERIC, 2005). Self-employment offers 
this population an avenue that provides better options for their skill sets and background than can be found in low-level employment opportunities (Portes, 1998). In reality, most entrepreneurial endeavors are pursued with a mix of opportunity and necessity driven motivations. It is important to understand these underlying motivations when investigating Latino immigrant entrepreneurs and their potential as transnational development agents.

\subsection{Transnational Case Study Review - Central America \& Mexico}

A review of selected case studies focusing on immigrants from the area of Central America and Mexico that engage in transnational activities was conducted to provide a general overview of the nature of the transnational field as it pertains to this region. This case study review reveals the areas of research that have already been conducted in this field and helps build a more comprehensive understanding of the essence of the transnational space created between the receiving country of the United States and the sending countries in the Central American region.

The Web of Science Core Collection database was utilized to perform an initial search with wide parameters to identify a pool of studies for further review. This preliminary search utilized three levels of keyword combinations undertaken simultaneously (Table 9). The three levels attempted to find papers that included information combining the areas of migrants that maintain relationships with their home countries, an analysis on development from the sending country level perspective, and an inclusion of at least one country from the selected region. The original search provided 712 results. A review of titles was administered to further narrow the scope to studies relevant to the focus of this paper. This second phase review located 72 possibilities for 
further exploration. The third phase of review comprised an abstract examination of the chosen articles. The abstract analysis searched for incidents of migrants based in the United States that were actively involved in activities involving their home countries, specifically in a collective manner, and a discussion of community level analysis. The abstract review resulted in 23 articles that were utilized for this literature review.

\section{TABLE 9: Literature Review Search Parameters}

\begin{tabular}{|ll|} 
& $\begin{array}{l}\text { WEB OF SCIENCE CORE COLLECTION - SEARCH } \\
\text { PARAMETERS }\end{array}$ \\
\hline Level 1 & "transnation* or organiz* migra* or diaspora or hometown association \\
\hline Level 2 & "develop*” or "well-being" or "sustain*” \\
\hline Level 3 & $\begin{array}{l}\text { Belize/Costa Rica /El Salvador /Guatemala /Honduras/ } \\
\text { Mexico/Nicaragua/Panama/Central America }\end{array}$ \\
\hline
\end{tabular}

The 23 selected articles express the relationship between the diaspora and home communities within Central America and Mexico represent a range of professional journals and research methodologies (Table 10). It is relevant to note that this topic appears to be of interest to a diverse range of disciplines and is not rooted in a specific, narrow field of study. This illustrates the complexity of the issue and highlights multiple layers of developmental, temporal, spatial, ecological, economic, political, and sociological issues that must be considered when attempting to understand the relationship between the community of origin and the receiving community.

Although this review takes a regional approach, ten of the articles focus on Mexico. This is understandable as immigration between Mexico and the United States greatly surpasses that of the other countries and a large number of communities composed of the Mexican diaspora exist throughout the United States (Garip, 2012). The 
literature noted that Mexican diasporic engagement strategies are often emulated by other countries in the region (Flores-Yeffal \& Aysa-Lastra, 2011), which provides a beneficial framework in which supporting institutions and policies can be adopted by countries interested in engaging their diaspora. This focus on Mexico is also limiting due to the fact that most of the countries in the region differ substantially in terms of the level of immigration as well as operate on a different geographic level with distinctive political and economic structures (Zamora, 2005). Further research performed in the Central American region would be beneficial to provide more relevant best practices for these diverse countries.

Table 10: Selected Articles for Literature Review

** ID numbers utilized in this section to refer to articles

\begin{tabular}{|c|c|c|c|c|}
\hline $\begin{array}{l}\mathrm{I} \\
\mathrm{D}\end{array}$ & ARTICLE & $\begin{array}{l}\text { COUNT } \\
\text { RY }\end{array}$ & $\begin{array}{l}\text { JOURNAL/DISCIPLI } \\
\text { NE }\end{array}$ & METHODOLOGY \\
\hline 1 & $\begin{array}{l}\text { Ambrosius et al. } \\
\text { (2016) }\end{array}$ & Mexico & World Development & Mixed Methods \\
\hline 2 & Beard et al. (2010) & Mexico & $\begin{array}{l}\text { International } \\
\text { Development }\end{array}$ & Case Study \\
\hline 3 & Boyer (2010) & $\begin{array}{l}\text { Hondura } \\
\mathrm{s}\end{array}$ & Peasant Studies & Case Study \\
\hline 4 & Delano (2014) & Regional & Political Geography & Policy Analysis \\
\hline 5 & Gamlen (2008) & Regional & Political Geography & Comparative \\
\hline 6 & Garip (2012) & Mexico & Demography & Quantitative-Survey \\
\hline 7 & Hartel (2006) & Mexico & Global Governance & Case Study \\
\hline 8 & $\begin{array}{l}\text { Hobbs et al. } \\
\text { (2011) }\end{array}$ & $\begin{array}{l}\text { Nicaragu } \\
\text { a }\end{array}$ & Applied Economics & Quantitative \\
\hline 9 & Lafluer (2015) & Regional & Democratization & Comparative \\
\hline 10 & Mercado (2013) & Mexico & Journalism & Mixed Methods \\
\hline 11 & Miraftab (2011) & Mexico & $\begin{array}{l}\text { Planning and } \\
\text { Education }\end{array}$ & Ethnography \\
\hline 12 & $\begin{array}{l}\text { Moran-Taylor } \\
\text { (2008) }\end{array}$ & $\begin{array}{l}\text { Guatema } \\
\text { la }\end{array}$ & Human Organization & Ethnography \\
\hline 13 & Noorloos (2011) & $\begin{array}{l}\text { Costa } \\
\text { Rica }\end{array}$ & $\begin{array}{l}\text { International } \\
\text { Development }\end{array}$ & Qualitative Review \\
\hline 14 & $\begin{array}{l}\text { Nyblad et al. } \\
\text { (2014) }\end{array}$ & Various & $\begin{array}{l}\text { Comp International } \\
\text { Dev. }\end{array}$ & Quantitative \\
\hline
\end{tabular}




\begin{tabular}{|c|c|c|c|c|}
\hline 15 & O’brien (2015) & Mexico & $\begin{array}{l}\text { Social Science \& } \\
\text { Medicine }\end{array}$ & Mixed Methods \\
\hline 16 & Phillips (2009) & Regional & Political Economy & Conceptual \\
\hline 17 & $\begin{array}{l}\text { Portes et al. } \\
(2002)\end{array}$ & $\begin{array}{l}\text { El } \\
\text { Salvador }\end{array}$ & American Sociological & Quantitative \\
\hline 18 & $\begin{array}{l}\text { Portes et al. } \\
\text { (2009) }\end{array}$ & Mexico & $\begin{array}{l}\text { International } \\
\text { Migration }\end{array}$ & $\begin{array}{l}\text { Quantitative/Comparat } \\
\text { ive }\end{array}$ \\
\hline 19 & $\begin{array}{l}\text { Sandoval et al. } \\
\text { (2013) }\end{array}$ & $\begin{array}{l}\text { Guatema } \\
\text { la }\end{array}$ & $\begin{array}{l}\text { Planning and } \\
\text { Education }\end{array}$ & Case Study \\
\hline 20 & $\begin{array}{l}\text { Schmook et al. } \\
\text { (2008) }\end{array}$ & Mexico & Human Ecology & Quantitative - Survey \\
\hline 21 & Stewart (2012) & $\begin{array}{l}\text { Guatema } \\
\text { la }\end{array}$ & $\begin{array}{l}\text { Contemporary } \\
\text { Ethnography }\end{array}$ & Ethnography \\
\hline 22 & $\begin{array}{l}\text { Taylor et al. } \\
\text { (2011) }\end{array}$ & $\begin{array}{l}\text { Guatema } \\
\text { la }\end{array}$ & $\begin{array}{l}\text { American } \\
\text { Geographers }\end{array}$ & Case Study \\
\hline 23 & Waldinger (2014) & Mexico & Theory and Society & $\begin{array}{l}\text { Comparative Case } \\
\text { Study }\end{array}$ \\
\hline
\end{tabular}

The articles were reviewed based on the two main variables of interest: level of collective action undertaken by the diaspora and the degree to which the home community was examined. The majority of the articles provided unique insights into key institutional arrangements and activities undertaken by the diaspora. There was a substantial variance among the level of coverage of the two key variables (Table 11). For this review, it was desired to find research that fell within high levels of both variables. However, only two articles $[2,19]$ focused on both collective action of the diaspora and an in-depth analysis of the home community development indicators. If the parameters are broadened to also include medium level analysis, the results expand to include 9 more cases $[3,5,7,10,11,12,16,21,23]$.

Research exists that incorporates the idea effects on the sustainable community development of organized migrants. The focus generally lies in describing the activities from the destination country point of view as well as exploring national level engagement policies from the sending country level. Less research is produced with a focus on 
exploring the community level effects of these activities. It is evident that more research with a community level approach is critical to examining the true implications of migration on sustainability and development

\section{Table 11: Matrix of Inclusion Level of Selected Variables}

** Numbers utilized correspond to literature ID identified in Table 10

\begin{tabular}{|c|c|c|c|c|}
\hline & \multicolumn{4}{|c|}{ COMMUNITY LEVEL ANALYSIS } \\
\hline \multirow{4}{*}{$\frac{\text { COLLECTIVE }}{\frac{\text { ACTION OF }}{\text { DIASPORA }}}$} & & Limited & Medium & High \\
\hline & $\underline{\text { Low }}$ & $18,22,9,17$ & $\begin{array}{l}20,14,6,8, \\
13\end{array}$ & 15,1 \\
\hline & Medium & 4 & $3,23,10$ & $7,12,16,21$ \\
\hline & High & & 5,11 & 2,19 \\
\hline
\end{tabular}

The type of activities diasporas engage in are also demonstrative of the level of sustainable community development taking place within this transnational network (Table 12). The vast majority of the articles illustrate an emphasis on economic related endeavors, such as investments, remittances, and business creation. The main objective of many of the groups focused on increasing employment opportunities within the sending community or directly investing in community based organizations and other local businesses $[1,4,6,13]$. Collective remittances were also noted as a type of economic activity that was often associated as a complement to societal level activities $[11,19,21$, 22].

The social and cultural activities explored have parallel aims of fostering the binational relationships, maintaining traditions and value systems, while also sharing these rituals with the receiving communities. Moving a step further, three of the papers highlighted the use of advocacy networks to promote equity and aim to empower 
typically marginalized groups, specifically gender related rights (O’brien, 2005).

Philanthropic actions were demonstrated in five of the papers $[4,18,3,2,21]$, ranging from supporting already established endeavors to the creation of NGOs to promote positive advances within home communities and regions. Political and civic focused programs were illustrated as a sending community and country engagement strategy to foster the continued participation of immigrants in national and community level activities of their home country. These strategies include allowing immigrants to maintain voting rights while living abroad to encourage individuals to maintain an interest in their country of origin (Nyblade \& O'Mahony, 2014). It is suggested that civic engagement has the ability to mobilize community members to generate development momentum and shape the future of a community (Mercado, 2013).

Activities with a focus on the environment were present in three of the papers [22, 19,3]. These undertakings included the observation of a transition to more efficient and environmentally friendly cooking methods in communities with strong relationships with diasporas in Guatemala (Taylor, Moran-Taylor, Castellanos, \& Elías, 2011) as well as the advocacy and initiation of activities specifically focused on developing the agriculture sector with more ecologically friendly technology (Stewart, 2012). It is evident that the environment is not the primary focus for diasporas. However, more focused research regarding the effects of the other types of activities on the local environment would add a more comprehensive understanding of the true influences of migration on community based conservation. 


\section{TABLE 12: Description of Diaspora Activity Identified in Reviewed}

\section{$\underline{\text { Literature }}$}

** Numbers utilized correspond to literature identified in Table 10

\begin{tabular}{|c|c|}
\hline DIASPORA ACTIVITY & CASE NUMBER \\
\hline Environmental & $22,19,3$ \\
\hline Political & $\overline{13,14,5}, 16,9$ \\
\hline Economic & $1,4,22,11,13,19,2,5,16,6,17,21$ \\
\hline Advocacy & $\underline{7,11,15}$ \\
\hline Social & $10,4,11,18,2,11,21$ \\
\hline Philanthropic & $4,18,3,2,21$ \\
\hline Civic & $\underline{10,14,18}$ \\
\hline Cultural & $2,18,5$ \\
\hline
\end{tabular}

These articles provided a breadth of information that serve as a foundation for a constructive overview of the association between diaspora activities and sustainable community development. The Mexican government has established a comprehensive diaspora engagement plan that includes active outreach to diaspora communities and the extension of continued rights and privileges (Flores-Yeffal \& Aysa-Lastra, 2011). The same level of national level policy development was not found throughout the rest of the region. This is understandable as the Central American diasporas are considerably smaller and the countries of origin have significantly fewer resources than Mexico. Some countries, including El Salvador and Guatemala, have attempted to establish similar engagement strategies although these programs are at a smaller scale and still in nascent stages (Sandoval, 2013) (Portes, Guarnizo, \& Haller, 2002). Extending voting rights is another engagement strategy that serves the dual purpose of influencing local policy while maintaining civic relationships with individuals that have left the country but still demonstrate a level of concern for the wellbeing of their home country and community (Lafleur, 2015). 
A non-governmental strategy that has aided in linking these two groups is the development of communication channels and media publications that connect interests within these networks (Mercado, 2013). This creates a bidirectional flow of ideas, concerns, and current events, allowing immigrants to directly connect with their home country while also receiving information directly from members of the sending community. This produces an ongoing conversation, increases real time understanding, broadens knowledge bases, and serves as a historical artifact of the interactions within the network. Other transnational networks cited included activities focused on technology and business as well as advocacy. It was noted that even when local policy is weak and local movements are non-existent, advocacy networks focused on women's human rights generate high levels of impact on a community level (O’Brien, 2015).

\section{$\underline{\text { Sustainable Community Development }}$}

The relationships and activities found throughout the review of these 23 scholarly papers provide a valuable basis for understanding the impact of transmigrants on the three pillars of community sustainable development, economy, environment, and society. The review also highlighted future areas of potential research to construct a more comprehensive knowledge base and integrate diasporas into established development activities in an efficient and inclusive manner.

The research revealed an emphasis on economically based endeavors undertaken by the migrant groups. These endeavors incorporated various areas, including publicprivate investments, establishment of businesses in the home countries, as well as simple remittances. The outcomes of the endeavors varied greatly, ranging from beneficial to damaging. One common finding was that the initial purely economic impact of focused 
activities created an inequality in wealth. Even when remittances were distributed in a more collective manner, or businesses were established to provide community wide employment, the wealth tended to concentrate amongst the wealthier and middle class community members. It is important to note that this wealth disparity was observed to decline over time, especially when migration continued to increase (Garip, 2012).

A review of how households managed these increased finances provided an interesting observation in the challenges associated with economic remittances. The capital is advantageous for building household assets and reducing risk, however often the existing formal institutions within a community are unable to absorb the monetary influx (Hobbs \& Jameson, 2011). For example, data collected from Mexican households found that these remittances did not facilitate increased level of interactions with financial institutions (Ambrosius \& Cuecuecha, 2016). This suggests that economic activities revolving around creating establishments that offer increased employment opportunities and promote a sustained monetary cycle will likely offer more lasting, positive steps towards a sustainable community.

A common thread within the literature involved the inclusion of activities that influence the community on a societal level. The various types of transnational networks have opened up communication lines between sending and receiving communities. The flow of ideas and societal values are expanding the awareness of inclusion and equity as well as promoting citizen mobilization and social well-being. Including the societal perspective as a base element in any activity undertaken by the diaspora will encourage sustainable community development and prevent the possible negative externalities associated with unequal dispersion of migrant benefits. Societal level activities, such as 
civic engagement, philanthropic pursuits, advocacy, as well as social and cultural ties, will develop the ability of communities to engage in dialogical interactions and build the confidence and know how to develop projects independent of the diaspora that are focused on community well-being.

The environmental component of the sustainable community receives less focus within these community-to-community relationships. In some instances, a transition away from harmful environmental practices are noticed when communities receive increased financial flows from migration (Taylor, Moran-Taylor, Castellanos, \& Elías, 2011). This tends to be associated with the ability of community members to utilize technologies and procedures that are more efficient and produce an externality that is more ecologically sound. Other instances focus on the establishment of NGOs and projects with a focus on promoting environmentally friendly practices. These were not prevalent but do show the slow progression towards activities that are more far-reaching than purely economic advances.

It is clear that the increased social capital fostered by organized migrants has the ability to impact communities in a variety of ways. However, it is difficult to ascertain a comprehensive overview of this relationship due to research focused primarily on Mexico and the lack of community level data. Established research provides descriptions of activities that indicate influence within the areas of economy, society, and environment, however it is not always clear if the actions are inclusive and if the benefits are lasting. Further research directed at immigrants of the Central American region, excluding Mexico, will provide insight into the unique challenges, motivations and strategies of 
these diaspora groups that lack the large ethnic network and dynamic home country engagement.

Conclusion

These studies focus on describing the nature of the transnational activities of immigrant groups. This provides a rich description of what types of activities are prominent among immigrant groups as well as a measured understanding of the impact of these activities at the community level of the country of origin. However, there is minimal attention aimed at exploring the experience of the transnational immigrant. In order to promote meaningful and constructive transnational engagement and develop effective support systems and policies, it is essential to understand the challenges and opportunities the individual immigrant experiences in the transnational space. This study will address these key gaps by conducting deep, qualitative research with immigrant entrepreneurs from the Central American region, excluding Mexico. The research will aim to explore the immigrant experience in the transnational space and provide a rich depiction of the motivations and struggles of this group as well as the strategies utilized to facilitate 'transnationalism from below'.

This literature review has demonstrated that the relationship between migration and development is complex and can be viewed from both negative and positive lenses. Transnationalism offers a potential framew ork to understand this migration-development nexus in the current globalized atmosphere and provides an approach that empowers immigrants to be productive members of both their sending and receiving communities, allowing for a transition to the positive and beneficial migration-development relationship to emerge. Immigrant entrepreneurs are a particularly interesting set of 
individuals to study through a transnational lens. They have developed a unique set of skills and networks that could be useful to their home communities, but also face a distinct set of challenges and motivations within their integration and business practices in their host communities. Understanding how they are able to navigate this complex experience, integrate into their host country, and maintain ties back home, will create an illustrative view of transnationalism from below as well as provide a meaningful understanding of policy and programmatic interventions that could better support impactful transnational engagement by this group.

\subsection{Nicaragua}

Nicaragua is Central America's largest country, bordered by Costa Rica and Honduras. The population is currently slightly over 6 Million, with the majority of people living in the Western region. Nicaragua is the second poorest countries in the Western Hemisphere and has struggled with uneven development and governmental corruption. The country endured a civil war in the late 1970s that transitioned Sandinista leader Daniel Ortega into power (Nicaragua, 2018). This was followed by a continuing internal conflict between the Sandinista government and anti-Sandinista contras that lasted throughout the 1980s. Daniel Ortega lost the elections in 1990 to Violeta Barrios Torres de Chamorro (Nicaragua Profile, 2017). Daniel Ortega was later reelected as president in 2006, 2011, and recently in 2016. These elections have been riddled with inconsistencies and irregularities and the democratic institutions have been weakened under the Ortega administration, creating a difficult development environment, an increase in gaps in wealth distribution, and an increasingly challenging relationship with the United States leadership (Nicaragua, 2018). 
Nicaragua's economy is based on the agriculture sector with its top exports being beef, coffee, and gold. Income distribution is very uneven throughout the country, and many have low levels of access to adequate healthcare services. Access to potable water and sanitation is also a chronic issue, along with limited educational attainment levels. The infrastructure and economy of the country were damaged by Hurricane Mitch in 1998 (Walker, et al, 2017). The national, regional, and local institutions have been deteriorated by repeated national disasters and the internal political turmoil and have had difficulty reestablishing in an equitable and effective manner. Despite being one of the poorest countries in the Western hemisphere, Nicaragua has showed recent improvements in water and sanitation, life expectancy, child mortality rates, and education rates (Nicaragua, 2018).

Nicaraguans primarily emigrate to neighboring Costa Rica for seasonal employment as well as to Spain and the United States for long-term migration. An increased flow of refugees entered the United States between 1970-1990s due to the civil unrest and natural disasters. Besides humanitarian migration, other Nicaraguans immigrate to the United States based a familial relationship or attempt to enter or stay illegally, without documentation (Lesser \& Batalova, 2017). The Nicaraguan population within the United States has steadily increased from 164,000 in 1990 to 222, 000 in 2013 (Lopez, 2015). U.S. born individuals that are of Nicaraguan decent has also, in turn, increased steadily (see Figure 8). Of the Nicaraguans living in the United States, almost $60 \%$ have lived in the U.S. for over 20 years and 56\% are U.S. Citizens. English acquisition is an obstacle for this diaspora as almost $40 \%$ report a low level of language ability and over $80 \%$ of Nicaraguans age 5 and older continue to speak Spanish within the home. The Nicaraguan 
diaspora is younger than the U.S. population with a median age of 33 compared to the U.S. average of 37. Also, the average Nicaraguan's personal earnings is reportedly lower than that of the average U.S. population but higher than other Hispanic populations within the U.S (Lesser \& Batalova, 2017).

Figure 9: Nicaraguan-Origin Population in the U.S., 1990-2013

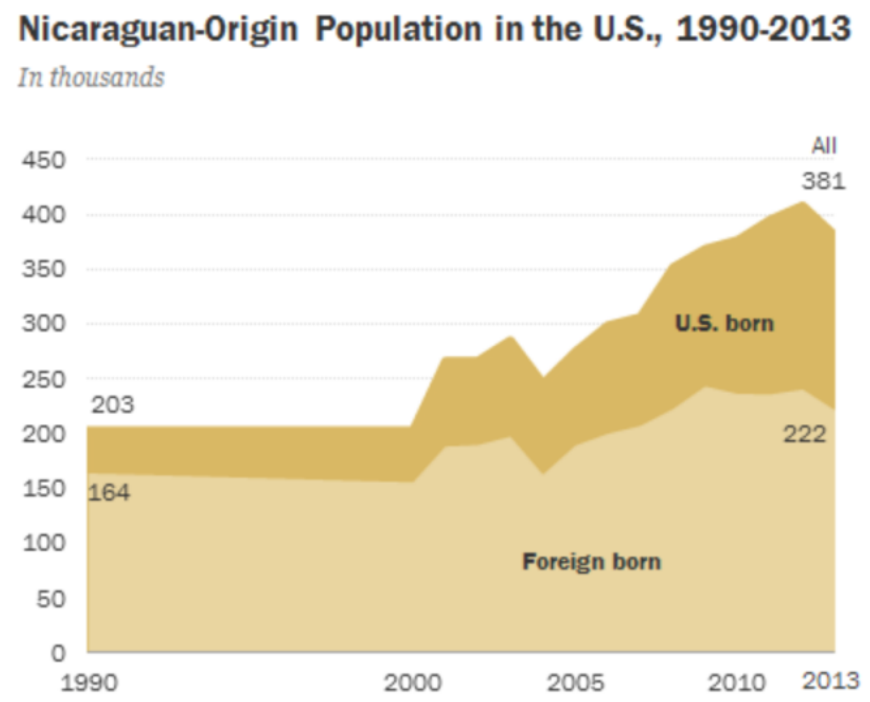

Source: (Lopez, 2015)

\subsubsection{Villa Sandino}

Villa Sandino is a rural community located in the central Nicaragua region of Chontales. This region's economic sector centers around cattle farming and dairy production. The Chontales department produces $90 \%$ of the beef in Nicaragua. Outside of livestock and dairy there is little formal economic activity. Many households run small grocery, home goods, or food service businesses out of their residence. The residents of the region are predominately Catholic while a small portion practice Evangelicalism. The age structure of the region reflects that over half of the population, $51.7 \%$, fall between $0-24$ years of age. The average years of school life for youth is 10 years for males and 11 years for females and literacy rates are approximately $78 \%$. 
Income distribution within the region is extremely uneven and the rural regions, specifically in Chontales, have seen smaller gains locally, specifically in many development areas, such as improvements in water and sanitation, life expectancy, child mortality rates, and education rates (Nicaragua, 2014). 


\section{Chapter 3: Methods}

\subsection{Purpose and Objectives}

This study explores the nature of Central American immigrant entrepreneurs from Villa Sandino, Nicaragua that have immigrated to the United States. Specifically, the determinants, motivations and strategies of these immigrant Latino entrepreneurs that participate in transnational engagement were examined. Also, the experiences of the immigrant entrepreneurs were explored to understand the local ecosystem and institutions that supports these individuals' entrepreneurial success in their receiving communities of San Francisco and Miami as well as investigate the concept of transnationalism from below through their experiences. This investigation assists development practitioners and policy makers to create platforms that can further support the effective engagement of diasporas, build institutional capacity for engagement and coordination activities, and understand the unique perspectives and challenges of this specific migrant group.

\section{RESEARCH QUESTIONS:}

1. What are the determinants, motivations, and strategies of Latino immigrant entrepreneurs that participate in transnational engagement?

2. What are the conditions that facilitate transnational engagement by Latino immigrant entrepreneurs?

3. What does transnationalism from below look like through the experiences of these Latino immigrant entrepreneurs?

\subsection{Research Design}

This study is descriptive in nature to allow for a broad understanding of attitudes and activities within the Latino immigrant entrepreneur population that has immigrated 
from the community of Villa Sandino, Nicaragua and currently reside in the Miami and San Francisco area. This study utilizes semi-structured interviews to explore the external experiences as business owners as well as the intrinsic motivations and determinants that influence transnational engagement activities that are undertaken with their country and/or community of origin of immigrant entrepreneurs. A qualitative approach is best suited for this research because it allows for a deeper understanding of the unique experiences and perspectives of a select group of individuals. Merriam (2009) describes qualitative inquiry as "interested in understanding how people interpret their experiences, how they construct their worlds, and what meaning they attribute to their experiences." (p. 5). Creswell (1998) further elaborates that qualitative work is "an inquiry process of understanding based on distinct methodological traditions of inquiry that explore a social or human problem. The researcher builds a complex, holistic picture, analyzes words, reports detailed views of informants, and conducts the study in a natural setting" (p. 15). Qualitative work allows a researcher to understand a phenomenon within a particular context and empowers the participants to share their own narratives in a straightforward manner. Patton (2015) offers a simple, straightforward explanation of the qualitative inquiry as a way to document "the stuff that happens among real people in the real world in their own words, from their own perspectives, and within their own contexts; it then makes sense of the stuff that happens by finding patterns and themes among the seeming chaos and idiosyncrasies of lots of stuff' (pg. 12). Table 13 offers additional contributions of qualitative research and provides a breakdown of the multifaceted benefits of utilizing this approach when attempting to explore and understand the experiences and perspectives of individuals within a unique, bounded group and then 
attempt to analyze similarities and differences and ultimately discern patterns and themes

that rise from the diverse individual stories.

\section{Table 13: The Contributions of Qualitative Inquiry}

Qualitative Contribution

Illuminating Meaning Qualitative inquiry studies, documents, analyzes, and interprets how human beings construct and attach meanings to their experience.

Studying how things work

Capturing stories to understand people's perspectives and experiences

Elucidating how systems function and their consequences for people's

lives

Understanding context: how and why it matters

Identifying unanticipated consequences

Making case comparisons to discover important patterns and themes across cases
Qualitative inquiry can illuminate how any human phenomenon unfolds as it does, and the effects on those who participate.

An in-depth case study tells the story of a person, group, organization, or community. The story opens a window into the world of the case(s) studied.

Systems involve complex interdependent dimensions that interact in ways that affect the people in those systems.

Qualitative inquiry systematically gathers perspectives on what happens within systems, and how what happens has implications for those involved.

For qualitative inquiry and analysis, contextual sensitivity is central. Context refers to what's going on around the people, groups, organizations, communities, or systems of interest.

Leaders, planners, social innovators, politicians, etc. strive to attain their intended goals. The modern world is highly goal oriented, but things seldom go as planned. Much of what was intended never occurs, and things that are never intended, and never even imagined, do occur. Qualitative inquiry documents both intended and unintended consequences of change processes.

Comparisons involve analyzing both similarities and differences. Case studies provide rich data for teasing out what cases have in common and what sets the apart: successes versus failures, those who are resilient and those who are not, etc.. Comparisons illuminate the enormous diversity of humanity even as we seek and find patterns across the diversity.

Source: Adapted from (Patton, 2015, p. 13)

This qualitative inquiry specifically focuses on a case study, comprised of semistructured case study interviews. The case study offers the investigator an opportunity to explore a contemporary, real-life bounded system (a case) through comprehensive, detailed data collection. The unit of analysis for a case may be a single case (a within- 
study) or multiple cases (multisite study) (Creswell, 2013, p. 97). This study involves interviews with multiple immigrant entrepreneurs, from the same community of origin, in order to understand the differences and similarities of their experiences and make comparisons to find thematic patterns that may lead to a fuller understanding of how transnational engagement may be better supported and encouraged. The interviews of this study weave together stories that illuminate what transnationalism from below looks like for these individuals and provide insights into the underlying motivations that drive this transnational engagement while identifying the strategies utilized by these entrepreneurs to navigate the transnational space.

The case study method transfers focus from the individual to an issue, event, program, or activity, and utilizes a systematic approach to understand the relationship between the issue and participant's lived experience. Case studies allow for the collection of rich descriptive data and can give insights into a phenomenon that may not be accessible through other approaches. Case studies are able to delve into an individual's experience in a more structured and targeted manner, providing the opportunity for rich analysis. Also, case studies have the potential to be used as a primary research method to dredge out initial findings that can be further examined through other methods, including quantitative approaches (Yin, 2009).

The case study approach is best suited for this research focused on transnational engagement of Nicaraguan, immigrant entrepreneurs because it allows for deep inquiry while providing structure and leveled exploration into selected areas. Because I am focused on the issue of transnationalism, I was able to explore the concept through 
directed, semi-structured interviews that allowed me to focus on specific areas of interest that have been identified through literature and case reviews. The study explores the participant's migration experience, entrance into the entrepreneurial arena, integration into their receiving community, and maintained ties back home, by following an interview guide to ensure all relevant data is collected. The semi-structured interview allows participants to expand upon or diverge from directed questions to provide tangential information that may expose new areas of interest or focus and provide a richer description of the participant's experience (Creswell, 2013).

This research collected multiple case study interviews to offer a richer exploration of the issue through the experiences of diverse individuals that share the attributes of being an immigrant entrepreneur and a native to Villa Sandino, Nicaragua. This study first provides a within-case analysis, uncovering themes and patterns that emerge within each specific case. This internal analysis is followed by a cross-case analysis. The cross-case analysis is a powerful approach to mobilize knowledge of the individual case study by comparing and contrasting information between cases (Yin, 2009). This technique is useful to breakdown case study material into a more digestible format. The cross-case analysis allows the researcher to utilize categories or dimensions to explore in-group similarities as well as intergroup differences (Eisenhardt, 1989). The cross-case analysis compels the researcher to look at the data in divergent perspectives, challenging the initial impressions and creating a higher level of reliability and significance to the findings. Cross-case analysis helps the researcher delineate the combination of elements that contribute to a certain outcome and construct a reason that explains the differences and similarities between cases (Khan \& VanWynsberghe, 2008). 
Cross-case analysis will be a valuable component to my research by allowing me to organize and explore the collected data in a holistic and representative manner. The criteria utilized to operationalize this method will focus on the temporal dimension. The cases will be broken down into specific timeframes, such as before immigration to the United States, the transition period, the establishment of the entrepreneurial enterprise, and the experience after the enterprise has been established. By organizing the analysis in this manner, I can delve into the similarities and differences between individual experiences and overlay the experiences of transnational engagement behaviors within the findings. These temporal dimensions can be utilized to compare and org anize the collected case study interviews.

\subsection{Role of the Researcher}

Self-reflexivity is central to qualitative inquiry and the importance of understanding a researcher's own personal values, theoretical assumptions, and experiences that have the potential to influence the research is critical for the reader to be able to fully examine study and legitimize the analysis and inferences imparted (Maxwell, 2013). It is often argued that reflexivity is not well understood or operationalized and if a more explicit understanding is not developed, the concept will be of little value, posing only as a tactic to create the appearance of academic rigor within research designs (Pillow, 2003).

Beyond a recognition of self, reflexivity can also encompass a recognition of the other and truth as well as the concept of reflexivity as transcendence beyond subjectivity. It is evident that reflexivity is not a straightforward or universally agreed upon idea or process. However, reflexivity can be viewed as an analyst's "reflexive engagement in the 
world" (Macbeth, p. 38, 2001). The outcome of incorporating reflexivity at multiple levels into a study is to create research that is introspective and questions itself, and the production of knowledge, with the objective of creating less distorted, more accurate accounts (Pillow, 2003). In research, reflexivity brings forth the researcher's agency as a deliberate and foundational field of analysis that is undertaken at the beginning and throughout the investigation process. This allows for the notion of subjectivity to be incorporated and understood within the study rather than 'leveling' out the playing field or sterilizing the processes to ensure a singular, detached voice (Machbeth, 2001). This concept reflects that data collection is affected by who the researcher is, their past experiences, how their attributes and unique position in the world affect the way they process information, and their overall identity contribute to how knowledge is acquired, structured, and deciphered and has implication to the relevancy of the final findings and interpretations (Pillow, 2003).

Reflexivity can also be used as a focused approach to qualitative research. Power dynamics are often central to the idea of self-reflection, as the researcher is typically in a position power or authority as compared to the participant. Developing reciprocity with research participants in an attempt to equalize the power relationships is a potential reflexive approach. This requires the researcher to approach the study with a perspective of doing the research with, instead of on, the subject. This includes incorporating the participant into the research design or creating a space for verification and discussion of results and allowing the participant to navigate and direct certain parts of the process. By approaching a study in this manner, the researcher's authority and voice can be deconstructed to allow for the authentic data to emerge (Pillow, 2003). Reflexivity can 
also move beyond the self and desire for objectivity to include epistemological perspectives. Epistemological reflexivity encourages the researcher to question the research question and approach to understand the limitations that are imposed by the research construct and explore how other approaches and questions could be investigated differently (Gadamer, 1989).

My research presents a study that includes semi-structured interview with multiple individuals. These individuals were selected based on their country of origin and their engagement in entrepreneurial activities. Because I worked with an immigrant group, reflexivity was especially important to approaching the cross-cultural dynamics that exist. In cross-cultural qualitative research, the researcher is approaching the subject group as an outsider. It is essential to understand the power dynamics that exist between the researcher and participant group as well as for the researcher to take time to explore their own experiences and attitudes as it relates to the subject group and their intentions for the study. When working in a cross-cultural context, both the researcher and the subjects are experiencing each other through professional, cultural, and personal filters. These filters are based on past experiences and assumptions and create a distinct environment in which information is shared and received (Weiss, 1994).

To recognize my distinct position as it relates to the subjects, initial and continued reflexivity was essential in my study. I did not approach the research with a blank slate but instead carried with me the various experiences I have had working with similar individuals throughout my career. I have a background in international development and currently work with the federal government as an employee of the United States Citizenship and Immigration Services (USCIS). I have worked with migrant populations 
within both sending and receiving countries. Although I am an outsider with this group, I have spent large amounts of time in Central America, mainly Nicaragua, working with entrepreneurial development and have worked within the United States with refugee and immigrant groups that were seeking employment or attempting to start a business. My experiences working with immigrant populations and living in communities abroad undoubtedly impacted my research. From one perspective, the challenges that I have faced attempting to implement projects with immigrant groups may have led me to approach this research with an ingrained set of limitations imposed on the potential of this group to undertake impactful development initiatives. I approached these individuals with a mindset that they are unique from my past experiences and conduct the interviews with a curiosity to understand their distinct experiences and perspectives.

On the other hand, my values are entrenched in the importance of empowering individuals to become change agents in their own communities. My central belief is that top-down development has shown weak results and the most sustainable and meaningful change often comes from below. Because of these beliefs and values, I was hopeful to find that these Latino entrepreneurs have great potential to become development agents for their home communities. I needed to be realistic in my approach and realize that there may be challenges and barriers that could prevent these individuals from becoming as impactful as I hope. I also needed to approach the interviews from a broad perspective as not to impose a specific, narrow type of transnational engagement on this group, but to allow for diverse relationships and interactions to emerge. Intentionality is an important aspect of reflexivity and to understand the researcher's purpose and objective of the study can lend transparency to the process (Weiss, 1994). My intention for the study was to 
understand transnationalism from the perspective of Latino immigrant entrepreneurs in order to influence program development and policy reform in both the business and migration fields and to guide the development of more supportive engagement strategies in both the receiving and sending countries/communities. By understanding my intention, it is evident that I am approached the study with an expectation to find positive and meaningful connections and potential relationships between immigrant entrepreneurs and the transnational field. This was expectation important to identify to avoid leading the research in a certain direction or allowing bias to encourage or entice research subjects to demonstrate transnational behavior when it is negligible or non-existent in reality.

Also, I approached this study from a constructivist worldview. Constructivist research focuses on the unique contexts of individuals lived experiences and attempts to understand the complexity of views and perspectives by relying on open ended discussions with the participants. This is an inductive process that empowers the participants and gives value to their unique experiences and views (Creswell, 2014). Approaching qualitative research with this worldview supported my intention to interpret the perspectives of immigrant entrepreneurs and understand their transnational experiences from their distinct points of view rather than forcing them into a predetermined theoretical framework. The discussions were exploratory and the data was emergent, creating space for authentic and relevant findings.

In order to integrate reflexivity into my research process, I maintained a reflexivity journal. This was in essence a collection of memos that were created throughout the research design, interview/data collection, and analysis stages. This journal provided a space where private thoughts and contemplations can be captured in 
regard to my methodological decisions, reactions to data collection and interviews on an individual basis, and reflections on my feelings, interests, and values as it relates to the study, research subjects, and topic in general. This allowed me to acknowledge my assumptions and possible biases and provided a space where I could identify how these suppositions may influence the overall study while allowing me to reevaluate my findings and incorporate this reflexive insight into subsequent interviews, or if necessary revisit previous subjects for follow-up interviews. Also, I incorporated a verification step in my process that will allow me to revisit the immigrant entrepreneurs that participated in the study, or a at least a portion of the participants, to share my findings and validate the analysis with the subjects. This allowed the participants the opportunity to clarify meanings or question the interpretations that I have made. This step was reflexive as any incorrect assumptions can be exposed and will also empower the participants to become active members of the study. These steps created an iterative research process and strengthened the validity of my findings.

\subsection{Population and Sample}

The Hispanic-Latino population reached 57 Million in the United States in 2015 (Krogstad, 2016). The Nicaraguan population was estimated to reach 381,000 in 2013, nearly doubling in size since 1990. (Lopez, 2015). Further, the study targets entrepreneurs from Central American, specifically Nicaragua. The reasoning for this selection is to provide research focused on an area of Latin America that are under researched. As many studies have been undertaken focusing on the Mexican population, this study attempts to provide alternative perspectives for a Central American country 
with a smaller diaspora populations in the United States while highlighting challenges and opportunities for this specific group.

The Nicaraguan diaspora is estimated as the $12^{\text {th }}$ largest Hispanic immigrant population in the United States. The majority of Nicaraguans are dispersed in the South, mainly Florida (36\%) and the West, mainly California (29\%) (Lopez, 2015). This study further narrows the sample population to focus on immigrants originating from one specific community in Nicaragua, Villa Sandino. This allows for a more focused and concentrated exploration of the transnational activities of this immigrant population, allowing for contextual understanding of their home communities and providing a bidirectional overview of the community perception and support of transnational engagement of the immigrant entrepreneurs. I have the benefit of having a large social network in the Villa Sandino community because I lived and worked in this area for 2 years. The community is small and closely connected, signifying that individuals that have immigrated to the United States are readily known and easily identifiable by town members. By communicating with various community leaders, the local government of Villa Sandino, and through household level inquiries, 42 individuals from Villa Sandino that have immigrated to the United States were identified. Of this population, fourteen individuals were classified as engaging in entrepreneurial endeavors within their receiving communities. These individuals were located in the Miami and San Francisco area. This population was targeted as the sample for this study. After communicating with these immigrant entrepreneurs, two of the individuals communicated that they were not interested in participating in the project and two were initially agreeable but ultimately nonresponsive when setting up interview appointments. Ultimately, ten of the 
fourteen individuals identified as immigrant entrepreneurs from Villa Sandino, Nicaragua were successfully interviewed for the study.

To further clarify the sampling criteria, it is important to define the concepts of immigrant and entrepreneur. Most literature focuses on high-growth, high-tech entrepreneurship, however as described in earlier sections, the Latino population often becomes self-employed due to lack of job opportunities and economic necessity (Immigration, n.d.). For the purposes of this study, an entrepreneur is defined as an individual that is self-employed and is a business owner, regardless of scale or size of the business. The term immigrant includes first generation immigrants that are native to a country identified in the Central American parameters.

\subsection{Data Collection}

Access to this immigrant group was achieved through the established social network of the interviewer. While serving as Peace Corps volunteer from 2008-2010 in the town of Villa Sandino, Nicaragua, I was able to foster and maintain relationships with institutions and individuals that enabled an inclusive and extensive sample identification data collection process. I initially reached out to the local government as well as individuals and households to identify immigrants from this town that now resided in the United States. I worked with this group to further narrowed the sample to include only those individuals involved in entrepreneurial endeavors. As noted in the previous section, Villa Sandino is a small-knit community where the happenings of neighbors and community members is well known by other households and institutions in the town. The social connectors of Villa Sandino were then instrumental in creating the initial contact and introduction with the immigrant entrepreneurs. These initial introductory 
connections were made through phone calls, emails, Facebook messages and WhatsApp messages. After the initial introduction was made, I sent the potential participants a waiver and information sheet describing the study and followed up with a phone call to further discuss the parameters of the interview and answer any questions.

Data was collected through semi-structured interviews with Nicaraguan immigrant entrepreneurs in the Miami and San Francisco area. Because of the geographic distance of the sample population, interviews will be conducted via telephone and Skype. An interview guide was utilized to provide consistency and uniformity to the data collection process while allowing for the adaptability and flexibility inherent in semistructured interviews (see Appendix A for interview guide). The interviews were conducted in 60-90 minute increments and the participant will be asked if they would be open to follow-up conversations in the instance the further questions arise after the initial meeting. The qualitative interview provides access to the nature of transnational social life and engagement, which consists of events and relationships that would otherwise be unobservable because of the cross-border nature of transnationalism. A qualitative interview often "sacrifices uniformity of questioning to achieve fuller development of information" (Weiss, 1994, p. 3). This technique was utilized to create an informal, comfortable environment that allowed participants to feel confident to explore the topic area while providing the interviewer the freedom to allow the conversation to organically develop without a rigid parameter. The semi structured interviews utilized an informal approach and a general interview guide to ensure that all topic areas are covered while allowing for tangential conversations that may illuminate previously untapped areas on interest and perspectives. 


\subsection{Data Processing and Analysis}

Qualitative inquiry is not linear in nature but rather an iterative process. The data analysis process goes hand-in-hand with the data collection stage of this research. This is one area that qualitative research differs from quantitative. Quantitative studies have clear linear path and a division between data collection and analysis. Qualitative research allows for a constant interchange between collection and analysis. While interviews were being conducted, preliminary analysis was also taking place. This process helped guide subsequent interviews by ensuring that important topical areas are included (Creswell, 2014). Memos were written during these preliminary stages that provided early insights and aided in the encapsulation of the thought process during each stage of data collection and processing. When multiple case interviews are included in a study Creswell (2013) recommends "a typical format is to provide first a detailed description of each case and themes within the case, called a with-case analysis, followed by a thematic analysis across cases, called a cross-case analysis, as well as assertions or an interpretation of the meaning of the case" (pg. 101). Similarly, Yin (2009) suggests identifying issues on a case by case basis followed by a macro analysis of common themes that link together the cases and transcend the individual to group level issues. I utilized the steps offered by Creswell (2014) (see Figure 10) to ensure that my data was collected and analyzed in an organized and uniform manner. Although this illustration (Figure 10) appears hierarchical in nature, I approached these steps in a cyclical, iterative fashion to create a fluid and adaptable study. 
Figure 10: Data Analysis in Qualitative Research

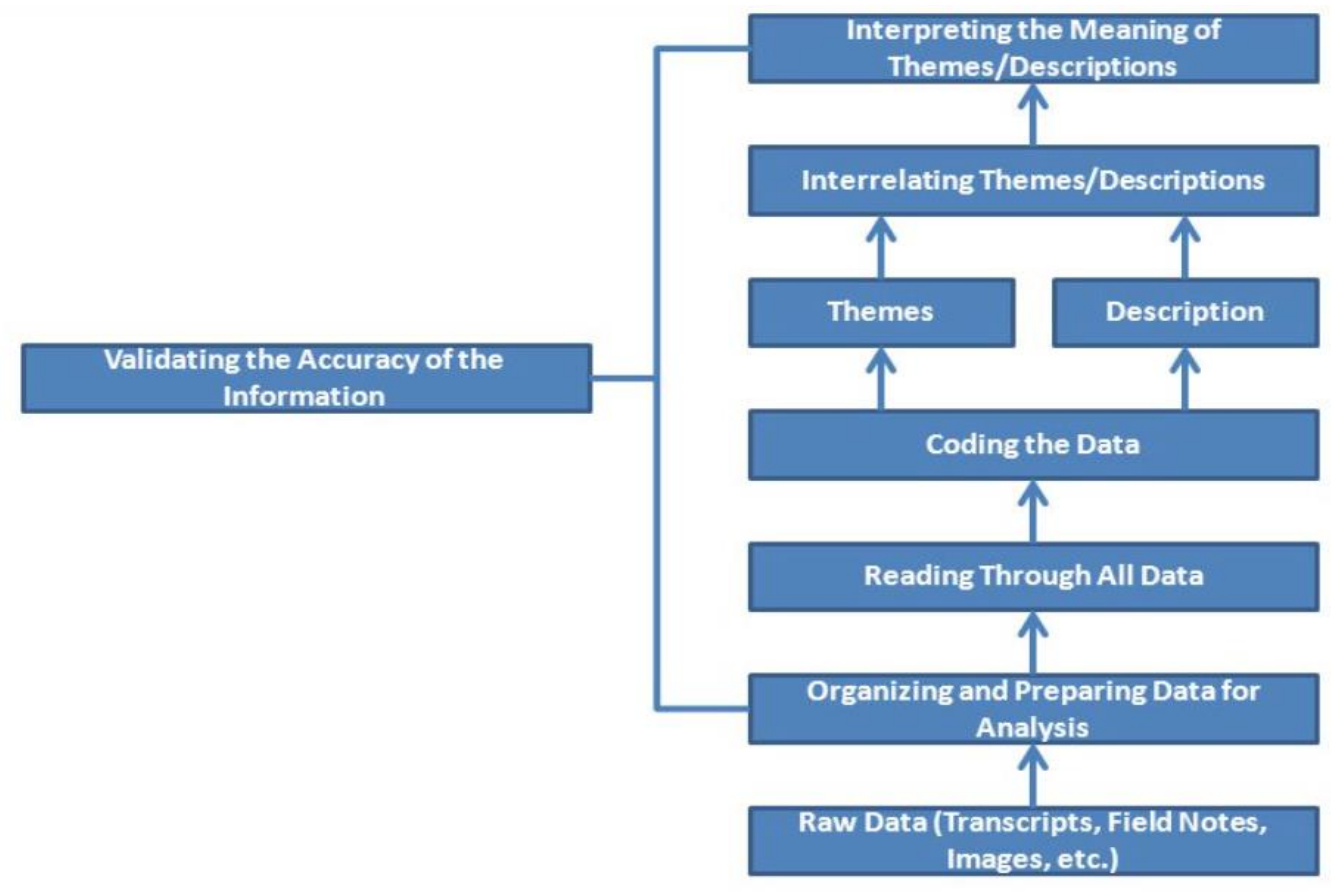

Source: Adapted from (Creswell, 2014, p. 197)

The interviews were recorded and transcribed to allow for coding for themes and patterns. Once initial interviews were transcribed, an initial review was conducted to begin to identify broad areas of interest. I allowed the codes to emerge based off the information collected through the interviews. Tesch (1990) provides eight steps in the coding process that I used to guide the analysis of the data collected through these interviews. These steps include: 1) understanding the whole through careful reading and notetaking, 2) evaluation of the underlying meaning of individual cases, 3) clustering and listing emergent topics, 4) reviewing clusters/lists and reexamination of data, 5) develop organization plan for emerging data, 6) create codes, 7) gather data and categorize within each topic area, 8) review and recode if necessary. The themes and categories that transcended the individual cases and emerged as a commonality among the immigrant entrepreneurs were extracted and further examined to gain a deep understanding. When 
further inquiry was needed, interviewees were contacted to request follow-up interviews, which consisted of a shorter conversation to clear up any questions or delve deeper into certain topics. The outcomes were compared and contrasted with the underlying theories presented in the literature review and demonstrated through current transnational research to confirm findings or highlight areas of divergence.

\subsection{Limitations and Validity}

Qualitative studies provide a deep look into a specific case or multiple cases, however a drawback to the small, localized sample size is the inability to generalize the findings to a larger population. Quantitative research follows a more structured approach and are often equated with positivist views and power inequalities between researcher and researched. Qualitative approaches are less structured in nature but allow for deep focus into a specific phenomenon, which may differ between individuals or cases being studied and require tailored, individualized methods. Maxwell (2013) asserts "less structured methods trade generalizability and comparability for internal validity and contextual understanding" (p. 88). Although the case study is a valuable method, it also is limited by issues of reliability, generalizability, and validity. This is referred to as an "unusual problem of ethics", where a case writer could presumably pick and choose data to illustrate a particular position that they hold bias towards (Guba and Lincoln,1981). Another potential downfall of the case study method is that the researcher may prematurely draw conclusions because of the difficulty of processing the large amounts of data collected. This qualitative study explored a specific group of Nicaraguan immigrant entrepreneurs from the community of Villa Sandino and currently residing in the San Francisco and Miami area. Although not generalizable, the study can 
be viewed as a manner to identify contextual elements that can later be tested in a more quantitative manner.

Validation of findings occurred throughout the collection and analysis process to check for the accuracy from the standpoint of the researcher and participant. Multiple strategies were incorporated into the study to ensure validity. Member checking was employed by revisiting participants to share the themes and insights deduced by myself during the analysis and coding process. This provided participants an opportunity to comment on the findings and clear up any misunderstandings. Rich, thick descriptions were utilized in the analysis to properly convey the findings. Direct quotations were included to highlight the perspectives and thoughts direct from the immigrant entrepreneur participant. Triangulation was also used to examine the qualitative analysis against other data sources. One particularly interesting and well aligned quantitative data source is The Comparative Immigrant Entrepreneurship Project (CIEP). The CIEP contains survey data from over 1,200 Colombian, Dominican, and Salvadoran family heads and was designed to examine the prevalence of transnational entrepreneurship in immigrant communities ("The Comparative Immigrant Entrepreneurship Project", n.d.). This data provided a valuable source of information to compare and contrast the findings of this qualitative study. 


\section{Chapter 4: With-In Case Study Analysis}

\subsection{Case Study Interviews I (Immigrant Entrepreneurs)}

This study attempts to capture two interconnected, but diverse aspects of Latino immigrant entrepreneurs within their receiving community. The focus has been to first understand how immigrants engage in entrepreneurial activities at a local level. What challenges exist as well as what support systems help foster these entrepreneurial endeavors? Secondly, we attempt to understand how Latino immigrant entrepreneurs relate back to their home country. What are the determinants, motivations, and strategies of these individuals? The integration of these immigrants is vital to their ability to engage in transnational development initiatives. Because of the dual intent of this study, we examined the results in a two-step process. The first is a "within case" analysis, uncovering themes and patterns that emerge within each specific case. This internal analysis will be followed by a cross-case analysis. The cross-case analysis is a powerful approach to mobilize knowledge of the individual case study by comparing and contrasting information between cases (Yin, 2009).

The within case analysis will be presented in this chapter as way to explore the immigrant's individual stories. Because the individuals are located in San Francisco and Miami, Skype and phone conversations were utilized to capture the interviews. A general interview guide (see appendix A) was used to ensure the conversations followed a similar flow and included pertinent questions regarding the integration, entrepreneurial, and transnational experiences of each Nicaraguan immigrant. Because the focus of the interviews was on capturing the unique and rich stories, limited demographic information was captured. An overview of the key demographic information is presented in Table 14 
and will also be referenced within the individual case studies.

Table 14: Demographic Information

\begin{tabular}{|l|l|}
\hline \multicolumn{1}{|c|}{ DEMOGRAPHIC INFORMATION } & \\
\hline SEX & 6- MALES \\
& 4- FEMALE \\
\hline AGE RANGE & 28-63 YEARS \\
\hline LEGAL STATUS & - PERMANENT RESIDENT \\
& 3 - U.S. CITIZEN \\
\hline EDUCATION LEVEL & 5 - HIGH SCHOOL LEVEL \\
& 5 - COLLEGE LEVEL \\
\hline CITY OF RESIDENCE & 5 - MIAMI \\
& 5 - SAN FRANCISCO \\
\hline
\end{tabular}

Each interview was analyzed to allow for emerging themes. This is an explorative study, so pre-set theme groups were not utilized and each case was examined as a unique account. A brief description of each individual is offered at the beginning of each case to provide context and situate the analysis with the appropriate background information. The biographical description is followed by an analysis of the prominent themes that emerged and connected the experiences of each immigrant within the transnational and entrepreneurial spaces. The content of the themes is delineated between individual level and community level information in order to provide clarity to the results and focus the direction of the study. Direct quotations from each interview are added to provide a rich description of the participants journey through their own words and narratives. These themes are further utilized in chapter 6 of this study to create a comprehensive understanding of the atmosphere of transnationalism from below within this group. 


\section{Walter}

Walter lived in the town of Villa Sandino for over 30 years before immigrating to the United States. He was very socially integrated into his home community and worked primarily as a housepainter for both residential and commercial properties in the area.

His large immediate family all lived within 10 miles of his house and he had no plans on leaving his community in pursuit of work in other areas. His decision to immigrate to the United States was predicated on his courtship and subsequent marriage to an American woman working with a development organization in a nearby town. Walter has moved several times within the United States and eventually settled in the San Francisco area after moving to California for a career opportunity for his wife.

Walter is a high school graduate and had difficulties finding suitable employment upon initial immigration. His first positions were in restaurants, alongside undocumented Latino immigrants, without insurance and for low pay. He was able to transition to a better position within a hospital medical facility because of a connection made through an immigrant service institute where he was enrolled in an English class. He has held a wide array of positions and has used his social capital to find connections in many distinct areas. He now works for a cabinet manufacturer, where he is content working with his hands and incorporates his love of painting and woodwork in a stable environment with opportunities for advancement. Because he and his wife are now in a more stable position, he was able to start a fishing and wildlife transnational entrepreneurship venture with family members approximately three years ago, in 2015.

Themes that emerged through the conversation with Walter about his transnational experiences include; lack of cultural connections leads to expanded social 
network, leveraging stability to create opportunity, supporting individuals to foster financial sustainability, focusing on interests, and transition from informal to formal.

\section{Lack of cultural connections as catalyst to expanded social network.}

Individual Level: Walter initially moved to the St. Louis, MO area and his first connections were with the friends and family of his American wife, none of whom were Latino and none spoke Spanish. He had to quickly find employment while simultaneously studying the English language, because he was not able to rely on an ethnic enclave to help him transition. Walter began his life in the U.S. as a documented worker but his first jobs were at the bottom of the workforce. He was working in the same position as others without documentation. This intense work schedule and position provided his first concrete step into building his new life, but he was placed at the same level as other immigrants without residency status. Walter describes his transition as very difficult initially.

I started working two jobs in two different restaurants. One was cleaning a restaurant and one was as a dishwasher in a different restaurant. I worked nights in downtown St. Louis and mornings in an Irish restaurant in a suburb of St. Louis. I would get home at 2AM every day and get up at 5AM to go to my other job. It was pretty hard because I did not have much free time and the time I had off was when my wife was at work..., so I had to study and try to learn as much English as I could right when I got here to be able to get started and be able to work and help support us.

This initial experience created both empathy and resentment towards the American labor force. Experiencing the same scrutiny and judgement of undocumented immigrants provided him a unique insight into the complex identity and struggles of immigrants in the U.S. Walter described his attempt to learn a language as another initial difficulty. He came to the United States in his 30s, past the time where he would be immersed through education but in the stage of life where the establishment of career and family are 
prevalent. He had to take initiative to make connections. Walter enrolled in a community college course and took weekly English classes at a local immigrant integration center. Through these experiences, he met many other immigrants, both Latino and non-Latino, that allowed him to connect to his new community on a different level. Walter describes this experience as both challenging but also comforting.

I was so tired from working both my jobs that going to English class was really hard. But once I would arrive it would be so nice to be around others trying to learn the language. Ifelt like we were all going through some of the same struggles and we could vent to each other and kinda let off some steam. Sometimes in my day to day life I felt low, like I wasn't as good as the other people I was around....you know the Americans, but in English class I was around Mexicans, people from Vietnam, from Africa, from Syria, you know... from all over the world with all sorts of backgrounds, but we shared this need to learn a new language. I really loved that group of individuals and still have some good friends from that time.

Although his initial transition was uncomfortable, he was quickly gaining skills that would allow him to integrate into American society at a quicker rate. A few months after arriving to St. Louis and working this difficult schedule, Walter was able to secure a more lucrative position at a nearby hospital in the research lab. He found out about this position through the immigrant integration center where he was taking English classes. This lack of initial cultural connections led to an expanded social network for Walter. His language acquisition and upward mobility of employment happened quickly and he also was creating a larger social network that would be beneficial in his subsequent ventures. Community Level: Walter realized the importance of building an expanded social network for the purposes of language acquisition and upward mobility. After his initial move to St. Louis, he continued to seek out friendships and professional atmospheres that allowed him to integrate into the non-Latino based American culture. He used this as a strategy for quicker integration and described how he maintained friendships with 
Nicaraguans from his community and some local Latino friends, but focused on not isolating himself with these groups in an effort to feel more comfortable in his surroundings. When asked if he surrounded himself with other Latino friends and coworkers he referenced his focus on maintaining an expanded network.

Some, but not really. I mostly work with people from here, and some other places like Cambodia. I go fishing with a couple of guys from Mexico but when I have parties or a get together its mostly just guys from America. I tried to get jobs from when I first moved here where there were not a ton of Spanish speakers because it was very important to me to learn English as fast as I could. For instance, my wife and I had the opportunity to move to Miami or San Francisco and I preferred San Francisco because I knew if we moved to Miami I would only speak Spanish all day every day and that would not be the best thing for me.

Walter's lack of initial cultural connections when he immigrated with his non-Latino wife to a Midwest town led him to recognize the benefits of building a diverse social network. He spoke about how uncomfortable his initial months were, which differed from other immigrants that were able to quickly move to an ethnic enclave which mirrored their home culture and community. However, this helped him learn the language, successfully connect with diverse community services and resources, and find better employment in a more expedient manner. He used this experience to continue to reach beyond the Latino network when he made a second move to San Francisco.

\section{Leveraging stability to create opportunities.}

Individual Level: Walter eventually moved to the San Francisco area and secured a position that he enjoyed with a cabinet manufacturer. Approximately three years ago, he decided to delve into an entrepreneurial venture with family members still living in Nicaragua. The entrepreneurial endeavor that Walter developed was a transnational business that he created as a side project while still working full-time. He was able to utilize his steady employment and the secure lifestyle he had spent years establishing to 
leverage his sense of stability into the creation of an entrepreneurial opportunity for himself and his family. He was able to capitalize on his access to information and products in the U.S. and the unmet wants and interests of individuals in his home country. He decided not to open the business in his hometown but instead opened it in a larger city $1 \frac{1}{2}$ hours away. Walter shared how he used his familial network to establish the physical location and started slowly building his business inventory through return trips.

My cousin he had a small store a long time ago but he didn't have enough lures or weapons because it's too expensive over there to get a lot of these items.........So, it started that when I would go back home I would bring over a lot of the items I found here and he would sell them for a profit... He used his channels to allow us to import some items for a low cost to Nicaragua to allow for the inventory to be restocked more than once a year.

This showed a certain level of business acumen and understanding of market potential. It also indicated that he has not only maintained ties to his home town but at the very least his region/state. Walter maintained employment while operating the transnational business on the side. This employment related to his previous areas of expertise and skills developed in Nicaragua. This is also a stable operation that added to the sense of security he previously mentioned.

Stability and security were reiterated in other sections of our conversation. Walter and his wife started off with very little money or assets and have slowly accrued education, employment, and resources. Building wealth through assets is how Walter measured his financial success. The business added a sense of security to Walter's finances. Walter had to allocate his earnings to the maintenance of his life here in America and to assist his family in Nicaragua, before the development of his business, which caused a strain. He was able to find a solution where he could create wealth through buying a house and still provide remittances. Security was a big theme in this 
sense, security for himself and wife, and security and stability for the family that he left in Nicaragua.

I'm happy right now because we bought a house last year, which I'm so happy about. We were renting before but we were able to find a nice beautiful house to move into and it feels like we are making progress. I still work another job, but the business helps me to add to my monthly income and hopefully will provide opportunities for people I know back home. I'm happy with the money I make now and feel more secure than I did before.

Community Level: Another interesting reference to security and stability in our conversation related to the turbulent Nicaraguan history and its lasting effects on both his family's day-to-day life and his mentality towards development. The family members of Walter are not part of the political party in power and have suffered years of marginalization and oppression because of their political stance. Walter's father was once very active politically and his uncle was falsely imprisoned for years during the war. Many of his relatives immigrated to the United States as refugees during this time but his immediate family all stayed in Villa Sandino. This lack of stability in his home community is a meaningful parallel to his achieved stability in his receiving community.

It's a mess. A lot of people from my town are trying to go to Costa Rica because they are afraid. I am scared for my family. They think there may be another war soon. People are afraid to send money or things because they think the government is going to steal the money. This is one of the things that makes it hard to help my family or my community, the government is always trying to rob the people and sabotage those that aren't Sandinista. If I can't use MoneyGram, I'm going to have to reach out to my friends that travel to Nicaragua to give them the money directly when they travel there. I don't know, I wish it were easier.

Although he has reached a level of financial, professional, and personal security he still must navigate a way to support his family and community in an environment that is very turbulent and unsure. 


\section{Supporting individuals to foster financial sustainability.}

Individual Level: Walter relies on social capital for his transnational engagement.

He realizes that by supporting individuals to foster financial sustainability, he can decrease the vulnerability of his immediate and extended family. His transnational business has supported his cousin and brother and created a successful and reasonably lucrative business. These family members, in turn, utilize their heightened financial status to provide assistance to Walter's mother and other siblings as well as other family

members. While Walter maintains monthly remittances to his family, assisting his family members to find success creates a multiplier effect that creates even more support and resilience against the vulnerable nature of the position of his family.

Walter has also provided direct investment and guidance to the in-home flower arrangement business of his mother. This is an informal business that his mother engages in when she has the appropriate time and resources. He supports his mother the best he can because he knows it is yet another source of income for her as well as an emotional outlet that she takes great pride in. He spoke about his mother's business and his interactions briefly in our conversation.

I don't do much, but I send her money as investments and I have also bought her books and magazines with ideas about how to make new and different arrangements. Sometimes I just try to help her come up with new ideas or think creatively. But she does the work in her house and sells the arrangements on our front porch...I see how there are so many companies selling flowers and arrangements here [San Francisco] and think that she has a lot of possibility to make things that people in La Villa have not seen before... So I'm always taking pictures and sending her ideas. When she visits here, we spend a lot of time at crafts stores and going around to stores to check out new ideas

This shows that apart from financial capital, Walter also transferred knowledge through his access to innovative and creative environments. 
By supporting his family through direct investments and knowledge transfers, he is creating an environment where they are able to create an internal safety net and mitigate issues without a high reliance on outside sources. Walter continues to supplement their income with remittances, but they don't feel the high level of dependence many families of migrants experience. They developed a sense of agency and are empowered to make steps towards development, including creating a safer internal environment through home repairs while investing in the younger members of the family through education. Walter spoke about how his mother utilized her enhanced financial flows due to her increased business presence.

My mom uses it for her flower business and to make repairs on the house. She just changed the tiles on her patio and all of us brothers chipped in to help her with that. She is talking about putting a new roof on the house next. The house is old so there are a lot of repairs that need to be done. For instance, my mom fell through the floor last year because the wooden slats are rotting out and are weak. She broke her leg doing that. So we are trying to make sure the house is safe for the family. She also uses the money for food and my little sister is going to college at the moment so we are trying to help her with tuition and with her transportation costs for that.

When speaking about his transnational activities, Walter relayed interests in community wide interventions, but describes mistrust in the community leadership and a history of misused resources. Although he has the interest in advancing community level initiatives, his current transnational engagement is primarily focused at the individual and household level.

\section{Focusing on interests.}

Individual Level: The transnational activities Walter engages in included transferring financial capital in multiple ways. First, direct remittances were provided for daily functions, but he also transferred financial capital in the form of investments. His 
business was an investment that he benefits from but also provides economic opportunities for family members. He also invested directly in his mother's self-made business. Where his remittances provided short-term benefits, and allowed the family to supplement their lifestyles on a daily basis, his investments provided a more sustainable benefit, creating agency and empowering members of his family and community to create their own revenue streams. Walter capitalized on the interests and a base that already existed to expand a transnational arrangement that involved family, interests, and an existing market.

Walter's choice to pursue his fishing and hunting business with a cousin and brother required a sense of trust, especially since he lived so far away and could not be part of the daily operation. The business was started because of necessity, specifically the need for extra money for remittances, and opportunity, because his cousin was already working in a similar area. Walter's business had the double impact of creating economic opportunity for family members back home while increasing his income, allowing him to better support his nuclear family. It appears that he was able to maintain a more suitable life in the US but the extra responsibilities of providing for his family in Nicaragua drove his entrepreneurial endeavor. Walter described how his passion for fishing and hunting drove his decision to enter into this transnational business.

I think one of the reasons this business worked out for me is that it doesn't feel like work. I mean I work hard every day in my normal job, so I didn't want more stress on top of that. I go fishing every weekend for fun and love learning about new fishing gear for my personal use, so using that information to work with my family in this business doesn't add much work...or like I said stress...I remember the first time I went back I brought actual fishing poles, we don't use those down there. Everyone was so interested in them I would be out in the middle of the street showing people how to cast, it was so fun. I love it, they love it, so why not make some extra money from it, it makes sense. 
He created a business that capitalized on his interests and the interests of his family. The relationship with his Nicaraguan business partners may also tighten their bonds through shared experiences and conversations related to their outside interests of fishing and hunting. Enjoyment and fun was prioritized over stressful, but possibly more lucrative, types of interactions. It is possible that the limited time that Walter had to interact with this business and the fact that he is working with family members made it necessary to create something that they could all enjoy instead of creating tension. Walter was mixing business with personal relationships and the nature of the relationships seem unchanged from the business venture. When speaking about the business relationship with his family and the time commitment, he reiterated that the stress-level was low and the underlying catalyst for this endeavor was building on a passion that he already spent his free time pursuing.

No, my cousin and brother are in charge of most of the day-to-day operations, so I do not have to work really hard on the second business. I just have to keep in communication and be looking at new products that people would want in Nicaragua. And I like doing that anyways because I hunt and fish here, so it is a fun thing for me to do and not very stressful.

It is unlikely that Walter would have built a transnational business in an area that was not focused on his interests and pastimes, because he would be unable to invest time and resources to build in an area outside of his expertise. Family, friends, and mediating stress were central to his happiness and adding another initiative that would take away from his family time would not have been feasible at that point in his life.

\section{Transition from informal to formal.}

Community Level: Walter weaved the idea and relationship of informality and formality through our conversation in various ways. Walter pointed out the social norms 
that differ between countries. He observed his home was more informal, slow paced and prioritized family and social ties over economic endeavors. In contrast, he felt the United States was more fast-paced and prioritized work and formality over social connections.

I would say my town, it's about 3000 people. It's not as stressful like it is here. There aren't so many bills like here and you have more time to be with your friends and family. Mornings are happier there, you get up and go get fresh tortillas and sit on the porch with some coffee and talk to people in the street. Of course we work over there, but it's not as strict or structured as here. There aren't set hours and we can ease into our day or take more breaks to socialize... Here in America work comes first, in Nicaragua family comes first, or at least that's how it feels. I miss my family, my neighborhood, the food. I do love it there.

Walter also noted the difference in the professional culture between Nicaragua

and the United States. He referenced how the formality and professionalism found in the United States was lacking in Nicaragua. This idea emerged when Walter was speaking about his future goals of transferring business knowledge back to his community and possibly opening up another physical business in his hometown. He connected the concept of professionalism to formality and stated that businesses were run in a less professional manner in his home community.

Well, I'll need to save money here, then find a place and train some people over there. I want to teach them the things I've learned from here because it is so different. I know that I could help them learn business skills and technical skills that I have learned in my job here. Over there we are less professional and the businesses are not run that well. By training some people with the skills that I have learned they will have a better advantage and I think the store could be very successful. I would like to do that job over there.

It is interesting that informal is used in both a positive and negative lens. Informality allows for tighter social bonds and better family interactions but can be detrimental in business. This is noteworthy because Walter used informality in many aspects of his first business venture but has formalized some channels while leaving others very informal in 
nature. He began with informality because the culture requires it and was more accepting of that approach, but he then injected aspects of formality to create efficiency and effectiveness as he has seen his experiences in U.S. businesses. Walter initially utilized informal channels to transfer products and then used his social network and an existing entrepreneur in Nicaragua to formalize arrangements. The transition from informal to formal business operations and the use of bridging social capital was an interesting aspect in the way the business developed. This was illustrated when he spoke about the initial business his cousin started and the transitions that occurred after he began collaborating on the endeavor.

So his store was in the living area of his house and it was very informal. But when I came here, I would always send him pictures of the fishing stuff I found in stores here like BassPro or even Wal-Mart and we started talking and comparing prices and decided to expand his business into something more formal by utilizing products I could find here.

This transition and intermingling of informal and formal norms and institutions was something that appeared crucial for successful transnational engagements in this culture. Walter had a unique position from which to appreciate the social and cultural norms of both his receiving and sending communities and was able to leverage this knowledge to formulate a targeted approach that combined the positive aspects of both informal and formal social and professional arrangements.

\section{Patricia}

Patricia initially immigrated to the Washington D.C. area with her mother as a teenager and later moved again to San Francisco with her husband. Patricia's mother was petitioned for by a brother and they were able to immigrate together after receiving a family based visa approval. She first arrived in the United States with no English skills 
but was integrated into a largely El Salvadorian neighborhood in her receiving community. She also had many family members already living in the United States that helped her transition to her new life.

Patricia became interested in pursuing entrepreneurial endeavors after she got married and was trying to find a way to balance caring for her young children while making an income for the family. Patricia and her husband moved to San Francisco because her husband had family connections in the area that indicated that the labor market was stronger on the West Coast. Upon arriving in San Francisco, her husband obtained a position with a local construction company but they had difficulty earning enough money to rent their own apartment and live independently. There were no opportunities for advancement. Patricia had her first child shortly before moving and she was therefore unable to contribute financially. As her daughter got older and her husband was still working long hours in two jobs, they decided to open their own restaurant to offer flexibility for Patricia to work as a mother and created a space where they could work together towards a more prosperous future.

Themes that emerged from our conversation regarding her immigration and transnational experience are; Integration into a parallel culture, familiarity as security, familiarity as incubation, and cultural translation of resources and ideas.

\section{Integration into parallel culture.}

Community Level: Patricia moved with her mother at a young age and settled in her Aunt's house in a neighborhood of Washington D.C. Her mother quickly began working in one of the many El Salvadorian restaurants in this particular area as there was 
a large El Salvadorian diaspora in Washington D.C. Patricia socialized exclusively with El Salvadorian as well as other Central American youth, but did not have a particularly large Nicaraguan diaspora to connect with. She began to integrate into the El Salvadorian community, which shared many similarities with Nicaragua but also had a distinct culture. She described her first experiences and impressions within her new community.

It was difficult because I didn't speak English and had to go to classes in a language I didn't understand. It was really really hard to catch up. But a lot of the students in my class were Latinos, from the Dominican Republic and actually most from El Salvador. We lived in the 'Little El Salvador' part of D.C., so it felt very much like home even but still kind of different. And then outside of a few blocks it was completely different, there were other immigrants from Ethiopia and Asia and then the very American part of town.

Patricia shared that this mode of reception created a safe and comfortable transition, but inhibited English language acquisition and created some integration issues later in life when she moved to the San Francisco area, where she lived in an area with a smaller Central American diaspora.

Patricia assimilated into a diaspora that was similar to her home country but was also unique and displayed many differences. Many immigrants chose to live within Latino enclaves that mix various Central and South American cultures into one community, however because this diaspora was almost exclusively El Salvadorian, it created a situation where Patricia had to adopt the cultural and social dimensions of the community while dismissing parts of her own cultural heritage. Patricia described some of the nuanced issues she faced.

I loved my friends in D.C., I mean I was lucky to live in an area that I could survive with my language and feel comfortable for the most part with the food and just general way of being. But it was strange sometimes, I mean, El Salvador is our neighbor but we have different words some different food, different ways of celebrating...And they are a little more intense. In Nicaragua we are laid back 
and spend a lot of time with family making food and telling jokes. But the El Salvadorians are more particular and it felt like there were more rules in their get togethers, not as laid back as I was used too

This integration experience allowed Patricia to feel comfortable immigrating at such a vulnerable age and supported her through a challenging educational experience. At the same time, and because she transitioned during her teenage years, it shaped her identity and influenced her personal and professional aspirations. As an adult Patricia married an El Salvadorian man and identified as both Nicaraguan and El Salvadorian, as well as American.

I feel El Salvadorian half the time. I mean, my husband and his family are from El Salvador, I grew up with most of my friends from El Salvador, and we try to visit El Salvador at least once a year, but at the same time my Nicaraguan roots are strong and I love visiting Villa Sandino too. I feel like I belong to three countries, Nicaragua, El Salvador and America. It's special but also can be tiring at times.

Patricia's dual integration into the United States while simultaneously incorporating into the El Salvadorian diaspora demonstrated a noteworthy added layer that many immigrants experience upon initial arrival to their host community. Balancing an identity and close relationship with three nationalities offered many benefits to both Patricia and her family, but also added stress and tension when trying to simultaneously balance responsibilities and social norms of multiple distinct cultures.

\section{Familiarity as security.}

Individual Level: Patricia continued a pattern of building social ties with other individuals that were ethnically similar and shared the same language. She attended a school that forced her to broaden her social base in one manner, but the challenges that arose in this new environment made her revert to a reliance on her close bonds with other 
Spanish speakers during non-school hours. Patricia used the term familiar various times throughout the interview. She was attracted to familiarity in times of difficulty or struggle. The idea of familiarity first arose when Patricia described her first day in the United States.

We arrived in Washington D.C. in February and it was so cold. I didn't know that kind of cold existed. I stepped outside and could see my breath and thought that my insides had shattered and they were escaping through smoke in my breath. It was crazy. Everything was so different... I felt paralyzed, like I was scared to move because I was going to run into something. We went directly to my aunt's house, that's where we stayed for the first few months and I remember feeling much calmer when we arrived there and had a bowl of Sopa de Frijoles and tortillas. It felt familiar and I liked that.

Environment played a role in Patricia's her first years in America, as she was living in a parallel of her country within a new 'different' country. This may have made it more difficult for her to connect with outsiders, but she continued to depend on the insular, ethnic-based area where she established her primary connections.

Community Level: The community served as a protective force but was not actively preparing her to leave.

Like I said, we lived in the 'Little El Salvador' part of D.C.,. I hung out mostly with other girls from El Salvador and would spend after school in our parent's restaurants and at their homes. So the friendships felt very familiar, but the school was very different and I struggled quite a bit.

Patricia noted that although she felt comfortable in her day to day life, she had problems when having to leave her ethnic enclave. School presented challenges as she had trouble acclimating to a different educational system and process. She rarely left her small community. Although blocks away different ethnic enclaves existed and the entire city was well connected through metro transportation, she was leery of leaving the safety of 
her small neighborhood.

Patricia's Husband is El Salvadorian and she has maintained a strong connection with immigrants from her country of origin. She did not speak of many strong connections that reached outside of this network, especially in her first 10 years after migrating. When Patricia and her husband moved to San Francisco they lived in an area that was not prominently Latino based. However, she noted that they spent a significant amount of time in a nearby neighborhood that had many Latino-owned businesses. She once again sought out familiarity to gain a sense of security in her new surroundings. Patricia was able to leverage her sense of security, based on the familiarity of becoming involved in the Latino business sector, to pursue an entrepreneurial endeavor. She explained that she did not seek to open a business out of pure desire but utilized her past experiences and knowledge base to create an opportunity that was essential to the protection and maintenance of her family.

I moved to San Francisco three years ago. I married my husband, who is El Salvadorian and he had a cousin here. My husband wanted to move here because his cousin was able to get him a job. But when we got here the job wasn't as good as we thought... when we realized that his job did not have a great future we tried to think of other possibilities. My mom had worked in a restaurant in DC and had eventually created her own catering company and so the food industry was something I was familiar with.

Patricia was resilient through a move that resulted in a negative outcome for her husband and was able to capitalize on the strong bonding capital she had developed within this specific Latino business district in the San Francisco area to pursue new and different opportunities. When Patricia decided to become an entrepreneur she relied on the familiarity she had with the restaurant industry to direct her decision. 
Patricia spoke about many issues in Nicaragua and referred to a sense of guilt upon returning. Patricia related her sense of security to familiarity and not specifically to a safe and protected environment. She had a personal sense of security when she returned to her home country, although from an external perspective the community demonstrated a higher level of uncertainty and danger than her host community. This reality influenced her transnational perspective. She continued to prioritize security through the familiar, such as close communal bonds, but also realized the need for external opportunities.

When we go back to El Salvador and Nicaragua, I always feel calmer, but I also sometimes feel guilty. There are no good hospitals, or schools, and sometimes there is nearby violence that is moving closer and closer to my town. I wish that I could help my community have more opportunities. I wish for them that they could keep the best parts, like the slow pace of life and tight relationships with family but also create new opportunities.

This may reflect Patricia's experiences living in multiple locations. She was drawn to relationships and traditions that she was accustomed to but realized the benefits that could occur by creating space to cultivate opportunities with unfamiliar counterparts.

\section{Familiarity as incubation.}

Community Level: Patricia spoke about growing up around the restaurant industry and reminisced about how she spent her hours after school at the restaurants of the friends of her mother. She knew the general processes but needed assistance with the technical components of running a business. There was a certain sense of fear or hesitation about attempting to open a business within the American regulatory environment. She found a sense of confidence because she started her business in a Latino neighborhood. She found a place that provided her the protection and familiarity 
of her home culture inside a larger more complex system.

We were living by this area in Southwest San Francisco where there was a large Latino population and we spent a lot of time in the business area a few blocks over from our house. One day we saw that a store was open for rent and so we thought that we could probably do a really good job with a El Salvadorian restaurant. There aren't as many El Salvadorians in the area so there wasn't another restaurant like it, there were many other Mexican restaurants but we offered something a little different.

Throughout our conversation, it was apparent that the experiences Patricia encountered in San Francisco expanded beyond the isolated involvement that she referred to during her primary migration to D.C. In San Francisco Patricia was able to depend on a broader Latino community to provide her a strong social network and referrals, and also found support in a local organization that promoted Latino-based entrepreneurial practices. This illustrates the difference between a protective and incubating force. An incubator protects while actively preparing one to cross boundaries. Patricia spoke about the encouragement and assistance that the local community and a specific non-profit organization provided as she and her husband took the initial steps to open their restaurant.

It actually worked out really well. One of the guys that owned a sports shop a block down from the store we wanted to open gave us a contact to an organization that helps small business owners...I think it was called the LBA something like that... They have different services and trainings, they offered a free consultation to see what exactly we needed and to kind of point us in the right direction. Opening a business in the U.S. is much different than in Nicaragua... This organization made sure we were on the right track and didn't miss anything.

The local business community provided a transference of resources and knowledge to Patricia, connecting her with the LBA. The LBA was an institution with a good reputation and therefore was able to rely on word of mouth to spread knowledge regarding the services they provided. Community members in the neighborhood 
demonstrated a willingness to help new entrants and seemed to be supportive and a good source of information.

Individual Level: The LBA provided structured information in the form of documents that easily transferred basic, conventional information to potential business owners. Classes were offered and trainers complemented the general informational packet by providing individualized assistance ranging from basic to complex. This type of formal institution complemented the informal business structure by providing knowledge and assistance that provided a safe entrance into the local business market. This specific combination of a strong insulated community base along with an external, well-respected organizational support system, provided a unique incubation system that helped Patricia launch her business smoothly and find quick success.

The LBA seems to offer positivity and support and diminish the fears created by the complex business environment of San Francisco and the U.S. in general. Patricia's biggest fear was the technical paperwork and regulations. Her connection with both the community and the LBA facilitated the development of an entrepreneurial identity within Patricia. Patricia spoke about this mental shift when she described a consultation with a LBA staff member.

Ed suggested we attend a four week program that was for 'entrepreneurs'. I had never thought of myself as an entrepreneur. I thought that was someone inventing I-phones or something very innovative. I was just trying to open up a restaurant, something ordinary. But we signed up for the classes because we weren't sure what else to do, we needed guidance.

Patricia's reaction to the term entrepreneur was very noteworthy. The impetus for her business was to navigate a challenging situation, not solely to take advantage of a 
market opportunity. Her engagement with the LBA helped her move beyond her insular nature to expand her thinking and business practices outside of this community. After opening the restaurant within the Latino business community, Patricia expanded her business to include catering services and actively marketed her activities in other areas of San Francisco. Patricia grew her business to work all over the city and developed contacts with diverse sets of individuals. She still enjoyed working in her main, physical business in the Latino centric area but developed the confidence and wherewithal to work and socialize in diverse and disparate settings.

\section{Cultural translation of resources and ideas.}

Individual Level: Training and assistance from formal institutions had supplemental positive attributes for Patricia as a transnational actor. Knowledge gained through the workshops she attended and training materials she received were often transferred back to her community of origin. Patricia conducted a small training for two friends in her home community that subsequently opened a restaurant in there. They approached the business venture in a unique manner, different from other businesses in the area, because of the connection with their friend in America.

Two of my best girlfriends in Villa Sandino opened up a restaurant in their town last year. I think they were inspired by my experience. Although it is common to open small, informal restaurants over there, people do it all the time, my friends made sure to take their time to plan a restaurant that offered a better overall experience. I sent them some of the training materials I used with LBA and also we had skype meetings once a week to discuss their plans. Instead of just opening up something quickly without thought, they actually did a community survey to understand what people wanted and preferred.

Patricia was able to reformulate the information she received from the local LBA during her business training into materials that were suitable to the context of her hometown. This illustrates that opportunities beyond purely remittance-based transfers 
exist. Patricia created a knowledge bridge where ideas and concepts from one area were transferred to a different area and be adapted to best fit the needs and realities of that specific situation.

Instead of making financial investments in the business start-up she acted as a business consultant, transferring the skills she learned from her experience with her business to friends in her community of origin. Subsequently, these friends also transferred that knowledge to a local high school.

Something that my friends did that was really neat was, they went to the local high school after starting their own business and gave a workshop. Similar to the workshop I gave them. Just providing some of the basic information regarding how to start thinking of a budget, how to see what the community wants and needs, thinking of ideas that are different and original. I was happy to hear that, I think the high school students probably loved it too. It's something different than the normal, boring type of learning they experience.

This was a substantial transnational bridge and showed how an individual could act as a catalyst between institutional knowledge and community development based on an already established social network and the identification of individual and community needs.

Community Level: Financial remittances were the primary transnational activity that Patricia engaged in apart from the social remittances. She suggested that she wanted to become involved or create more social programs for her hometown but stated that she lacked the time and strategy regarding how to establish a systematic program that could create sustainable development. She did identify the potential benefits of creating an institution like the LBA in her community.

I think that my community could really benefit from something like a business training center, something like the LBA, but with different courses specific for Villa Sandino because San Francisco and Villa Sandino are very different places. I don't think you could just put something like the LBA over there, it would have 
to be adjusted quite a bit, but the general idea is what I'm saying I would like to see. I mean they need money of course but they also need guidance for how to create businesses or think of new ideas. Everyone thinks the same and any business that opens is just a copy of their neighbor's business. I'd like to see people think more creatively or start things that would really help the community. They need more education in this area, money alone would not do enough.

She was hesitant to take on this project because it required a more complex and involved dedication, but would potentially have high community level impact.

\section{Rachel}

Rachel first came to the United States as a non-immigrant, through an opportunity to study at a university in Colorado. Her original plan was to complete a university degree and return to Nicaragua in order to start her professional career. Her plans changed when she met and subsequently married an American man. This began her immigration experience, allowed her to adjust to a permanent resident status and later become a naturalized citizen. Rachel prepared to begin a career in education but shifted her plans as she became a mother. She started an entrepreneurial endeavor as a daycare owner and operator to be able to care for her children while contributing financially to her family after moving to San Francisco for an employment opportunity for her husband.

Rachel maintains a transnational relationship with Villa Sandino through continued contact and return visits. She also served as a connector between a San Francisco development group and a group of women in her hometown. Although she had no plans to return to Nicaragua on a full-time basis, she did express a desire to build upon her skills developed in her business to create positive impacts within her community of origin. Some of the themes uncovered through our conversation included: becoming engaged and finding community, navigating two worlds, problem-solving and 
development of an entrepreneurial spirit, partnership to overcome weaknesses, and 'Outof-the-box thinking',

\section{Becoming engaged and finding community.}

Community Level: Creating a sense of community and social interaction has been important to Rachel throughout her time in the United States. Rachel initially moved to Colorado to on a student visa and later moved again to San Francisco with her husband to pursue his professional career. This created a situation where Rachel had to integrate into new communities twice and in very different environments. Her first experience was as a student on a university campus and the second experience was that of a housewife in the suburbs of San Francisco. Rachel spoke about the closeness and openness of her community of origin and her struggle to find the same sense of community in her new town.

...in Villa Sandino it was a tiny community and everyone always had their doors open and ready for a visit. Here [San Francisco] it feels more closed off. I don't know my neighbors very well.

Rachel was able to overcome this distance from her neighbors and community be searching out small groups of individuals with commonalities to become engaged with and to find her own micro-communities within the bigger cities. This was a thread throughout her immigration experience, and was a strategy she utilized to integrate into both Boulder, Colorado and later in her San Francisco suburb. In Colorado she had the benefit of arriving as a student with many opportunities to meet other like-minded individuals also looking for connections. She lived on campus, which provided her a physical closeness to many of her classmates and she also joined various student led groups that further connected her with individuals with similar interests. 
Oh it was intimidating at first, but it's so easy to meet people at university. The first few weeks are all about connecting with people that don't know anyone else, so it wasn't hard to find a group of good friends quickly. I joined a theater group and played on a volleyball team. I also lived on campus so had loads of people my age around at all times.

Her second move was a more challenging integration experience. She was married with a child and did not have the benefit of the interactive student experience she received during her first transition. She spoke about feeling isolated and disconnected from her new home and this led to difficulties getting settled, finding recommendations for doctors and service providers and finding a sense of direction in her new life. Again, to overcome this disconnectedness, she searched for a way to shrink her community to a smaller and supportive group of individuals. She achieved this by connecting with a group of mothers through a connection with the wife of a colleague of her husband. This group generated a micro-community that overcame the isolation of the large city atmosphere and targeted an association with other women with similar experiences and objectives as Rachel. She connected this group to a communal feeling that she experienced with mothers in her hometown and was a crucial means of her integration into her new surroundings.

Here it feels more closed off. I don't know my neighbors very well. That's why that mother's group was a lifesaver, it gave me a group of women that I could connect with right away, otherwise I don't know how I would have made any friends... It was a great way to meet people in the area, many of them lived in or near my neighborhood. I don't know what I would have done without that group, it made me feel like I was back home with my friends and aunt's and family, all with our kids playing and gossiping, having a good time, you know.

Engagement and community were integral to the entrepreneurial endeavor

Patricia started. Her daycare was created in order to give mother's a safe space to bring their children. She approached this venture through an opportunity and partnership 
discovered through the mother's group. Rachel was able to leverage her connections within this group to create her initial client list and the word of mouth provided by these mothers ensured that she was at full capacity shortly after opening. This venture allowed her to prioritize the care of her children while also contributing financially to the household income

My daycare has a good reputation. I started by recruiting mom's I knew through the mom's group I joined when I first moved here. Then word of mouth from those moms strengthened the interest and number of individuals that were interested in sending their children to my location... We were excited when we met our goal of 15 children signed up. It happened relatively quickly, around 2 months after opening.

Finding a sense of community through focused engagement was essential to the immigration experience of Rachel and her entrepreneurial success. She came from a town that was small and connected and she sought to mirror this experience in her experiences in the United States. Although she moved to a larger city that lacked the communal environment of her hometown, she was able to recreate this experience by creating micro-communities and engaging in selected groups. She incorporated a sense of community into her business by creating a safe and open environment for mothers and children in the area through her full-service daycare.

\section{Navigating two worlds.}

Individual Level: Although she initially planned to return to Nicaragua and become a teacher, she ultimately ended up staying in the United States as a stay at home mom. After having her first child she had no immediate plans to enter the workforce. The reality of the cost of living in the San Francisco area created a necessity for her to contribute to the household income. 
A couple years later my husband got offered a better opportunity in San Francisco so we moved. It was way more expensive to live out here so we started looking at ways I could bring in some income, but it was important to me to stay with my small children too. I had two children by that time and I hated the idea of leaving them every day. My mom and grandma were always home with me and I loved growing up that way.

The decision to start her own business, and essentially become an entrepreneur, was predicated by a desire to maintain her status as a stay-at-home mom paired with the necessity to supplement family income. She was able to achieve both objectives by opening a daycare and becoming a business owner. Rachel's goal was to create a selfsustaining business that would allow her a flexible schedule and a child friendly environment.

So we invested in a daycare, where I could contribute financially but could also spend all day with my kids at the same time. So the idea to start a business helped me navigate both worlds that were important to my family at the same time, being there for my kids and helping out financially.

Rachel spoke about the importance of family and finding a sense of balance when speaking about her relationship with her family that still resided in Nicaragua. This idea of navigating two worlds also appeared in her transnational experience

I do really miss my family, especially my mom and sister. I feel it even more now that I have my kids. I wish they could grow up around all their cousins and aunts and uncles and of course spend more time with their grandparents...I mean I love our life here and don't ever see us moving back to Nicaragua for good, but I wish I could spend more time there. When we go back sometimes I feel like a visitor for the first week until I get settled in again. I guess I just want the best of both worlds, those are the sacrifices you have to make sometimes.

All of Rachel's immediate family still lived in Nicaragua and most remained in Villa Sandino. Rachel often mentioned missing being close to her family and having a large extended family available for her children. She hoped for that possibility in the future, 
after her business became more self-sufficient. She wanted to be able to take her kids back for multiple trips during the year and create a sense of home in both places.

\section{Problem-solving and development of an entrepreneurial spirit.}

Individual Level: Rachel repeatedly described herself in an entrepreneurial way and talked about ideas she had for projects or businesses but did not identify as an entrepreneur. Early in our conversation Rachel described her journey to Colorado to start school. I asked her if she was nervous about the transition but she felt very self-reliant and positive about the new undertaking.

Since I was young, I've always been a motivated, outgoing self-starter. I was ready for a new adventure.

The manner in which Rachel described herself indicated that she was resilient and a risk taker, characteristics central to an entrepreneur. When she spoke about a challenge she faced, she also indicated an innovative solution that would overcome the challenges. Her daycare was one example of this. She needed to find a way to stay with her children and make money, so she found a way to reach both goals through a business startup. She also indicated this problem-solving capacity when she was reflecting on her original plans to return to Nicaragua to start her professional career. She indicated that she was planning on returning to work in a private school in the capital city. When I asked her if she would consider returning to her hometown to work, she conveyed that she would love to live closer to family but the opportunities for teachers in the area were dismal. After communicating these concerns, she told me about a project that she was thinking of starting.

...I know of this school up in Jinotega I think...I think it's called El Bastillo. It is a tourism lodge and coffee plantation and school. The school uses the business to offer students real practical experience. They basically run it and get to do some 
interesting agricultural projects with the coffee plantation. There are lots of opportunities and its more interesting that the mundanity of classroom lecture type schools that are prevalent there. That would be a great project and really would benefit the area where Villa Sandino is. It's a big agriculture area and then to build real business skills so early as well, those kids would love it.

Rachel's identity as an entrepreneur was slow to develop. Her lack of initial business skills reduced her ability to identify herself in this way. She did not pursue a business as an entrepreneur seeking out an opportunity but actually developed her entrepreneurial identity after the business became established and successful.

Creating something from nothing is amazing, when I think back at the beginning I'm amazed at what we've created. I definitely have much more confidence now and truly feel like an entrepreneur.

She reflected on her success as the final piece of a puzzle that added a certain level of confidence and conviction and generated the realization within Rachel that she was an entrepreneur. Rachel has started strategically planning for future expansions of her business and possible endeavors in her home community.

\section{Partnership to overcome weaknesses.}

Individual Level: A strong strategy that Rachel has used throughout her life and specifically in her journey to become an entrepreneur was to pursue partnerships as a way to complement her strengths and supplement areas of weakness. She spoke multiple times about her lack of business skills as a deterrent to starting a business or pursuing entrepreneurial activities.

I was not very business minded at first. I mean I always had ideas ... but my focus was on the educational component, not the business side. I had to reach out to actually learn how to start and maintain a successful business. I was lucky to have met another mom in my same situation that actually had gone to business school. She is my partner and has really helped guide me through the process...It works out because I add the educational component and she has the business expertise. I would have really struggled without this partnership, but feel much more confident now. 
Rachel leveraged her expertise in the educational and childcare areas to create a solid business venture, but utilized a connection made through her community engagement initiatives to find a partner that would help navigate the logistical and startup concerns that she was unfamiliar with. Rachel did not just rely on her partner to take care of the business aspects, but attempted to learn from her business-related knowledge and developed her skill set.

Community Level: Rachel has expressed interest in pursuing larger projects in the region of Nicaragua that her community is located. She spoke about the idea of creating the technical school at the beginning of our conversation when she was relaying that her initial plan was to return home to be a teacher, but expressed the limitations of opportunities for teachers and students in her hometown.

The schools are run by the government and it's not an atmosphere I wanted to deal with. I would have loved to have started an experimental or technical school in the area that would have offered a different option to kids in that area. That would be really cool, I come back to that idea every now and again. It would be kind of a combination of a nonprofit project or even for profit project, but could incorporate practical learning with a business or something...I've always had that idea in the back of my head, but couldn't do it right away. I would need to figure out how to organize all the moving parts.

Her experience related to education and her newly developed business skills provide her a strong base to pursue her idea of creating a technical school in her home community, however her physical distance and lack of institutional knowledge on the local level prevented her from moving forward.

\section{'Out-of-the-box thinking'.}

Individual Level: Another theme that is related to the entrepreneurial spirit, but warranted some supplemental exploration was the use of the term 'out-of-the-box' that 
was weaved throughout our discussion. This phrase related to the idea of creativity and innovation in relation to some of the problem-solving techniques Rachel discussed.

Something that I learned in an intro economics class in college but always pops up in my head when trying to make a decision is this idea. My professor always said are you in-the-box or out-of-the-box. Basically thinking of something that is not the normal way of doing things, trying to find a new way of doing the same thing.

Community Level: Rachel views her current environment as a very creative and innovative atmosphere. Living in San Francisco she is able to observe diversity in cultural, social, and professional spheres. She related the idea of creativity with resourcefulness and productivity and felt that this ambiance allowed her to not only start her business but to grow it into something new and exciting. She shared how living in an innovative atmosphere affected her ability to pursue her entrepreneurial endeavors.

I love having a business here. There are so many new businesses opening all the time, it's a lot of competition, but the difference is everyone is doing something a little different. You don't really see two of the same small-business, everyone has their angle. I mean of course apart from the big chains like Starbucks and Walmart. But those of us starting from scratch, that's what is exciting. There is an energy in the air and it pushes you to think innovatively to come up with a way to make your thing stand out. It's fun

Rachel contrasted her diverse experience in San Francisco with that of her home community. She referenced the local business sector as an area that suffers from conformity and lack of creativity. Her experience as an entrepreneur in San Francisco allowed Rachel to observe the dramatic differences between the two business environments. Rachel recounted a necessity to inject creativity and social outlooks into the atmosphere in order to create more sustainable and successful entrepreneurs and to support ideas that would create more community-wide impact. She spoke about how 
there is a lack of creativity with businesses and a high failure rate created a fear of innovation.

It's hard to know where to start with supporting businesses in La Villa. I wish people would be a little more creative, but it's hard taking those risks because most businesses fail there. It's easier to start the same business as a neighbor that has had some success. I wish some people could think a little more out-ofthe-box and come up with businesses that would add benefit to the town. People don't need another place to buy chips, something that helped kids or supported education more or pregnant mothers would be interesting, but who knows if anyone would support them.

Rachel focused on social entrepreneurship and the use of creativity to pinpoint areas of need within the community. This was what she accomplished with her daycare that she hoped to expand to a full-service youth development center.

\section{ROGELIO}

Rogelio was born in Villa Sandino but moved to Managua, Nicaragua at the age of 18 to attend university. After finishing his degree, he started working for a company that exported tractor parts and heavy machinery to the United States. He married and had his first son shortly after and started his family and professional life in the capital of Nicaragua. Through his employment, he was given the opportunity to travel to the United States three times for work engagements. By the third trip he realized that his job would be ending soon because of looming layoffs and decided to stay in the United States to pursue other employment related opportunities. Rogelio had two brothers already living in the Miami area that helped connect him with his first job in a kitchen design and manufacturing business. He faced initial challenges related to his lack of documentation and language skills and was taken advantage of in his early work environments.

However, Rogelio felt that his future prospects were stronger in the United States than back in Nicaragua so he took advantage of opportunities to slowly move up the ladder in 
his industry by building a good reputation and establishing relationships with related business owners.

Rogelio eventually worked with a kitchen design business that allowed him to work directly with clients as an on-site manager. He built relationships with these clients, and individuals eventually started requesting his services outside of the business. This pulling force drew Rogelio into the entrepreneurial arena and he decided to leave his formal employment to start his own business. Rogelio has found a high level of success in the Miami area, but expressed a desire to eventually return to Villa Sandino to retire in a more peaceful and slow paced lifestyle. To date, he has not returned to Nicaragua but has provided continual financial support to his extended family and through church outreach. His goal was to save enough money to transition back to Nicaragua without the need to work when his sons were older. Themes that emerged through Rogelio's interview included: delayed gratification and resilience, ability to 'pivot' and adopt changes, connecting through religion, self-reliance above trust in others, establishing relationships built on respect and quality.

\section{Delayed gratification and resilience.}

Individual Level: Rogelio repeatedly chose to pursue paths that did not have immediate benefits or payouts. Many of his decisions actually worsened his current position, isolated him from his loved ones and required high levels of contribution with little acknowledgement or respect. However, he expressed that his decisions were based on what he thought would produce the greatest gains years in the future. One of the first decisions that displayed this characteristic was leaving his family and relatively secure life back in Nicaragua to stay in Miami and try to create a better professional career. He 
made this decision without documentation to permit him to work legally and with very little English language ability. When speaking about leaving Nicaragua for the last time he described his feelings at the airport.

Well it's always difficult, one always has that feeling that they don't know if they will see the ones they love in a very long time, or ever again, it made me feel bad, but I tried to be strong in the airport when I said goodbye to my family. I downplayed how I felt so that I didn't ruin our lasts moments together.

Rogelio spoke about this initial transition as incredibly difficult and relayed the importance of strength and conviction throughout this time. He had an internal awareness of the temporal aspect of creating comfort and success. He did not expect immediate fulfillment and acknowledged that time creates opportunities and helps one navigate difficult situation.

It was also difficult [to integrate into his community], because you have to build relationships with people that are from a different culture, with other customs, a faster world, so it makes you feel uncomfortable, but you have to know that time will help make things better, and little by little I started feeling better about my situation...The most difficult was to become accustomed to the tools that they use, in my work [in Nicaragua] none of them existed, in our country they don't exist, it is a totally different job...And the schedule was hard, we always have problems with schedules and time, us Latinos we have problems with this, it was necessary to adapt to the American work schedule.

Rogelio discussed that he pursued this type of work because he didn't want to get 'stuck' in a factory job. His objective was to learn a skill that he could build on and create better opportunities. He mentioned that it would have been easier to get a job at a factory but he was warned that he would get trapped in a low wage position through that type of job and he would always struggle with limited opportunities.

My first goal when I arrived was to find work, people recommended that I learn a trade, that I should not go to work in a factory, because I would not have a chance to grow or achieve a better job ever. Or in other words, I might start off making $\$ 1$ more an hour but I wouldn't have the chance to be my own boss, have 
your own business, I would never have the opportunity to know more people or learn much, that it would be limiting.

Rogelio's decision to enter a profession that had a high learning curve but provided the opportunity to develop a finite skill set demonstrated an awareness of foresight and planning that also demonstrated his ability to delay gratification and enjoyment.

The biggest sacrifice that Rogelio made during his immigration process was leaving his wife and young son without any definitive plans for reunification. Because he did not have lawful documents to legally immigrate to the United States, he was unable to return to Nicaragua for visits and his wife was unable to travel to the United States for a 6-year period. Rogelio described the separation from his family as an extremely difficult experience, but continually worked towards bringing his family back together and had confidence that they would maintain a strong relationship despite the distance.

This part was extremely hard, the fact that years pass [without seeing each other] it's hard to endure as a couple. And to not see your son also, is extremely hard, but the most important is that I made sure that we continued to foster our relationship, that we knew we could endure this difficult time, very difficult, and we knew we would be a family again, we would be together again in the future.

Rogelio noted that communication was difficult in the beginning but with technological advances, maintaining relationships became increasingly easier over the years. He initially communicated with his wife and son by buying calling cards, but with the emergence of Skype, Facebook and WhatsApp he was able to have more frequent conversations and even video chats with his son, wife and other family, creating a sense of connection through the distance. 


\section{Ability to 'pivot' and adopt changes.}

Individual Level: As discussed previously, Rogelio approached his immigration, business, and transnational experiences with a priority on future success instead of present-day gratification. Another characteristic that emerged through our discussion and paralleled his long-term perspective was Rogelio's adaptable nature that allowed him to quickly change direction in order to take advantage of opportunities that presented themselves but were not necessarily planned for. In various scenarios Rogelio discussed planning for a certain path, but changed his plan when better opportunities became available or when his original strategy became less beneficial.

This attribute appeared when he discussed his plans on returning to Nicaragua with his family. His wife and son originally travelled to visit him on a tourist visa and planned to return to their home country at the expiration of the visa. However, his wife was able to find employment and they decided to stay 2-4 years to save money, after which they planned on returning to Nicaragua with a more stable financial footing. His wife and son did not speak English and had limited social contacts in the United States. There was a sense of isolation at times and the pace of life in Miami proved to be faster and more stressful that Nicaragua. However, Rogelio and his wife made the decision to change their plans in order to stay in the United States until their children were able to take advantage of the education system and provide them with more opportunities for their future. When they made this decision, they had to readjust their future strategic plans, focus on further developing their professional careers in Miami, and work towards securing lawful immigration status. Rogelio discussed this shift in their plan and noted 
that he still wished to return to Nicaragua but had significantly delayed his proposed timeline to secure a better future for his children.

Things became more complicated, for instance the plans we had for the family, because we thought we would save a certain amount of money and then return to Nicaragua, but as my son and then my daughter was born, we decided not to go and to stay and work so that they could stay rooted here. We think we will eventually return yes. But in the future, not immediately, not like we originally thought, 2,3,4 years, no now we will stay until we are older, maybe around 50 years old, something like that.

The manner in which Rogelio started his entrepreneurial endeavor highlights his ability to approach situations in a flexible manner and to quickly adopt changes in order to benefit from environmental circumstances. Rogelio stated that he was happy in his employment position and was earning an adequate salary so was not required to search for a better employment opportunity out of necessity. He also did not express a profound interest in actively pursuing a business start-up. Rogelio's transition into entrepreneurship was facilitated by his ability to quickly make the decision to take a leap into self-employment when his internal and external work environment presented a promising prospect. Rogelio says he was pushed into becoming an entrepreneur, it was not something he planned, but it is clear that he was able to take the risks necessary to take advantage of a unique opportunity that he had created through diligence and attentiveness to his profession.

Well, at the beginning it was really hard, because I didn't have a big client list, more than anything I was pushed into starting this business. Because the place where I worked closed and I had to go to another workshop, where they gave me a manager position, but I still had certain contacts of the clients from the place that closed. So some of the clients sought me out and I started providing them services, and those clients told other clients, when they liked the way I worked. So even though I was manager in this new company, they let me do this extra work on the side. So, I started working for a few clients and the demand increased until I had more work than the owners. 
Now that Rogelio has created a stable business in which he enjoys the freedom and flexibility of working with clients he chooses and providing services in his respective style, he continues to approach strategic planning in a loose, adjustable manner. He does not feel the need to make a rigid strategic plan for his personal or professional life, but he is willing to make quick decisions when necessary. He is able to observe the ebbs and flows of the housing, construction, and remodeling market of the Miami area and believes he will yet again need to make a change in order to garner the highest level of benefits. The fact that he does not define goals and plans for 5 or 10 years in the future allows him the ability to modify his trajectory in an efficient and immediate manner. For instance, when speaking about his future career plans, Rogelio is contemplating another transition from a design business into a general contractor position.

I would like to, soon, when I have more financial security, I would like to take the next step, which would be to become a general contractor, this is what I would like to learn, to be a general contractor. That is my intention, you understand, to always be moving up a little....I feel like the atmosphere of this type of work is changing, we subcontract a lot of our projects and our profits on many projects if decreasing by half. I think the general contractor has more control in the Miami market.

This ability to quickly adapt and change direction without hesitation parallels the reality of living in an undocumented status. Rogelio has always had to be aware that his situation may drastically change with little or no warning and must be able to live with hope for the future but with short-term anxiety that allows him to move towards the most viable, immediate opportunities regardless of future plans. Rogelio spoke about the opposing experience of feeling well integrated and welcomed into the United States while also struggling with the limits of the immigration system that he has had to circumvent as well as navigate. 
In some moments, I feel comfortable here but the immigration system is not good. It's not good because even if you try to do things right, there is no motivation, understand, the system blocks people, there aren't many opportunities, because of this closed system.

Rogelio spent the first decade of his experience in the United States as an undocumented immigrant and has only recently found a path to permanent residency. Feeling closed out of the immigration system diminished his agency and stability. He expressed feeling that no matter how hard he worked or attempted to become a productive member of his community, he was aware that he was not going to be fully accepted into this country. $\mathrm{He}$ felt there was nothing he could do to improve this particular situation, because there were only certain manners in which one could become a legal resident and the barriers for immigrants like himself were extremely high.

\section{Connecting through religion.}

Community Level: Another common theme that arose throughout our conversation was the manner in which Rogelio has used his religion to connect to both his home and receiving communities. Upon arriving to Miami, Rogelio had a very small social network that included his brother and a few cousins. Initially, he spent the majority of his time working and was not particularly involved in outside community activities. However, he did express that he was able to integrate into his community through attending church. Religion was a significant influence in his life before immigrating and in Miami he found an avenue to continue celebrating important, culturally meaningful traditions through his integration into a local church. He spoke about maintaining the tradition of celebration of La Purisima, a Catholic tradition celebrating the Virgin Mary. 
The most special tradition that we maintain, that we celebrate every year in our community, with other people here, is the Purisima. We always participate in the celebration of Purisima, that happens every December $7^{\text {th }}$ in Nicaragua, every year. We contribute, we share, we buy shirts, we are always very active in this, in the December $7^{\text {th }}$ celebrations here.

This tradition serves as both a bonding and bridging event, creating a sense of familiarity of Rogelio's home community while also uniting him with members of his new community through shared values and beliefs. Rogelio expanded on how participation in this religious based event has supported his integration but has also allowed him to share his cultural traditions with other non-Nicaraguan and non-Latino members of his host community.

Now, there is a big Nicaraguan community in Miami, so people know about it, the people in our church know about the celebration, but not just Nicaraguans, there are people from different countries that enjoy participating in it too.

Rogelio expressed that his involvement with the local church and associated religious based organizations remain an integral part of his families social and personal life. At the beginning of his immigration journey, Rogelio relied on the church as a source of support in a time where he had little social or economic power. As Rogelio became more successful as an entrepreneur and has become a leader in his community, he became more involved in his church in a leadership and outreach role. Rogelio spoke about his involvement in a religious-based volunteer project that allowed him to give back to his host community.

Here, more than anything the people from our church. I have worked with a project called New Life (Nueva Vida) where we made all the food, because they sell the food there, and all the food that is left we take to the homeless people in the streets, we are always very involved in that.

Rogelio built on his religious involvement and increased connection with the local community to find a way to connect back to his community in Villa Sandino. Rogelio 
communicated that he has faced challenges actively engaging with his home community because of his lack of legal status and inability to return home. He articulated that he actively sent remittances back to his family and continues to communicate with a few close friends, but he had become more distant from the community as a whole. However, he was able to act as a bridge between the religious-based volunteer organization, Nueva Vida, where he was deeply involved and his home community of Villa Sandino. Because he still maintained ties with the church in Villa Sandino, and religion served as a fundamental base value, Rogelio felt that connecting the two organizations would be mutually beneficial.

I have worked with people from this project that go to Nicaragua and do the same type of work. Helping the most poor. I helped them contact our church in Villa Sandino and they spent time there working with providing food for people in the church and the schools. That's the best way I can help. I trust Nueva Vida, I know they are good people and I trust my church in Villa Sandino to work with them to provide beneficial services to my community.

Rogelio utilized his relationships in the United States to facilitate institution-to-institution connections in his home country and actively influenced community level development while not being able to be actively and physically engaged. He served as a liaison between the organizations, which brought a structured and directed development initiative at the local level. Developing these institutional relationships, based on trust and identified needs was a meaningful way for Rogelio to create lasting impact, become increasingly integrated into his home community and become an important transnational actor.

\section{Self-reliance above trust in others.}

Individual Level: Rogelio came to the United States with a small social network and a weakened situation based on his immigration status and language ability but maintained a 
strong sense of self and proceeded to take steps to become independent and maintain control over his circumstances. Rogelio's strategy when entering the workforce was to identify an area where he could develop a certain set of skills that would allow him a sense of autonomy. He indicated that there were easier entry-level positions that he could have obtained at factories, and they even had a slightly higher starting salary, but he wanted to make sure that he could develop himself and his skillset instead of entering into a position that would trap him in a herd mentality, or in other words where he would not have power over his success.

If you start working at a Wal-Mart here, or one of these big stores, you may climb the ladder but very slowly. People always told me that the most important thing was to learn a trade, with a trade I would have the opportunity to become independent.

Self-sufficiency is crucial to the approach Rogelio utilized within his professional career. Rogelio worked as an employee in three different organizations for a total of 6 years before being able to become and independent, business owner. His original plans did not necessarily include entrepreneurship, however he was led in this direction because of his intrinsic nature and the confidence that he developed throughout his career. He explained that he had a secure job that he enjoyed but eventually decided to start his own venture because of a tension between himself and his management and preference to make his own decisions and work without an authority figure.

Well the reasons, like I said, was more or less because, how do I explain?, I was earning enough money where I was but I also had a relationship with enough clients to start out on my own. It wasn't a situation where I decided I wanted to start my own business, it just happened little by little. You understand? I didn't feel comfortable working for someone else, especially because there were jealousy issues and because I had my own clients, so I decided it was best to work for myself at that point. 
The main and most consistent transnational activity Rogelio engaged in was providing financial remittances to his family on a monthly basis. One of the main reasons was that he found it an important transaction was that it provided his family with the ability to become self-sufficient and avoid reliance on outside assistance from community members or institutions.

I just would like them to be able to make their own decisions and not be controlled by those with power. That's why it's important that I continue to help my family as much as I can. So they can decide their own path and not only rely on help from others or the little handouts from government. And they do, they use the money to educate my cousins and younger siblings and that will help them create a life that they can be proud of and can provide for themselves. You never know how the politics and such will change, you can't rely on any services that exist.

This mentality weaved throughout his story and proved to be a significant catalyst to his success at an individual, professional, and transnational level. Apart from solely providing remittances to his family, he was also transferring the outlook of becoming a determined, autonomous member of a community. This was a social remittance, and his mentorship and guidance supported the development of his family to realize the value in self-development and independent thinking.

\section{Establishing relationships built on respect and quality.}

Individual Level: Rogelio described the importance of establishing relationships centered around respect and quality. As an entrepreneur, Rogelio is his own boss and does not have to answer to a designated authority figure, however he remains communal and intensely enjoys the social aspect of his business. He employs a staff and has built a large clientele list of individuals that he refers to as close friends.

I have many long-term clients that are more like friends than clients. We have built a great friendship, they visit me, I visit them, this is a nice part of my job, 
that they have trust in me to do a good job. I have always had a good relationship with my clients, the truth is I have never fought or had issues with any of them.

Rogelio was able to create his business because of a high level of respect and esteem that he built with clients from his previous company. These individuals sought out Rogelio, because of his quality work and honest professional interactions, to establish a continuing relationship after he started working in a new location. This base of loyal clients continued to market Rogelio through word of mouth until he had more outside work opportunities than internal projects with his new company. This reality prompted Rogelio to leave his company in pursuit of starting his own business. Rogelio suggests that his success and growing client base can be attributed to his dedication to ensuring quality outputs in order to satisfy the individualized styles and desires of each patron.

The most important aspect is to do good work. Our work is very artisanal, handcrafted, it's not mechanical generic work, it has style, you have to love this type of work because it is very hard, but the final result is beautiful and people appreciate this. This is not something that comes prefabricated, or arrives ready to be installed. Our specialty is creating specific, unique kitchens, this is important and it's important that our clients are satisfied.

Rogelio continued to focus on the fundamental characteristic of quality in his work. He used the concepts of quality as a base in which respect is built upon. He further clarified that he approached his kitchen design business with a focus on creating quality and specialization instead of focus on quick and timely results.

It was important that my work was consistently high-quality, that I was always present in the company, and that we always provided good work and customer service. With our clients, usually, they don't mind waiting longer for good results, because the work that we do never has to replaced, it is high-quality, not necessarily fast.

It was clear that Rogelio regarded quality as an important aspect of his tangible business outputs as well as an essential attribute in building relationships centered around respect. 


\section{ELIAS}

Elias immigrated to the United States as a 20-year-old. He was able to accompany his parents as part of the family-based immigrant visa process. His uncle was a U.S. Citizen and had petitioned for the family 17 years earlier. Because of the backlog of visas for this preference category, the family had to wait almost 20 years to qualify for the visa, at which time Elias was the only child under 21 that was eligible to accompany the family. His brothers and sisters were over 21 years old and married, so they did not qualify for permanent residency through this channel and therefore stayed in Nicaragua.

Entrepreneurship has always been a thread in Elias' life. His father started multiple business in Nicaragua and Elias spoke with admiration of his father's success and the relating status that his family enjoyed because of their entrepreneurial position in the community. After he and his parents migrated to the United States, Elias'siblings took over the businesses. Elias maintained involvement in these businesses and even leveraged his position in the United States to add value by importing clothing and other retail items that were popular and by sharing knowledge gained through his business degree. After marrying his wife and moving to the San Francisco Area, he eventually was attracted to starting his own entrepreneurial venture. He and his wife work on 6 month contracts travelling the country as marketing promoters. They were able to save for down payments on two real estate properties. Elias is now a budding landlord with a property in Florida and one in California, with plans on transitioning to a self-employed contractor to leverage his real estate prowess even more.

Elias has maintained strong ties with his community of origin and typically visits once a year to reconnect with friends, family, and work with the family businesses. $\mathrm{He}$ 
sees himself as a leader in his Nicaraguan community and offers guidance and advice to individuals hoping to pursue their own entrepreneurial endeavors. Some key themes that were uncovered through our conversation were; Change as growth, legacy and family tradition, connecting struggle with success, the importance of mentorship and guidance, information as power.

\section{Change as Growth.}

Individual Level: Elias referenced change during the difficult transition he endured in the first years of his immigration experience. This experience was transformative and the drastic shift of location, social network, and environment created an initial isolating effect for Elias. However, Elias does not view change as a negative, but in fact views change as a necessity for personal and professional growth. When I asked about how his initial plans have shifted since immigrating to the United States, Elias first connected the concepts of change and growth.

Without a doubt, changes are always good and I think that to be human without change, without learning every day, is like living without meaning. That's how I think, that the changes are always challenges of each day. I've always had changes in my life, different goals, I always continue to learn, this is the most important, never lose the hunger to learn and to get ahead, even when it's difficult.

Understanding that the transformative process is often uncomfortable while also

being aware that the tension will often result in greater results, is a cornerstone for accomplishment, especially in the entrepreneurial arena. Even though, he reflected that this neighborhood was comfortable for him because he could communicate in Spanish and shared similar cultural values, he believed that he would stagnate if he remained isolated. He spoke about his fear of leaving his neighborhood in his initial days. Elias 
intentionally looked for opportunities to connect outside his ethnically based neighborhood.

In the neighborhood there everyone spoke Spanish so I did not have trouble communicating. But yes, when I would leave the area to shop or to try to run errands by myself, I was really scared, because I didn't know anything, practically, I basically had no language skills, I couldn't even communicate on a basic level with anyone, or ask a favor, or ask directions, anything. This was hard, really hard.

He reflected that although leaving would be uncomfortable, especially because he had no English language ability, that he would find more success and happiness in the long-run if he expanded his network.

When speaking about his current and future plans Elias again referenced the importance of change and the destructive nature of complacency.

I am satisfied but not comfortable, no. I think that when someone feels like they are in a comfortable zone is when they stop growing. So yes, I am very happy, satisfied with my life and what I have achieved and what we have, but every day I strive to achieve more and get ahead and know more and, above all, grow.

Elias was able to view change as a positive and demonstrated a sense of resilience and flexibility essential for navigating the ever-changing environment of real estate and selfemployment.

\section{Legacy and Family Tradition.}

Individual Level: Elias told many stories about his respect for the journey of his father and described how he was able to become a successful business owner in Nicaragua with only a high school diploma. is father was respected as an equal by individuals from the highest social status of his community and related this pride to his desire to continue with the legacy of his father as an entrepreneur, both in Nicaragua and in the United States. His father owned a transportation business as well as a clothing store 
in Nicaragua and, after recently passing away, the businesses were inherited by the children. The siblings are the primary owners of these businesses due to their physical presence. However, Elias speaks about returning to his community of origin 1-2 times a year and one of the primary activities during his return visits is to bring inventory for the clothing store, examine the accounting books, and discuss strategy with his brother and sisters.

It is important that I make it back as much as possible. I try to go twice a year, once in summer and once right after Christmas. I like to stay around a month so that I have time to spend time seeing my friends and my family... But it is also important that I have time to spend with my siblings looking at the business. We are always talking when I'm back in the US, but when I visit I can actually see how things are going and we can strategize about what we need to change or adapt to in the future

His pride and respect for his family, specifically his father, radiated throughout his interview. The strong entrepreneurial legacy established by his father drew Elias to follow in the footsteps of his family and start his own business in San Francisco. Once Elias became established in the US, this entrepreneurial outlook reemerged as a central objective in his future plans. When deciding what type of business to establish, he once again referenced past advice he had received from his parents.

One of my biggest inspirations was my father and mother, they had started businesses in Nicaragua and I always heard them talk about how property was a good investment, because in time property earns income and gains equity. Right? One buys at a certain time and with time the property value increases.

Connecting his business venture with the guidance of his parent created a sense of continued association with his father and a way to honor his mother. He spoke about creating a similar lifestyle of financial freedom and flexibility of time within the family he was establishing. He shared his desire to build upon the experiences of his parents as 
an entrepreneurs by incorporating his wife into a business venture and providing a similar lifestyle for his future children that his parents were able to provide for him.

I want to be successful, with my wife. I was happy when she was onboard to enter into this lifestyle and be a partner with me in our own business ventures... With our own business we will be able to enjoy vacations, trips, visiting our friends all over the U.S. and the world without the constraints that a lot of jobs have. I want my kids to enjoy the same type of lifestyle that my parents provided me.

\section{Connecting Struggle with Success.}

Individual Level: Elias immigrated during a time when he had an extremely active social and academic life in Nicaragua. He was a successful soccer player on a semiprofessional team and had begun his career in university when his family was granted a visa to immigrate to the United States. He was unable to enter the social and academic arena in the same manner upon moving to Los Angeles and felt that he was unable to advance or find a clear path to success. Amongst his initial struggles, he described feeling isolated and dependent on his uncle and felt imprisoned living in his house with little social network to draw him out into his community. His initial desire to transition into an independent living situation along with his aspiration to continue his education were paramount to his feeling of incorporation and success within the American societal landscape. He described this initial experiences and challenges upon arriving to Los Angeles.

When we first arrived, we lived with my uncles, it was a difficult process, I really didn't enjoy it, because I spent all day in the house, the television was in English, I didn't understand it, I couldn't go to school because I was studying at the university level in Nicaragua and I couldn't enroll in university here because it was expensive and I couldn't speak English.

One of his first strategies he instigated to widen his social network and connect with his passions was to visit local soccer fields to play pickup games. He expressed that 
this was one of ways he felt "normal" like he was back home playing with his friends. He made some local acquaintances and became more comfortable in his community surroundings. Initially this was a tactic to overcome his early struggles of integration, but he was able to leverage this coping mechanism to create advantageous opportunities. While playing soccer in his free time he was noticed by a local college scout and was offered an athletic scholarship to attend university. Elias described his feelings after realizing he was going to be able to obtain a college education.

That was amazing. I mean the fact that I was only out there playing soccer because everything else was so hard and that was the only place I felt like myself. And then the next thing I knew I was being offered for someone else to pay for my college and be able to continue playing soccer on the college team. Two of my main goals and interests, soccer and school, all in one shot...I am still so grateful for that day.

His two main barriers to entering college in the United States were his language ability and the financial burden. He had been taking English classes at night and had reached a level adequate for basic college classes. The offer of a financial scholarship for his athletic ability mad it possible for him to overcome his initial barriers and take advantage of an immense opportunity for advancement.

Elias referenced that becoming independent from his family was important to him and that finding his own residence, apart from his uncle and parents, was an instance where he experienced a sense of self-sufficiency and accomplishment. Elias explained that his mentality of associating independent housing with attainment and self-realization influenced his entrepreneurial decision to enter into the real estate industry.

Well, after realizing that for everyone, the basic necessities that one needs to be human in whatever part of the world is a place to live and food, I started to think someday I would like to save and invest in this type of business. Something that would help people. Then I started teaching myself, through books about these concepts, and little by little we started saving towards this goal. 
Elias felt a passion for becoming a landlord because he associated the ability to offer individuals and families a safe home as a basic human right and as a service he could provide. Because this attainment of housing was instrumental in his early life it was significant to observe how he connected his past challenges with his future goals. Creating opportunity out of obstacles was a temperament and general outlook that aided Elias as he navigated difficult situations and generated success within diverse circumstances.

\section{The Importance of Mentorship and Guidance.}

Individual Level: Throughout our conversation, Elias referenced the importance of particular people in his life that have guided him through difficult decisions. His father and mother served this role but he has also experienced close and respected relationships with others throughout his journey. He cited his uncle and father-in-law as prominent influences in his past and present that enhanced his ability to make intelligent decisions and become a successful business owner. These encounters created an appreciation for the transfer of knowledge between successful individuals and those beginning on their professional journey. As an entrepreneur, he has taken on the role of an advisor and mentor to his friends and family. This allowed him to transition from advisee to advisor, fulfilling a role that he holds in high esteem.

With my friends, those that are interested, sometimes ask me 'what do you do?', 'How did you learn about these businesses?' or 'How do you do it?', because I also have businesses in Nicaragua, one bus transportation company that my dad left us when he passed away and a store, a boutique, that sells bathing suits and shorts, and other clothing and beachwear.

Elias continually seeks knowledge through his personal relationships as well as through gathering information through written materials. He actively shares his 
knowledge base with his social network in hopes to support their goals and ambitions as well as to process the information he is gathering.

I always like to share with my friends and family, especially the knowledge that I have from reading many of the business and entrepreneurship books, because after I read Rich Dad, Poor Dad, I started reading more books about finances and I learned more about all aspects of business.

Creating this knowledge transfer throughout his social network is mutually beneficial.

He was able to act as an information liaison in his dual role of mentee and mentor and gather knowledge from his advisors and reference sources and transfer this information to others.

Community Level: A self-reliant, progressive mentality resonates from Elias. He has shared how his family was an internal motivation and as he develops his own nuclear family he hopes to build it was similar building blocks as his parents. He has reached a certain level of success where he feels a sense of duty to encourage individuals to be active in the realization of their own goals. He articulated mentorship as a cornerstone for being a community leader and has developed an identity as a leader both in his receiving and sending communities.

I am the type of person that likes to be a leader, I like to guide people and I like to help my friends, my family, I'm always motivating them. Every opportunity I have I am always telling them how important it is to get ahead, and continue to make achievements.

Mentorship has served a dual role for Elias and its importance strengthened as Elias became more invested in his entrepreneurial endeavor. Mentorship provided Elias with a strong professional network of trusted advisors as he developed his real estate endeavors and has allowed him to capitalize on his success to strengthen his confidence and develop into a leader, heightening his transnational status. 


\section{Information as Power.}

Individual Level: Elias placed a lot of value in the acquisition of knowledge throughout his journey. One of his first objectives upon immigrating to the United States was to finish his college degree because he felt that building his intellectual expertise through continued learning was a cornerstone of becoming successful in his new community. He sought out and gathered information, in both the academic and social spheres, in an attempt to feel more integrated and self-reliant. Elias had previously described his initial feeling of isolation after moving to Los Angeles but expressed that he sought out community related information through the internet and his social connections and collected this material in a collected and searchable manner.

One of the things I did first was search my neighborhood on the internet. There were community forums and sites like Yelp for businesses so that I could get a feel for what was around me. I had a little notebook where I put information about places I wanted to visit or businesses that would be helpful to me... The more I learned about my community, the more comfortable I felt going out by myself.

Elias felt that being well-informed allowed him to balance the power dynamics of his community and avoid negative social and business interactions. Instead of integrating in an unstructured, unplanned manner, Elias utilized an intentional and premeditated incorporation scheme based on the knowledge and data he collected.

Elias worked in various different industries and although he had thought about becoming a business owner, his goals were not solidified until he happened upon an instructive book that became transformative to his experience. Elias referenced the book Rich Dad, Poor Dad several times throughout our conversation and suggested that it was instrumental in his decision to become an entrepreneur.

It turned out that this book was given to me by an uncle that lives in Arizona and visited me in California. I didn't read the book until 3 years after he gave it to 
me, but this book basically changed my life and changed my perspective on entrepreneurship.

This book, Rich Dad, Poor Dad, helped me learn a lot about business and all of this. It resonated with me, because I always thought about becoming a landlord, because it is a basic human necessity, when someone starts to work the first thing they think about is that they will work in order to buy a house or rent, they work primarily to have money to pay for somewhere to live. And, well the other need is food, so I thought buying and renting apartments would be a good investment and would be a good business idea, that's how I came to the decision to start a business in real estate.

He is able to connect practical, real-world situations with reference points by developing his knowledge base. This informative book allowed Elias to ground the unquantifiable, obscure nature of entrepreneurship in a fact-based, guided process. He was able to create a sense of tangibility in an environment that is uncertain and risky.

Elias focused on the importance of continued growth and personal development and constantly sought out new and insightful resources. He spoke about his personal quest for knowledge and how that translates to him connecting others to information through various outlets.

I like to share information, but at the same time I am always trying to become more informed myself, it's important to read, especially now that everything is written down somewhere, all knowledge is accessible these days. So it's necessary to read every day, it's one of the best habits that you can have.

The outward activities Elias engaged in aligned with the creation of local and transnational knowledge bridges because he valued information acquisition as a primary strategy for personal and professional success. He also referenced the accessibility of information. The fact that information was available in an open forum created an environment where he felt he was able to garner the same knowledge as those with more resources and power and thus balance power dynamics and create an atmosphere where anyone with conviction and motivation could gain specific expertise and succeed. 


\section{CAMDEN}

Camden immigrated to the United States in 2006 with his wife and son. His sister-in-law is a United States Citizen and petitioned for the family to come over as permanent residents. The process took a total of 13 years and the family was finally able to move to the San Francisco area in 2006. Camden had previously immigrated temporarily to the neighboring country of Costa Rica. His son was born in Costa Rica and they spent three years in this country before moving back to Nicaragua for 15 years before immigrating to the United States. Camden moved to Florida after initially moving to San Francisco because he had many contacts in the area and thought the similar culture would be a welcoming environment. He only stayed in the Miami area for 2 years before returning to San Francisco, where he has continued to live ever since. He found that he preferred the diversity and mixed cultural and professional opportunities of San Francisco. He noted that Miami felt like a fishbowl where he could not escape the mundanity and sameness of day-to-day life.

Camden was a successful pharmacy representative in Nicaragua and his primary motivation for moving to the United States was pursuit of better educational opportunities for his son. Camden found a job in construction when he first arrived even though he had no previous experience in construction. Camden was satisfied with his employment, but decided to pursue a supplemental entrepreneurial endeavor three years ago, in 2015, by opening a restaurant close to his home. His decision to start his own business was formulated after he faced the tragedy of losing his son in a health-related accident during a trip back to Nicaragua. 


\section{Exploring Individuality.}

Individual Level: The idea of individuality is particularly important when considering Camden spent the majority of his life in a very communal atmosphere. Integrating into a community with few social connections and in a city that is larger and less community focused than his small Nicaraguan hometown influenced the development of individuality within Camden. Camden focused on the responsibility of a person to reflect internally and take personal action in pursuit of their goals and cautioned against relying on external influences to steer one's pursuits when he spoke about his success.

I always worked hard in Nicaragua and I wanted to make sure I continued working here, so always finding good employment was a key. It's important to have personal goals for yourself that you will accomplish. You understand? This is an individual pursuit, your personal goals that you create and want to complete. You can't rely on anyone else, you need to have that personal component at your core. Only you know what you want and need, not anyone else, just you.

Camden leveraged his strong sense of self to start his restaurant business. He started a business in a field where he had no experience but formulated the idea by observing where his son worked. He noted that the guidance and feedback he initially received from his friends and family in the community were a little negative. He opposed the external negative feedback to his initiative and moved forward because he trusted himself and his idea and knew that he would be able to reach the personal goals he set out to achieve because of his ambition and independence. Camden spoke about this tension between internal and external pressures and how he is open to outside advice but relies on his internal voice above all else.

They weren't too excited about the idea. People told me how hard a restaurant business was to run and to make successful. They told me I had a good job and 
that I should just stick to that, why lose everything on a risky idea. But I knew, inside myself, I knew that I could make it successful. It's important to listen to other's opinions and advice but in the end I knew what I needed to do.

The idea of individuality also appeared when Camden spoke of his transnational engagement efforts. He discussed community wide initiatives that he felt were important, specifically the installation of a water management system and better support systems for the elderly and youth, but his actions were directed at the individual level. Camden expressed a lack of trust in community leadership to manage funds and conveyed a preference to support individuals instead of organizations or institutions. The conversation further exposed that Camden realized that financial resources given directly to a community member could also easily be mishandled, but he believed strengthening the individual was a better strategy than working at a higher level and hoping the benefits would 'trickle down'.

I prefer to help someone directly. That way they can do whatever they want, spend money how they prefer. If they want to spend it all irresponsibly, that is their problem but they had the chance to help themselves without being told what to do by some organization, the help arrives directly to their hands. Those that spend it to help themselves, send their kids to school, get better healthcare, start a business, they will then help others. Those that choose to go to the bar, well, that's not ideal but it's important that they have the choice for themselves.

Camden connected strengthening the individual with the concepts of empowerment and agency. He realized resources are mishandled at every level but believed in giving responsibility and choice to individuals to make their own path. He believed aiding the community at an institutional level takes away some of the individual power of the residents and could be destructive to the development of individuality within the community. 


\section{Systematic Evolution.}

Individual Level: Camden described many of his experiences related to integration and entrepreneurship, as learning new systems of thought and process. He approached changes in his life in very logical and analytical manner. It appeared that when change occurred in his life, he viewed the transition as learning a new system which may be difficult at first, but with proper guidance and instruction could be navigable. The term system came up several times throughout our discussion, and it became clear that Camden used a systematic approach to develop and integrate into a new community as well as to evolve and innovate into a new business arena. This perspective allows Camden to break down difficult situations into controllable steps that lead to a larger more challenging objective. He first used the term system when discussing the cultural transition of moving from Nicaragua to San Francisco.

When we left Nicaragua, you know, it was in 2006, we came to the United States as Permanent Residents. And you know, Nicaragua has a different system. The culture, everything, the language, you know it was difficult. I worked as a pharmacy representative there, and then coming to a completely different world, the atmosphere was just different. The labor system, a complete change for me.

Camden further related how learning the new systems of the workforce and culture of San Francisco allowed him and his family to integrate within a few months. This approach was very goal oriented. He was able to maintain some of his cultural ties to Nicaragua, such as the preparation of food from his home country, but took the initiative to learn the culture, values, and norms of his new community in order to feel a sense of belonging at an accelerated pace.

But after a little while, after we worked for a while, when we started working we felt better. When you first come over it's a hard process. You don't know anyone and all the systems are different and challenging to learn. After a few months, we 
started to learn these systems and we assimilated to the situation, we started to work all the time and we learned how to navigate the world better.

Camden added another layer to this concept by speaking about how he has been

able to maintain a successful business through innovation. He used a systematic

approach to learn the basics of business management and once he developed a strong

entrepreneurial base, he was able to continue to evolve and innovate using a similar

approach. He spoke of the importance of not stagnating after learning the system, but to

build upon that system of knowledge through continued evolution.

It's important to always be evolving, always, because remember that you always have competition, there are many surrounding businesses that are also trying to succeed. You have to understand your competition and if they are creating promotions and adding new products, you can't stay the same. You always have to keep up with the competition, its important to innovate each day, to be better. That's how you succeed.

This method was central to Camden's immigration, entrepreneurial, and transnational experiences. Learning systems and then continuing to evolve systematically helped him become successful in both his home and host community.

It's important to have a plan and think about how you can add to that plan to succeed. It's like a computer system. You start with a basic computer and the general programs that come with it when you buy it, but then you start adding software, attach a printer and scanner, maybe get a photo program if that's what interests you and then in the end your computer is much more effective for your daily life... You don't want to add too much too quick because it will slow it down, but you need to be strategic and understand what is available and then add programs and hardware slowly until you've got the best machine for you.

This strategic mindset has proven to be valuable to Camden. He instilled a strategic and intentional method of planning, created personal and professional goals, and developed at an appropriate pace in his home community. 


\section{Transparency and equity.}

Community Level: The concepts of transparency and equity emerged as principal values that Camden respected and held in high esteem throughout his journey. Camden communicated that he felt the law and labor systems in the United States actually created a sense of equity between himself and native born Americans when asked about any discrimination he felt upon arriving in the US. He stated that as long as you had a clean background and had followed the appropriate laws and regulations that everyone had the same ability to achieve their objectives. Conversely, he expressed the reality that those who did not follow the law would have a criminal record that would hinder their ability to secure employment and navigate the cultural and professional systems that he had spoken about earlier, and this would be true for both native born Americans and immigrants.

One of the fundamental things about living in the United States, for those that are native born or for those that have come like me as residents, one of the fundamentals is that they open their doors in whichever direction, if your background if clear, meaning that you have a clean past. And with this it isn't difficult to achieve whatever you desire...If you don't break the regulations, rules, laws etc. you can achieve what you want, if you take the other route, you will have problems, but that is the same for everyone in America.

Camden articulated a strong appreciation for the level playing field that he entered into when immigrating to the United States. The trust he placed in American systems when he decided to open his restaurants was instrumental in shaping his outlook on doing business in the US. He believed that because he had come to the United States as a Permanent Resident and had strictly followed the laws in both his home and receiving countries that he had the same opportunity to create a successful business as a native born American. Camden could not articulate many challenges in the start-up phase and he attributed the ease he experienced to his clean and compliant past. 
Well, I can't say I had many difficulties, no, I really didn't have any, because the first, you know, everything was done in line with the law, I was clean, no problems. The process of setting up the business was clear and there weren't any surprises or bribes or anything that you have to worry about. So I did not have any issues when I asked for the licenses and such.

Camden contrasted this sense of equity and transparency that he experiences in the United States system, with his experience in his home community. He did not feel that individuals in Villa Sandino were aware of how money was spent in the community and that resources were not distributed in an equitable fashion. He stated that starting a business was not as clear-cut in Nicaragua as in the United States. There was not a clear process and timeline, people consistently got stuck in situations where they had to offer bribes or were sabotaged because of their social or political position. Camden felt the idea of reaching out directly to community members also enhanced a sense of equity and transparency.

Yes, I try to help almost all of my family. I try to support everyone. I try to, how we say, to 'add a grain of sand to everyone over there', always.

He used the phrase 'add a grain of sand to everyone' to illuminate his powerful value for equity. He believed by planting seeds throughout the community and giving as many people a similar chance, they could have a similar starting place and in turn use their individuality to achieve different levels of success, on their own terms. They would not have to rely on the opaque actions of the community and country leadership. They could create a foundation of transparency through equitable actions.

\section{Power and control.}

Individual Level: Camden found control in his systematic approach to navigating the world but he acknowledged a lack of control over many things that happen in life. He described the passing of his son as a particular event that was out of his control. 
We tried to build this life in America for Camilito, that was the plan, but you know, he was taken by God at an early age, it was the worst tragedy of our life. We had to think about if our plan still made sense, we were happy in Nicaragua and came to the U.S. for him, now what. But we decided to continue on, God had a plan for us too.

Although he felt empowered in his business and professional life, he has experienced tragedies that he has no control over. He attributed the ultimate power and control to God and religion was a primary part of his life.

Camden realized there were also many aspects of life that were controllable in addition to the ultimate power of God. He acknowledged that although he may not hold a great deal of power in the American society he was able to navigate to a successful level because he felt that those in control allowed for certain amount of individual success and accomplishment. Camden arguably had a higher level of power and control in Nicaraguan society, but felt that even with the decreased level of power and influence in America he was able to achieve more.

I was successful in Nicaragua, I was well regarded. But there is only a certain level that the powerful will let you rise to. If you aren't the right political party and plugged into the top of the top, you will be squashed at some point. I'm not saying that doesn't happen in America too, but I feel like you can rise higher and you won't necessarily be sabotaged by becoming so successful. You may never be the top of the top, but you can become very powerful yourself, regardless.

Community Level: Camden acknowledged that the leadership of his community

and country of origin often abused their power and controlled the flow of resources to specific sectors of the population.

For instance, that one time I donated to the Alcalde's (local mayor's office) project that promised to paint the school and purchase new desks and books for the children. Of course it sounded like a good project, it was needed. All the desks are broken and there aren't enough, often times kids have to double up in one desk or sit on the ground or in a plastic chair from their homes. But of course, those projects never got done. 
This experience contributed to his concern about abuse of power in Villa Sandino and how the control of resources further marginalized many groups in his home community.

I always worry most about the most vulnerable people and try to help them directly, directly without intermediaries, because sometimes, you know, there are many people that attempt to help and this support and resources never make it to the people that need it. That's why I feel better helping someone that really needs it, directly. The way the people in power handle aid is ugly sometimes. They control where the resources go and they typically go into their own pockets or to their families, and the ones that really need them, because they don't have family in power, never get even a cup of rice. So I give directly.

Camden acknowledged the role of power and control in day to day life. He realized many things are out of an individual's control but also expressed a discomfort in the misuse of power by those in leadership roles. This intensified his focus on the power of the individual and the importance of developing oneself to navigate different environments and systems with diverse power dynamics.

\section{Diversity as an attribute.}

Community Level: Camden initially moved to the San Francisco area because of family ties, but decided to migrate to Florida because he felt he had a stronger social network there. After living in the Miami area for $1 \frac{1 / 2}{2}$ years he decided to move back to San Francisco. He noted that living in Miami felt very homogenous and that he missed the rich mix of ethnicities that he was surrounded by in his non-Latino neighborhood in San Francisco.

No, (they weren't all Latinos) it was a mixture of people, people from China, white people (Americans), all sorts from all different races.

When speaking about his short time in Florida he expressed that he missed working with such diversity, even though he enjoyed the comforts of being surrounded by his culture. 
Miami was nice because I felt like I was close to home, it was easy to talk to people, we had the same sense of humor, my wife liked spending time with our extended family there, but I have to admit I missed the adventure of being surrounded by people from different cultures. In San Francisco I felt like I learned more, like I was always exploring something new. And for some reason that also made me feel like there were more opportunities for me there.

Camden explored the different cultures and social norms in a systematic manner and realizes that there are great benefits, and opportunities to evolve, through collaborating and learning from these new systems. He shared that the clientele of his restaurant businesses was diverse and that he feels like he had a good reputation with many of the sub-cultures in the area.

Appreciation of the benefits of incorporating diversity into his life was illustrated in a discussion on the environment of starting up a business in Villa Sandino when he acknowledged that because the town was small, rural, and homogenous, individuals were not exposed to diverse ideas, concepts, and cultures and this paralyzed their ability to establish innovative businesses.

I see my friends opening up the exact same store as their neighbors, it's harder for them to think of a different type of business because they haven't been exposed to many different ideas. Here I can walk down the street and see people from America and from different cultures with businesses I've never heard of. Like I saw the other day a beauty shop where they had fish that ate dead skin off your feet...I had never heard of anything like that. But if you don't surround yourself with different people with different ways of doing things, it's hard to come up with something new to do.

Camden seemed to believe that a central reason businesses were not successful in his hometown of Villa Sandino could be attributed to a lack of diversity and subsequently a lack of diverse thought. He felt his experience integrating into a diverse area of San Francisco was fundamental to his professional development and personal acumen. 


\section{KRISTEN}

Kristen moved to the United States to reunite with her husband Rogelio (another participant in this case study) when she was 21 years old, in 2006. She had one young son and had lived separated from her husband for 6 years at the time of immigration. Kristen originated from a rural farm in the Villa Sandino municipality. She travelled to the United States on a tourist visa and decided to overstay the 3-month validity of her visa to build a family with her husband and the father of her son. She was able to secure a job in a beauty salon within $1 \frac{1}{2}$ months through a connection with the wife of someone who worked with her husband. She later parlayed her expertise in the beauty industry into an in-home business. She enjoyed the flexibility and increased time with her family that being an entrepreneur gave her.

Kristen described a relatively easy integration process, noting that her community was largely Latino and her lack of language did not prove to be an initial barrier to feeling comfortable in her surroundings. She was able to adjust her status to permanent resident through a relationship with a family member. She had become United States Citizen shortly before the time of our interview, which allowed her the freedom to leave and return to the United States with no physical presence restrictions and would afford her more rights as well as provide her husband a path to permanent residency. Her legal status afforded her the ability to obtain a stylist and salon license and subsequently open a beauty salon in her house.

Themes that emerged during our conversation included; the role of structure and organization, finding voice and agency, creating value through personalization and differentiation, and establishing connections and strengthening linkages. 


\section{The role of structure and organization}

Community Level: Kristen shared that her hometown and country of origin shared a relatively spontaneous and unorganized culture. She was accustomed to this so was able to navigate daily life with ease but this reality would make her transition as a migrant challenging. Kristen described her integration experience into the Miami society as relatively easy because she considered the American culture organized and structured. ...The American culture is pretty calm, very organized. They are very strategic with their things, Latinos are more spontaneous in a way, almost to that irresponsible level, but yes. We are like that, or at least in this area, they're used to it... We go up north because it's a little calmer. The places there are more quiet and calm, you can eat, because it's more of an American presence there.

This made her transition easier because she was able to learn the system and rely on processes to be consistent. There was a predictability to her daily life that provided a sense of dependability and confidence as she learned to navigate her community, run errands, and seek out services for her family.

Kristen continued to express her appreciation of the order and organization of her receiving country. Public services were a highlight of her experience as she felt the United States was able to leverage its ability for organization and strategic planning to create services that were inclusive and comprehensive. She compared her experiences in Miami with those of her life in Nicaragua and found a clear distinction with the ability, or possibly priority, of the United States to create structured public services that would benefit the majority of the population.

I adore this country, I love it, especially when you have kids, there are a lot more opportunities here, universities, better schools, better education. For example, in Nicaragua, everyone has to go to private schools in Managua. Why? Because the public schools are a disgrace. They don't even have bathrooms. 
Individual Level: Kristen had initially planned to return to Nicaragua within 1-2 years of moving to Miami, however, she later decided to build her life in the United States and provide her children the opportunities that existed because of the organized societal structure.

Kristen had grown up around many informal businesses started by her family members. In her home community, there were not many regulations or processes that were instituted for these informal business practices. For instance, her aunt had a beauty salon that she ran out of her house and Kristen remembered that all she had to do was buy the supplies and start telling people in the neighborhood what services she offered and the business grew from there. Kristen created a similar business, a home-based, hair salon, but described a very different process in regards to the initial startup, especially securing the appropriate licenses and authorizations.

The licenses. They're a bit stressful. But like everything, it's best to do things the way they're meant to be done, licensed and with the right authorization. I do my work from home but that's because I have a license to do so. You have to follow code, and you have to design a part of your home specifically for that only, you know. That was very stressful because I remember that to open your business within 15 days and you already had clients on the schedule, but none of the cabinets were ready...It was stressful. Also, that inspector would call me and ask, "Can I come today?" and I used to call and say, "Look, the delivery hasn't come." Let's make an appointment 2 days from now. The first time he agreed, the second time, oh well, and the third time, he said, "This is the last time. If you can't do it then I don't know. I can't keep making appointments just because you're not ready."

The added processes and regulations created a stressful experience for Kristen and also highlight the dichotomy of the views Kristen had regarding the organized and structured systems of the United States. These characteristics provide a consistent and relatively easily navigable experience for community members, especially newly arriving immigrants, but also created barriers to entry for certain activities. 
First you have to have a stylist license, you personally. After that, you need a salon license. You have to study for the stylist license. Here, it's like a year and a half...... With the salon, it's a structured process. So it depends on the requirements, city as well as state requirements for the space given that you'll be serving the public, so you have to pass a certain standard.

This illustrates that the structure permeated both the physical and non-tangible aspects of society. Kristen voiced her appreciation for the organization and order that this structure created but also expressed a heightened level of stress in traversing some of these regulatory frameworks. Kristen felt structure and organization may have created shortterm barriers but led to more sustainable and manageable long-term results.

\section{Finding voice and communication.}

Individual Level: Kristen shared stories about her journey that illustrated a clear development of her internal confidence that resulted in a heightened ability to voice her perspectives and make decisions affecting her well-being. Kristen grew up in rural area of Nicaragua and her initial social network and circumstances requiring her to interface with individuals in power positions was narrow. She reminisced that she was raised to obey authority figures and was not encouraged to speak her mind in social or professional situations.

For example, the first time I went to work, my boss was a Brazilian, a lovely woman, her associate was Cuban. The Cuban yelled a lot, very exaggerated in his manner of speaking, moving his hands a lot. We as Nicaraguans are more quiet, especially those of us from rural areas...Now you know that the Cuban yells a lot and the Colombian is more fun-loving and us Nicaraguans have our own thing as well, somewhat complex. Here you hear about everything. But over there, in your native country, we're all the same. We're all sewn the same way. Over there you can't tell a boss, "Look, no. I don't think so," because we weren't educated that way. We were educated to be quiet and obey. 
A sense of agency slowly developed through her years living and working in Miami. She began to feel more comfortable speaking up at work, partly due to a strong female mentor that encouraged her to express her thoughts.

Virginia helped me a lot. She was fearless, but not offensive when she talked to people, I admired that. I felt safe talking to her and telling her my thoughts, and she started to encourage me to be more assertive with my bosses. She was actually the one that supported me when I asked for my first raise, I remember being so nervous. I practiced with her and then went to my boss, and got the raise! That made me feel great, like I needed to speak up for my own good. If I wouldn't have asked, I wouldn't have gotten it and I would be stuck in the same position.

She was able to develop her voice through a close relationship, and subsequently received positive feedback when communicating with management. Her self-confidence began to grow. Kristen realized that she had to garner the power to articulate her needs and desires in order to make progress in her new position and recognized that if she did not develop this skill she would hinder her ability to create a prosperous future for herself and her family.

The ability to express her opinions did not spontaneously develop entirely. It was a slower progression facilitated by small interactions in different parts of her life. She learned the importance of advocating for her family through various interactions concerning her children

....Parent teacher meetings were another difference. We don't really do that in La Villa, kids just go to school and you don't really get feedback from teachers, it's much looser. Here I have to go in to talk with my son's teachers twice a year. At first I never said anything, I just listened and said okay to whatever they said. But in the second year I had some questions and felt like sometimes there were things they were missing... I mean it's little things, but there are things that I know that they don't, so I started to speak up.

Community Level: Kristen began creating more balanced power dimensions between service providers and felt that her views added value to these interactions. The 
emergence of voice and agency were instrumental in helping Kristen develop the conviction to become an entrepreneur. These attributes were also a dynamic aspect of her development as a transnational agent. She realized the power of her opinions and views and had the ability to influence the community members of Villa Sandino in a positive and effective manner. Her community level aspirations were focused on female related issues, especially maternal health and equal education opportunities for girls. She served as a role model for women in her community by presenting herself in a more confident and self-assured manner, and she had the ability to become a change agent for these types of development initiatives.

\section{Creating value through personalization and differentiation.}

Individual Level: Kristen was drawn to an industry that relied on a certain level of personal style and preference to gain a respectable reputation and build a client base. She expressed that her focus had been on developing her skills to best showcase her unique techniques and differentiated style. Kristen recognized that the more she was able to highlight her individualism and distinction from other beauty salons, the more she would be able to grow her brand and gain new customers.

The work. The way you work. Remember that this work is personal. This isn't a product that you go and just buy at a supermarket. A Coca-Cola can is the same no matter where it is. What I do is personal because I'm a human being, so it's my style, my signature in hair, in the colors, in everything. There are people who like how I work and they're with me because of that, because they like it.

Kristen derived a sense of pride from the fact that her business was successful because of her specific character and personal capacity. Kristen noted that businesses within Nicaragua did rely on the personal reputation of individuals and their unique skills would garner a higher following. 
In my town we knew who made the best cuajada [cheese] and tortillas for instance. In the morning you would go to the house on the corner for tortillas and walk two blocks away for cuajada because those were the best quality. Others made these products but they weren't as good so we had our favorites.

Kristen shared that although personalization was prevalent in her community of origin, business development in Nicaragua lacked the component of differentiation and distinction. She noted that individuals did not try to create new or innovative business ideas but relied on replication of businesses that already existed.

The problem is that there are very few new business ideas in the town. If something works, everyone tries to open that business and then there aren't enough clients to make them all successful. I mean our little town doesn't need 30 nail salons, there are only so many people that want to pay to get pedicures and manicures.

The attribute of personalization was engrained from her upbringing and respect for building a strong reputation through skill development. Alternatively, the idea of differentiation developed in her as she became integrated into the business community of her host country. She learned the importance of creating a diversified and high-quality product to enter into an established market place.

\section{Establishing connections and strengthening linkages.}

Community Level: Kristen shared that her hometown was very community oriented and she was part of a large extended family that was intensely integrated. Because of this interconnectivity, she enjoyed pre-established linkages throughout organizations and institutions within her community and the region in general. Her experience in Miami differed in that she was living in a more isolated atmosphere.

The first time I walked to the small store on the corner. I couldn't drive yet, but there was a store just a few blocks away so it was pretty convenient. But I remember walking down the street and didn't really see anyone, it was odd. In La Villa everyone keeps their front door opens and people are sitting on their front 
porch. You can't walk a few blocks without stopping two or three times to talk to someone.

Kristen missed the ability to rely on her social network in Nicaragua for support and entertainment. She talked about the necessity to recreate a tight social network in her new home while also maintaining the strong relationships she had with her family and select friends from her home community in Nicaragua.

While trying to maintain strong connections on an individual basis, Kristen also noted feeling an increasing distance from the community as a whole. She described feeling like an outsider and being bombarded with questions and interrogations about her life in the United States. This has created a propensity for Kristen to pull back from many community areas and has created a detachment from many of the linkages she previously enjoyed. This feeling arose when I asked her to describe how, or if, she shared her entrepreneurial experience with members of her community back home.

I'm pretty private as well, people don't know - if they do know, it's because someone told them, but no one has asked me what I do for a living, outside of my family. They have asked before how much I earn. There was someone at the corner store who asked me, "How much do you make in the United States?" and I thought it was like...he didn't even greet me. What is this? What does he want? .. he was like a megaphone with two legs.

The community had such an interest and preconceived perception of what life is like in the United States that they tended to treat Kristen in an insensitive and objectified manner.

People just assume that once you come to this country, you have your life made for you. You just come, go outside, and there's a tree made of money, and you just grab the dollars. People don't know 
Kristen decided to focus on strengthening the individual relationships with her friends

and family and fostered those connections for her children but faced challenges with

feeling like an outsider within the community where she was born and lived for 20 years.

Individual Level: Kristen was fortunate enough to have a relationship with a local

family that had served on a mission trip to her hometown in Nicaragua.

We did know someone, one of those people from church. They had gone to Nicaragua and I had been with them for 15 days, working with them on a mission. So I already knew them. And I remember they used to take us out on the weekends because we didn't have a car in the beginning. Here the whole world deals with their own lives, they make their agenda of what they're going to do during the week. Generally, they'll take you out the first time and the second time, it's your own problem to deal with. But they tried to have us do something different every weekend so that I could get to know this place, get accustomed and habituated to the new country with new people and a new language. The language... to this very day, I learn from my children.

Her son spent his first 6 years in Nicaragua and her daughter was born in the United States, so has never lived permanently in Kristen's home community, but she feels strongly that they cultivate their Nicaraguan identities. Her strategy to accomplish this objective is to return to Nicaragua 1-2 times a year for extended stays. Kristen shared that they attempt to return for around a month at a time so that the children can acclimate and start to feel comfortable in their new surroundings.

I try to go whenever the children have breaks because I like for them to come too, to love Nicaragua and to feel they are Nicaraguans, and for them to have fun, to take advantage of the country because here, they're a bit isolated, but there they can play with all of their cousins. They don't have cousins like that here.

\section{MOSES}

Moses immigrated to the United States for humanitarian reasons during the Nicaraguan revolution. Most of the other Nicaraguan immigrants interviewed in this study immigrated by choice and were able to become permanent residents through the 
family-based adjustment of status. The immigration experience of Moses could be categorized as forced migration as he became a permanent resident through the refugee/asylum process. Moses was the earliest immigrant from the pool of participants in this study. He moved to the Miami area in the early 1980s. He immigrated with his wife, who was pregnant with their first child. There was a high level of turmoil throughout Nicaragua at this time. Political tensions were driving a war that targeted certain individuals and Moses felt he and his family were in imminent danger. The United States opened special humanitarian paths to immigrants from Nicaragua at this time and Moses and his wife were able to take advantage of this opportunity to migrate to Miami.

Moses was able to slowly integrate through determination and progressive acquisition of new skills. He relied on the shelter of living in an ethnic enclave to allow him to socially incorporate without having to immediately dedicate his time and resources to language attainment. Moses did not have a clear objective or plan upon arriving to Miami because his immigration experience was forced. His sole focus was seeking safety and security. Moses ventured into the entrepreneurial arena in a slow and methodological manner. He deliberately began working side-jobs and building his reputation and client-base while still working full-time for a construction company. After five years of this he felt he had the adequate skill set and client-base to leave his job and create his own venture in the area of construction.

Moses did not travel back to Nicaragua for eight years after his initial immigration because of the continued turmoil. However, he now enjoys frequent trips back to Villa Sandino to reconnect with family and friends. Moses shared a distinct mix 
of disconnectedness and closeness to his community of origin. The context of his departure paired with the extent of the time he has lived outside of the community created an association where he identifies as a proud Nicaraguan but did not feel the same sense of responsibility and continued support as many other immigrants from the area. However, he did express a sense of pride centered around his achievements and level of success attained in the United States.

Some of the themes that emerged during our conversation were; managing expectations, determination, perseverance and self-reliance, expanding influence through relationship building, functional capacity building through hands-on experience and, selfadvocacy.

\section{Managing expectations.}

Individual Level: Moses explained that as part of his strategy for integration, he felt it necessary to create realistic expectations for himself and his family. He shared that Nicaraguans were very connected to American culture and often learned about the social and cultural norms of the U.S. through popular movies and television shows. This method of gaining insight into the American culture often creatd heightened expectations of wealth and luxurious living standards. Moses shared that when he was approved for humanitarian immigration many of his friends and family assumed he would be "living like a king". He explained that he felt a sense of tension upon arriving because he had assumed a level of ease and affluence and was shocked when the reality of his situation was revealed.

Arriving was a shock. I really didn't know what to expect, no one told us much at the beginning. We got our plane ticket and were told we would be met at the airport by our sponsor. I didn't know many people in the United States at this point and everyone I talked to told me how lucky I was and how easy my life was 
going to be. But looking back, in reality, we only really knew what we saw on T.V., when I arrived it was much much harder. Now I know that's not what life is like, but we had certain expectations and that made it harder at first.

He continued to share that he attended an orientation meeting his second day in Miami and was told that he would be supported for three months and then would need to be able to support himself. The orientation laid out sample budgets and the types of bills the family could expect on a monthly basis. Moses revealed that he was upset after this meeting because he had no idea how much responsibility he would have to take on in such a short period. He immediately adjusted his priorities and expectations and created a plan of action. He focused on finding a way to economically integrate and learn about the realities of his new community.

One of his first priorities was to adjust the expectations of his wife and his family back home. He knew his wife was in a precarious position, pregnant with their first child. He wanted to diminish her overall stress by sharing the challenges they faced while imparting his plan of action to provide for his family.

It was important that Ruweida [wife] also knew what we faced. I didn't want to lie to her and tell her everything was going to be easy. That's what created so much stress for me when I arrived. So I told her that it was going to be difficult and our lives weren't going to be like what we originally thought, but I made sure to let her know that I was going take care of things but I didn't want her to go through that same shock that I did.

Moses also communicated his situation with his family in Nicaragua. He knew that because he was in the United States there was a certain pressure to support his nuclear and extended family. He needed to let them know that his priority had to be providing for his family in Miami and then he would attempt to provide financial remittances when he had supplemental income, but that it would not be a large amount at first. 
Moses also explained how managing the expectations of his employees and clients was central to his business strategy when he became an entrepreneur. He tended to lower the expectations of his employees so that they were never in a position of anticipating more work and income than they will receive. Moses utilized employees on a contract basis and therefore they were paid based on the amount of work the company could obtain and manage.

Now I have quite a few employees, but I only use them for contracts so they don't earn a salary..... I usually am conservative when telling them what our projected workload is. I don't want them to depend on income that may not come, if they need to find other short jobs to supplement their income that is better for their family than expecting to make $\$ 1000$ a week but making half of that or nothing at all...It's better than me telling them we are going to have a lot of work this next month and then only really get one or two projects.

This was a method employed to protect his employees in times where jobs may not come to fruition and heighten the positive feedback when he was able to over deliver and provide expanded opportunities for his staff. Moses utilizes this expectation management system in his daily life as well. He created realistic or lowered expectations to protect himself, his family, and his associates as well as to induce the ability to make back-up plans and harness an adaptable disposition.

\section{Determination, perseverance and self-reliance.}

Individual Level: Moses endured a lot of strain and instability during the years leading up to immigration and continued to face many barriers and challenges after moving to Miami. He demonstrated a high level of determination and perseverance during this especially demanding period of his life and he leveraged this resilient mindset to accomplish many goals that seemed out of reach. 
Moses was repeatedly threatened and targeted by the Sandinistas during the revolution because of his political affiliations prior to his immigration to the United States. He had family members that were killed and others that were falsely imprisoned and kidnapped. Moses knew he was not safe in this environment and took the initiative to pursue an immigration path. Obtaining humanitarian based immigration was not easy, but he continued to apply and gathered evidence of the peril that he faced. He explained that the process was not immediate and as he was applying, he faced even greater threats.

The parole process was not fast, it wasn't like I went to the Embassy one day and the next I was on a plane to the United States. No, I had to prove that I was in actual danger. So little by little I gathered evidence of the threats, documented the damage to my family, and continued to visit the Embassy to state my case. I filled out a lot of paperwork, had to have a background check and many interviews, and keep building my case. I think I probably made 6 or 7 trips before I was granted the parole. But I knew it was important to keep making these little steps towards parole and eventually we would make it to the United States.

The initiative and patience that Moses demonstrated was impressive, especially during such a perilous time. His perseverance continued to be illustrated as he integrated into the Miami community, developed a professional career, and became a leader in his social network. His progress in these areas was typically slow and he faced many setbacks, but he continued to move forward with whatever resources he had. He used the term 'poco a poco' many times throughout his conversation, meaning little by little. He did not expect large leaps or undeserved rewards in his activities but felt that he would eventually meet his goals with resolute and determined purpose.

When I started my job, I was at the very bottom. But I was happy to have found something with a steady income and knew that if I worked hard, was respectful, and did a good job I would be able to move up. Eventually, after maybe 4 years, I knew a lot and I was put in charge of a small team. Some of the young people now expect to shoot to the top immediately, but I've always known that if continued and persisted I would be successful. 
The perspective Moses took that allowed for slow growth was central to his experience and also resonated through his expectation of others. He expected this same level of determination from his employees and instilled these values in his children.

Moses did not expect handouts or unwarranted support from his social and professional network. He believed that he was in charge of his own destiny and looked inward to analyze his weaknesses and created plans for the future. This self-reliant temperament was highlighted in his immigration experience and also emerged during the period of his entrepreneurial startup. Moses created his business through a resourceful and gradual process. He spoke about initially beginning to work side-projects on his own, autonomous from his company.

I wanted to create this for myself and the way I wanted to, so I didn't involve the people at my company. I didn't want them to think I was relying on their guidance or direction. I started my side projects one-by-one and learned how to manage projects on my own and eventually could increase my workload.

Moses relied on his own strengths and wisdom to navigate his business and did not incorporate many outside advisors. He felt more secure making his own mistakes and adjusting his business as he saw fit.

Self-reliance seemed to be important in his transnational activities as well. Moses assisted with financial remittances when necessary and supported certain projects during his return trips, although he did not engage in a recurrent manner with Villa Sandino. He valued the development of individuals such that they could act independently. He gave direct donations or remittances to individuals in need because he wanted them to be able to direct their own investments and decisions. It was evident from our interview that selfreliance, perseverance, and determination were characteristics that Moses has developed within himself and also valued in those he associated with. 


\section{Expanding influence through relationship building.}

Individual Level: Moses identified influence and connective skills as important concepts that he utilized in various aspects of his life to increase his confidence and find targeted success. Moses began his immigration journey as a refugee, with very little power or control. He was initially integrated into his community through the assistance of a refugee resettlement program and was directed where to live as well as maintained by this organization for his initial months. This early dependency led Moses to seek manners in which he could control his daily life and gain power over his future. His particular strategy for expanding his influence within his physical community was to become a social connector. Moses described the informal process he employed to gain status within his neighborhood and professional environment.

I became important in Hialeah, I knew it was important that I was well respected, like I was in Villa Sandino. So when we got our own apartment, I made sure to spend a lot of time outside, walking around, meeting people, getting to know the local businesses and their owners. I was always out by myself or with my family and soon everyone knew me and I was well-known. Once I got to know people and the neighborhood better, I started helping people and advising them. I knew the best mechanics. I tried to get some people jobs with my employer... I always think it's important to be central in your community.

Community Level: Moses created a large informal social network that facilitated goodwill and generated social capital. Although Moses did not have formal power within his community he utilized informal communication and relationship building skills to garner influence and become a prominent community member. This heightened his external influence while simultaneously increasing his internal confidence and selfworth. 
Moses expanded his influence through informal connective activity, as well as some more formalized methods, within his professional environment. He described a pattern where he created strong bonding relationships within his team and leveraged these connections to create bridges to external resources and associations.

Even though I was at the bottom when I started I was popular. I had a good relationship with all my coworkers. I would bring in chicken tacos for the crew so that we could have nice lunches together, they loved that, even our bosses and supervisors would join us when I cooked. That was nice, because then I also had a better relationship with my boss too and I felt more comfortable going to him to ask for raises and other stuff.

Moses utilized this approach to level power dynamics and create an enhanced reputation. Building these relationships resulted in him being appointed as the liaison to management for his team, a position that allowed him to advocate for his coworkers with high-level entities and subsequently communicate managerial directives to his team.

Because the bosses knew me and knew that I was well-respected in my team they told me that I would be a good candidate to take a position where I met with our management department every month to touch base on our concerns or what was going on the ground level and then to learn about any upcoming changes and share them with our team. It didn't pay anymore but it was an honor to be asked to serve in that role.

An ability to build relationships in a familial and communal manner emerged from his experience living in a small town in rural Nicaragua, where social capital was essential to navigate the informal nature of the economy and collective environment. Building a similar communal atmosphere in his receiving community allowed him to leverage his innate skills and replicate the comfort and security of his community of origin. His capacity to facilitate connections provided a larger level of influence than he would be able to establish through purely formal methods. This allowed him to achieve a heightened social and professional status at an expeditious rate and 
continued to support his success as he became an entrepreneur. He continued to value relationships as the basis for influence.

\section{Functional capacity building through hands-on experience.}

Individual Level: Moses did not initially seek out institutional training resources to foster technical or English language skills. He shared a perception that there was very little organizational support outside of the refugee resettlement organization that he worked with at the time of his immigration. Moses deprioritized the acquisition of language skills in order to focus on developing professional and technical skills that would assist with his economic integration. He entered into the construction industry in the Miami area, a career tract that he had no prior experience with. He had a high learning curve to secure his position and create advancement opportunities.

No, I had not worked in construction before. In Nicaragua I was an attorney, so this was quite a change. Since I was hired last, I knew I was at the bottom of the hierarchy. I made sure I focused on learning as many of the job tasks...I figured the more things I knew the more valuable I would be so I made sure to not only learn one thing, I constantly asked others to teach me different skills. It was exhausting, very different from being an attorney.

Moses continued to prefer hands-on-experience instead a more academic or classroom instructive approach to skill acquisition as he began his entrepreneurial ventures. He slowly transitioned from employee to business owner, starting with small side jobs and slowly increasing the volume of his side business until he eventually made a full conversion to entrepreneur.

By that time I knew the technical aspects of the job, but I needed to build up my machines and needed to learn the management and financial side of the business. I didn't really want to go to a class to learn these skills, sometimes it's harder to connect that type of learning to real life. So I started little by little. First a few little jobs for friends then a little more. And each project helped me try different approaches and didn't overwhelm me with those parts of the business I didn't know well. 
Community Level: The high esteem Moses held towards hands-on learning throughout his personal experience contrasts with his perspective on how his community of origin should approach development. He believed his community should offer more technical and business development trainings to both youth and adult populations.

They need more education and training. It should start with the youth so that they can find better opportunities. Trainings that are practical, not just academic. For instance, a workshop on how to create accounting books so that when they try to create a business they are handling their money correctly. Over there, people usually don't keep track of their income and profits. Money just comes and goes and if there's something left in their pocket at the end of the day they are happy.

Moses initially assumed the trainings offered in Miami were above his language and academic level and that they would focus on more scholastic and less applied topics. This lack of institutional resources in his receiving community and his suggestion of training as a development tool indicate the need for more practical, entrepreneurial centric workshops offered throughout communities with high populations of immigrants. He consistently spoke about the practicality of the educational interventions and suggests circumventing any education that is too theoretical. However, he believed that for community level interventions, training should supplement hands-on experience to create the most impact.

\section{Self-Advocacy.}

Individual Level: Moses demonstrated a high level of inner-dependence and personal resilience throughout his journey. This may have been influenced by his refugee immigration experience, as he moved to a community with no social ties or network. He relied on himself to determine a successful trajectory in his new community and this shaped his relationship with external entities. Instead of relying on individuals or 
organizations to support him, Moses depended on himself to advocate for his needs and the needs of his family. Self-advocacy was demonstrated when Moses embarked on a job hunt the second day in his new community. He had no connections or possible leads, but instead walked around his neighborhood and promoted himself as a valuable employee. This was particularly impressive as he did not have English language skills or an understanding of the local social and cultural norms or experience with many of the jobs he was applying for.

They told me I would have to find my own place to live and support myself and wife and baby with no help in only a few months, so the second day I was there I started looking for a job. I knew I couldn't by a lawyer without a law degree from the U.S., so I was looking for anything to get me started. I had to explain to restaurants, and grocery stores, and construction businesses how my skills would translate and make sure they understood I was a serious and hard-working man. I had to sell myself, but I am comfortable with that, because I knew I would be a good employee for them.

The theme of self-advocacy complements characteristics of the theme 'determination, perseverance, and self-reliance' by highlighting his ability to convert his personal resilience into an external action, allowing Moses to improve his quality of life by asserting his personal goals, making calculated decisions and connections, and speaking up for himself in social and professional situations. This trait was also prevalent in his attempts to ensure his family was well taken care of. He spoke about his interactions with school administrators when his son was first entering school and demonstrated an ability to gather information and enter into thoughtful discussions with individuals in power positions regarding his points of view.

I love my community and the opportunities that it has given my family, my son was able to get an education in a good school and he is now a successful engineer. I remember working hard to get him into one of the better schools when he was just 5 years old. There was a school close by, but it had a bad reputation and was a little dangerous. So I met with some other schools in the area and found one that we loved. We had to apply and interview and I had to prepare 
myself to communicate why my son would be a good addition. It was a hard process, but worth it, it set him up to be successful and it was a great school. We sent our other two children there as well, which was easier since [his first son] had already been admitted and they knew our family better.

Moses appeared to have an innate level of confidence that translated to his ability to advocate for himself in his new environment. However, his lack of external support seemed to heighten the need for him to promote himself in this manner and placed pressure on his vulnerable situation may have accelerated his adoption of self-advocacy methods.

It is important to understand your values and objectives and make sure you fight for your position in your community. No one else is going to hand you things for free, it's up to you to get what you want and need.

This perspective was reflected when he discussed the perspectives of individuals in his community of origin. Moses had the perception that in Villa Sandino community members often approached life in a lethargic and passive manner. He felt that the mentality of the community needed to shift and suggested an approach aligned with heightened personal responsibility and self-advocacy.

\section{FABRICIO}

Fabricio immigrated to Miami at the age of 16 . He had previously travelled several times with his mother from Villa Sandino to Florida as tourists to visit family members in the area. Fabricio lived a normal adolescence in Villa Sandino, attending the local secondary school and assisting his family on a local farm. His mother thought he would have better future prospects in the United States and, at the age of 16, decided to send him to Miami to live with her sister and start working in a local family business. Fabricio did not resume school upon immigrating to the United States. He lived with his uncle and worked full-time in a toy store for children. He expressed that it was difficult to 
leave his community at such a young age, but he knew that he would have better prospects in the United States and was excited to take advantage of the opportunities that awaited him.

Fabricio lived with his aunt and worked with one of his uncles for the first few years he was in Miami and later transitioned to work with a construction company. He had a few friends that persuaded him to transition careers because there was ample demand and high pay for construction related jobs at that time. He was able to secure a job through a company that worked closely with the University Miami Dade, where he had been taking English classes. This career transition allowed him to learn a wide array of skills that eventually supported his entrepreneurial trajectory and provided a solid knowledge base for him to become self-employed. The initial transition to construction work for Fabricio was predicated on the higher pay, but shortly after changing jobs he realized that the expertise that he was gaining would allow him to work independently in the future. Fabricio began his business as a painter.

Fabricio remained connected with his home community of Villa Sandino. He invested many of the profits from his business into buying land and farms in Nicaragua. He became an entrepreneur in Nicaragua as he expanded his ownership of farms and cattle in the Villa Sandino area and has employed many of the local community members in his ventures. He has spent extended periods of time on return visits. He had just returned from a 6-month trip back to Nicaragua when he was interviewed for this project. He appeared to live a dual-life, balancing his integration into both countries on a rather even scale. 
Some of the themes that emerged included; gaining exposure through diverse connections, focus on opportunity identification, collaborative approach, sustainable and diversified investing practices, and vision and foresight as strategies for personal realization.

\section{Gaining exposure through diverse connections.}

Individual Level: Fabricio arrived to the United States as a minor, with no social connections outside of a few family members. He began working with an uncle and lived with his aunt, limiting his initial exposure to external associations and creating a social isolation for his first few years in Miami. Fabricio valued the creation of diverse social and institutional connections as he slowly became more independent and searched for autonomy from his family base. Fabricio was grateful for his tight familial relationships that allowed him to transition to a new life in the United States with little discomfort, but he knew he wanted to expand his perspectives and understand his new community.

Fabricio felt social relationships with diverse individuals was important to this journey.

I appreciate everything my family did for me, but eventually I wanted to have my own social circle. I left a lot of friends in Nicaragua and wanted to make a new set of friends here. It was hard, the first three years, I only went to work and home and was surrounded by a handful of people. But after I turned 18, I started taking language classes and began trying to find my own job outside of my uncle's business. At that point, I was really interested in making friends with new and different people... I needed to learn the language and I needed to step out of my comfort zone. Through my English classes at Miami-Dade I met other nonLatino immigrants and I made sure to spend time with them outside of class. I learned about their culture and they learned about mine and we helped each other out.

Fabricio experienced an initial limited integration followed by a burst of expanded immersion. He moved to Miami as a minor and was not able to establish his own integration trajectory until he reached an age that allowed for more independence 
and self-rule. He applied the same value of diversified connections as he began his entrepreneurial venture. He mentioned how his strategy for growing his business was to build his clientele through word of mouth referrals and by associating with distinct groups that would further his reach and influence.

I started getting to know people through construction, for example, through one of the men that worked plastering houses I started with painting jobs, so when he plastered a house he would recommend me to do the painting, and I would start getting to know more and more people and they would recommend me, and in that way I started forming a chain of clients.

Fabricio experienced a surge of business when he began working with different entities that serviced distinct areas. He was able to increase his workload and eventually hire employees to help with the surplus jobs. He saw a multiplier effect when he began integrating associations with individuals and institutions that were not in his immediate social circle.

I had told you about the English classes I took at Miami-Dade. And I kept in contact with those teachers and would go by campus every now and then to say hi. They were able to connect me with work on campus which was great because I always got paid on time and the projects were big. And after I did good they called me back, there are always projects to do on a big campus. And then, from that job, I got recommended to a building manager that gave me jobs in his offices throughout town. Those are the types of jobs I wouldn't have gotten through my other connections and they turned out to be the most lucrative and stable.

An outlook on diversity and expanded exposure trickled into Fabricio's transnational engagement strategy. He kept a rather narrow focus on who he allowed to be directly involved in his farm businesses in Nicaragua. He relied on his father to oversee operations while he was not present and employed trusted individuals. He has also created some cross-industry relationships that allowed him to establish resilient income streams. For one example, he has an ongoing relationship with a local dairy 
processing plant, but has also maintained a business partnership with a dairy product export company, based in another town, that helped him supplement the demand fluctuations of the local markets. He focused on a diversified social and professional network to develop an integration, business, and transnational strategy that decreased his vulnerability and expanded his reach in both his home and receiving communities.

\section{Focus on opportunity identification.}

Individual Level: Fabricio had the propensity to focus on potential prospects instead of dwelling on obstacles and challenges. He was able to look through tough situations and expose constructive outcomes.

When I decided to quit my job and trust that I could survive working on my own I was nervous. The first 3, well no probably the first 6 months were extremely hard. There were many times I thought I made a bad decision. I couldn't find enough jobs, people wouldn't pay me, I was in a bad situation. But I knew if I could survive through the beginning I would be better off. So, I sat down looked at my situation and made a plan. Because I was on my own, I could start by charging less than my competitors and working harder, it was my way to get started and gain clients... and then later I knew I would have a good reputation and could raise my prices. It was worth sacrificing in the short-term to breakthrough in the market.

Fabricio utilized his knowledge of the market prices to derive a plan to undercut his competition and create opportunities that didn't exist at the beginning of his venture. He was able to become established this way and persevered through a strenuous start-up phase.

Fabricio was able to utilize his diverse social connectedness to uncover distinct opportunities. His connection with the dairy export company in Nicaragua led him to recognize a market gap in the Nicaraguan marketplace. He realized that there was a high demand for the Nicaraguan-based cheese, cuajada, in the Miami area through meetings with this company. He worked with the export company to provide dairy and cheese 
products for export to this market. He also realized from living in Miami that another cheese, quesillo, was in high demand. There were few imports in this area and Fabricio worked with his connections to pinpoint a marketplace gap and created a new export product line. He was able to utilize his transnational perspective to identify these opportunities and operationalize an implementation strategy to capitalize on it.

The majority of the opportunities Fabricio identified were activities isolated to either Miami or Villa Sandino with very little overlap. He utilized approached each in a singular manner and typically kept his business interests in both countries separate.

If I'm over there, I'm there, If I'm here, I'm here. Or in other words, I don't worry about the things that are outside of my immediate control, I focus on the present and where I am and deal with the other stuff when it comes up.

Fabricio approached his life as well as entrepreneurial ventures in a detached manner. $\mathrm{He}$ focused on opportunity identification in each market independently instead of looking for cross-boundary connections and opportunities. He was able to take advantage of crossboundary connections and opportunities when they presented themselves but that was not his primary focus.

\section{Collaborative approach.}

Individual Level: Fabricio is an independent and self-driven individual, but he articulated an appreciation for selective collaboration as a strategy for success. Fabricio spent his first years in the United States in an isolated and insular environment. Once he began expanding outside of his familial ties he realized the benefits of creating associations with diverse individuals. He utilized these relationships initially as a way to heighten his social bonds and connect to outside social circles. However, he eventually realized that creating collaborative connections enabled him to magnify his resources and 
augment his areas of weakness. For instance, working closely with entities in both Nicaragua and Miami has allowed Fabricio to spend extended periods of time in each country without interrupting his business practices in either place.

If I go to Nicaragua for more than a month, I usually join forces with my buddy who has a similar business. He is able to make a lot of the management and logistical decisions and keep my workers employed. We have an arrangement and I still make a high percentage of the profits and he makes some extra money just for delegating some easy tasks, it's a good thing for both of us...it's important to associate with people you trust.

Trust and respect are central to his strategy. He sought out relationships with individuals that he had confidence in and that could boost his relative position. He used mutually beneficial relationships but has been hesitant to enter into permanent partnerships.

Fabricio expressed the need for flexibility and autonomy in his associations and his focus on reciprocal and synergetic connections.

I think it's important to work with people, there are things I can't do and need someone with more expertise to fill in my gaps, but only people I trust, I have to trust them deeply to want to create something with them or let them into my business. That's why I don't have an actual business partner, I don't want to be tied down, but I rely on my close associates to supplement what I do. It's like building a house, I can paint, but I can't do electricity.... can only build a house by working with others. We help each other, force each other to grow and expand but aren't eternally tied to each other.

Community Level: The collaboration strategy allowed for adaptability with extra support for the immigrant and can translate to effective transnational engagement. Fabricio utilized this collaborative approach in both Miami and Villa Sandino. He has been able to maintain multiple successful enterprises with intermittent attention and focus as he transitioned back and forth between countries.

There is a jealousy in Villa Sandino. People want to succeed but they don't want their neighbors to succeed. They don't understand that if they found a few select individuals to work with that they would be better off. Instead of wishing bad or competing, they need to join forces and resources. That would make their 
business stronger. For instance, my neighbor wanted to open a bakery but didn't have the equipment. At the same time a man two blocks over had equipment from a bakery he used to have in the neighboring town but didn't have the money, business know-how, or packaging to start. Why don't they join forces? Because they don't see things like that, they think only one of them can win. That's the problem.

This anecdote illustrates a lack of internal trust and a high level of antagonism and resentment between community members. Fabricio articulated how a strategy in which building selected, trusting relationships in order to supplement and complement skills and resources while maintaining a professional distance could be translated within these community endeavors.

\section{Sustainable and diversified investing practices.}

Individual Level: Financial success and security for Fabricio is rooted in a diversified investment strategy. He saved money from his construction job to invest in equipment and resources to open his own painting business. He reinvested some of his profits in his Miami-based business and utilized the remaining portion to begin investing in land and cattle in Nicaragua as he became an established entrepreneur. This dualinvestment approach allowed him to spread his financial risk among divergent industries and economies as his business grew.

I grew up on a farm and always wanted to own land in Nicaragua. So, once I began earning enough in my painting business I started buying up farmland in the rural areas around Villa Sandino. Now I have 5 properties and 4 have cattle. I love it and it is a good contrast from my business in Miami. Here I am out on the land, there I am more city based. They are completely different and that's what keeps things interesting. So when times are bad in the United States, when no one is buying houses, like back in 2008, I can come back to Nicaragua, live for cheaper and focus on the farms. And vice versa, if cattle prices drop here and I can't maintain the four functioning farms. 
His investment practices were not necessarily based on a risk mitigation mentality, rather they were aligned with his interests. Nonetheless, it reduced his vulnerability to marketplace fluctuations.

\section{Vision and foresight as strategies for personal realization.}

Individual Level: Fabricio demonstrated a very presented-minded approach in many of his activities. For instance, his linear involvement in the business practices of the country where he was currently located, showed that he was able to focus on the objectives directly affecting him without worrying about extenuating circumstances. This approach allowed him to concentrate on the most imperatives tasks without getting lost in small, trivial issues, but also hindered his ability to create cross-business connections. However, Fabricio showed the attributes of foresight and imagination along with a clear vision for the future in the nexus of personal and business dealings. Various times throughout the conversation Fabricio indicated that he utilized a forward-looking approach to planning his business ventures based on how he envisioned his personal and social expectations.

I didn't initially want my own business, or at least I hadn't thought about it. But I wanted more freedom in my life to travel to Nicaragua or to other places when I wanted and for as long as I wanted. I'm not usually a planner, but this was my life and if I wanted to make it what I wanted, I thought a business of my own might be the best path.

Fabricio rarely spoke about strategic planning in the business context without pairing it with a non-professional narrative or goal. He typically spoke in a very presentminded manner, but allowed himself to delve into an imagined space when asked about how and why he made decisions in his entrepreneurial ventures to expand. When asked 
this business-related question, he began speaking about his wishes for his family in the future.

Oh the businesses, well I make them bigger when I can so I have more options for my family. Eventually I want to build a house close to Villa Sandino. I can just imagine it. My wife and I have a little house by a river, outside of town. We come back to Miami from time to time, but spend the majority of our time in that house. We have the farms so we can have a flow of money, but other people are working them, so we don't have day to day stress... I don't know if it'll happen that way, but when I make decision, that is in the back of my mind. I don't want to be 70 working in all these businesses, I want them to allow me to live a life like that.

Fabricio created these businesses, not out of a desire to be a professional entrepreneur, but instead to support a dream of personal realization and self-actualization. He does not implement foresight into his business practices, but created a vision for the future based on his family and social aspirations and paired his entrepreneurial practices to those objectives as a means of attaining those goals.

\section{Rosa}

Rosa grew up in Villa Sandino, and after studying in a nearby college secured employment in a bank in a town 10 minutes from her home community. She was content with her employment and had a large social network. She worked for 3 years as a bank teller before her sister asked if she was interested in immigrating to the United States in order to find employment with more economic opportunities. Rosa showed interest in moving to the United States and her sister petitioned for her immigration and provided her with financial resources to cover her visa interview and paperwork filing fees. After waiting $1 \frac{1}{2} 2$ years she was called for an interview at the U.S. Embassy in Managua and was granted a visa to travel to the United States.

Rosa immigrated to the Miami area because she knew a few family members and friends in the area. The main objective for Rosa when she arrived in Miami was to find 
gainful employment in an expedient manner. She secured a job as a childcare provider through an employment assistance program at a local church that she began attending. Rosa worked as a childcare provider for 3 years before being connected to a position as an elder in-home care provider. She worked for this family for 3 more years before she began to entertain the idea of becoming an entrepreneur. Rosa began to think about opening a catering business, specializing in Nicaraguan cuisine, because she observed an increasing demand for this type of service in her surrounding community.

The community of Villa Sandino remained very important to Rosa as she has returned to Nicaragua 3-4 times a year. She expressed a high level of transnational engagement ranging from interchanges of ideas and experiences with her friends and family to an interest in a community related development project and the promotion of possible linkages between her receiving community in Miami and her home community of Villa Sandino. She believed the immigrants in the Miami area from Nicaragua, specifically those from her community, would benefit from organizing their efforts and resources to create larger impacts on the most pressing issues of her home community. She also felt the local community members of Villa Sandino have a responsibility to organize and communicate their needs effectively to the local government.

Themes that emerged from our discussion included; Building on cultural capital, faith and preparedness as complementary qualities, shifting perspectives, progress through a participatory and forward-looking approach, authenticity and value-based decision making. 


\section{Building on cultural capital.}

Individual Level: Rosa utilized her strong cultural connections to bridge experiences and support professional and social interactions in both her home and receiving communities. When she decided to enter the entrepreneurial arena, Rosa looked to her cultural roots to create a strategy and theme for her business plan. She utilized a strong base of culinary cultural knowledge to identify an opportunity in the market and take advantage of a demand for Nicaraguan-specific cuisine. The business aspects of her venture were not her strong suit but her familiarity with the business product gave her confidence to move forward. She intentionally began small by making and selling a few Nicaraguan specialties and slowly added other items to the menu.

I wanted to get ahead and have my own business, be my own boss, and that's when I decided, I remember, to open my food service business. I focused on Nicaraguan food, I started by selling enchiladas, tacos and tamales, I remember just those three things and I started to sell. And after a little while, I started selling nacatamales and also rosquillas. Some of my clients said, 'Why don't you make other types of food besides Nicaraguan food?', but that is what I knew best and I knew that there were many people that would appreciate a Nicaraguan focused restaurant.

Community Level: Rosa celebrated and paid homage to her native culture by observing important dates and maintaining traditions. This was central to her life in her receiving community and she was involved socially in Nicaraguan-based celebrations and activities through her church and social network. This allowed her to recreate cherished memories from her community of origin and fostered a sense of home and comfort within unfamiliar surroundings. She also capitalized on these special days and events to bolster her business activities. She focused on promoting Nicaraguan specific food items at two special events where she found high levels of demand for her entrepreneurial venture.

For example, for the Purisima, in November, I always make my packets/gifts. We go to mass at the church and that's where I make 500, 600 packets and I make 
Nicaraguan candies and American style chocolates. It's really special, because I always maintain this tradition from my country in my heart and for Christmas I make the stuffed hens, a lot of my clients ask for these. More or less for the 24th of December or the 25th I sell 40 to 50 stuffed hens.

Rosa also demonstrated a propensity to share the culture from her receiving country with her community of origin. Her cultural focus was not solely concentrated on maintaining her native traditions but also incorporated immersion into the traditions of her receiving community and illustrated that culture is an important aspect of integration and the transnational experience for Rosa. She relied on integration into the culture of society and sought out opportunities to learn about and practice the customs that were both engrained in her past but also part of distinct and different way of life.

Yes, I explain to them the idea of Thanksgiving, how we eat turkey, in Nicaragua we call it the 'trompite'. I remember one time in Nicaragua, I went there over Thanksgiving, because I wanted to share this tradition from the United States...So I made turkey and invited my friends and family and they were so surprised, the turkey was delicious and I even brought some pumpkins that we painted and put candles in, we decorated the house just like in the United States.

Rosa tended to focus on food as an important cultural artifact. When she spoke of sharing her native traditions or learning new customs, her first instinct was to describe the cuisine that was typically associated with the event. This reinforced the importance of her esteem for culinary customs when she decided to open her business. The rich and deep cultural awareness she had gave her the knowledge base and confidence level to become an entrepreneur and enter an industry where she had little experience. Her appreciation of customs and traditions also built a transnational bridge that allowed for a fluid exchange of ideas and shared experiences between her home and receiving communities.

Faith and preparedness as complementary qualities.

Individual Level: Faith was a central theme in Rosa's life and was prevalent throughout our discussion regarding her immigration and entrepreneurial journey. Her 
first social interactions in her receiving community, outside of family contacts, were within a local Catholic church. Rosa maintained regular attendance to a local church and was able to secure both social and professional connections through this association. This initial religious-based integration offered Rosa a way to engage in parallel activities that she was accustomed to in her home community, while expanding her social network with a group of individuals with similar values and beliefs. Her engagement within the church also led to valuable linkages to local employment opportunities.

Well, the first job that I found was through the Catholic Church. I went to church every Sunday, just like I did in Nicaragua, I remember there were some programs through the church where they offered employment opportunities, different types of jobs for people that were permanent residents here in the United States and that still didn't have a job. There were opportunities, for example, in construction, painting, childcare, senior care, and many other things.

Finding employment through the church provided Rosa the ability to economically integrate into her community in a trusted and supported manner.

Rosa also expressed an intangible faith-based approach to life that aided her to navigate difficult situations. She felt she was able to take risks and enter into ventures that were unfamiliar because of an overarching belief that she would be led in the correct direction through her spiritual beliefs and connections. This sense of faith was shared throughout her family and religious based social network, augmenting the importance of faith in her decision-making process.

Well, there were difficulties, like in all businesses, when I started with my food, I didn't sell much. The little bit that I did make didn't cover my costs. My profit was very small, it was hard, I remember my sister told me "The beginning is always hard, all businesses have challenges", she told me "Have patience, have faith, everything will turn out okay".

Community Level: Her outlook evolved as she become more immersed in other areas of her community, specifically when she began to develop as a business 
owner. Rosa maintained a strong sense of belief and religious conviction, but realized that she could not rely on faith alone to achieve her ample goals. She recognized the importance of self-development to serve as a base for her objectives and expressed a belief in the duality and complementary nature of faith and preparation. Rosa believed that if she invested in herself in the form of training, education, and targeted skill development, she could then trust that her efforts would be guided by a larger force and success would be forthcoming.

So, after three years working with the elderly couple, I had an idea, there were opportunities here in Miami for Nicaraguan food, this was a big market and was growing and so I started working at a fritang a [Central American fast-food establishment] for a year, because I saw the opportunity, and I wanted to learn, I wanted to experiment with this type of job...they gave me the opportunity to start as a cleaner and then one day the owner asked me 'Would you be interested in another position' and I asked 'What type of position?' and they told me 'in the kitchen area, working with food preparation'. This helped me learn more facets of the business. I knew I would open my own business one day and had faith that it would be successful, but it was important for me to learn as much as possible first.

Rosa mentioned that community members in her hometown often relied solely on faith but did little to develop themselves in preparation.

\section{Shifting Perspectives.}

Individual Level: Rosa repeatedly spoke about the manners in which she had to

allow her mindset to be flexible in order to transition into new and unfamiliar

situations. She shared that she often had preconceived notions that were dismantled through applied experiences.

I had an idea of how life would be in the United States. I had seen many movies and my sister shared information, but those things did not prepare me. When I came over, from my rural town, I was overwhelmed by the enormity of Miami. It was beautiful but I couldn't find my place. I thought things would be very easy quickly, but it wasn't like that. I remember, one day I had to sit down and wipe my mind clean of what I thought it was going to be like and start from the beginning with no expectations. 
Later in our conversation Rosa repeated this sentiment when explaining her transition to small-business owner.

It was another big adjustment. Like when I first came over and had to readjust my outlook, I had to take a step back when I opened the fritanga. I mean I had worked in child and senior care for 6 years and thought I knew what it would be like to become a caterer. I knew how to cook and worked in the restaurant for a bit, but the reality was different than I imagined. I thought I would have more time and power, but at first I was working all the time and didn't feel like I had control. Once again, I had to take some time, change my outlook from focusing on the short-term challenges to focusing on the goals I was working towards.

Apart from shifting her own perspective, Rosa also communicated that she

continually shared information with individuals from her home community to help shape and shift their perceptions of life in the United States as well as other behaviors and customs. She believed entrenched perceptions were a hindrance to the development and advancement of her home community and suggested that sharing of information and experiential exchanges can deconstruct preconceived ideas and allow individuals the freedom to enter into situations with an open and adaptable mindset.

Well, with my family and friends, I speak with them a lot, when I'm in Miami I use video calls and Whatsapp, but I talk to them about my business, what the hours are like, or in other words, I share all the challenges, I explain to them that I get up very early and it's a very tough life, very different than Nicaragua, because in Nicaragua we are used to living with our family for our entire life. Here it is different, here you have to become independent and it's hard, you know, paying the electricity, air condition, all of these bills.

Community Level: This sentiment exposed the central idea that Rosa felt that the differences between life in the United States and Nicaragua were not understood by members of her home community. She believed the opportunities were vast in her receiving community, but also felt it necessary to ensure her friends and family in Villa Sandino realized the sacrifices that were necessary to take advantage of these prospects. This is an essential component of her transnational engagement strategy. She 
felt she could transfer a mentality of industriousness and productivity to the community members by increasing an awareness of the reality and methods for success she utilized in her receiving community. Rosa believed that if they were able to realize life was not necessarily easier in the United States and with hard work and creative thinking one could get ahead, they may embrace a more diligent and innovative perspective on their economic and community development objectives.

\section{Progress through a participatory and forward-looking approach.}

Individual Level: Rosa spoke about the importance of creating long-term goals in order to guide short-term actions and decisions. She related this belief to her personal experiences and also suggested this as an attribute that was very present in her receiving community that she would like to see adopted by the leadership and community members in her hometown of Villa Sandino. Rosa highlighted the use of participatory methods to gain skills, knowledge, and insights into the components of her larger goals when she spoke about creating strategic plans for her future. Reaching immediate targets through hands-on experience was central to her success and was an approach that she implemented throughout her journey. Rosa practiced this strategy when she decided to transition into the entrepreneurial arena.

That's how I started to work with them [restaurant owners] and yes it was difficult, very demanding, but I liked it because I was learning and at the same time I was seeing how they ran the business and the inside workings of the business, what the clients wanted, how they marketed their business, what hours the customers frequented the restaurant, which days were most busy and later this helped me start my business. Well, after about a year, I opened my business making Nicaraguan food, with all of this knowledge.

Rosa set a long-term goal of establishing a Nicaraguan food-service business and in order to accomplish his objective she worked for another business to gain hands-on experience while achieving short-term, fundamental knowledge gains. 
Community Level: Rosa found the concept of learning through direct, collaborative experience partnered with a grounded foresight useful in her personal experience. She expressed that her hometown would benefit from this type of strategic thinking and participatory development techniques. Her discussion illustrated the reality that her home community approached issues with temporary, interim solutions and lacked the ability to formulate intentional and tactical strategic planning. She reiterated that this is a problem at both the community and individual level and emphasized this area as a primary issue that she would like to impact through her transnational engagement activities. When asked what type of relationship she maintained with her community of origin, she observed the differences between Miami and Villa Sandino in terms of the association between success and the temporal aspects of planning and preparation.

I think my relationship with my community is very strong, because I want to help them, I want them to get ahead and to see the community progress. Here in Miami I see the businesses thrive, the construction, or, the way of life in Miami or the United States, the way people think is very different. They are always thinking about how they can become successful, they think about the future a lot. I don't see that way of thinking in Villa Sandino.

Rosa continued to focus on the potential development of her community of origin and cited the lack of foresight as a central reason that many projects fail.

...And here we, the Nicaraguans, you know the people in my country, sometimes we don't think much, we just think about little things. This is how was are accustomed to thinking, but we don't think about the future, we never think about what could happen. For example, with a community project that is started, they are rarely finished because we don't think about what could go wrong or how to deal with potential problems. A challenge occurs and the project gets shutdown.

Rosa included herself in the description of the short-term, present-minded approach of Nicaraguans. She still placed herself into the overall Nicaraguan population and treated herself with the same judgement as she did her country mates although she had incorporated this approach into her individual success strategy. 
Rosa emphasized the importance for community members of becoming active participants in community development issues. Rosa seemed to be referencing participatory development approaches that incorporated and integrated individual community members to become empowered change agents for their community.

The people in my community need to get together and discuss the issues that exist in Villa Sandino. There's the water issue, and the health and education issues, and more. But the people need to talk together and decide what is most important and go to our local government with ideas. They might not be able to do them all at the same time but they could start getting something done. But they need to come up with a plan and show that they have thought it through. They can't just say, fix this. They should figure out how to do it, how much it would cost, what might go wrong, what is most important, you know create a proposal together.

Rosa believed participatory development had the potential to increase the individual agency of community members as well as strengthen community-level resilience. Rosa approached this through transnational engagement on an individual level be utilizing communication and mentorship practices.

\section{Authenticity and value-based decision making.}

Individual Level: Rosa placed a high level of importance in her values and beliefs and credited authenticity as an essential component of her personal and business relationships. Her deep religious base and a well-maintained connection with her community guided her ambitions. Her initial reasons for immigrating to the United States were guided by a feeling of responsibility and desire to create a better life for not only herself but also her family and community in general.

Well, I came with the intention to work hard, to save, in order to be able to have a little house in Nicaragua in the future, help my family, people in need in my hometown. These were my aspirations; I came with a hope to work in order to create a better life for me, my family, and my community.

Rosa's original plan was to work in the United States for a few years after which she would return to Nicaragua to resume her life with a more secure financial position. She 
has since decided to stay in the United States and was pursing U.S. Citizenship at the time of her interview. Rosa relied on value-based decision making in her election to pursue her U.S. Citizenship and reside in Miami permanently. She was able to connect her values and economic achievements within this landscape and felt that this unique atmosphere would help her thrive in the future while allowing her to maintain transnational support of her family and hometown community.

I believe in the United States and what it stands for. Here I know if I work hard I can achieve success. I am able to find people that believe in what I believe in and they create my community. I go to church, I have a successful business, and I can still help my community and family. The United States has offered me a place to find financial success and find a community of people that have my same values at the same time.

Rosa continued to emphasize the creation of a strong base of mutual respect and trust among relationships and associations. She avoided relationships with individuals and institutions that did not share her values of transparency, openness, and cooperation.

It's important to align yourself with people that are genuine. You want to find friends and partners that will tell you the truth and have similar views on the important things in life. It's not worth it to work with fake people or liars that only care about themselves.

Rosa was able to leverage her faith and beliefs to ensure that her business practices moved forward in a reputable and constructive manner. She also operationalized this within her personal and transnational connections. Values and authenticity were central to her decision-making practices throughout all spheres of her life.

\subsection{Case Study Interviews II (Leadership Group of Villa Sandino)}

This study has focused on the experiences of the immigrant entrepreneur living in their receiving community and engaging through transnational boundaries with their community of origin. A supplementary set of interviews were conducted with three 
community leaders in Villa Sandino, Nicaragua in order to add context to the interviews conducted with these entrepreneurs. These interviews offer a complementary perspective to those of the immigrant entrepreneurs in regards to their perceptions of the challenges, opportunities, and effects of migration of their home community. The three selected community leaders were chosen to provide a broad overview but were also limited by their primary roles with the local government. Two individuals, Gustavo and Jennifer, worked with the Mayor's office in economic and social programming at the time of the interviews. The third individual, Lorenzo, was an outside consultant to many of the government planning and programming objectives. He provided a perspective and voice as a representative to the political party not currently in power at the local level at the time of this study, the Sandinista party.

The overarching purpose of this study is to understand transnationalism through the experiences of immigrant entrepreneurs with the aim of better supporting transnational engagement through policies and programs. The ultimate goal is to affect community development within the sending community. These interviews provide insight into the atmosphere and environment at the community level of Villa Sandino. The exploration of the community through the insights of influential leaders provides a preliminary illustration of the nexus of community and transnationalism while understanding the limitations of the selected participants.

There were four main areas discussed for within each individual conversation in order to explore community from different angles and provide as comprehensive overview of Villa Sandino from the local level as possible. First, a general overview of the community Villa Sandino from the perspective of each leader was explored. This 
overview included a discussion on the vulnerability, resilience, and various capitals inherent to the community. These areas are foundations to understanding community and provided a base understanding of Villa Sandino and an informative outlook for further discussion on other more specific community field topics. Second, a deeper discussion of community development was explored through the specific experiences of each leader. They spoke about initiatives they had been a part of, projects that have succeeded and those that have failed, and potential areas of development for future endeavors. A look at sustainability wove through the development dialogue in order to construct a foundation for effective transnational engagement priorities. Third, the topic of migration and community were discussed in order to explore the effects of out-migration of community members at the household and community level. This presented an interesting perspective on the consequences of individuals leaving Villa Sandino, creating an interpretation of the relative brain drain and brain gain that resulted from this movement. Understanding out-migration from the community level provided a contrasting perspective from that of the individuals emigrated out of Villa Sandino and created a life in another country. Lastly, the relationships and continued connection of emigrants with the community of Villa Sandino were delved into in order to understand the current transnational engagement of this group as well as to consider the potential of supporting and expanding interactions and constructive interventions in the future with these local leaders.

\section{GUSTAVO}

Gustavo was the director of economic projects for the local government in the office of the Mayor at the time of the interview. He had lived in Villa Sandino for 27 
years and was originally stationed in the town to serve as a police officer. He worked 12 years as a police officer and transitioned into a government position as an assistant to the Mayor. He worked his way up in the ranks and was ultimately elected as Deputy Mayor for the town in 2000. He served four years in this position and stepped down to pursue a position with more hands-on applications where he saw a definite need in the community. Gustavo became the advisor for economic programming for the local government because he observed a lack of opportunity for youth as well as many adults and believed the community was in need of support in the areas of workforce development and the expansion of small business development. Gustavo had worked in this position for 10 years and shared his experiences with both successful as well as failed projects in the area. He has had the opportunity to observe the migration of community members to other areas and was able to offer an insightful reflection on the relationship between emigration and economic development.

\section{Community Overview}

Gustavo is not native to the community of Villa Sandino, but spent the majority of his adult life as a prominent leader in the town. He focused on the human and social capital aspects but also mentioned the natural resources as important elements when asked about the community. He felt the community derived strength from its small, intimate nature where people relied on each other for support and assistance in times of need. Villa Sandino operated in an informal nature, with only a few established businesses. Gustavo believed most community members were engaged in some type of informal business or service and people were aware of these operations and could easily navigate the informal economy to meet their needs. 
Most people have some type of business. You just have to know who is doing what, and it changes often. Like who fixes broken cell phones and for that matter who sells minutes for your cell phone. Young women often provide nail services or other beauty services but not in an established business. You can buy milk and eggs if you know someone that owns a farm. You can get a guy up the street to build you some cabinets or another guy to fix your bike. But you see it's not like they have a big business with a sign. It's just people doing what they know how to and finding business through word of mouth. But once you know who does what, it is much more personal and you can even barter, trade your service for theirs. There is some beauty to that.

This community has a tight internal social network that is concentrated with bonding relationships. This creates a tight-knit atmosphere but limits the possibility for growth and innovation due to the insular nature.

Human capital was also an important theme. Gustavo believed community members had limited opportunities to develop themselves professionally. Local education was flawed and lacked resources such that individuals often have to leave town in order to access trainings and other types of preparation to enter the workforce. He noted that because the local formal workforce is small, there is a dangerous cycle of lack of development of human capital and diminishing employment opportunities.

Villa Sandino is difficult. For one reason, it's small and rural, which is good in many aspects but it difficult for the youth and people of working age. The local schools are not the best. Private schools are much better, but you have to be in a larger city to attend these. The local public schools do not even have textbooks, and the teachers are constantly leaving after one or two years. It's not great preparation for the youth. The smartest and most capable youth tend to leave, go to Juigalpa or Managua to pursue better opportunities. And then that is hard because there are only a few good jobs in Villa Sandino. What would our brightest youth even do here if they stayed, that's the dilemma.

Gustavo arrived in Villa Sandino during the end of the Nicaraguan Revolution.

He witnessed the polarizing effect of this internal conflict on the town and relays that interpersonal connections and family associations are still greatly affected by the divisions and affiliations present 30 years ago. 
People's mindsets are stuck in the past. It is hard for us to move forward when everyone is always looking backwards and remembering the terrible things that happened. Families have deep connections that are valuable and strong, but there are also many fractures in the community. Kids are replicating what their parents think and judge their peers based on old perceptions, this can be damaging.

Gustavo has also navigated government appointed work with the police department as well as with the local office of the Mayor in various capacities and through changing political parties in the country. He has been able to observe the town during the time period of a severe internal conflict as well as how the community has progressed in the years since the war.

Gustavo also referenced the natural space as a significant element to the Villa Sandino community. He spoke about the reliance on the expansive farmland for the majority of the local economy and the constraints that exist with access to other natural resources like water. The natural environment is clearly a core resource for the community well-being and also a point of pride.

One of the best parts of Villa Sandino is our location. People come here from the city and are surprised when they look around and see green everywhere. In the morning a favorite past time is to go to a farm to drink fresh milk and be surrounded by nature. On weekends and for special days the entire town packs up some food and goes to the river to socialize and enjoy a swim. We have petroglyphs that were discovered a while ago and are a very interesting historical link, people travel here from other parts of Nicaragua and the world to see those. Our location is spectacular. There is something special about being surrounded by so much beauty and peace, very different than the big city life.

The natural capital of the community is important for recreation, the economy, tourism, and socialization. The outdoor space surrounding Villa Sandino provides a platform for social interaction and is the cornerstone for the maintenance of the agricultural sector of the community. Gustavo relayed that although the families live in tight quarters within their indoor living space, they are able to enjoy the freedom and expansiveness of the 
outdoor areas, providing the opportunity to achieve a balance between attachment and independence.

\section{Community Development}

Gustavo has worked on community development initiatives in various roles during his tenure in Villa Sandino. He was the director of economic programming for the local government during the interview and was able to share his experience with both successful and failed projects as well as share his insights on the future development objectives for Villa Sandino. Creating space for socialization surfaced was a characteristic of successful projects. This often took shape in the form of the creation of built capital in order to support social capital development and to some extent foster the maintenance of cultural capital. For instance, two specific projects that he highlighted included the enhancement of the community outdoor sports court and rebuilding a rink on the outskirts of town that hosted bull riding events.

One of the best projects we presented was putting a roof on the outdoor court. This way the community soccer and volleyball games can take place in any weather. It also made the space more comfortable and we began allowing small food stalls to setup there so it draws more people and provides a few more jobs opportunities. We also host dances on the court sometimes, it is one of the most communal spots in the neighborhood so improving it created benefits for everyone.

The other project that we did just last year and was very well received was the reconstruction of the bull stadium. The old stadium was old, made of wood and falling apart. It was getting to the point where it was dangerous for people to sit in the stands. We demolished it and rebuild it with metal so that it would last longer, be safer, and we wouldn't have to keep cutting down trees to repair the old one, you know that is hard on the environment. So the new stadium is better all around and provides more seating for spectators. It is important because bull riding happens during our fiestas patrias (local festivals) and other important events, it is important to have a stadium we can be proud of. 
He noted these areas were important to provide community members with safe places to gather and take place in culturally important events. These projects also created structures that were utilized by the entire community. The wide accessibility may have been an important factor in gaining broad support for the chosen projects. It appeared that projects targeted at specific segments of the population were more difficult than support for benign structures that could be utilized by any and all members of the community. I don't know why, but some projects have been really difficult to get off the ground. We tried to plan a program where we would go out to rural areas and help them build stoves or biodigestors to give them access to cleaner and more effective cooking methods but we were only able to gather the resources and man power for a couple homes and then the interest just diminished.

Lack of resources and authority at the local level is another obstacle the local government faces when planning and introducing development. The local government (at the time of the interviews) was part of the opposing party of the national government. This created tension between local level objectives and national support. Gustavo shared that they were trying to obtain permission to undertake a water project but had negative encounters with the national level entities.

One of the most needed projects in our town is access to clean water. It is ridiculous because we are surrounded by water but our pipes and water distribution system is very old. Houses sometimes only get water once every 1-2 weeks. People need water to drink, wash dishes, bathe, wash clothes, etc., but they are put in a position where they are dependent on waiting until the water comes and sometimes they have no idea when that will be. This has been our top agenda item for years, but we cannot get it approved. A similar water project was started in Hamaca but we lost support for it after one year and now it just sits, partially done. We need government resources to support this big project and we have submitted the request every year with no movement. If I could accomplish one thing before I leave it would be this.

Some of the development priorities of the community are directed by the national government agencies, however these agencies have very little awareness of what is 
needed within the town. It appears these agencies set priorities based on national level objectives and priorities that are politically aligned but not necessarily practical at the local, community level. The tension between the local level government and the national political party created strains on the community. However, it also was a source of checks and balances, ensuring that one party was not overly powerful locally, further marginalizing those of the other party and limiting their power or control.

Currently, one of our biggest projects is the repaving of the main road in town and the pavement of a new road that was dirt until now. This creates better access for vehicles and we have also been able to give jobs to quite a few local men. It should be done in the next 6 months.

This project not only created built capital but also provided local economic opportunities. The timeline for the project was long and may not have been the most efficient manner of construction, but by employing local residents it created a multiplier effect and injected more financial resources directly into the community.

Gustavo believed workforce development, particularly for the youth sector was an important development goal. He believed there needed to be better opportunities for individuals as they leave school and began their economic integration. He emphasized the dual need for better developed, formal establishments and institutions in the community that could provide job opportunities as well as more targeted and meaningful trainings for the youth to be able to lead in the future.

We have to focus on the younger portion of the community. The way I see it, they are becoming more apathetic and that is going to hurt the town. It is a vicious cycle because there aren't good opportunities for them to find good employment here but also they aren't really ready to take on the challenges either. If there were more opportunities maybe they would be more driven ....OR...if they were more driven maybe they could create more opportunities... but neither exist right now so we need to find an intervention to break that cycle. 
Gustavo has observed a destructive, cyclical relationship between the economic opportunities and youth development. This appears to demand a focus on human capital development along with access to financial capital and investments to create a healthier workforce atmosphere to support the advancement of the youth sector. Human capital development had not been mentioned in any of the prior development initiatives but emerged as a priority for Gustavo.

\section{Community and Migration}

Costa Rica is a close destination for migration with a stronger economy. People typically move to the country for temporary, economic migration purposes and because of its proximity, community members have been able to return to Villa Sandino regularly and have migrated back to Nicaragua for extended periods of time throughout their seasonal employment in Costa Rica or eventually move back for good when they became more financially stable. This migration pattern has been fluid and flexible. Spain has also been an option for migrants because it shares a language and some cultural norms but is a larger geographic distance for migrants and the community. Gustavo noted that individuals that moved to Spain returned less often and often become more detached from the community as time went on. The United States is geographically closer than Spain but farther than Costa Rica but has also presented the most difficult immigration path. Migrating to the United States has been seen as superior than Costa Rica by local community members but has not often been attainable. Gustavo shared the financial and physical risk that many people undergo when trying to enter the United States without documentation. He shared that families paid thousands of dollars for uncertain outcomes and many were treated brutally during the long journey. Those that were able to find a 
legal path to immigration to the U.S. were viewed as lucky and obtained a heightened status locally. Those that immigrated without documentation were also viewed as fortunate but were unable to return or to engage as fully with their community.

Gustavo mentions immigration has often been a goal for individuals in his community but immigration to the United States was lofty for many and only achievable for those that already had an established familial connection with a US citizen or permanent resident. From his perspective he saw migration as beneficial for many households but detrimental to attitudes and motivations of community members.

Many people hope to immigrate. To go to the United States is a dream, a lot of kids think that life is easy there. It is true that there is more opportunity for work but I don't think life is easy there and they don't understand that. But the problem is, if everyone's goals are looking outward or trying to move to the Grand America, they devalue their situation here. People that have moved to America are celebrated when they come home and many try to ask for money or financial assistance from them. They see them as the golden ticket. But that isn't fair to them or to those that live here. It just seems to drag the focus away from what we can accomplish here and instead people want to flee to another country in search for the easy way.

Perception as a central influence migration at the community level was echoed in many of the conversations with the immigrant entrepreneurs who felt misunderstood because of their immigration journey. The perspective from the viewpoint of a community leader illustrates that immigration to the U.S. is romanticized, causing relational distance with immigrants and stagnating the mindsets and motivations of local citizens. They feel as if they are stuck in an undesirable situation so their motivations turn outwards, negating their commitment and enthusiasm for the possibilities that exist or could be developed within Villa Sandino. Migration has created a perceived power dynamic that depresses the agency of the community members and establishes an atmosphere of superficial reliance on outside sources for success. 


\section{Emigrant Engagement in Community of Origin}

Gustavo shared his perceptions of specific engagement activities between individuals that have emigrated out of Villa Sandino to the United States and noted that the immigrants typically maintain strong ties with those whom they were closely connected with before moving. These relationships affected their community engagement in a few ways. For instance, immigrants that had previous ties with local leaders were more likely to become engaged in government projects in a transnational manner.

For example, Walter and I were good friends for a long time. We trust each other and he knows I don't want to take advantage of him just because he lives in the U.S. now. So when he comes back we typically go to the pool hall and have some beers and talk about what is happening in the community. Then he offers his opinion on what we are doing and in the past he has even supported projects. He has younger siblings that still live here so when I told him about an initiative that we were working on to revamp the school, he bought and donated the paint that we needed for phase 1.

This demonstrates the importance of established and maintained relationships that are built on trust. It makes sense that prior relationships would be cherished and could be utilized to build transnational associations that create a collaborative space because of the shifting power dynamics that occur between the community and immigrant,

Gustavo concurred that immigrants primarily focus on supporting their immediate family through financial remittances. He mentioned that families with immigrant members are well known and are assumed to be more financially secure because of remittance activities. This can complicate expanded transnational activities.

I think that these individuals could be quite influential but sometimes our ideas conflict. They often don't want to just invest in projects we have planned but believe we should prioritize other things, usually something that is beneficial for the people they are close to. But because we can only do so much within our office, we have to plan for what our resources allow. So it's hard to work together 
many times, but I think they should and could do some valuable projects of their own.

Many of the immigrant entrepreneurs shared a distrust for the local government and a reluctance to work with an agency they perceived as dishonest and incompetent, especially in the administration of funds. The perspective from the other side focuses on a misalignment of attitudes and objectives as the primary preventive factor for effective collaboration.

\section{JENNIFER}

Jennifer was born in Villa Sandino and has been employed with both nonprofits and the government for the past 20 years. She has spent the past 10 years working with the local Town Hall in several capacities. She was the manager for social development programming at the time this interview. Jennifer worked with a NGO named CAININ before entering government work,. She was as a technical lead for projects focusing on children nutrition in rural areas. She has also volunteered her services to assist in local community development efforts with a women's cooperative. She was awarded the opportunity to study and receive a diploma in leadership and policy because of her volunteer service. Jennifer has also taken advantage of other training opportunities because of her active community involvement. She has a degree in public administration and a technical certificate in social development.

Jennifer also has a daughter and a son and lives with her parents in a small house connected to and in home small grocery business run by the family. She has been very integrated into the community with a large social network. She completed primary and secondary school in the local education system and has a first-hand knowledge of the 
services that are available and those lacking within the town. Jennifer offers her

perspectives as a resident, a mother, and a local leader in the community.

\section{Community Overview}

Jennifer has lived in this town her entire life and is able to provide a native perspective on the community. However she does not have a great deal of external experiences with which to to draw comparisons.

This is a calm town, with nice people, it's very cozy and has everything you need. Villa Sandino is the district center, there are three more places in the district that make up the more urban areas, Muhan, La Gateada, and also Chilamate, which is growing rapidly. Villa Sandino is the district center, here we celebrate 'fiestas patronales' (community festivities) as do Muhan, La Gateada, and Chilamate.

Jennifer continued to speak about the importance of the local festivals and events to the community members and as a way to incorporate outsiders into local traditions. Her discussion revealed that the surrounding rivers are an important natural area where community members come together to celebrate and she shares her concerns about the environmental impact of the overuse and under protection of these area.

This is a very interesting thing about Villa Sandino, there are always community events and festivals, when one ends another is starting. So for a person that has never been here, they can come to celebrate with the town with the townspeople. By celebrating during these times, people can learn about our culture, celebrate our patron saint San Pedro and also in Semana Santa they can come to congregate in the rivers and have a good time. It's true that the rivers have dried up a bit and are contaminated but they are trying to treat them and make dams to fix the problems.

This indicates a focus on social capital and shows that natural capital is important in supporting social events but is also negatively impacted by overuse and limited protection protocols. Natural capital is an essential element of both the economic and social realms of Villa Sandino society, however limited focus on sustainability has been revealed.

Jennifer focused on the personal safety and security that the small town afforded 
as a positive trait.

Well, apart from being calm, there is not a lot of danger or crime, its safe for people to leave their doors open and children to play outside. The whole town watches out for each other. The majority of people here work on farms and ranches. They have cattle and sell milk products. If you aren't a farmer there are limited employment options. They could work at the Town Hall or MINED (Ministry of Education), the MINSA (Ministry of Health), or Aguas Claras (local water purification plant).

There are limited opportunities outside of farm work for residents because of the reliance on the agriculture industry for the local economy. The best opportunities outside of agriculture could be found in local government agencies and one private business. The formal economy of this town is restricted and outside growth has not been allowed to prosper. However, the limited opportunities are balanced with a steady and reliable community culture. Individuals often make the decision to leave based on economic objectives, however many residents chose to stay even though opportunities are sparse because of the community roots and close social network that is developed within the small township.

\section{Community Development}

Jennifer provided a multifaceted perspective on community development within Villa Sandino. She shared her experiences on different levels of the community structure based on her work in the nonprofit and government sectors. She also brought the unique perspective of a woman and a mother within this development context. The development landscape changed dramatically on a national level with an effect on local level opportunities.

No, now with the current government, our president that is in office now, they have shut down many of the institutions and the NGOs that were sponsored by 
outside organizations and countries have left the country so we have less options of assistance outside of the government

This shift in national level structuring has contracted the level of outside support that was once available in the region surrounding Villa Sandino. A focus on government support has created a reliance on political capital to obtain much of the needed assistance.

Her direct experience in community development focused on gender equality and youth health. A large issue in the community has been the history of the machismo culture that contributes to high levels of domestic violence and a passive, subservient culture for many females, especially in the more rural areas. Jennifer shared her experiences working with this group to promote equal rights and included the male population in an effective dialogue about the mistreatment of women and girls in the community.

This was a good project, especially in the more rural areas, there they are accustomed to the woman being submissive. If she has a piece of chicken, the chicken is for the husband, she never has any rights or respect. That is how they are used to being treated. So we tried to educate them with workshops about equality, gender rights. We taught the women that they have the same value as the men, that we can perform the same as them. And of course we involved the men too, we had open discussions with the couples, because it doesn't work if you exclude the men. They would just get angry and make their wives and daughters stay home.

Yes, it's difficult because some women demonstrate more leadership, others do not, they are very submissive because their husbands are violent, many are alcoholics. So what happens sometimes? The women come to the meetings with two children in tow, many have several children, one in her belly, another hooked on her waist. And all of this hidden from her husband. That was dangerous for both the women and her children. This is changing now. Now the men have learned to yield to the women and giver her this space. They accompany her to the talks, because they see the benefit and it's not as scary or alarming now that it's not hidden.

Gender equality is a deep-rooted issue that stems from cultural norms of the society. It is not an easily corrected problem, but is essential for the growth and progress of the 
community. The inclusion of men in these interventions is a principal theme and demonstrates an awareness of interpersonal dynamics within the local society. There may be an increased chance of sustainable success and meaningful change by addressing female rights with a broad strategy.

We had volunteer positions for some of the leaders of this mother's group. These volunteers came from the community, we had 75 members of the group. There were two leaders that helped organize the volunteers and work to spread word within the rural communities. We tried to offer opportunities to the individuals in the group that expressed interest and leadership ability. We paid them a small stipend and offered them opportunities to obtain certifications in leadership and community organizing.

Jennifer also pointed out that they not only provided services for at risk women in the area, but they also provided opportunities for advancement and leadership development within this group. There has been an emphasis on developing human capital through training and personal development as well as influencing social capital by creating more equal relationships throughout the community.

There was also discussion on focusing on educating and creating awareness among female youth and children's health in the community.

I am also a member of the Chontaleñas Women's Network. I have worked with several projects with the Women's Network, one that is particularly important was to decrease the degree of pregnancy in adolescent girls, that had a great impact. We were able to decrease these pregnancies through community education and through follow-up small and individual counseling. So that was enough, a very big impact in the municipality. The girls were also given training in artisan work. This provided the adolescent girls and young women economic opportunities and a chance to get together once a week, so that they would be independent and could support each other.

The intervention for young women in the community was undertaken with an integrated an multi-pronged approach with a focus on education and training to support social interaction and provide an opportunity for them to enter the local economy which created 
a stronger sense of independence and self-worth. This program attempted to develop human, social, and financial capital among this group, creating longevity to the benefits and outcomes.

Jennifer echoed other leaders and immigrants by speaking about the issue of water distribution in the community. This problem has been emphasized by many individuals in this study and appeared to be one of the most complex and least successful efforts in the community. Jennifer shared that one of the issues is the owner of property where the distribution system must pass through will not collaborate with the government on this project.

The problem seems to be the wells, the engines and another way is to distribute the water, there is a hill that the system needs to run through to provide water to the individuals in town. But this was the problem? That the owner of that property did not want to give access to this hill, he did not want to sell the property or simply allow the system to be laid under it to supply almost the entire municipality. So every time the project starts, they cannot find another option to run the pipes and it stalls.

It also seemed that the inconsistent leadership created continuity problems. When l eadership has changed, new priorities were brought to the forefront and projects initiated by the previous administration were suspended. This created an atmosphere where resources were not utilized in an efficient manner and projects were constantly starting and stopping before completion. This is reflected in the perspectives of many of the community members who also cite misuse of funds and maladministration of projects.

Yes, what happens is that the same thing happens, like the mayor who managed that in his time, you know it is by period, then the next mayor who comes does think the same projects are important. The new Mayor comes in with his own priorities. Another problem is that people are not interested, we are not organized 
to promote and to defend our rights.

Jennifer points out that community members are not able to successfully organize in order to have their voices heard. This imbalance of power created a community leadership that is not accountable to the residents. She also shared a few areas that she believes would be valuable for the community development agenda.

Yes, one has been the municipal market. We do not have a market, there is a small place or an area that could be used for this but it has been abandoned. In the past, the Women's Network proposed a municipal market, because many times there are communities and individuals that have their products, products that they harvest or make. Having an area dedicated to where they could come and setup and directly sell their products to the community would be great for them and the residents. People travel to the next town to go to a market like this and they are buying products from other people, not their neighbors. It seems like a lost opportunity.

This project idea emphasized a place to create economic opportunities where individuals and families could access a direct market and also create an environment where financial resources were directly invested back into the community instead of allowing a large percentage to lead into outside economies. This project has a social aspect, creating a space for community interactions and gatherings, which is like other projects that have been suggested.

Jennifer continued to focus on the creation of social spaces for her subsequent suggestion in another project she suggested focused on creating safe and productive social spaces for youth gatherings and other resident activities.

At least one other idea is, we have here the communal house that is where we hold dances. It's really only used for dances, nothing more for. So, one of the projects that would be good is to put it to put games, table tennis, something recreational, as a recreational center, it could serve both functions. A recreation center most days, and then a space for dances during community festivals and events. It would give people options other than the bar and the pool hall, 
somewhere where both girls and boys could go and have safe fun. It would economically make an income for maybe three people who could manage it here in the communal house. And also for youth and children because it is something that lacks here, because here more than anything they play football or volleyball and it would be like implementing other games, somewhere that is aligned with their interests but gives more opportunities.

Jennifer also recommended the creation of a maternity center that would provide services for expecting mothers and could serve as an education center for pre-and postnatal needs. She believed that the local health clinic has been inadequate and there was a dire need for more doctors and emergency services in the area. Jennifer's focus on social progress and equality was demonstrated through her discussion and a focus on women and youth is evident. She believed that by empowering these marginalized segments of Villa Sandino overall community resilience will be strengthened.

\section{Community and Migration}

Jennifer believed that a large number of women that have been forced to leave their children in search of better economic opportunities abroad. This is logical as Jennifer has spent much of her career working with marginalized women and has had experience with the forced migration of this group.

The majority of them are single mothers, there are no big sources of income here in Villa Sandino, hardly any employment opportunities. And if you work as a domestic worker, the pay is very low. Maybe the most they can pay you is $C \$$ 2,000. So what happens? One wants better for their children, then the mothers emigrate, sometimes the parents are also looking to support the family, because the salaries are very low, at least in the mayor's office the salaries are very low.

Her first impression of immigration was as a necessity that pushed people out of the community because of lack of local economic opportunities. This reality has fractured families, as mothers were forced to leave their children so they can focus on sending financial support back home. They often took jobs as nannies or maids in households 
abroad, filling maternal roles in the homes of other people but abandoning this role within her own family.

No, they leave alone, I have two friends who immigrated to Spain, they left their baby here, there are some who have not returned, there are others who had the luck that they did get their documents and have come, but they come by seasons and they come back.

The legality of the migration affected family unity. Those that left without documentation were stuck in their new location, not able to return for visits, until they wished to return to Nicaragua permanently. Those that were able to secure legal documentation could at least return for visits with their family and attempt to bring their children over to their new location once they have reached a level of stability.

She noted some individuals left for Costa Rica to find work but were able to return for extended periods of time to Villa Sandino because of the open borders that allow for easier travel between the two countries. She described this type of immigration as temporary migration, where individuals would leave for 6 months and then return to Villa Sandino for 6 months to live off of their earnings. This type of migration transfered financial resources back into the community, but the human capital was not utilized effectively. The immigrants tended to spend their money in nearby towns or larger cities because there are limited institutions and organizations in Villa Sandino, which limited their financial contributions to the community.

Jennifer explained immigration to the United States as either lucky or dangerous because of the stricter immigration policies and geographic distance. Individuals and families either secured visas to enter the U.S. which was lucky as many do not have this opportunity and others wishing to pursue life in America had to go 'mojado', or illegally, 
to the U.S. The process of illegal immigration has been expensive and dangerous and many that leave were not able to return, disappear, or became detached from the community. Those that were lucky and legally immigrated were seen as having an advantage over the other community members. Furthermore, the family and close friends of these individuals were seen to have an advantageous position as well.

Those that end up in the U.S., with documents, have an advantage. They usually do very well and are successful. Their families and those close to them are more secure after they get settled in the U.S. So there are certain families in town that have really benefited from immigration, but not everyone. Many are left behind, many don't have a tie to a successful immigrant so they aren't able to benefit.

Jennifer spoke of immigration as a livelihood strategy for certain households in the community. It has provided external support and decreased the vulnerability for many friends and family of the individuals that were able to settle in the U.S. and find stability However, because the benefits have only been realized by a small, select portion of the residents, the community benefits have been limited.

\section{Emigrant Engagement in Community of Origin}

Jennifer shared a hesitantly optimistic perspective of the atmosphere of current and future engagement behaviors by emigrants that have left Villa Sandino. She stressed that the key connection between emigrants and the community were through their family and household of origin. This relationship has often been the catalyst to community participation by the emigrant groups. Jennifer shared that it often a family member or a close friend that would solicit assistance for specific projects from individuals living abroad.

No, it's often difficult to get support. Most of the time it is family that ask "I am working on this project, could you give a contribution. Or there is this interesting project that we need support for, could you finance or help with this?" People 
communicate mostly with their family and trust them, so when they ask for assistance for a project or event, they are more likely to get it.

This further demonstrated that the household connection is key to operationalizing an effective transnational engagement from the emigrant community. Because trust is an essential component for garnering support from this group and constant communication exists within these relationships, it may be beneficial to formalize the inclusion of emigrant households into the development planning process.

Jennifer described a limited level of existing support from the emigrant population for community level projects or programs administered by the local government. She believed that these individuals have not offered their support because of either a lack of resources or a lack of interest.

Sometimes I think it's like lack of interest or sometimes they do not yet have adequate resources. I know there are many people with the resources to help but they do not. I think sometimes when people live abroad, they have the resources but lack interest. They forget about what we need, they don't feel the need of our community anymore because they live somewhere else, they forget. Others have the interest, but they don't have the resources. So it's about tapping into both those with interest and resources.

Jennifer further discussed the potential impact of transnational engagement by emigrants by focusing on the areas of contribution that would be most advantageous to the community.

Well, first of all it is most important for them to introduce or contribute to projects that could really impact the town. I don't think this should be infrastructure necessarily, but more likely something that helps our people have more capacity. For instance, something that enhances the aptitudes and competencies of women in the community. And a project that promotes jobs so that mothers have better opportunities, so they don't have to leave the town to search for better jobs

Jennifer also observed that a prospective synergy exists for emigrant entrepreneurs that 
have established businesses abroad. These individuals could replicate their businesses, or at least versions of their businesses, within Villa Sandino to broaden the local economy.

It is important to sensitize them about the problems we are experiencing. Especially those that have created their own business. They know what the economic climate is here and know that we need businesses in town to provide jobs. If they could use their know how, or expertise, to put businesses in Villa Sandino that would be one of the best ways they could support us. Like the Centenos, they have a bakery in Costa Rica. Villa Sandino would benefit from a bakery, if they could help establish that here there would be jobs, we would have more of a local economy.

Jennifer believed that current emigrant engagement was limited in nature but has the potential to become instrumental in local development initiatives. She realized the specialized knowledge and enhanced resources that this group holds and believed that through better community to emigrant communication these individuals could become fully engaged with their home community and play a profound role in creating a healthier economy and improved opportunities for its residents, especially the marginalized groups.

\section{LORENZO}

Lorenzo was also born and raised in Villa Sandino. He was in his early 20s during the Nicaraguan Revolution and experienced a strong political shift within the country as well as observed the effects of this transition at a local level. He offered a distinct perspective to this study because he was a community leader affiliated with the Sandinista party at the time of this interview. Gustavo and Jennifer were both aligned with the party of the current local government. The Nicaraguan government was controlled by the Sandinista party at the time of this interview, the local elected officials of Villa Sandino were of the opposing party. Lorenzo has often been included in community development planning 
initiatives as an outside consultant so that the Sandinista point of view was represented and included in strategic planning initiatives. This was done in hopes of creating cohesion and trust within a community typically divided along party lines. Lorenzo provided a unique perspective and allowed some insight into the differences and similarities found within local leadership and dynamics within the town.

\section{Community Overview}

Lorenzo ruminated on the positive aspects of the past and how things have changed in a negative manner over the past 20 years. He recalled a town with a thriving agricultural sector with strong community bonds. He immediately evoked imagery of the past and did not concentrate on the present when asked to describe his town.

Villa Sandino was a wonderful place to live and grow up in. There was a real sense of community. People helped people, we laughed together, we cried together, we celebrated together. Most people owned a farm or worked with a cattle rancher and had enough money to support their family.

This retrospective attitude was interesting and indicative of an obstacle to a progressive approach within community organization. He focused on an idealistic view of the past which tended to demoralize current state of affairs and provided barriers to forwardthinking strategic planning. Two areas that Lorenzo focused on were community cohesion and agriculture based economy. These two concepts seem to be steadfast within Villa Sandino and reflected in other interviews in this study as well the rest the conversation with Lorenzo. The economy at the time of this study was still based on agriculture with many successful individuals in this industry. In addition, the community still enjoyed a tight social bond. However, it appeared that the external atmosphere has 
shifted and the internal environment of Villa Sandino has been slow to transition and therefore by comparison has been affected negatively by this global shift.

Lorenzo did eventually relay both positive and negative characteristics of the current state of his town when asked to provide details about the present community atmosphere. He felt optimistic about the quality and reputation about the products yielded by the agricultural sector.

Our strength is in our industry. We are known for our dairy products and we are very proud of that. They say Chontales is where 'the rivers are filled with milk and the rocks are made of cheese' (local saying). We are known nationally and some of our products are even exported to other countries like the United States.

However, he also recognized that this market has not been capitalized on to a degree that created enough financial benefits for the entire community. Lorenzo imparted his reflections on the shift that he has observed within the local economy.

But it just doesn't seem like enough anymore. Some families, the owners of the farms, are very well off, but there are only so many other jobs that come from this industry and only some people in the community can make money off of this, if they aren't land owners. Before many people owned farms and were selfsustained. Now there are fewer owners, with more land each, so there are fewer people benefitting fully.

Local economic power had become consolidated into a small sect of wealthy land owners and a larger population of community members dependent on a limited number of small income generating positions offered by these amalgamated farms. The transition of property ownership and wealth distribution appeared to be an underlying factor in the current economic conditions and financial capital of the community.

Lorenzo also had a discouraging perspective of the resolve and motivation of many of the community members. He believed that a lack of purpose, combined with a changing economic state, created internal fractures and jealousy within members of the 
community. He still perceived a tight social network as an attribute that the small, rural town possessed but he also observed a changing interpersonal ecosystem that negatively affected community solidarity and resilience.

One of the changes that I have seen is the way we treat each other. Before you could count on your neighbor. Now there is more of a sense of jealousy between people, but really only those that have success. So what I mean is, if someone is struggling, their neighbor will help them out. They will give them food, help them fix their house, watch their children. But if that same neighbor starts to become successful, opens a business or starts earning more money somehow...then that same neighbor will try to sabotage them. They will not shop at their store, in fact they will go to a store in the next town just to make sure that persons business does not succeed. It's like they wish to stay at status quo. No one suffers too much, but no one gains to much success either.

This insight by Lorenzo helped explain how Villa Sandino enjoyed a high level of bonding social capital but also struggled to progress and advance in social and economic areas. Maintaining the status quo was significant to the exploration of community organizing and planning and was an underlying assumption in his discussion on development initiatives within Villa Sandino.

\section{Community Development}

Lorenzo concentrated on expanding economic opportunities and undertaking infrastructure projects as a main area of focus when speaking about community development initiatives he believed were vital for Villa Sandino. He was optimistic about the possibilities of connecting agencies in other areas throughout Nicaragua to create regional and national networks for enhanced distribution of locally produced commodities and increased opportunities for the expansion of the local agricultural industry. He believed that the heart of the economy of Villa Sandino remained in the dairy farms and cattle ranching sectors and focused on the expansion of this established market rather than a diversification strategy. 
The way we will benefit the most is to create strong partnerships throughout the country. In Leon, I have helped make a connection with a company that makes different types of cheeses and we are now delivering 10 times more milk products to this area than before. Creating more partnerships like this will bring more opportunities locally.

Lorenzo is proposing a focus on the development of bridging social capital to support the homogenous economic landscape of the community by suggesting the expansion of external connections Lorenzo also noted that the power and control in the agricultural industry was concentrated within a few families, so the isolated expansion of this industry could cause even greater wealth gaps and deepen the fragmentation of community power. However, he felt increasing bridging capital could lead to diversification through the introduction of distinct and different points of view and ideas, an injection of parallel opportunities, and opportunities to gain new and valuable relationships on the individual level.

Lorenzo also cited built capital as a main area of development in the town. He focused on this capital type as a driving force for developing workforce opportunities as well as keeping pace with other communities and modernizing the internal infrastructure in attempts to become liberated from sluggish progress and a diffident community mindset.

One of our focuses, well for the projects that I have worked with anyways, is improving our existing structures and building new systems, roads, buildings to support the community. This is helpful because it employs people for a while and builds our community. We just repaved our main road and added on to the Town Hall, built a new stadium for events, and are talking about investing in new piping for the water distribution. It is important to maintain our existing structures and progress through new, modern construction. 
This type of development could create local employment opportunities but these jobs would be temporary so would have little to contribute to lasting, sustainable workforce development.

Lorenzo spoke about projects that were unsuccessful within his tenure such as the development of an archeological park to highlight a group of petroglyphs discovered over ten years ago in the surrounding rural area. This discovery created an initial interest within the community and garnered support from a Japanese NGO that funded the development effort. Lorenzo cited disorganized planning, ineffectual communication with the foreign collaborators, and infighting between project organizers for the stalled progress.

The archeological park is an example of a project that had unanimous support but still could not succeed. This was a huge discovery and was meaningful to our community. After the discovery, a Japanese NGO sent archeologists to view the petroglyphs. They were very interested and worked with us to fund more exploration and help create an area that would preserve the artifacts while allowing tourists to view them. This would have added a tourism flow to our community. We started training tour guides and building restrooms and paths throughout the park. Everyone was excited, but when success did not happen immediately people stopped investing their time. The owner of the land wouldn't allow us to buy the areas of interest and halted development. The guides stopped training. Eventually the park became overcome with weeds and the progress we made disappeared.......The NGO was frustrated with our management and decided to stop their interests in the area. It is still there, and every now and then we still talk about it, but it's just a fairy tale at this point. The commitment to the long-term was not there.

This example illustrated a lack of ability to collaborate effectively with outside entities.

The other leaders echoed a similar sentiment when they spoke of projects initiated in cooperation with external agencies that were never finished or came to fruition because of competing objectives, ineffective communication, and a lack of ability to work collectively. This example also demonstrates a short-term mindset in the community. 
The inability to create lasting motivation and support on a long-term basis was a chronic issue that weakened the resolve of individual community members and created a reactionary rather than strategic and goal oriented atmosphere.

Political infighting was another challenging issue that Lorenzo touched on as an underlying barrier to all development initiatives. The reality that the local political influence conflicts with the national level power created tensions within the community political capital. Lorenzo shared that he represented the national interests and often conveyed opposing views to the local objectives.

It's important that I am involved in planning, that someone that represents the national interests is involved. If it was left to the local government, they would go in an opposite direction as what our nation wants. But it's difficult. It's difficult to agree and to find projects that fits both our goals or at least to find a compromise.

The atmosphere of divergent political landscapes between the community and national level has created development challenges for Villa Sandino. Conversations and discussions often became paralyzed due to an inability to find a middle ground and a nascent capacitation for appropriate mediation and facilitation between parties. However, the inclusion of viewpoints from both political parties created a more equitable approach that could garner a more sustainable outcome and avoid marginalization of certain community segments based on political stances.

\section{Community and Migration}

Lorenzo observed a range of migratory patterns during his lifetime in Villa Sandino beginning with the era of the revolution and the violence that ensued during this period. There was a flux of immigration out of Nicaragua based on refugee status because 
of the tenuous state of affairs. The United States accepted a certain faction of these refugees.

...during that time \{revolution\} many people were accepted by the United States and they relocated there until the end of the war. Some came back after the conflict ended and others stayed and made their lives over there. That was really the beginning of this type of immigration...I mean immigration to the United States at least.

This initial refugee population was able to become permanent residents and subsequently pursue U.S. citizenship. This humanitarian migration created a base for subsequent familial related migration as these refugees were able to petition for family members in Nicaragua once they obtained their permanent, legal status.

He noted similar immigration patterns as Jennifer and Gustavo, citing Costa Rica as a large draw for temporary out-migration and the United States and Spain as the most prominent areas for long-term and permanent immigration for Villa Sandino natives when discussing the effects of the current migration patterns on the community of Villa Sandino. Lorenzo focused on the potential for immigrants to become ambassadors for Nicaragua within their host country.

Those that live in the United States are still Nicaraguan. It is their duty to share the Nicaraguan culture and represent our country in a positive way.

This is the only mention of how immigrants can have important influence within the country where the immigrate to rather than a sole focus on how they can transfer positive remittances back to Nicaragua. This dual, bi-directional relationship placed the immigrant in a complex role of maintaining and representing the interests of their native country while becoming an integrated member within their new community. These expectations placed a great deal of power with the immigrant, but also created tension and pressure on the individual during an already stressful transition. This approach many 
not have a direct community impact but it could have a more macro level, diplomatic effect by creating potential bridges between countries and opening dialogues that could be beneficial at both national and local levels within Nicaragua.

Lorenzo also focused on the loss of human capital that emigration from Villa Sandino has caused. He mentioned that some of the prominent and most educated members of the community left for better opportunities. This has had a draining effect on Villa Sandino and he worries that the trend will continue.

I am always happy when someone gets to take advantage of a better life. We have had several high level employees from the local government and other organizations leave to go to the United States and Costa Rica. We have lost some good role models to migration, some individuals with vision and aptitude, that is hard, it's hard to replace them.

Lorenzo acknowledged that migration patterns often lead to a loss of human capital within Villa Sandino. He observed that those who tend to migrate to the United States, or other countries, were some of the more skilled residents. He also used the term role model, recognizing that the loss of this human capital had a lasting effect on the younger generation. The local youth would likely have less direction and guidance to reach a successful and fulfilling future without a strong pool of community members to act as counsel. Migration had a generational effect and without activating a platform that generated a return, or brain gain, the community will likely continue to experience a deficit of human capital and well trained, driven leaders and professionals.

\section{Emigrant engagement in Community of Origin}

Lorenzo was asked him to describe some ways that immigrants were able to maintain meaningful connections with Villa Sandino after leaving.

Those that do not have documentation can only stay in contact by WhatsApp or phone calls, but most people that leave with legal status come back to our town 
often. It is a special community and they like to return for events or special community festivals to spend here with their friends and family. When they return they often share about their experiences and people are always interested in hearing what life is like in the U.S. Also it allows them to remember our struggles and help where they can.

Return trips have been important for maintaining a sense of connectedness and create a physical space for communication and sharing of norms and values. These exchange generated an environment where social remittances could be transferred from migrant to community. Through discussions and conversations, immigrants were able to challenge engrained norms and transfer values and beliefs that have been developed through integration into their receiving communities, such as gender equality, democracy, professionalism, and other societal concepts. Conversely, by returning to Villa Sandino for regular visits, the immigrants stayed integrated into community life and were present minded about the development challenges. They were able to observe areas in need of intervention and will be more likely to respond positively to solicitations for expanded involvement in community endeavors by comparing and contrasting their lives and experiences in both sending and receiving countries.

Lorenzo noted that financial support was one of the primary avenues that immigrants could positively engage with the community, but establishing this financially based relationship has not been successful.

Those living in the United States are more secure...financially. They can help their community by investing in projects, but it is has been difficult to get their investments. I'm not sure if it is a lack of interest or just a lack of knowing what we are planning or how to contribute, but they usually send money to their family but not as often do they send money for community projects.

Obstacles to financial engagement at the community level emerged from both the immigrant and leadership points of view. Lorenzo shared his outlook from the 
perspective as a project consultant on the potential impact that financial remittances could produce, but lacked insight into some of the underlying issues that the immigrants have shared such as issues with a lack of trust of the local government to handle funds and manage programs effectively. Lorenzo pointed out a significant barrier to this type of exchange by speaking about a lack of interest by the immigrant community as well as the complementary issue of a lack of inclusion of this group by community organizers. This issue could be a symptom of weak immigrant engagement strategies by the local community. Villa Sandino might be able to create a more inclusive and active emigrant population and foster an atmosphere conducive for financial investments by creating a plan to actively engage with emigrant communities abroad.

\section{Summary}

The insights of these community leaders provided a baseline understanding of community level dynamics and explored the relationship between migration and community well-being. There were only three leaders included in this study as their purpose was to provide a general context. However, this small sample does not provide a broader exploration of the local level atmosphere. For future research, it would be beneficial to include a larger, diverse sample of individuals, migrant and non-migrant households, and other leaders to delve deeper into the effects of transnationalism on Villa Sandino at all levels.

The community capitals framework was used to summarize the information garnered from these interviewees. This framework lays out an approach to sustainable community development that includes seven types of capital: natural, cultural, human, social, political, financial and built (Flora \& Flora, 2008). These capitals, along with their 
intertwined relationships, were weaved throughout the conversations with community leaders. The leaders expressed weaknesses in built and human capital and cited a lack of financial capital as well as resources and institutions to support the development of human capital and investment in needed infrastructure.

There was a clear emphasis on the importance of social capital within the community. The leaders shared that the most successful community projects focused on the creation of built capital that supported social capital and community events, such as the bull stadium and sports court. Natural capital was also cited as a fundamental foundation to support social capital and maintain the important bonding networks that were indicative of a strong sense of belonging amongst community members. Natural environment was a point of pride and central focus for social interactions, such as trips to the river and excursions to the farm. This type of capital was also a basis for the economic health of the community, as the local economy was based on the agriculture industry. Little investment or focus on natural capital when speaking of development objectives even though natural capital is crucial to sustain the social and economic components of the town. Political capital was mentioned several times as a point of contention and weakness at the local level. The local and national governments were controlled by opposing parties and created paralysis in terms of efforts in strategic planning and the negotiation of budgets. This relationship also created a perception of mismanagement which propagated mistrust in projects handled by the local government agencies.

Migration was mentioned as having both a potential for harm and benefit when it came to community capital development. The act of emigration was perceived as a drain of human capital at the local level. The overall observations indicated that there was a 
greater level of brain drain than reciprocated brain gain, but they also communicated an optimistic outlook on the potential of recapturing this human capital. Cultural, natural, and social capital were presented as key connectors between the community of Villa Sandino and the emigrant population. The leaders indicated that the most beneficial areas of engagement by the emigrant population would be in the financial and human capital stratospheres. Technology created a consistent connection between emigrants and community households and physical return trips were also mentioned as important components of maintained relationships. The leaders believed these two relational spaces could be better developed to create more community level connections and engage the emigrant populations into the development efforts that are crucial for the future of Villa Sandino. 


\section{Chapter 5: Cross-Case Analysis}

\section{Introduction}

This chapter will present a temporal cross-case analysis of the ten case studies examined in chapter four. The cross-case analysis supplements the individual themes uncovered in the with-in case analysis and adds a temporal dimension to the exploration of the entrepreneurial journey and transnationalism engagement stories of the Nicaraguan immigrants. This type of analysis will allow for the examination of similarities and differences across cases by comparing and contrasting information among the experiences and perspectives of the immigrant entrepreneurs (Yin, 2009). Cross-case analysis allows for the categorization of dimensions to explore in-group similarities as well as intergroup differences (Eisenhardt, 1989).

Cross-case analysis can be used to help delineate the combination of elements that contribute to a certain outcome and construct a reason that explains the differences and similarities between cases (Khan \& VanWynsberghe, 2008). A temporal approach will be utilized to explore their immigration, entrepreneurial, and transnational experiences. The analysis will utilize four sequential periods within the journey of the immigrants. These periods will be categorized as 1) pre-immigration, 2) initial integration, 3) preentrepreneurial endeavor, 4) entrepreneurship start-up to present. Sub-themes have been analyzed that contribute to the unique conditions that incubated as well as hindered the integration and entrepreneurial encounters of the immigrants and add another layer of understanding to the emergence and development of transnational activities during the different stages of their transition to life in the United States. 


\section{1 Pre-Immigration and Immigration Experience}

The focus of the conversations did not center around the lives of the immigrants before migrating to the US. However, there were discussions related to the context of departure and the overall impressions and sentiment towards their home community that add a valuable perspective on the juxtaposition of the pre-and post-immigration life of the participants. Presenting a general overview of the experiences of the immigrants within their home community and country is beneficial because the study focuses on capturing the immigration, entrepreneurial, and transnational experiences of immigrants from one specific community that have migrated to the United States and started a business. The immigrant entrepreneurs that participated in this study all originate from the community of Villa Sandino, Nicaragua.

Space (Physical and Personal): One common theme that emerged from the conversations was the concept of space. This was particularly interesting because space was discussed in both an environmental and communal context and demonstrated a clear difference between the home and host community experiences. When describing their experience growing up in Villa Sandino, the participants commonly referred to the wideopen spaces, time spent on the farm with animals, and the connection to the land through daily chores and responsibilities. Individuals either lived on the farm or lived in the town but had a connection to a farm through ownership or family associations. Kristen, Fabricio, Rosa, and Camden grew up in the 'campo', meaning rural areas surrounding the town of Villa Sandino. Their livelihoods were directly rooted in raising cattle on farmland and they were separated by the town center by a 30-60 minute horse ride. This 
reliance on the land and physical space that was created by their lack of proximity to other dwellings was instrumental in their upbringing.

I lived about a 35 minute horse ride to town. By mom and dad, aunt uncle, cousins and siblings lived on the farm and helped with the daily chores, moving the cattle, and milking the cows twice a day. We went into town about once a week to go to stores, visit friends and family, sometimes go to important meetings or church. But a lot of our time was spent out on the farm, entertaining ourselves and helping prepare food and take care of the land. [Kristen]

The other interviewees, Patricia, Walter, Rogelio, Elias, Moses and Rachel, lived in the town of Villa Sandino, but also referenced their unique connection with the physical space and the land through connections to the agricultural industry. Because the agriculture and cattle industries are the economic base for this region, most families own farmland or make their living as a farmhand or as an employee to a farm owner.

The physical environment also provided community members with prominent leisure activities apart from the clear employment based reliance on the land.

We loved getting up early, usually around 3:30 or 4am and would ride out to the farm with our dad. We would bring pinolillo [a corn based powder] and we would milk the cow and mix it in and have a nice fresh drink. Then dad would milk the rest of the herd, he was so quick, and we would play around the farm with the other animals or just relax in the peaceful setting.[Patricia]

The interviewees also mentioned trips to the river as the most common activity to spend free time and to celebrate special events. The town is surrounded by various river systems and these areas serve as a popular destination for town members to commune, bring food and drinks, and spend time cooling off while enjoying time spent together outside of the town.

We always go to the river. Pack a cooler with some beers and rum and some food to prepare there and spend all day swimming, playing cards, eating and drinking. It's a popular spot so I get to see a lot of friends. This is something I miss from living in Nicaragua so when we go back we make sure we go to the river as much as possible. [Fabricio] 
Use of distance and expansiveness to define space was common in the description of the physical environment, but contrasted the reality of space on the communal level. The immigrants interviewed consistently referenced the closeness of community relationships and the lack of personal space in their home community. Homes in the community were described as small with a few rooms, typically an inside or outside kitchen area, a living area, and one or two bedrooms. The parents and smallest children usually slept in one area and the rest of the children and other family members shared another room. Individuals did not have a lot of private space or personal possessions within their homes and most items were considered communal or shared amongst the family. The neighborhood atmosphere was also very open and collective in nature. It was common to walk through the streets and see most doors open and individuals sitting on the porch open to conversation and interaction. A typical errand to visit the health center, or to run an errand to buy a household item, or to attend a meeting typically was intermingled with multiple stops at community member's homes to share greetings and talk about recent town events or gossip.

The commonality of interviewees experiences around the ample physical space and scarcity of personal space, resulted in increased communal intimacy and familial connection, was a main point of difference in their post immigration experience. The concept of space was described in an opposite manner when discussing their experiences in their receiving communities. The Nicaraguan immigrants consistently mentioned the lack of physical space in their receiving communities, San Francisco and Miami, and a clear distance between the community members within their new neighborhoods. 
In La Villa everyone keeps their front door opens and people are sitting on their front porch. You can't walk a few blocks without stopping two or three times to talk to someone. But in Miami, the doors are closed of course and people are working or are inside with the door shut. I walked straight to the store without even saying hello to anyone. That was a strange feeling. [Kristen]

Rachel also shared this sentiment regarding the contrast she felt relating to the openness of community relationships Villa Sandino compared to San Francisco.

... in Villa Sandino it was a tiny community and everyone always had their doors open and ready for a visit. Here [San Francisco] it feels more closed off. I don't know my neighbors very well. [Rachel]

This distance between neighbors created integration challenges for many of these individuals that were accustomed to a very attached and open community. The immigrants encountered busy, crowded physical spaces. Two areas of settlement were large cities, defined as densely populated areas. The immigrant participants found the presence of so many people in such a small space, contrasted with an atmosphere depicted by larger personal space constraints and less public interaction, as an unfamiliar environment that led to an initial isolation.

The environment was a central characteristic in both the labor and leisure parts of these individuals lives in their hometown of Villa Sandino. The Nicaraguan immigrants did not find the same experience of reliance on the environment for their employment integration into their new communities but did continue to seek open physical spaces and a connection with nature for their pastimes. Camden and Walter shared that they spend their free time fishing with friends and family. Kristen, Rogelio, Fabricio, and Moses described spending their weekends by taking family trips to nearby beaches, where they could spend time outdoors with a small budget. Most of the interviewees identified spending time in nearby parks as a way they are able to find peace and a safe space to 
bring family and friends together in an easy and efficient way. It is clear that these individuals sought ways to maintain their connection to natural spaces, a connection that was influential in their pre-immigration stories.

Diverse range of age and travel history at time of migration: Beyond the shared element of physical and communal space, the pre-immigration experiences of this immigrant group differed due to their age at time of immigration and the nature of migratory movements prior to permanent immigration to the United States. Some of the participants had visited the United States as tourists for vacation, to visit family, or as part of their employment on various occasions before making the decision to immigrate. Rogelio worked at a tractor parts manufacturer and was sent to Miami on two prior occasions before permanently moving to the area after separating from his company. Fabricio, Camden, Elias, and Rachel also previously visited the United States on tourist visas to visit family members already residing in the area. Tourist visas were easier to get, and were given for longer periods of time, before September 11, 2001. Tourist visas were regularly given for a period of 10 years prior to enhanced security measures taken after the 9/11 terrorist attacks, allowing families to come and go to the United States without man legal barriers. However, the current visa situation requires more red tape, evidence of a planned return to the country, and a time limit of a maximum of 3-month travel within a 6-month period. This requires families to ask permission every time they hope to travel, creating more barriers to consistent back and forth tourist travel. The other immigrant participants had not made previous trips to the United States prior to immigration, they made their permanent move with no previous interactions with the American culture and limited awareness of what their new life would entail. 
Some of the individuals that migrated to the United States later in life had previous internal and external migration experiences. Rogelio, Camden, and Elias had moved to the capital city of Managua to pursue education and employment opportunities and did not migrate directly from their home town of Villa Sandino. They had a transitional migratory experience. Camden also had previously moved to Costa Rica for a period of three years to engage in the labor force before moving back to Managua after his wife gave birth to his son. Having previous migration experiences played a role in preparing these individuals for the permanent move to the United States while the other interviewees made the transition with no previous familiarity with the strains and processes of migratory behaviors. For instance, Fabricio and Patricia immigrated during their teenage years. Their pre-immigration experience was limited to that of a youth, primarily centered around primary and secondary education and reliant on family as a structure of support and sustenance. They did not enter the labor force before moving to the United States and made the transition to their host community during the formative years of their lives. This differed from others that migrated later in life.

\subsection{Initial Integration}

The age of the individuals at the time of initial immigration to the United States ranged from 14 to 30 years of age. The most prominent was the focus on family relationships supporting the ability for the individuals to immigrate as well as their providing their primary integration support system. The focus on employment as the primary goal and future aspirations indicated that economic integration took priority over social assimilation. Language also emerged as an initial obstacle to integration and was an area that many immigrants focused on as a strategy for enhanced social and 
economic integration. A notable difference in the initial immigration experience was evident between the immigrants settling in Miami and those residing in San Francisco. This difference was illustrated through a tendency towards secondary migration amongst the individuals that ended up in California versus a singular migratory pattern for those in Florida. The themes that emerged during this segment of time were; family-based migration, reliance on family and religion for initial integration, focus on employment, language acquisition, and secondary migration.

Family based immigration. An interesting and significant similarity among the immigrants is the use of family connections to lawfully immigrate to the United States. Some initially came over undocumented and later adjusted their status to permanent resident and others waited in Nicaragua until they were granted a visa prior to travel. All but one individual relied on a family connection to initiate the immigration process. Moses was the lone outlier in this pattern, as he was granted humanitarian status during the civil unrest in Nicaragua in the 1980s. He was able to come over and gain a special status as an asylee, which allowed him to adjust his status to a permanent resident and eventually became a United States Citizen (USC). The rest of the immigrants utilized a connection with a family member, such as a brother or sister, a parent, and marriage to a USC spouse, to start their immigration process.

Kristen, Rogelio, and Fabricio originally came to the United States on tourist visas that allotted a three month stay. They overstayed their visas in order to stay with family members and began working as undocumented immigrants. All three were subsequently able to use a family connection to gain lawful documents. Fabricio and Kristen had siblings that had already immigrated lawfully, which allowed them to 
petition for their brother and sister to become lawful permanent residents (LPRs). Five years after becoming a permanent resident the individuals were able to start the naturalization process to become U.S. Citizens. Kristen became a citizen and was then able to petition for her spouse, Rogelio. Rachel and Walter both married a USC that allowed them to transition to permanent resident status expeditiously. Walter and his wife went through the process in Nicaragua prior to moving to the United States. Rachel initially came to the United States on a temporary, non-immigrant visa, which allowed her to reside in Colorado while maintaining status as a university student. She would have had to return to Nicaragua after completion of her degree, however she met and married a USC during her stay which allowed her to become a legal permanent resident (LPR). The remaining immigrants pursued their immigrant visa while residing in Nicaragua and did not immigrate until they had the appropriate documentation. Patricia and Elias were children of parents that were granted immigrant visas and because they were under 21 years of age at the time the visa was granted, they were able to join their families as permanent residents. Each had siblings that were over the age of 21 at the time of immigration and that were forced to stay in Nicaragua because they were not eligible to receive a derivative status from their parents. This created fractured families. Camden and Rosa were petitioned for by USC siblings and waited in Nicaragua until their priority dates became available for their visas. The process for petitioning for a family member that is not a spouse of a USC can take many years. Many Nicaraguans pursue immigration as brothers or sisters of a USC. This means the immigrants have to wait until their siblings living in the United States are able to naturalize to become USCs, after which they can petition for their brother or sister in Nicaragua. The Nicaraguan 
relative must then wait until their priority date becomes current according to the Visa Bulleting published monthly by the Department of State (DOS) (Visa Bulletin for December 2017, n.d.). This process can take years of waiting. Elias shared that it took his family almost 20 years to be granted an immigrant visa and Camden waited 13 years to be able to immigrate, with the appropriate documentation, with his wife and child.

This overview demonstrates the various manners in which individuals can legally immigrate to the United States through familial relationships. It is clear that these Nicaraguan Citizens relied heavily on family based immigration as well as the humanitarian assistance programs that were available during times of crisis. A noteworthy observation is that none of the immigrants in this study were able to utilize labor-based immigration avenues to move to the United States. This is significant as immigration policy discussions are shifting focus from family-based immigration to a merit-based system relying high-paying job offers, English language skills and education to select the most qualified individuals to provide immigrant visas (Center, A. I., n.d.). This shift in policy could have a dramatic effect on the Nicaraguan immigrant landscape and the ability for these individuals to find a path to lawful immigration to the United States in the future.

Reliance on family and religion for initial integration. Family relationships were important to initial integration of the immigrants into their receiving communities in addition to the support they provided to the immigration process. The interviewees shared that they initially lived in the homes of a relative upon arriving in the United States. The decision to settle in a specific city was determined by the familial connections that were available to provide support. They were able to gain shelter and 
basic support from these family members while they were attempting to find employment and gain independence. Many of the participants relayed a sense of initial isolation and relied heavily on family as their primary social incorporation and connection to the external community. The sentiment of the immigrants ranged from a sense of remoteness and loneliness to a feeling of comfort and familiarity. However, the initial dependence on family was a unifying tie throughout the interviews.

Religious based interactions proved to be a secondary incorporation strategy that was utilized by this group. Many discussed finding a local church as their first connection to a community institution outside the confines of their home base. This connection allowed the individuals access to an expanded social network and promoted community involvement through volunteer work and participation in church related activities.

I went to church with my parents. Besides church, the only people I knew at first were my family. In church I met a few more friends my age. I actually found my first job through a friend I met at church. He connected me to a temporary position with the company where he worked. [Elias]

Well, the first job that I found was through the Catholic Church. I went to church every Sunday, just like I did in Nicaragua, I remember there were some programs through the church where they offered employment opportunities, different types of jobs for people that were permanent residents here in the United States and that still didn't have a job. There were opportunities, for example, in construction, painting, childcare, senior care, and many other things.[Rosa]

Rogelio also discussed how his involvement in church functions transitioned from being merely a participant to taking an active role in a related nonprofit that eventually led to the creating of a transnational bridge between his receiving community and his community of origin, in which he served as the main liaison and connector.

I am very active in the program Nueva Vida that works with our church........I have worked with people from this project [Nueva Vida] that go to Nicaragua and do the same type of work. Helping the most poor. I helped them contact our church in Villa Sandino and they spent time there working with providing food for 
people in the church and the schools. That's the best way I can help. I trust Nueva Vida, I know they are good people and I trust my church in Villa Sandino to work with them to provide beneficial services to my community. [Rogelio]

Religious based organizations, including local churches and associated programs, were a primary community gatekeeper that provided a secure and welcoming environment for these newly arriving immigrants and also provided connections to outside resources, assistance, and opportunities.

Focus on employment. It was evident that the primary objective of these Nicaraguan immigrants was to achieve economic integration and the social dimension was less influential in their initial decisions and actions. The interviewees consistently discussed gaining employment as their primary aspiration upon arriving in the United States. Creating social connections was secondary to being able to support oneself financially. Many of the immigrants noted working extremely long hours during their first years in the United States, leaving little time for other community or social activities.

Camden shared, My first goal was to find a job and work, work, work.

Similarly, Rogelio relayed a comparable sentiment. I didn't feel settled until I got my first job, that's when I started to get more comfortable in my new surroundings.

In fact, this was a unifying attitude shared by most of the respondents. Economic integration was the primary focus and catalyst to a feeling of acceptance, stability, and immersion into their receiving communities.

It was interesting to realize that the true purpose of their immigrant was labor based and economic, although the prevalence of family-based immigration amongst these individuals indicated a primary goal of family reunification. The interviewees noted that 
they did not feel like they were truly settled and secure until they obtained their first job and that securing gainful employment was their primary motivation. The intensity of this sentiment correlated with an underlying strategy of proposed return migration. The individuals that migrated with the sole purpose of labor-related activities, instead of a mix of labor and socially constructed reasons, indicated that they believed they would return Nicaragua after a few years of working and saving. Most individuals changed their strategies after they became established and planned to stay until at least retirement before making a permanent transition back. Rogelio and Kristen, a married couple, both expressed an initial plan to return to Nicaragua after 2-3 years of working and saving, but now have decided to extend their return migration until their children are grown.

I initially planned on going back with Kristen after she came over to visit. But then instead she decided to stay and found employment in Miami as well. Again, we thought we'd stay 2 or 3 or 4 years and then go back, but the education and opportunities are so much better for our children that we will stay until they are older. Maybe when we are around 50 we will go back and retire in Nicaragua. [Rogelio]

This shift in perspective typically related to their ability to start their own business and become more socially integrated into their communities denoting the significance of both economic and social integration in creating a sense of incorporation and inclusion that culminated in an attachment and commitment to the receiving community.

Language Acquisition: Another unifying characteristic of the integration experience for this group was language as a both a barrier as well as a path to integration. Most of the immigrants shared that they had little or no English language ability when arriving to the United States. Rachel was able to obtain language training in Nicaragua prior to immigrating which allowed her to attend university, but she still indicated that her lack of complete fluency created challenges for her with the English-based 
curriculum. The other individuals had extremely limited English language ability and noted that this created a sense of isolation and a fear that made it difficult to explore their new surroundings and create new connections.

I didn't know hardly any English when I arrived. That was the hardest part, I was stuck in my Uncle's house and didn't feel comfortable leaving to explore. It felt like I was in prison.[Elias]

The lack of language ability influenced their options in regards to the employment opportunities that they were able to secure. They typically obtained employment through an initial social connection and typically worked with other immigrants, primarily Latino immigrants, where English language ability was not a requirement. Many of the immigrants were lawfully documented when they obtained their first job but they were treated similarly to undocumented workers and ended up with employment that did not require a valid immigration status. It appeared that the lack of English language ability was related to an assumption of low-skill sets and lack of immigration status, creating a limited scope of entry into the labor force.

Yeah, the only job I could find at first was in the restaurants. I was a dishwasher and cleaner. The people I worked with didn't have papers and it was frustrating because I assumed by immigrating legally I'd be able to get better employment, but it was hard at first. I think I was judged because I couldn't speak much English, people just assumed I was undocumented or didn't have any skills.[Walter]

English language acquisition was therefore a primary strategy for economic as well as social integration. The interviewees shared that they attended community colleges and community-led immigrant integration assistance programs to enhance their language ability with the hopes of creating more economic opportunities and producing a stronger level of confidence to be able to navigate their daily community level interactions. Access to language assistance programs was readily available and well publicized 
throughout the communities where these individuals initially settled. They were able to find programs with little or no cost that were within a close proximity to their homes. These programs allowed these individuals to meet other immigrants in similar situations and expanded their social networks both within the Latino population as well as with other nationality groups. These relationships were built on mutual understanding and an empathetic perspective. They created a sense of an equal power dynamic that was essential to building trust and creating a supportive network. The immigrants were able to collaborate as they sought community resources and secured enhanced employment as well as provided each other emotional support during the difficult transitional time. The English language centers also served as connecting institutions to other community assistance programs. Walter was able to find a better job through an employment assistance program connected to the English language program that he was attending.

Luckily, the institute where I took my English classes also had a connection to a group that helped immigrants find jobs in the area. I met with the coordinator, created a resume with him, and then he took me on a few interviews. Then I got a job at the local hospital. Better hours, better pay, and a job doing something I liked. A lot of my friends in the English class got jobs through this program too, mostly in hotels, but I was lucky to get a better position as a laboratory technician. That was great.[Walter]

These programs were critical for providing immigrants with the opportunity to enhance their language skill set but also served as bridges to other institutions and organizations throughout the community. They were a key connector and could be leveraged to reach this vulnerable group and provide valuable opportunities, including entrepreneurial development services.

Secondary Migration: Another attribute amongst the group was the prevalence of a secondary migration by the individuals that ultimately settled in the San Francisco area. 
This pattern is contrasted with the fact that the individuals that moved to Miami did not make subsequent moves after their initial immigration. Camden originally moved to San Francisco, but shortly after arrival moved to Miami for $1 \frac{1 / 2}{2}$ years before returning to San Francisco permanently. Patricia immigrated as a teenager to Washington D.C. and later moved to San Francisco with her husband in pursuit of a better employment opportunity. Elias also initially immigrated with his parents and settled in Los Angeles. After he became independent he moved to San Francisco to pursue joint interests with his USC wife. Rachel originally lived in Colorado to attend university, but moved to San Francisco shortly after graduating so that her husband could accept an employment offer. Finally, Walter immigrated to St. Louis after marrying his USC wife in Nicaragua. They ultimately moved to San Francisco to pursue educational opportunities and stayed in the area after securing employment after his wife obtained her degree. This secondary migration pattern is noteworthy as it necessitated two separate integration attempts by the immigrant participants. The first was a willingness and prevalence to move a second time that demonstrated these individuals had a level of confidence to take on the challenges of creating social networks, gaining employment, and navigating a new community multiple times. The individuals that ultimately settled in San Francisco also showed a proclivity towards creating networks outside of Latino ethnic enclaves. They displayed an inclination to value external connections and leverage these diverse associations in both their economic and social landscape. The individuals living in Miami tended to live within Latino communities and took a longer time learn English and adjust to nonfamiliar customs and traditions. 


\subsection{Pre-Entrepreneurial Endeavor}

A commonality in the stories of these Nicaraguan immigrants was that there was typically a significant amount of time between their initial immigration and their decision to pursue an entrepreneurial endeavor. Observing common themes amongst this group during this time is significant in determining what factors supported transition into that of an entrepreneur. These years were formative in developing relationships and skills that created an atmosphere conducive for these individuals to take the risks necessary for the creation of self-sufficient business. Common themes found throughout this period within this immigrant group included: A focus on technical skill development, perceptions of discrimination and community inclusion, emergent independence and autonomy, a complex blend of opportunity and necessity driven motives, frequent communication, return trips, and household remittances. Observing the transnational actions during this time is also beneficial to examine the evolution of transnational engagement and contrast the activities and relationships between the immigrant and their community of origin before and after the entrepreneurial endeavor.

Technical Skill Development Many immigrants with lower levels of education and skillsets tend to find employment in factory level positions or enter into a part of the workforce with very little upward mobility (Sequeira, Carr \& Rasheed, 2009). Some of the individuals in this group had to begin with low-wage, low-skilled jobs but they quickly found ways to leverage their small social network to acquire more meaningful positions or to make moves within their company to ensure they were able to develop pertinent skills and apprentice with the leaders of the organizations. Rogelio described his 
primary objective of securing a position that would allow him to gain a useful skill set and present more opportunities for upward mobility.

My first goal when I arrived was to find work, people recommended that I learn a trade, that I should not go to work in a factory, because I would not have a chance to grow or achieve a better job ever. Or in other words, I might start off making $\$ 1$ more an hour but I wouldn't have the chance to be my own boss, have your own business, I would never have the opportunity to know more people or learn much, that it would be limiting. [Rogelio]

Patricia able to develop competence in the restaurant business by assisting her mother in the restaurant where she worked and gained insider expertise by spending time with the owners observing the backend and financial components of the establishment. She later leveraged these skills to open her own restaurant. Similarly, Rosa spent many years working in childcare and senior care positions but ultimately sought out employment in a restaurant to develop the knowledge base necessary to eventually open her own foodservice business. She made it a point to gather information from the different elements of the business structure and created a strong relationship with the manger that allowed her to assist with job duties that were not directly part of her responsibilities. She was able to eventually open her own catering company with a robust base of knowledge and the skills that helped her avoid many potential obstacles and make successful decisions from the commencement.

Working at the fritang a was important so that I could learn the business before starting my catering service.... This helped me learn more facets of the business. I knew I would open my own business one day and had faith that it would be successful, but it was important for me to learn as much as possible first. Remember, I had no experience in this type of business so I had a lot of learning to do.[Patricia]

This strategic mindset allowed these individuals to work towards a higher level economic position. These individuals had a forward-looking mentality rather than a focus 
on the present. Many of them did not have specific goals of becoming an entrepreneur, but their ability to collect expertise and proficiencies throughout their experiences in the workforce put them in a position to be able to take advantage of the opportunity to become self-sufficient business owners when the opportunity presented itself.

Perceptions of Discrimination and Community Inclusion: Another aspect that relates to the outlook and mindset of this group was their perception of discrimination. Many of the participants described instances that could be categorized as discriminatory in nature, however their overall perception of their integration experience was inclusive and accepting. Judgement and prejudice were weaved throughout their experiences but they did not dwell on this negative treatment, but rather advanced towards their objectives of stability and economic security. Moses described an initial experience upon moving to Miami where he had difficulty finding an apartment because some landlords were hesitant to rent to a refugee and others assumed he was an undocumented immigrant. However, he went on to describe his integration experience as "very inviting and secure”.

Rogelio shared that he was treated unfairly by his first employer and was taken advantage of because of his lack of status.

I worked 12-14 hours a day and never got overtime. There wasn't much I could do because of my status but I left as soon as I could because I felt like I was being exploited. [Rogelio]

He subsequently shared that he felt "welcomed and able to pursue opportunities" that were not offered to him in Nicaragua. He expressed that he felt more encouraged and constructive as a minority in the United States than in his home country. Camden shared similar stories of initial discrimination but offered that the clear laws and regulations of 
the United States created a landscape that he felt was fair and just. The transparency and order provided helped him navigate his new community which helped him maneuver through initial discriminatory practices.

Ifelt that we were all on the same level. If you have a clean and clear background you can achieve the same as anyone else..... one of the fundamental things about living in the United States, for those that are native born or for those that have come like me as residents, one of the fundamentals is that they open their doors in whichever direction, if your background if clear, meaning that you have a clean past. And with this it isn't difficult to achieve whatever you desire.......If you don't break the regulations, rules, laws etc. you can achieve what you want, if you take the other route, you will have problems, but that is the same for everyone in America....I didn't have any problems opening my restaurant, I did everything legally and within the rules and everything went smoothly. [Camden]

The ability to constructively move forward in an atmosphere that is oppressive in nature without dwelling on imbalanced power dynamics and prejudice is an important attribute shared by this group. These individuals realized the external pressures existed, but were able to find mechanisms and tap into an inner-strength that helped them navigate through the negative realities by focusing on the positive and working towards future objectives. They did not see themselves as victims but rather prioritized the fact that they were in a privileged situation and had many opportunities available to them. Elias, Camden, and Fabricio all related the sentiment that they "had to take advantage of the American Dream" and many used the phrase "grateful" and "lucky" to be in this position in the United States. They seemed to contrast their situation with that of their friends and family back in Nicaragua and felt an obligation to take advantage of their position as a part of the American workforce, a situation that was envied by many of the community members from Villa Sandino. 
Emergent Independence and Autonomy: Another attribute that was prevalent amongst this group was a focus on becoming independent. As mentioned during the preimmigration portion of this analysis, the immigrants in this group heavily relied on their family connections during the initial integration experience. They shared a sense of isolation and dependency and felt little autonomy in their own decision making process. They frequently were connected to their first job by a family connection, many times in a field that they had little or no interest in, they had limited language ability and felt insecure leaving their residence to explore their new community or run errands. The first months of the immigration experience was often directed by family members that had a better established sense of their community. The immigrants expressed a gratitude to their family during this time, but also shared that they did not feel in charge of their choices and path at this point. A common word utilized by almost all the participants when asked about their journey was the need to 'independizarse' or to become independent.

Elias focused on developing the ability to move out of his uncle's home and to find an apartment of his own. $\mathrm{H}$ felt 'trapped' relying on his family and having to follow their norms. He wanted a space where he could develop his own identity within this new community. Kristen moved to Miami with a young son and shared that she needed to feel confident in finding medical and educational resources for her child. She initially relied on her aunt and her friends to connect her with community resources and to speak to medical practitioners and school administrators on her behalf. She knew it was important for her to be able to take care of all of her sons needs by herself and be able to be independent in the care of her child and decision making process as a mother. She 
expressed this sentiment as becoming "an independent mother" and being able to "trust myself while taking care of my son's needs in this new place". An essential key to becoming independent for her was to learn to drive and to begin English classes. This allowed her to take her son to appointments and activities and interact with non-Latino community organizations. Moses came to the United States on a humanitarian parole and was offered initial assistance through a refugee resettlement organization. He shared that the assistance was provided for a temporary time of three months after which he was required to become self-sufficient. He spoke about finding a job within the first week of arrival because of the fear of having his support taken away in a short period of time. He had a designated timeline to become economically independent.

Economic independence was the most frequently type of autonomy discussed. The immigrants felt a higher sense of agency and began making calculated decisions to positively affect their futures once they achieved economic independence. They all went through an initial adjustment period, characterized by dependence on a small social network and the lack of ability or proficiency to create strategic plans. During this period of time, they were reliant on the perspectives and recommendations of their trusted community members and family and had a more present minded, survivalist approach to daily decision making. They were not creating an environment of complex, forwardlooking choices but were attempting to create stability and security in their present-day livelihoods. Once this stability was reached, they began the process of becoming independent and their individual agency was heightened. The immigrants were able to build skill sets, forgo opportunities that were not in line with their objectives, and make strategic decisions because of their agency. Their confidence grew and in turn their social 
networks expanded. They became in charge of their future. This process of becoming independent was an essential building block that equipped them to take become an entrepreneur when the opportunity presented itself.

Complex Blend of Opportunity and Necessity Driven Motives: Research has indicated that many Latino-immigrants enter into self-employment due to the inability to gain employment that pays a fair wage (Portes, 1998). They are often categorized as a group of necessity-driven entrepreneurs, indicating that they chose the to open a business because they had no other meaningful option (Portes, Guarnizo, \& Haller, 2002). However, the interviews conducted with this group showed a different perspective. In reality, there is a spectrum between these two reasons for becoming an entrepreneur, very few individuals land strictly in the necessity or opportunity driven categories. Contradictory to the work of Portes and his colleagues, these Nicaraguan entrepreneurs did not tend to pursue entrepreneurship out of necessity-based reasons. Many of the participants had reached a fairly successful level of employment before deciding to start their own business. Entrepreneurship was not pursued during the initial years of entering the workforce but was a strategy undertaken after the immigrants had established themselves economically.

The reasons given for to starting their entrepreneurial endeavors ranged from hoping to have more free time and flexibility to care for children (Kristen, Patricia, and Rachel) to creating more overall freedom to direct their own economic path for many of the others. Walter and Camden created an entrepreneurial business based on a passion that was divergent from their full-time job duties. They did not become entrepreneurs because they had no other option or were purely driven by necessity. On the other hand, 
these individuals did not necessarily intend on becoming entrepreneurs. They did not begin their journey with an entrepreneurial identity, continually searching for a great opportunity. These individuals were able to reach a point of stability in their work and life situations while honing skills that allowed them to take advantage of economic opportunities when they presented themselves. They sought manners in which to develop their professional knowledge base and portfolio and engaged in activities that heightened their confidence and individual agency to the point of being able to take an entrepreneurial risk at a certain point in their lives. It was interesting that many of the participants did not demonstrate an entrepreneurial identity at the time leading up to starting their business.

Well the reasons, like I said, was more or less because, how do I explain?, I was earning enough money where I was but I also had a relationship with enough clients to start out on my own. It wasn't a situation where I decided I wanted to start my own business, it just happened little by little. You understand? I didn't feel comfortable working for someone else, especially because there were jealousy issues and because I had my own clients, so I decided it was best to work for myself at that point....I was basically pulled into my business start-up, it wasn't really an active choice. [Rogelio]

Frequent Communication All participants shared that communication with family and friends upon immigrating to their host communities was an important part of their adjustment. The frequency of communication tended to continue in a stable manner throughout their time in the United States and in many cases advancements in technology allowed for more meaningful and regular connections with their hometown. Kristen shared how difficult it was to reach her family when she initially immigrated and described how the advancement of technology in general along with the expansion of communication services in her hometown as created a tighter more unified connection with her family. 
Well, now it's better than before because of Whatsapp. Before, I remember when I came, also my mother used to live more on the farm, now she's closer to town. And on the farms in Nicaragua back then there were no cell phones. It was really bad. There are some areas entirely without coverage. There was only coverage in the capital so before a phone was essentially useless. Now, it's different, I call them and they can answer. I can't do video calls through Whatsapp because the reception is bad on the farms, but I can chat, and if I want to call, then I have to buy a prepaid card and call them. And if they're in town, then I can all them however many times I want. I talk to them every day. [Kristen]

Return Trips: The immigrants attempted to physically travel back to their country and home communities on a fairly regular basis. Most described returning to Nicaragua on a yearly basis for a duration of 1-2 weeks during their initial years. The exception from this norm were Kristen, Rogelio, and Fabricio who originally moved to the United States without documentation, limiting their ability to travel back to Nicaragua. These individuals did not travel back to their hometowns for multiple years, until they were able to ultimately adjust their status and obtain lawful presence, after which they began making yearly trips back to Nicaragua as well. Return trips allowed the immigrants to create economic injections into their home communities through normal spending and purchasing activities. They also had direct contact at a household and community level, creating an atmosphere where social remittances, including concepts such as gender rights, business acumen, and environmental awareness, could be transferred. Camden and Rogelio describe sharing the importance of punctuality and professional responsibility in creating success. Many of the individuals also expressed the importance of sharing the realities, including the struggles, of living in the United States. The common sentiment amongst the group was that individuals from their hometown felt that life in the United States was easy. Kristen observed that people felt like "money grows on trees and we just have to pick it off over here". The misconceptions of the ease and simplicity of the 
American life is a shared frustration amongst the group. They felt it was necessary to share the hard work and diligence that led to their success. Transferring the importance of perseverance, planning, and accountability were central to the concepts and ideas that the Nicaraguan immigrants felt imperative to share with their communities of origin.

Household Remittances: The immigrants interviewed noted a continued act of sending home financial support to their family on a regular basis, ranging from monthly to quarterly. They shared that they would initially send home any extra money that they had after paying their expenses and the amount became more regular as their positions in the U.S. economy stabilized. Elias and Patricia were exceptions as they immigrated as children with their parents, but they did indicate that their parents engaged in this type of continued financial support. Along with the regular financial contributions, the immigrants also supported their families, extended families, and close friends with assistance in times of need. Walter spoke about sending money back to pay school tuition bills when his brother was graduating from university as well as paying for doctor bills for another brother when he was diagnosed with cancer. Moses attempted to send back extra money when his cousin was imprisoned during the Nicaraguan revolution. Kristen supported close friends and families that were pregnant by covering their medical bills and sending prenatal care packages. The trend of this type of financial-based transnational activity provided a steady and constant flow of money coupled with extra support in times of crises or unexpected need. This indicates that the livelihoods of the families of immigrants in this town were closely tied to the ability of their family members to become economically stable in the United States. The immigrants felt a continued responsibility to their family and home community and considered financial 
remittances a regular part of their financial plan. They did not indicate many higher level financial contributions during this time, but a clear focus on the individual and household level was noted.

\subsection{Entrepreneurship Startup to Present}

The final segment that will be discussed in this temporal cross-case analysis is the startup of the immigrant's entrepreneurship venture to the present. This will explore the actual process and motivations of moving to a self-employment structure and will examine the barriers and support systems utilized as the business became established and grew to its current position. The themes that surfaced through our discussions about this period of time were; a reliance on personal financial capital, focus on informal training and guidance, slow growth, emergence of entrepreneurial identity, knowledge bridges, community needs and individual investments, and connecting resources at the community level.

Reliance on Personal Financial Capital: One of the main constraints cited for Latino-immigrants entering into an entrepreneurial venture is the lack of accessibility to financial resources (Fairlie, n.d.). Many diasporas have created internal financial support mechanisms that are accessible by immigrant members. However, research into Latino diasporas does not find the same established support systems. It is found that these immigrants typically rely on personal savings for initial investments in business startups (Portes, Guarnizo, \& Haller, 2002). The discussions with the Nicaraguan immigrant entrepreneurs showed a similar pattern of self-reliance in the financial arena. Many of the interviewees transitioned to a business that was in the same vein as their full-time career. This allowed them to slowly obtain the appropriate tools and devices to transition to a 
small startup. For instance, many individuals worked in the construction business and transitioned to an entrepreneurial endeavor in the same field. This allowed them to pair their expertise and their personal equipment to begin working small projects immediately. They were able to reinvest the profits to expand and upgrade their equipment inventory and make larger investments in rental properties and company vehicles. The reliance on personal funds and credit created a necessity for these businesses to start small and scale up at an incremental rate. Many of the entrepreneurs shared that they actually made significantly less money in the first months of their business startup compared to their full-time position. They had to take a step back in order to build the capital necessary to implement their full business plan. Time and resources were significant components during this time.

The one exception to this trend was Rachel. She applied for a grant with her partner to open a daycare. Rachel described a lack of entrepreneurial acumen as a constraining factor to her business startup, but addressed that with a business-minded colleague to complement her expertise in education and childcare. Her partner was able to find financial resources that Rachel would not have found without assistance. They applied for a community funded grant that helped support their initial business costs.

My friend, the one that I partnered with, was able to connect us to an organization that provided grants for small businesses in our area. I would have never have known how to find that type of help, but she is great at searching for resources, she's very smart and connected. We applied for the grant and were provided \$10,000 start-up assistance. That made our beginning much less stressful.[Rachel]

Many of the other immigrants were in similar situations, garnering technical expertise but not as familiar with the business side of operations. They all learned through trial and error. The small startups allowed for quick transitions and pivoting of 
actions with a high level of flexibility and adaptability. However, connections with local business mentors and institutions that provided connections to financial support to entrepreneurs could have been useful for these individuals in their beginning stages.

Focus on Informal Training and Guidance: Training opportunities and basic business skill workshops are often available through community-based organizations and local community colleges. However, this group of Nicaraguan entrepreneurs did not connect with these institutional resources during their transition to entrepreneur. These immigrants relied on the internal skills they had developed throughout their professional career to facilitate their business startup. The only individual that was able to utilize a resource center to assist with their business was Patricia. Patricia was connected with a local community organization that provided one-on-one guidance and skill-based workshops where she was able to connect with other local business owners.

One of the guys that owned a sports shop a block down from the store we wanted to open gave us a contact to an organization that helps small business owners...I think it was called the LBA something like that, the Latino Business Association I think. It's an organization that works specifically with people like me from a country like Nicaragua, that want to start businesses. They have different services and trainings, they offered a free consultation to see what exactly we needed and to kind of point us in the right direction. Opening a business in America is much different than in Nicaragua. Over there you don't have many regulations or paperwork, you just start something when you want. Here it's a bit nerve-racking because I felt if I made a little mistake I would ruin my chances. This organization made sure we were on the right track and didn't miss anything. [Patricia]

Patricia connected to this organization through a recommendation from a business owner from the Latino business community where she was well integrated. The organization had a good reputation and had built relationships within this business community that allowed for quick and easy referrals for individuals hoping to enter the entrepreneurial arena. Patricia indicated that this experience provided a sense of confidence and helped her navigate the confusing regulations of the U.S. business environment. 
The rest of the Nicaraguan immigrant group often relied on advice and guidance from members of their social network because they did not connect with institutional or organizational support for their business startup. These networks were often comprised of family members and work associates. Camden, Rosa, Walter, Elias, Rogelio, and Fabricio expressed that they were able to rely on family members with previous business experience to help guide their initial decisions when opening their business. Family was the primary connection upon arrival and integration and it is clear that the family ties remained strong and instrumental in this groups social and professional lives even after they were able to separate from the dependence on these relationships. This demonstrates that as the immigrants become more independent they were able to balance the power dynamics within their familial relationships and create a mutually beneficial and collaborative affiliation. In fact, some of the immigrants ended up employing their family members as they became entrepreneurs, indicating a type of reciprocity and constructive exchange. Some relied on written resources provided by an individual within their social network for added direction. For instance, Elias pointed to a book given to him by his uncle as a pivotal moment in shaping his plan to become an entrepreneur.

That book, Rich Dad, Poor Dad, that my uncle gave me changed my life. Like I said, it took me awhile to actually read it, but once I started I couldn't stop, it just connected with what I wanted to do and gave me a path to realize my ambitions of starting a business...... I read in all my free time, I always feel more knowledgeable and prepared if I keep up with the information that is out there... you know, on the internet or in books. [Elias]

Immigrants also relied on their professional associates to support their business knowledge acquisition as well as family connections. Kristen, Moses, Rosa, Rogelio, and Fabricio described seeking advice from previous employers when deciding to start their own business. The individuals that actively sought out this type of assistance tended to 
be starting a business aligned with their previous employment. For instance, those that worked in construction and decided to enter into a related business actively reached out to past supervisors and coworkers for guidance. Kristen had worked in beauty salons for years before opening her in-home hair stylist business. She described maintaining good relationships with her past employers which enabled her to meet with them to ask about the licenses and accounting aspects of her business.

When I started, there was a lot I had to learn. All of the regulations and licenses were a little intimidating, but I had maintained a good relationship with my past boss and she sat down with me and went through some of the basic business ideas that I needed in order to get started. She connected me with the people I needed to talk to about my paperwork and let me see how she kept her financial books and the computer systems she used to book clients. I called her from time to time in the beginning to ask little questions as they came up and she was always happy to help out. [Kristen]

She did not feel like a direct competitor with her past employer and they were happy to see her take the initiative to start her own salon so were a great resource for her. Building on professional relationships to bridge the transition into entrepreneurship provided a vital source for filling in the business knowledge gaps that were an area of initial weakness for many in this group.

Slow Growth: The initial businesses tended to start small due to a limitation of financial resources and initial business acumen. Some businesses started as side projects while the immigrant maintained their full-time employment and slowly transitioned into a full-time entrepreneurial venture. It did not appear that there was not a desire to scale the businesses in an expansive manner, but rather the propensity was to keep the businesses smaller and manageable, which allowed for flexibility and quick adaptation. For instance, Rogelio owns a kitchen design business and was hoping to shift the central mission and strategy of the venture to that of a contractor with a peripheral design 
component in order to take advantage of the economic environment of Miami and circumvent the many obstacles he has faced with the shifting regulatory and contractual obligations of his current business structure. He employed between 5-7 individuals and was not necessarily hoping to grow the business, but rather shift the core function to take advantage of the changing marketplace and in turn garner higher returns. Camden described that he had a previous restaurant and has recently opened another. Upon opening the second location, he dissolved his first property. His second restaurant is located in an area with higher traffic, closer to his full-time job and residence, and was larger which allowed him to promote rentals for special events. His experience also showed an inclination to focus on adding quality and adapting the original business plan rather than focusing on growing larger by adding more business locations. Overall, this immigrant group demonstrated a general preference and disposition towards shifting business strategy instead of growing the business through an approach that involved scaled planning and efforts. This strategy may have allowed the business owners to focus on the ever-changing market in a manageable way while displaying a present-minded approach instead of forward-looking strategic attitude.

Emergence of Entrepreneurial Identity: Another component related to the ability of the Nicaragua immigrant entrepreneurs to start, maintain, and grow a business is their identity as an entrepreneur. Understanding how these immigrants see themselves situated in the business world is critical in exploring their entrepreneurial potential and the manifestation of their identities as leaders, a vital element in the success of their current and potential future endeavors. This group did not express an entrenched desire to become entrepreneurs but instead transitioned into this role due to a combination of 
professional skill development, an awareness of external opportunities, and an ability to take mitigated risks. These individuals did not begin their business with a strong entrepreneurial identity. Patricia shared her views of starting the business and the disconnect with the idea of herself as an entrepreneur.

We started this to spend more time with our family. We aren't like the real entrepreneurs, like over there in Silicon Valley. We are just working towards making enough to create security for the kids and ourselves and to be able to enjoy our lives. When I thought of an entrepreneur I thought of those big companies making millions of dollars. [Patricia]

Walter shared a similar sentiment when discussing how he viewed himself in his transnational business arrangement.

No, I don't really think of myself as an entrepreneur because this is just something that I do because it's fun. I love fishing and it just kinda fell into a business when I connected with my cousin and brother. It doesn't feel really serious and I don't consider myself a big business man. Just a guy doing something he loves and making a little extra money. [Walter]

However, through our discussions it was evident that this identity did develop after the business was established and they found a certain level of success. The Nicaraguan immigrants became assertive in the decision-making processes and engages to a fuller extent with the business community as their confidence grew. Their entrepreneurial identity seemed to be strengthened by engagement with other business leaders in the community and in some occasions inclusion in business-related events within the community, such as entrepreneurial luncheons or chamber of commerce events..

Now, yeah, I would say I'm an entrepreneur, but not before...not when I was starting. I was just stumbling around trying to find my way and figured it out. I think I just started feeling more like a business woman, or an entrepreneur, in the last year. When my business started to become successful and I began thinking of new ways to create more value and services. I connect with other business owners in my community and feel like an important part of the local business climate. So yeah, now I consider myself a strong female entrepreneur. [Rachel] 
External forces were pivotal in guiding the immigrant's self-reflection and expression as an entrepreneur. Moses, Rosa, Elias, Patricia, and Fabricio all expressed feeling more like an entrepreneur when other individuals began soliciting them for business advice.

I feel respected in the business community. I have a lot of contacts and people look to me for advice and guidance now because they see how well I've done. I get invited to luncheons for business owners and have been asked to speak at a local Chamber of Commerce meeting. I have always been well connected and as I grew stronger and stronger in my business I became a well-known business man. [Moses]

Recognition from outside people regarding their business expertise added value to their sense of self and materialized through the production of an identity centered around entrepreneurial attributes. Further, the manifestation of an identity as an entrepreneur was also tied with reaching a level of financial success that allowed the individual to delegate tasks and enjoy a level of freedom and time flexibility to create a family-life balance.

Now that I'm established I can control my own schedule. I don't have to work all the time because I have hired employees that can do the work when I am not around. So now I can make sure I spend plenty of time with my kids, which was important to me since I worked so much for so much of their lives. Now I can start work late so that I can make them breakfast and take them to school. Or make sure I have weekends free to take them to the beach or to a movie. [Rogelio]

It was also valuable to explore the evolution of transnational engagement during this period of time in order to examine the specific potential of immigrant entrepreneurs to affect change within their community of origin. Communication and remittances remained constant after the immigrants became business owners but subtle shifts in engagement strategies did present themselves during our conversations. The immigrant group expressed an overall feeling of pride sharing their experiences starting a business and returning to their home communities as a business owner. Walter described the shift 
in his experience returning home after starting his transnational fishing and wildlife business.

I feel different when I go back. I'm no longer just a struggling painter, but I'm someone that people admire. Every time I go back people come to my house to talk with me and ask advice. I even give consultation to our Mayor and the school board. My mom is so proud that I've become such an important type of person. It feels good, I mean I don't feel so high and mighty when I get back to the US. Here I'm just a normal person, but there I'm something a little more special.[Walter]

His heightened status gave him a position from which he could influence and shape the perceptions and ambitions of community members. They valued advice that he was able to provide regarding small business development. He, like many of the other immigrants interviewed, often share their skills and knowledge through informal channels. They enjoyed speaking with friends and family in a casual setting and impart their wisdom in a natural and organic manner.

Knowledge Bridges: Patricia discussed providing an organized business training over Skype for two of her friends hoping to open a new business. She utilized materials she obtained through a community organization to offer a coordinated workshop that resulted in the town residents conducting many strategic business related activities and eventually opening a successful restaurant. Some immigrants also noted speaking at formal engagements in their communities of origin, such as within the high schools and in community leadership meetings.

An increase in these types of knowledge bridges appeared to be the most significant initial change in transnational engagement strategies of this group. However, there was also an increase in collaborations and direct investments in individual business initiatives in the Villa Sandino area. This group shared stories of supporting friends and family that expressed interest in starting a business through an injection of financial 
capital. Walter, Kristen, Rogelio, Elias, Patricia, and Camden all discussed how they provided financial support to a family member or close friend that was engaged in small business development. This is different from the household-directed remittances they provided on a consistent basis with little control or direction from the immigrant on how it would be spent. The direct investment financial remittances invested in small-business development were linked with a higher level of direction and management by the immigrant. The immigrants noted that they paired their investment with advice and expected to be able to guide the business in a constructive manner if they felt it was being mismanaged. The immigrant group tended to provide small investments without requiring a return payment. They felt it was part of their responsibility as a successful entrepreneur in the United States to return some of the fortune and opportunity that they received to their hometown.

Community needs and individual investments: The shift in awareness of largerscale, community-wide issues was prevalent, but there was a hesitation about becoming involved at a higher level. A common theme amongst the group was a mistrust in providing support through community leadership and government run programs. The immigrants all indicated several fundamental issues that needed resolution within their town and presented ideas about how to rectify or enhance these areas, but political tensions and historic mismanagement of resources hindered their willingness to get involved on this level. Camden noted a need to invest in infrastructure and water management, as many households did not have access to what he called a "basic human right". Kristen, Rachel, and Walter indicated that health care and maternal health were areas that were underdeveloped and created a grave condition for many of the individuals 
in the community. A majority of the interviewees perceived the educational system as the area that needed the most immediate attention as the youth were the future of their community but were not being developed in a constructive manner. When they discussed how they could intervene in these areas, they mentioned the political landscape as a hindrance towards beneficial change. Most commented on how they would rather invest directly in the individuals and spread around the resources fairly on their own rather than trust that community-level investments would reach the people in an equitable fashion

I always worry most about the most vulnerable people and try to help them directly, directly without intermediaries, because sometimes, you know, there are many people that attempt to help and this support and resources never make it to the people that need it. That's way I feel better helping someone that really needs it, directly. The way the people in power handle aid is ugly sometimes. They control where the resources go and they typically go into their own pockets or to their families, and the ones that really need them, because they don't have family in power, never get even a cup of rice. So I give directly.[Camden]

The individuals expressed a sense of mistrust in the local leadership and displayed the tendency to intervene in development initiatives in a controlled and directed manner.

Connecting Resources at the Community Level: The one area where communitylevel engagement did take place was when immigrants were able to connect U.S. based institutions with their community of origin. Several participants shared stories of connecting resources at this level, and felt more confident in serving as a liaison between a trusted institution and their community. Rogelio spoke about connecting a religiousbased nonprofit with his church in Villa Sandino and noted that he trusted this organization and felt that they would make a positive impact to the individuals in Villa Sandino. Rachel shared that she was able to connect a group based in San Francisco that specialized in fostering women entrepreneurs with her hometown as they were already planning a trip to other communities in the Nicaraguan area and were able to include 
Villa Sandino in their international outreach strategic plan. This group was able to work within the local schools and present a workshop for the local women's cooperatives through a week-long visit. This demonstrated a very valuable transnational activity that incorporated their ability to integrate into their receiving community and make valuable connections that can then be shared through transnational connections. This is also a way in which individual entrepreneurs could make community-level impacts and circumvent mistrust and uneven power dynamics inherent in their community leadership structure. 


\section{Chapter 6: Transnationalism from Below \\ 6.1 Transnationalism from Below}

This study explores the individual experiences of migrants from the community of Villa Sandino that have become entrepreneurs as immigrants in the United States. Through semi-structured interviews, their unique entrepreneurial journeys and transnational engagement were examined and themes emerged that created a more comprehensive understanding of the determinants, motivations, strategies, and external conditions that fostered entrepreneurship and transnationalism within this group. The information that emerged from the with-in and cross case analyses will now be explored through the original research questions to recapitulate the findings within the lens of transnationalism from below. The themes found within both the with-in and cross case analysis were viewed in a comprehensive manner to provide targeted insights into the initial research questions. The themes were grouped based on their similarities and connected associations. Broader themes were then derived from these grouped subthemes to present the collected information in a manner that directly addresses the research questions and develops a representation of the transnational landscape of this group as a whole. For a complete table representing the sub-theme groupings that developed the transnational themes refer to Appendix E. Table 15 provides a synopsis of the themes that emerged from the case study analyses. 
Table 15: Transnational Themes

\begin{tabular}{|c|c|c|c|}
\hline Determinants & Motivations & Strategies & Conditions \\
\hline AGE & $\begin{array}{l}\text { RESPECT \& } \\
\text { RESPONSIBILITY }\end{array}$ & $\begin{array}{l}\text { INVESTMENT IN } \\
\text { INDIVIDUALS }\end{array}$ & $\begin{array}{l}\text { TRUSTED } \\
\text { INSTITUTIONS }\end{array}$ \\
\hline GENDER & $\begin{array}{l}\text { APPRECIATION \& } \\
\text { GRATITUDE }\end{array}$ & $\begin{array}{l}\text { KNOWLEDGE } \\
\text { TRANSFERS }\end{array}$ & $\begin{array}{l}\text { IMMIGRATION } \\
\text { CLIMATE }\end{array}$ \\
\hline EDUCATION & PRIDE & $\begin{array}{l}\text { RELIGIOUS BASED } \\
\text { INVOLVEMENT }\end{array}$ & $\begin{array}{l}\text { ADVANCEMENT AND } \\
\text { ACCESS TO } \\
\text { TECHNOLOGY }\end{array}$ \\
\hline $\begin{array}{l}\text { TECHNICAL } \\
\text { ABILITY/PROFESSIONAL } \\
\text { ACUMEN }\end{array}$ & $\begin{array}{l}\text { BELONGING \& } \\
\text { CONNECTEDNESS }\end{array}$ & LINKING INSTITUTIONS & $\begin{array}{l}\text { STRUCTURES OF } \\
\text { ACKNOWLEDGEMENT }\end{array}$ \\
\hline IMMIGRATION STATUS & $\begin{array}{l}\text { FREEDOM \& } \\
\text { FLEXIBILITY }\end{array}$ & RETURN TRIPS & $\begin{array}{l}\text { ACCESS TO FINANCIAL } \\
\text { CAPITAL }\end{array}$ \\
\hline $\begin{array}{l}\text { LENGTH OF STAY IN } \\
\text { THE US }\end{array}$ & $\begin{array}{l}\text { RETURN } \\
\text { MIGRATION } \\
\text { ASPIRATIONS }\end{array}$ & $\begin{array}{l}\text { CONNECTING THROUGH } \\
\text { TECHNOLOGY }\end{array}$ & \\
\hline $\begin{array}{l}\text { CONTEXT OF } \\
\text { INCORPORATION }\end{array}$ & $\begin{array}{l}\text { IDENTIFICATION } \\
\text { OF OPPORTUNITY } \\
\text { GAPS }\end{array}$ & ADAPTABLE PLANNING & \\
\hline SOCIAL CAPITAL & $\begin{array}{l}\text { OPPORTUNITY VS. } \\
\text { NECESSITY } \\
\text { DRIVEN }\end{array}$ & $\begin{array}{l}\text { REPLICATION/CULTURAL } \\
\text { TRANSLATION }\end{array}$ & \\
\hline
\end{tabular}

This chapter will discuss the individual research questions pertaining to the

determinants, motivations, strategies, and external conditions that support

transnationalism within this group of immigrant entrepreneurs and will culminate with a discussion on transnationalism from below within this unique context. Figure 11

illustrates the interrelation of these distinct variables and provides a visual representation of the transnational space that links the immigrants to two communities and countries. 
Figure 11: Transnationalism from Below -

Latino Immigrant Entrepreneurs (Villa Sandino, Nicaragua)

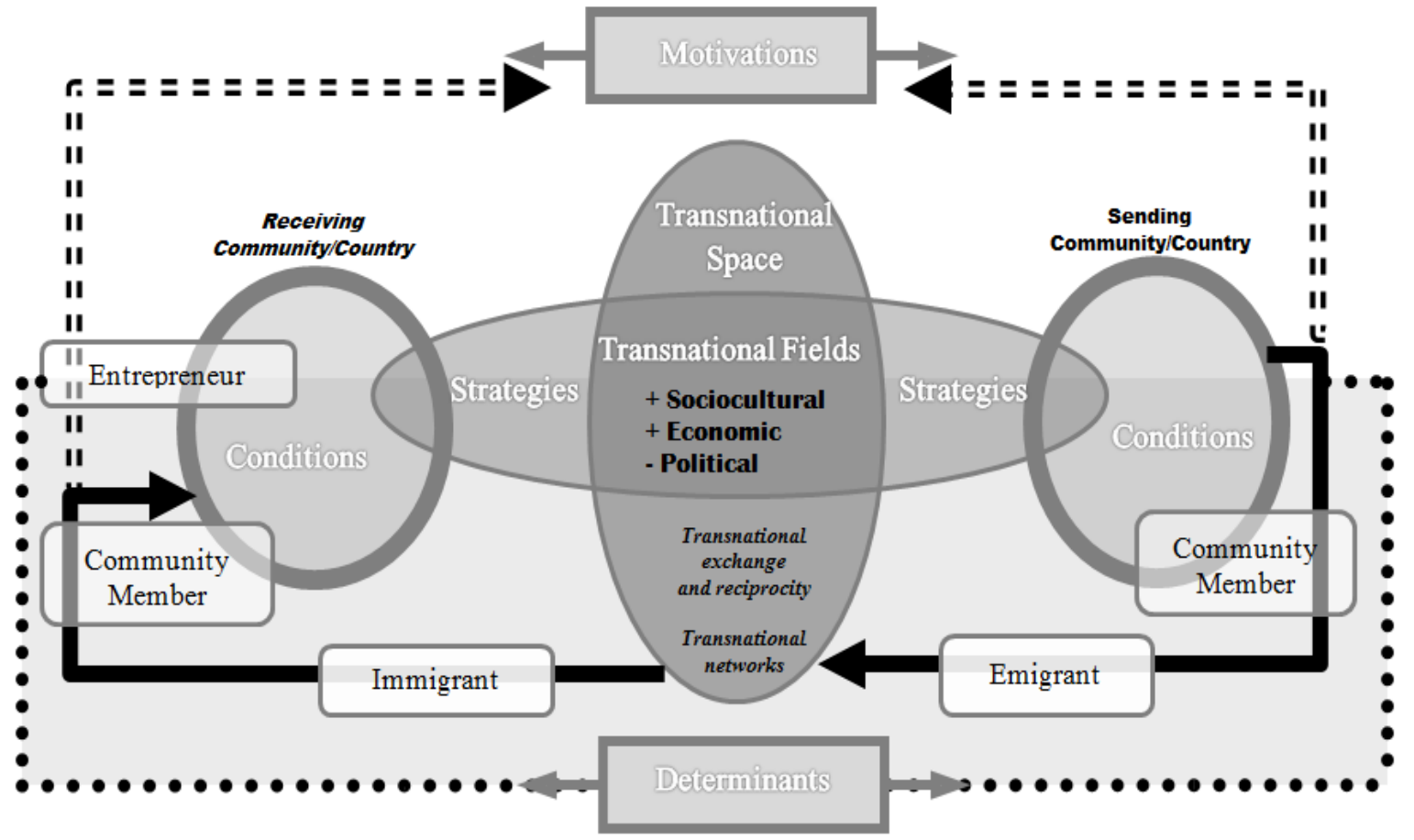

The circle on the right side of the diagram represents the sending community and country of Villa Sandino, Nicaragua. The bold border signifies country level landscapes while the inner circle is representative of the community level, embedded within the national environment. Similarly, the circle on the left side represents the same dynamic for the receiving community and country, specifically Miami and San Francisco within the United States. The bold, black line illustrates the individual's physical journey from sending to receiving community. This line also highlights the evolution of identities and memberships that the individual accumulates through this journey. They begin as an integrated part of their home community. They become an emigrant leaving their town and simultaneously are also an immigrant arriving in a new environment. They eventually are able to successfully integrate and become a community member in their new city. Eventually the individuals in this group also became entrepreneurs during this 
journey. It is important to note, that the individuals do not move from one role to another but flow through this process while maintaining their previous memberships and functions. This demonstrates the complexity of the identity of these individuals and creates complementary as well as competing characteristics that they must navigate.

The determinants related to these individuals becoming entrepreneurs and actively engaging the in the transnational arena is shown at the bottom of the diagram and is joined by the bold, dotted line and shaded area encompassing and connecting the immigrants journey and various roles. The determinants range from key demographic indicators to areas that require more acute development such as education and training. Thus, these determinants are a culmination of the underlying, intrinsic characteristics that the individuals demonstrated and developed throughout their journey. Similarly, the concept of motivations if displayed at the top of the diagram. The idea of motivations is embedded in in the emotional space and is less tangible in nature as compared to the determinants. Therefore, it is placed in the opposite position of the physical attributes and represents a mental, perceptual space. Motivations is connected to both the sending and receiving communities and expresses a bidirectional flow. It was found that motivations emerged as both push and pull forces, stimulating unique transnational engagement relationships. The external conditions that influenced the immigrants entrepreneurial and transnational activities are inserted within the sending and receiving communities and countries. The favorable conditions were expressed as an incubating force that emerged from community and country landscapes and dynamics. Lastly, the strategies utilized by this group are located in the oval connecting both communities through the transnational fields. The strategies are tactics the immigrants utilize to effectively move through the 
transnational space and provide benefits and support to their home community. These strategies often leverage the conditions and are stimulated by the distinct motivations that are represented within this model.

The transnational space and transnational field are the two interconnected concepts that represent the idea of transnationalism from below, discussed later in this section. The transnational space exists between the home and host country and is produced by the integration patterns and movement of information and culture that the immigrants produce. Within this study the transnational space was expressed through the typologies of transnational exchange and reciprocity and transnational networks, both of which are explained further later in this chapter. The transnational fields create the bidirectional flow between the receiving and sending communities. The transnational activates produced within these fields can be categorized as political, economic, and sociocultural. These activities produce an active link between immigrant and their communities as well as creating a way to operationalize and leverage the transnational space.

\section{Determinants}

By examining the determinants that influence the immigrant that is engaged in transnational activities we are able to understand the factors or elements that are inherent in these Nicaraguan entrepreneurs and observe a pattern of similarities that are shared by the group. For the purpose of this study, these determinants are attributes, skills, attitudes, and proficiencies that supported the immigrant in their entrepreneurial pursuit as well as their transnational activities. The common determinants cited in transnational research, and specifically explored in the Comparative Immigrant Entrepreneurship 
(CIEP) study, are categorized as demographic (age and gender), human capital (education level and technical ability or professional acumen), assimilation (visa status, and length of U.S. residence, and the context of incorporation) as well as the size and scope of social networks (Guarnizo, Portes \& Haller, 2003)). We will begin by examining these determinants and comparing the findings from the interviews with the Nicaraguan entrepreneurs with the CIEP study results.

Of the entrepreneurs identified from as immigrant entrepreneurs living in the United States and originating from Villa Sandino, the makeup was six males and four females. It is important to note that all of the female entrepreneurs are married, which may expose an underlying factor that marital support is an important component to the gender lens. Two of the women are married to entrepreneurs, one is actively engaged in the same business as her husband and the other has a separate entrepreneurial venture but initiated her business after her husband was an established entrepreneur. The other two women are married to men with established careers and could rely on their spouse for stability and support while starting their venture. In regards to age, this determinant was not specifically emergent within the immigrants involved in this study as their ages ranged from early 20 s to mid-50s at time of entrepreneurial pursuit, however there was a more direct temporal relationship between the time spent in the United States and start of business endeavor, which will be discussed later in this section.

The CIEP study found that the transnational immigrants typically held a college or advanced degree and those without education were less likely to engage in activities within their country of origin. The immigrants interviewed in this study had education levels ranging from incomplete high school to college educated. However, a determinant 
did emerge that was closely related to education level but followed a more informal path. This determinant could be characterized as the pursuit of informal personal and professional development. The immigrants did share a propensity for seeking out ways to develop their human capital in specific and targeted manners, although formal education was not a primary indicator for success with this group of entrepreneurs. This often took shape in English language training and expanded from that point. Becoming proficient in English was a primary goal for many of the immigrants when they arrived in the U.S. Establishing a working language level allowed them to also take advantage of other trainings offered by community groups or to engage more actively in their place of employment. Workshops in business related themes were popular among the group as was the pursuit of individualized learning plans through informational materials such as books, internet documents, and other free community resources. The immigrants also relayed that during their initial years of formal employment they often took initiative to learn diverse areas of the operations of companies where they worked and sought out mentors to help provide guidance and support. This tactic of pursuing personal and professional development was central to their success and also served as an underlying basis for their transnational activities. The entrepreneurs often preferred creating knowledge bridges with their community of origin, further enforcing their respect for the development of human capital with the realization that formal education is not necessarily the best path for themselves or the members of their hometown.

Two central determinants of visa status and length of residence in the U.S. were also seen in the findings of my study. Research has found that a secure and documented immigration status is central to the development of transnationalism and immigrant 
entrepreneurship (Portes, Escobar \& Radford, 2002). This concept emerged as critical to the pursuits of the Nicaraguan immigrants participating in the study. Seven of the ten individuals who immigrated to the United States did so as permanent residents or with a legal humanitarian status and three overstayed their tourist visa and initially stayed without legal documentation. All three of the immigrants who came undocumented were subsequently able to adjust their status to a Legal Permanent Resident status through familial relationships. Two out of three of the initially undocumented immigrants did not start their entrepreneurial endeavors until after they obtained legal documentation. The remaining immigrant, did initially start his business as an undocumented immigrant but was forced to put all of the paperwork and startup documents in the name of his brother because of his status. These examples demonstrate the importance that legal immigration status provides in terms of individual agency, power, and control within their receiving community. Legal visa status also meant the immigrants were able to freely travel back and forth from their country of origin. This is significant when considering transnational engagement through return visits and the ability of the immigrant to maintain strong connections with their home community, family, and friends. The immigrants that were initially undocumented recounted a feeling of detachment during the years they were unable to travel back to visit their country and in one case their wife and child. All the immigrants participating in this study were traveling back to Nicaragua at least once a year at the time of this study. Many were making multiple, extended trips back, opening the stage for a deeper transnational connection.

The length of residence in the U.S. was also discussed as a core determinant. The CIEP study cited a positive correlation with a longer period of time in the receiving 
community and transnational entrepreneurship (Portes et. al. 2002; Guarnizo et. al. 2003). This finding conflicts with some previous research that suggests that the longer an immigrant resides in the U.S. the better assimilated they become to their receiving community and this weakens the ties to their country of origin (Portes, Escobar, \& Radford, 2002). The findings in this study are similar to those of the CIEP study. The interviews revealed that during their initial years in the U.S. the immigrants were overcome with the objectives of integrating into the local economy, coping with a lack of resources, and becoming comfortable in their new environment. It was not until they found a sense of safety and stability that they were able to pursue entrepreneurial ventures and expand their transnational engagement.

There are conflicting views on the relationship between assimilation and transnationalism as well as its effects on entrepreneurial development. My study found two diverse patterns of assimilation and found that each had distinct benefits and challenges but both were able to foster entrepreneurial development and transnational engagement. The differing assimilation paths were specific to the receiving community of the immigrant. The Nicaraguan immigrants that settled in Miami exhibited a primary integration into an ethnic enclave of the Latino community and had minimal incorporation into other segments of their city. The immigrants that settled in San Francisco demonstrated a more expanded integration pattern, connecting to more diverse segments of their community. A significant attribute of this group is that many of them moved to San Francisco as a secondary, internal migration, meaning the originally moved to another city or state in the U.S. before moving to San Francisco. These integration patterns influenced their entrepreneurial endeavors but each was able to leverage their 
unique social network to create a successful business. Further, the integration strategy did not affect the propensity to engage in transnational activities, but did have some influence on the nature of the engagement.

The different integration patterns affected social capital of the immigrant. Research indicates the size of the social network has a direct correlation with entrepreneurial activity, the larger the network the more likely an immigrant is to become self-employed (Portes, Guarnizo, \& Haller, 2002). This study did not measure specific dimensions of the social networks of the immigrant but it did explore how social networks developed in association with their integration patterns and maintained transnational ties. The immigrants in Miami had close bonding capital that incubated their ventures and their cultural ties which reinforced their connection to their homeland and created a safe environment to establish their entrepreneurial venture. The immigrants in San Francisco displayed a social network with more bridging relationships. This allowed them to build their businesses with support from various sources and a deeper community reach as well as serve as connectors of individuals and institutions between their host and home communities, transferring diverse resources, knowledge, and ideas to Villa Sandino residents. Both forms of social capital were useful in the transnational field and each had unique obstacles and benefits, one creating an incubating force and the latter generating a more innovative and diverse connecting pattern.

The social capital determinant also considered the immigrants transboundary scope of the social network. This related to the manner in which each entrepreneur maintained relationships in their country and community of origin. These relationships were fundamental to transnational behavior; however, it has also been found that a larger and 
more diverse pattern of cross-boundary relationships can foster transnational entrepreneurship endeavors (Portes, Guarnizo, \& Haller, 2002). The immigrant group demonstrated strong, lasting ties with households and extended family members. This was the strongest tie revealed. However, continuous communication with close friends, past colleagues, and members of a unifying institutions, mainly church were also cited. The relationships that were maintained were typically well established before the individual immigrated and continued contact was dependent on two-way communication patterns. These specific relationships lead to immigrant engagement in specific projects and initiatives that were recommended by their transboundary social network and a couple incidents of transnational entrepreneurial endeavors developed out of these associations. This is an area that can be further explored to foster higher levels of immigrant involvement in local community projects and small business development within Villa Sandino.

\section{Motivations}

The underlying motivations of immigrants that retain strong connections with their home countries are meaningful driving factors that are important when exploring the transnational migrant. The impetus to maintain and grow a relationship with their community of origin was primarily an internal drive and often stemmed from an emotional foundation within the participant group of Nicaraguan immigrant entrepreneur. Family considerations were a large driving factor cited by all the immigrant entrepreneurs. In fact, the transnational engagement typically started at the household level and expanded outwards from this primary point of connection. A desire to remain connected to ones' ethnic identity, eased the feeling of 'in-betweeness', and created a 
more flexible lifestyle. Apart from the emotional and familial motives, the immigrant's future aspirations for return migration or expanded involvement at the country or community level also influenced their connectivity. Lastly, a recognition of key differences found in social and business fields between receiving and sending communities, based on the immigrant's experience in both locales, generated a desire to share knowledge and resources that could improve the well-being of their household and community of origin.

Respect and responsibility, appreciation and gratefulness, and pride were the main positive emotional associations foundational to transnational engagement mentioned by the entrepreneurs when relating to their communities of origin. A common theme throughout the interviews was a profound respect for their family and a sense of responsibility to create a better life for those that remained in Villa Sandino. The sentiment of respect was often associated with parental figures that were instrumental in the upbringing and formation of the individual. Responsibility stemmed from an attitude of respect, expanding the transnational outlook to an actionable arena. A sense of responsibility drove the immigrants to engage in financial and social remittances that were beneficial at the individual, household, and less frequently community level. The vast majority of the entrepreneurs sent financial remittances to their families on a monthly basis and many also spoke about funding education and medical expenses for siblings, extended family, and friends. This type of transnational engagement, predicated by a sense of responsibility, was also seen as a reciprocal relationship. Immigrants often supported their family and community members because they felt these individuals had assisted them directly or indirectly in the past. It was clear that the sacrifices and constant 
dedication of the parents of the immigrants was the principal motivating factor. Most of the participating immigrants referenced their continuous support for parental figures as the first and longest-lasting type of transnational activity.

This foundational, transnational relationship was bypassed when the immigrant did not have close familial ties that remained in their community of origin. For instance, Elias and Patricia immigrated to the United States with their parents at a young age. They no longer had parental ties in their host community that were so important to establishing transnational connections. However, both individuals cited siblings that remained in the country, aunts and uncles, grandparents, and other non-biological parental figures as anchors that maintained their relationship to Villa Sandino. Another interesting reciprocal relationship was highlighted by the social support between community members. For instance, Walter spoke about community members that helped his brother during his struggle with cancer. He mentioned friends that would travel to the city to pick up medication, help his mother bathe and care for the brother when he was in hospice at home and those that regularly prayed for and visited his family during this difficult time. Other individuals mentioned feeling a sense of respect that translated into a responsibility to support individuals that had initiated similar social support for their family members. This was illustrated through providing transport, gifting food and other merchandise produced by the family's farm or business, as well as other informal favors and acts of kindness. This community level social support systems translated into transnational involvements that expanded through the social network of the household of the immigrant. 
Another related emotion that drove transnational immigrant interventions was a feeling of appreciation and gratefulness for the opportunity to live in their receiving community and pursue the 'American Dream'. The participating entrepreneurs regularly mentioned a sense of being grateful for the ability to establish a life in the U.S. and integrate into the local economy of their receiving community. The entrance into the workforce was a primary objective for many of the immigrants and they cited an appreciation for the future social, educational, and economic prospects for their children. Where the sense of respect and responsibility was a pulling motivation from the community of origin, the feelings of gratefulness were a push incentive initiated at the receiving community level. This sense of appreciation and gratefulness complemented the motivations derived from respect and responsibility, creating a cyclical emotional response that generated lasting transnationalism within this group. The sense of responsibility of the immigrants was heightened to supplement the well-being of their community members that did not have the same opportunities they were granted because they often felt gratified and thankful for their ability to immigrate. The feeling of gratitude may be associated with skewed power dynamics within the receiving country. An incorporation based on gratitude may construct an integration environment where the immigrant feels 'less than' or indebted to their host community. Although gratitude is primarily a positive emotional reaction, it is necessary to appreciate the potential for exploitation or manipulation that uneven power dynamics can entail.

There was an absence of the emotions of guilt and shame as motivating factors. Guilt and shame are often noted in research as primary driving factors for transnational engagement (Katigbak, 2015). These sentiments were only mentioned once, by Kristen, 
when explaining her motivations to maintain relationships and assist her family and community members in Villa Sandino. Kristen mentioned that she felt guilty for those individuals 'left behind' and this influenced her associations with Villa Sandino. Kristen was the only instance that these emotions arose throughout my conversations with the entrepreneurs. The remaining entrepreneurs that we interviewed focused on the more positive angles of respect and gratitude, highlighting the potential and capacity of the individuals in their host community rather than focusing on their weaknesses. Guilt and shame may be associated with the concepts of responsibility and gratefulness but these immigrants were able to frame their purpose in a more positive manner. This outlook illustrated the importance of fostering constructive and progressive perspectives of origin communities rather than focusing on the limitations and shortcomings.

Another emotional response that wove throughout the experiences of the immigrants was the feeling of pride and status. One way this was demonstrated through continuing a family legacy of entrepreneurship. Many of the families of the immigrants were entrepreneurs in and around Villa Sandino. The majority owned farms or small businesses in the community and the pride the immigrants had in their familial entrepreneurial legacy and reputation was a driving factor in their eventual entrance into founding their own small business. This was consistent with entrepreneurial research that cites upbringing as a key factor in establishing an entrepreneurial culture (Bisin \& Verdier, 2000). The entrepreneurs also consistently mentioned feeling a heightened sense of status when returning to Villa Sandino after had established their businesses. Familial pride and desire to continue a legacy of entrepreneurship tended to be a motivating factor to start the business while the heightened community status and 
individual pride cultivated the motivation for continuing entrepreneurial drive and business expansion endeavors.

Immigrants noted that they consistently engaged in transnational communication, return visits, and other activities in order to maintain a feeling of belonging and connection with their community of origin. Often immigrants experience a sense of "inbetweeness", meaning that although there is often an increased sense of home in both places, there was also a sense that these migrants no longer fully belong to either place. They are "in-betweeners", enjoying benefits but also confronting challenges on both sides of the border (Barajas, 2009). A common sentiment shared by the immigrant group was a feeling of shifting sense of place and acceptance when returning to Villa Sandino. Return visits and continued communication was the primary activities undertaken to maintain their identity as a part of the community of Villa Sandino. However, as the immigrant spent longer periods of time outside of Nicaragua and as their status shifted, they often were received in more distant or expectant manners.

Many of the interviewees noted that they were often solicited for financial support from distant acquaintances when returning to their community. They felt that community members have many false assumptions about life in the United States. Community members presented a prevalent feeling that life in the United States is easy, 'money grows on trees', and the immigrants must have an abundance of wealth. However there is little awareness of the difficulties and constraints of establishing a livelihood in the U.S.. These assumptions and expectations created a distance and detachment between the immigrant entrepreneurs and their community of origin. Educating the community members about the reality of life in the U.S. and sharing the difficulties of their journey 
was a tactic that was initiated by the entrepreneurs to combat the common postulations and increase their continued belonging. Although the sense of 'in-betweeness' often complicated the immigrants sense of community they simultaneously were attempting to heighten their social status within Villa Sandino through their transnational engagement strategies. They demonstrated a complex desire to stay integrated as a Villa Sandino community member and prevent distancing themselves through their immigration status while simultaneously wanting to climb the internal social ladder and shift their community standing in a manner that did not create an increased sense of 'inbetweeness'.

The immigrant entrepreneurs also shared that a central reason for pursuing entrepreneurial endeavors and a contributing factor to increased transnational engagement was the pursuit of a job with flexibility and a sense of financial and temporal freedom. Gender played a role in this dimension as the female entrepreneurs often entered the entrepreneurial arena to be able to contribute financially to their family while caring for young children. The male counterparts also cited flexibility and freedom as motivating factors, but highlighted aspirations to be their own boss and separate from formal authority figures as the underlying objective. The flexibility of owning a business and establishing their own schedule created an ability for increased transnational focus. Immigrants shared that before starting their business they attempted to return to their community of origin once every year for 1-2 weeks. After establishing their own enterprise, they were able to make multiple return trips to Villa Sandino every year and tended to spend extended periods of time in their home country, ranging from one to six months. This shift in return visits, was an important transnational activity. Return visits 
allowed the immigrants to inject increased levels of financial support into their local community on return visits, maintain and strengthen connections with community members, and created opportunities for the immigrant to identify areas for prospective investments or interventions (Portes, 1998).

The future aspirations of return migration of the immigrant entrepreneurs emerged as a motivating factor within their level and type of transnational activities. An interesting distinction between the study participants was the divergence in future return migration aspirations. The individuals that married a non-Nicaraguan native demonstrated a desire to spend more time in their country in the future or even to eventually purchase a vacation property for extended trips home, however did not intend on moving back to their country in the future. The individuals that were single or had Nicaraguan spouses indicated that they believed that they would eventually migrate back to their country of origin after saving an adequate amount of money or in some cases after their children were grown. Many intended to retire full-time in Nicaragua and this influenced their transnational strategy. The prospect of return migration, and to some degree extended travel, created an environment where individuals invested in property and business interests with expectations of leveraging these ventures in the future. Return migration created an intensified desire to invest in Villa Sandino community endeavors, become involved in community level leadership or decision-making and influence the well-being and comfort of their community of origin.

An occurrence that had an impactful influence on transnationalism within this group was their development of deep cultural and professional experiences in both their home and receiving communities. This parallel community involvement and 
understanding created an environment where differences and similarities were identified and evaluated. The participating immigrants cited their ability to observe the distinct norms and practices in both of these communities and identify areas where their home community could benefit from change or modifications. Social norms were highlighted through this concept. Many of the entrepreneurs shared that they realized the importance of professionalism, timeliness, and self-development through their experiences in Miami and San Francisco. When speaking about how their home community could develop in a positive manner, they often referenced the necessity to adjust their social and professional norms to mimic the United States. Conversely, this ability to experience diverse communities also allowed them to appreciate many aspects of Villa Sandino's customs and values. The focus on family and balance of priorities was cited as an area that should be preserved in Villa Sandino and was something their U.S. community lacked. Awareness of differences is vital to creating knowledge bridges and establishing social remittances that are culturally appropriate and beneficial.

Lastly, it is essential to consider the reasons that drove the immigrants to pursue their entrepreneurial endeavor within the opportunity versus necessity driven lens. Entrepreneurs are often categorized in a binary manner, meaning their motivations for starting a business is either related to a lack of better opportunities and a need to find a manner for economic integration or in pursuit of an unexploited business opportunity in the market. Opportunity driven entrepreneurship often entails a matured idea and a strategic plan to take advantage of the underdeveloped market. However, research has indicated the Latino population often pursued entrepreneurial endeavors from a necessitydriven perspective (Portes, 1998). Latinos are frequently driven to self-employment 
options because of lack of opportunities in the local workforce and relatively low entry level wages. Self-employment offers this population an avenue that provides better options for their skill sets and background than can be found in low-level employment opportunities (Portes, 1998). This study shows that this binary classification of entrepreneurial motivations is simplistic and does not portray the multi-dimensionality that was demonstrated within the group of Nicaraguan entrepreneurs in this study. This group of immigrant entrepreneurs did not seek out their business purely based on a lack of ability to enter the local workforce in a sustainable manner. In fact, they often waited a long period of time, developed more economic capital, and became deeper integrated into the local economy before deciding to transition to self-employment. Their entrepreneurial journey was often characterized by an ability to develop their professional acumen while maintaining gainful employment in a stable environment and slowly transitioning to selfemployment in order to gain a sense of autonomy, flexibility, and professional fulfillment. Their experiences were comprised of motivations that combine both necessity and opportunity driven characteristics. This is significant, as immigrants are often placed in this necessity-driven framework due to their perceived lack of economic and social power. However this group has demonstrated a path to entrepreneurship that involved the manufacturing of personal and professional expertise in order to take advantage of the unique environment of their receiving communities.

\section{Strategies}

A common and prevailing theme among the immigrants was a propensity to bypass local leadership and government in their transnational activities. The lack of trust in the way finances were handled and distributed and a history of political polarization 
and general mismanagement within the government created an unappealing environment for transnational connections for this group of immigrant entrepreneurs. The entrepreneurs utilized several strategies to create effective interventions within Villa Sandino while avoiding direct collaboration with government sponsored programs and projects. A common tactic the immigrants utilized to circumvent the local leadership was to cultivate transnational relationships at an individual and household level. The primary and fundamental transnational connection that immigrants foster is with their immediate family. Further engagement was not typically pursued until the household level was adequately supported. This support was usually undertaken through continuous communication and financial remittances.

The immigrant entrepreneurs noted that they also felt the most significant interventions they engaged in were at the individual level. Many of the interviewees shared accounts of supporting a friend, extended family member or other acquaintance. This support took the form of financial remittances, social remittances, or transference of knowledge and guidance or other relevant resources. Working at the individual level provided the immigrants a controlled and responsive interaction. Although mismanagement of funds was cited as a detriment at the local government level, the entrepreneurs did not resent the misuse of funds at the individual level. This contradictory attitude emerged from a respect of autonomy and independence. The immigrants found success in entrepreneurship because of these characteristics and consequently prefer to foster these attributes in their community counterparts. In addition to financial support, the immigrants noted that they frequently served in a mentorship role by providing advice 
and counsel to community members interested in starting a business or pursue other relevant interests.

The transference of knowledge was central to the individual level involvement. In fact, apart from financial remittances, the creation of knowledge bridges was the primary source of transnational engagement. These knowledge bridges often took the form of providing direct guidance through telephone calls, skype meetings or during return visits. Also, the transference of knowledge took place through cultural translation of resources and informational documents acquired through personal development and institutional connections within the host community of the immigrants. It was common that the immigrant acquired beneficial material through their entrepreneurial journey and shared these resources with individuals in Villa Sandino. The significant intervention within this interaction developed when the immigrant converted the information and knowledge into materials that were more appropriate and targeted for the atmosphere of Villa Sandino. One instance this where took place was when Patricia utilized the resources she received from a local business incubator to advise her friends in the planning of a local restaurant business. She shared that the booklet she received included financial advice and business strategies targeted to the San Francisco community and was not appropriate for the community climate of Villa Sandino. She edited the information to extract the most relevant topics and adjusted the financial capital tactics and marketing schemes to be more appropriate for a small, rural community. This intervention was extremely valuable and demonstrated a very constructive transnational strategy that can be best undertaken by immigrant populations. They are in the best position to serve as a cultural translator of meaningful, beneficial resources, creating an accessibility to knowledge that would 
otherwise be unattainable by members of the community of origin because the immigrant has a unique knowledge of both the receiving and sending communities.

These individual level connections have proven to be effective and satisfying to both members of the community of origin and the immigrant. However these types of selective interventions may also have detrimental effects at the community level. First, individuals that are able to immigrate to the United States typically have some financial means or external connections. These individuals are usually not the poorest of the poor and therefore the household, and many of the individual level connections, are established with community members that are middle to upper class citizens (Orozco, Porras \& Yansura, 2016). Because these individual level transnational activities are targeted to people with established relationships with the immigrant, the very poor community members are often excluded from involvement. This creates an environment that may further marginalize the poorest sector of a community, generating higher levels of wealth disparity and constructing internal social fields that cultivate conflict and damage an already vulnerable segment of the population (Zamora, 2005). Also, the families of immigrants often experience a higher status within the community and power dynamics may shift (Barajas, 2009). Only households with connections to migrants enjoy benefits in this structure and an exploitation of power and control can materialize as this dynamic persists.

It is important to understand how the immigrant group connected on a more macro or community level because of the issues inherent with solely individual level transnational engagement. The lack of trust and confidence in local leadership created a complicated obstacle to community level engagement for this group. All of the 
entrepreneurs cited community level issues as critical areas in need of support and assistance but were not comfortable contributing their time and resources to be filtered through the local government. However, the entrepreneurs were able to find strategies to circumvent the local government while still operating at a more communal level. Many of the immigrant entrepreneurs utilized the strategy of linking institutions from their receiving community to Villa Sandino as a method of bypassing local leadership while creating community level benefits. This strategy often emerged through collaborations with local religious institutions. A commonality among the group was the importance of religion and faith. Many of the immigrants shared that they initially integrated into their receiving community through involvement with faith-based organizations and by attending local churches. This proved to be an effective assimilation approach and typically built upon their upbringing centered around religion. Many leveraged this connection to support their transnational activities because religion was central to their lives in both the receiving and sending community. This method developed as financial support for their local church in Villa Sandino, specifically support of community programs and projects initiated and administered by the church. A couple of the entrepreneurs also were able to foster connections between religious institutions in their host community and their churches in Villa Sandino. This created a transnational link where members of the American churches and religious organizations travelled to Villa Sandino to collaborate with the local Catholic Church on projects aimed at development activities for local women's groups, delivering food supplies to surrounding schools, and creating educational workshops for youth. 
Another strategy commonly employed to create a lasting transnational space was frequent return trips to Villa Sandino. The immigrant enterprises cited return trips as an important manner in which they interacted with their community of origin. Many of the immigrant entrepreneurs returned for special family occasions, community events, and cultural activities. This physical connection aided them in maintaining a sense of belonging, engaging in important cultural activities, and strengthening relationships with community members. In fact, the entrepreneurial endeavors of the immigrants often allowed them the flexibility in their schedule to return to Villa Sandino more frequently and for extended periods of time. Because all of the immigrants interviewed were currently legally documented as U.S. Citizens or Permanent Residents, they could move freely between countries. Three of the individuals initially immigrated to the U.S. without documentation, limiting their ability to travel back to Nicaragua. These individuals noted that the inability to return to their community of origin created a distance that was difficult to navigate. The physical connection with their home community was a tangible transnational connection and created a platform for deeper and more impactful transnational interventions as the immigrant was able to reconnect with friends and family and observe potential areas in need of development at the community level. Return trips allowed the immigrant to spend money within their community, injecting financial resources directly into the local economy (Braziel \& Mannur, 2008). The return trips also allowed the immigrant to physically transport resources and supplies to individuals within their community. Most of the immigrants shared that they utilized return trips to provide friends and families with requested items not available locally. Many mentioned anecdotes of packing their personal items in a carry-on and using their 
check baggage to transport items requested from members of their home community. Walter and Elias actually used this physical transportation of supplies as a basis for their transnational business activities. They bought fishing and wildlife supplies and clothing in the United States and brought those items back to Villa Sandino to resell in their locally established businesses. The importance of return trips was a shared theme within the transnational strategies of the entrepreneurs.

The advancement in technology and proliferation of access to devices and technological connectivity was incredibly significant to the transnational engagement strategies of this group. The majority of these individuals have been in the United States for many years and shared how the evolution of technology shaped their connection with individuals in Villa Sandino. The entrepreneurs that immigrated over 20 years ago communicated that they had to utilize calling cards and schedule infrequent phone calls with family members and limited their conversations because of the expense. At that time there was no internet connection in the town and phone communication was the only possible means to stay in touch. Ten years ago, the immigrants shared that an internet café opened in their town and they were able to start limited communication through email and nascent social media. Most individuals had phones, but smart phones were not prevalent. Telephone communication still took place via calling cards and was restricted and imperfect. The rapid expansion of technological advancements has made present day communication efficient and high-quality. The entrepreneurs cited daily connection with family and friends from Villa Sandino. All utilized Facebook and Facebook messenger to connect with the town and keep up on current events. Villa Sandino even maintained a community page that allowed a community level connection and may be a valuable 
platform to further expand the transnational connectivity for the immigrant population. WhatsApp was a prominent means of communication and allowed the immigrants to talk to individuals from Villa Sandino for free through text, phone calls, and video chats. The immigrants noted that many of their friends and family had smart phones and were readily accessible. Also, internet connectivity expanded with more than five internet cafes in the small town and internet connections available were available at the household level throughout the town. Technology was core to all of the transnational strategies of the immigrants and is the basis for many of their activities. As the transnational field expands, technology may become increasingly significant and further advancements will likely influence the development of transnationalism from below.

A remarkable approach that appeared to develop within this immigrant group was an integration of short-term flexibility and adaptability paired with a forward-looking, strategic mentality. This multi-leveled outlook can be described as adaptable planning and was threaded throughout their integration, entrepreneurial, and transnational journeys. The entrepreneurs often described finding success or dealing with challenging obstacles by quickly pivoting their actions and strategies. For instance, when starting their businesses, many of the immigrants began on a small scale and shifted their pursuits to better fit with the market demands or the economic environment. This adaptability was an essential component to their success as an immigrant and entrepreneur and seemed to be a natural characteristic that arose from maturing in the informal environment of their community of origin. Because they were used to navigating an unstructured community environment and were forced to acclimate to new, diverse environments during their integration experience, the immigrants tended to be very 
comfortable veering from a predestined path in order to better situate themselves in changing atmospheres. However, these individuals also demonstrated a proclivity to consider the future and create malleable goals that they constantly worked towards. Having a future target generated a sense of ambition and supported the entrepreneurs in their efforts to maintain a high level of motivation and initiative even when they were faced with temporary obstacles and barriers. Adaptable planning was a skill that they communicated as important to transfer to the community members of Villa Sandino and also was a mentality they utilized within their transnational activities. The immigrants shared that the residents of Villa Sandino often did not think in the future and were extremely present-minded, which created problems with strategic and future planning. This short-range mentality meant that individuals rarely worked towards a larger goal and were easily discouraged when they met temporary challenges. Pairing a flexible mentality with an ability to plan for the future and have confidence in attaining a larger goal is vital to creating agency within community members which would translate into a more beneficial community development ecosystem.

Another tactic that was especially valuable in creating knowledge bridges between receiving and sending communities was a strategy of replication and cultural translation. The immigrant entrepreneurs conveyed that they often supported the pursuits of individuals from their home community by sharing information, resources, and knowledge gained through their experiences in the host country. This was accomplished through Skype conference calls where business start-up information obtained through workshops was communicated in mentoring sessions. Similar guidance and advice sessions were undertaken during return trips to Villa Sandino. A significant component to 
this transference of knowledge was the unique ability of the immigrants to culturally translate the information into digestible and appropriate material for the specific economic and societal environment of Villa Sandino. This placed the immigrant entrepreneur as a key liaison between sending and receiving community and created a knowledge bridge where valuable information from an advanced economy was converted into a resource practical for a rural, Nicaraguan community. The idea of replication was also brought up by the community leaders as a potentially powerful form of transnational engagement. They expanded on the idea of replicating information and knowledge at a community level by suggesting that immigrants develop businesses similar to their entrepreneurial endeavors within Villa Sandino. An example was the idea of an individual that owned a bakery abroad could open up a similar venture in Villa Sandino in order to increase workforce options and develop the local economy. This idea is promising as the immigrant could adapt the valuable attributes, specific to their business, that they have acquired through their experiences within a developed economy into a business that would function within their home community context. However, this would take a large amount of time and resources from the immigrant. To better foster this objective, it may be beneficial for the community and country of origin to create engagement strategies that would incubate business startups from the emigrant diaspora and at the same time integrate local community members in the process to create sustainability and local level support and benefits.

\section{Conditions}

The conditions that support transnational engagement by Latino entrepreneurs are external elements of the environment that foster and support the development of the 
immigrants within their receiving community and foster active interactions with their community of origin. These conditions may emerge as push and pull components at both the host and home community and country levels and begin to illustrate the complex dynamics that encourage a productive transnational space. We have previously explored the significant determinants, motivations, and strategies found through interviews with the Nicaraguan immigrant entrepreneur group from Villa Sandino, Chontales. A deeper understanding of the areas that are critical for transnational success can be uncovered and a dialogue for programming and policy related interventions may emerge in a more targeted and effective manner by investigating both the internal motives and strategies paired with the external supporting environmental conditions.

A significant finding related to both host and home community conditions is the importance of trusted institutions for both human capital development and connectivity. Through my conversations with the immigrant entrepreneurs it was evident that a primary point integration into their receiving communities was often an institution that provided English language training. This took shape in the form of community colleges, local nonprofits, and immigrant integration and refugee resettlement organizations.

Conversely, there was a lesser degree of institutional connections when speaking about business startup assistance or trainings. However, some of the immigrants did share that they were able to find extended connections and outside opportunities through the connections made at their English classes. These connections came from friendships fostered with classmates from various ethnic backgrounds as well as services and support presented or through the organization. These peripheral connections allowed the immigrants to find clientele, acquire guidance about important civic services, medical 
care and immigration assistance, and occasionally connect with other organizations that provided targeted trainings or support. A great deal of gratitude was expressed when speaking about these institutions and a level of confidence was established through these initial relationships. Typically, these classes were offered for free or at a discounted fee, allowing the immigrants to take advantage of the services during a time that was crucial for language acquisition but also when many of the individuals had very limited resources. The fact that this type of organization was often a fundamental, initial connection between the immigrant and the community was a crucial condition for immigrant success and provided a potential opportunity for creating more connective opportunities. English language institutions have the unique opportunity to establish trust and confidence with immigrant groups and support their personal and professional development by creating opportunities to connect with other community services and training opportunities that would be otherwise bypassed or unknown by the immigrant populations.

A second type of institution instrumental in the integration and transnational journeys of the immigrants was religious based organizations. Faith was a themed weaved throughout the interviews, and a connection with church was often a way for the immigrants to maintain their value-based cultural roots in their new communities. The Nicaraguan entrepreneurs commonly cited finding a local church as one of their first endeavors within their receiving communities. Church attendance helped them feel connected to home while forging new relationships and expanding their social network locally. Some of the immigrants found employment through the connections and services found in the church setting and other became involved in external community assistance 
programs in both recipient and leadership roles. Religious associations also provided a means for lasting transnational connections on the institutional level within the communities of origin. This is significant because there were limited organizations and institutions in the small, rural township and with a profound lack of trust and confidence in local leadership and government, the churches of Villa Sandino, primarily the Catholic church, provided a more macro level point of connection that was utilized to generate community centric development. In fact, the immigrants have even able to connect the religious organizations in their host community with those in Villa Sandino to create development linkages and build transnational capacity. This was one of the most effective examples where transnational activity was undertaken on an institutional level, increasing the scope of benefits to community members.

Another condition that was exceptionally instrumental for immigrants to become entrepreneurs and fully engage transnationally was the immigration climate and ability to obtain legal status in the United States. Documented, legal immigration status was fundamental to the confidence and capacity of the Nicaraguan entrepreneurs. As mentioned previously, all the immigrants were in legal status as either Permanent Residents or U.S. Citizens. Three of the individuals began their journey as undocumented immigrants but were later able to secure residency through familial connections. These three individuals also expressed a detachment from their country of origin and a lesser ability to integrate and diminished power and control over their economic situation until after their status was adjusted. A significant commonality amongst the stories of the immigrants was the fact that all but one pursued immigration to the United States through family-based adjustment of status. 
Family-based adjustment of status can be pursued through a relationship with a sibling, parent, child, or spouse. If this relationship is considered an immediate relative of a United States Citizen (USC), such as a spouse or parent of a USC, the immigrant is instantly eligible for permanent resident status. If the relationship is with a brother or sister of a USC or with a Lawful Permanent Resident (LPR) under a family-based preference category, the immigrant will have to wait until a visa is available (USCIS, n.d.). Waiting for a visa to become available for preference categories can take an extremely long time. Many of the immigrants were petitioned for by USC siblings and waited over 20 years in Nicaragua to finally obtain a permanent resident status and immigrate to the United States. All of the Nicaraguan entrepreneurs interviewed were either already U.S. Citizens or expressed interest in becoming USCs in the future. They cited gratitude for the opportunities they received in the U.S., a desire to become more involved through the ability to vote in elections, and a hope for a heightened sense of security with an ever-changing political climate as their reasons for pursuing citizenship. Citizenship also impacted their ability to become transnationally mobile. The immigrants were able to freely move between Nicaragua and the United States because of legal status, opening an opportunity for a maintained physical connection through return trips to their community of origin. However, physical presence and continuous residence restrictions do apply when they are in permanent resident status. LPRs, immigrants may not be out of the country for more than 6 months at a time without special permission. They also must by physically present in the U.S. for thirty months within the preceding five year period before applying for citizenship (USCIS, n.d.). USCs were able to spend extended periods of time in Nicaragua without worrying about these restrictions and 
many aspired to split their time between both countries in the future. The mobility and security that a legal immigration status provided was paramount to the transnational behavior of the immigrants. This condition is especially significant in the current political climate. There is a current push to limit family-based immigration and expand laborbased immigration in the United States. This policy shift would dramatically affect the Nicaraguan immigrant experience, as familial ties and humanitarian programs are the most significant opportunities to migrate legally for this group. Labor-based migration is typically targeted at individuals with high skill and education levels and marginalizes those with less initial resources and connections. A shift away from family-based immigration may have a significant impact on developing countries immigration opportunities, especially for those migrating from rural areas.

Another notew orthy condition that has transformed the transnational space within this immigrant group was access to and advancement of technology. As discussed previously, technology is utilized by this group as a strategy to maintain connections and to allow for a flow of information and knowledge across the transnational space. Access to technology and advancement in the areas of communication and connectivity in both the receiving and sending communities is one of the most vital conditions to support the development of active and dynamic transnational fields. Innovations in technology will likely continue to strengthen the transnational connections in the future. Technology is a mechanism that creates an environment of connection and awareness between individuals and communities. A focus on the nexus of the transnational space and supporting technological endeavors would be beneficial in creating specific and meaningful 
platforms to connect immigrants and their communities and act as an instrument to encouraging other forms of transnational activities.

Another characteristic that often emerged as a key to immigrant entrepreneurship is access to financial capital. Latino immigrants commonly use personal savings for business startups because of a lack of access to traditional financial support (Fairlie, (n.d.)). The limitations of financing options has been cited as a key detriment to entrepreneurial success (Audretsch, 2004). The interviews with the Nicaraguan immigrants corroborated a reliance on personal savings for investing in their entrepreneurial ventures. One individual was able to secure a grant through a local nonprofit organization. However, the rest of the participants funded their business through their personal funds or loans from family members. The findings in this study differed from others by highlighting the benefits of this financing strategy rather than focusing on the limitations. Their venture typically started small and grew slowly because the immigrants were unable to secure formal loans or larger investments in their business. Many cited working on their business during nights and weekends while maintaining steady employment for a long period of time before becoming full-time entrepreneurs. This allowed the immigrants to develop business skills that they were not yet proficient with as they learned the administrative side of their enterprise and quickly adapt to changing environments. The slow growth supported a real time, practical training that would have been detrimental and ineffective if the enterprise had started at a grander scheme. The immigrants were able to pinpoint their weaknesses and seek resolution to problems in a manageable scale and pivot their strategic direction as they learned the realities of the local business atmosphere. This is not to say that access to financial capital 
would not have been beneficial for these individual, especially as they began to scale their operations, but to note there are benefits of starting a business in a manageable and malleable manner for individuals with technical skills but limited business acumen. The strength in technical ability paired with limited business knowledge was a commonality among the group of immigrants. Many of the immigrants found employment in their receiving community that allowed them to develop a specific technical skill. Many found this opportunity in the area of construction, but did not have the background or educations in management and business administration to support their transition into an entrepreneurial role. This reality influenced their mindsets as they approached business planning as well as their transnational roles.

Pride was a strong driving force for the immigrants to become entrepreneurs and to become involved in their community of origin in meaningful ways. The community condition that incubated this sense of pride were structures of acknowledgement. These acknowledgement mechanisms were valuable at both the host and home community level. The immigrants shared that receiving acknowledgements in the form of community awards, invitations to local luncheons for the business community, inclusion in Chamber of Commerce events, and articles in the local newspaper as well as stories on the local news all promoted their confidence as business owners and helped them develop an entrepreneurial identity. Similarly, acknowledgement from their community of origin had a profound effect on their transnational engagement and aspirations. When they received special recognition when they returned to Villa Sandino, such as being invited to speak at the local schools, provide guidance to local business owners or speak at government sponsored events, acknowledgement during community festivals and engaging in 
interviews on the local radio station, the immigrant entrepreneurs demonstrated a heightened level of motivation to seek innovative and enhanced methods of transnational engagement. Formalized opportunities of recognition and acknowledgement for these individuals incentivized their development as both entrepreneurs and transnational actors while their strengthening their self-confidence and individual agency.

\section{Transnationalism from Below Analysis}

The last research question that this study explores is to unveil what a broad understanding of what transnationalism from below looks like within this group of Nicaraguan immigrant entrepreneurs. The unique ecosystem of transnationalism from below is best explored through the two complementary dimensions of transnational social spaces and transnational fields. For this analysis, transnational social spaces consider the whole network perspective and will view transnationalism from below 'from the outside' while transnational fields explore the egocentric, personal networks that create specific interactions and will view transnationalism 'from the inside'.

Transnational Space: Transnational space has been defined as "configurations of social practices, artifacts and symbol systems that span different geographic spaces in at least two nation-states without constituting a new 'deterritorialised' nation-state" (Pries, 2001). Migrants increasingly live a dual life, speak two languages, have homes in receiving and sending countries, maintain regular contact across borders, and create transnational spaces that allow for a bidirectional flow of information and culture (Portes, Guarnizo, \& Landolt, 1999). Immigrants are embedded in both home and host country and transnational space is produced from these integration patterns. 
Faist (2000) offered a typology of transnational social spaces based integration in domestic networks in both the sending and receiving countries and the temporal stability of these interactions. These typologies include 1) dispersion and assimilation, 2) transnational exchange and reciprocity, 3) transnational networks, and 4) transnational communities. The premise is that we move along these typologies, from 1 to 4 , as the amount of social capital in the spaces increase. The Nicaraguan immigrant entrepreneurs demonstrated a relationship of 'transnational exchange and reciprocity' by maintaining a strong level of embeddedness in both countries and a short-lived duration. The entrepreneurs that participated in this study immigrated directly from Nicaragua and therefore fit into the typology that is typical for first-generation migrants. These patterns demonstrate that this group of immigrant entrepreneurs are able to create a strong sense of belonging in both sending and receiving communities in the short-term.

The 'exchange' dimension is represented through continued consumption of goods from the country of origin. The immigrants shared that they typically continued to connect with their culture of origin through food, religion, and important celebrations. They were able to integrate into their home communities while incorporating these cultural lynchpins from Villa Sandino. The reciprocity dimension was most prominently demonstrated through remittances sent back to kinship networks in the community of origin. This reciprocity dimension was also the underlying component that created a transnational space that fostered the building of knowledge bridges and the transference of social remittances. Another element core to this type of transnational space is the immigrant's intention of return migration. Many of the individuals interviewed expressed a desire to return to Nicaragua for retirement or to at least return to Nicaragua for 
prolonged trips in the future. This continued connection further demonstrates the temporal aspect of this transnational space and creates a transient relationship within this relatively high level of embeddedness on both a local and international level.

The Nicaraguan entrepreneurs were first-generation migrants that demonstrated a medium to high level of embeddedness in both receiving and sending countries. This could be indicative of the fact that they had lived in the United States for an extended period of time, allowing them to navigate their early struggles and find a path to successful integration while simultaneously being relatively recently removed from the country of origin, creating a maintained sense of closeness. It would be interesting to investigate this phenomenon within second and third immigrant groups to determine if this level of embeddedness shifts as the relationship to the native country becomes more distant and removed.

As the temporal dimension is extended this group resembled the 'transnational networks' social space. This typology is described by weaker integration pattern and a long-lived durational affiliation. These immigrants predominantly migrated due to an established network with an existing family member that had permanent status in the United States. This created an established network opening the transnational space for specific movement patterns. Within this type of transnational space social ties are utilized in one or more specific areas, such as business, politics, or religion. The Nicaraguan entrepreneurs built upon their social networks for individualized transference of ideas and resources. They reported engaging with their community on a primarily individual and household level rather than at a larger community or country level. This individual to individual connection created a bridge for transference of knowledge, ideas, 
and resources. There was minimal evidence of the 'transnational community' typology in this group. The 'transnational community' would entail a strong level of embeddedness and long-lived engagement in both countries. The transnational community also displays a strong interconnection amongst the individual entities within the diaspora and larger, community level engagement within the host country. The relatively recent immigration history of this group of Nicaraguan immigrants along with the relatively small and geographically dispersed nature of this specific immigrant population within the United States created a weakened diasporic in-community. The group also expressed a hesitation for community and country level engagement due to lack of trust and history of corruption within local leadership and government agencies.

The discussion of transnational space through these typologies is further built upon through additive, synergistic, and antagonistic interactions between host and home country embeddedness patterns. These types of interactions emerge on both a sociocultural and structural integration and transnational spheres. Additive relationships represent an immigrant that is able to establish and maintain strong ties to both home and host country. Conversely, antagonistic relationships refer to a negative correlation between integration and transnational engagement, where connections to one place result in a feeling of displacement in the other on a socio-cultural level, and demands in one country limit one's ability to engage in the other on a structural level. Lastly, the synergistic interaction presented as the possibility of positive experiences in one country being able to be leveraged to create a multiplier effect of benefits for the other (Erdal \& Oeppen, 2013). The group of Nicaraguan immigrant entrepreneurs demonstrated a primarily additive type of interaction among integration and transnational engagement 
spheres during their initial years in the United States. During this initial period of time, immigrants were able to integrate into their host community through economic incorporation, and a successful navigation of the unique social spaces in both ethnic enclaves and more diverse community structures. As the immigrants spent longer periods of time in their host community, and specifically established their businesses as entrepreneurs, their interactions shifted towards the synergistic relationship. There was still a strong presence of the additive element, but the immigrants were increasingly able to use their entrepreneurial experiences and the skills and intelligence developed through their journey to transfer specific knowledge and information back to their receiving communities. Several of the immigrants were also able to utilize their unique cultural positioning to create a specialization for their business, such as in the case of a Nicaraguan restaurant that leveraged access to special ingredients and distinct awareness of cultural norms to access an underrepresented segment of the market. However, the synergetic relationship was typically illustrated by the experience of the immigrants in the host community, creating a heightened ability to engage in the community of origin. The additive relationship showed an ability of the immigrant to live and interact in two spaces simultaneously. However, this placed the immigrant in a third dimension where they were incorporated in both communities separately but were not incorporated into a fluid transnational space. The nascent synergistic relationship showed an emergent duality that placed the immigrant in a more fluid position within both receiving and sending communities.

Transnational Field: Building on the description of transnationalism from below within this group of Nicaraguan immigrants, a discussion of the dynamics of the 
represented transnational fields supplements the exploration of the transnational space. An examination of the transnational fields prevalent in the engagement of these immigrant entrepreneurs is important to understand the distinct makeup of the activities undertaken by the group. The dominant breakdown of thematic fields in transnationalism segment the activities into economic, political, and sociocultural typologies (Reisenauer $\&$ Gerdes, 2012). These typologies allow for the examination of the specific mix of transnational activities undertaken by these immigrants and links activities to development outcomes in the host country.

Economic: The economic transnational field is often a primary focal point for examining the transboundary activities of the immigrants. This is especially evident when an individual has migrated from a developing country to an advanced economy. The movement of financial capital from the receiving country back to households within the sending community is one of the fundamental transnational activities established. This relationship was apparent within this study, as all of the immigrant entrepreneurs sent financial remittances to family members and friends from the time that they entered the local workforce. This transference of remittances began early in their journey and was often sent on a monthly basis, and often began as a larger percentage of their take home pay. As the immigrants integrated into their community and secured better employment the remittance level usually increased overall, but decreased as a percentage of take home pay. Remittances still remained prevalent in the group, even many years after living in the United States. They tended to send money back to a household member, or extended family member, and stated that this money was typically used for monthly expenses and to secure medical and educational support for the members of the family. The immigrants 
also provided financial assistance for emergent situations. These situations were typically a one-time occurrence or an unexpected happening, such as a medical emergency or a needed repair. This relationship lessened the vulnerability of migrant households and allowed the households to live with a higher level or resilience and economic integration within their community.

The predominant form of economic transnationalism happened at the household and individual level. The entrepreneurs cited a lack of trust in local leadership as a reason for avoiding investments in community projects. However, there were some incidents of higher level investment, demonstrating a potential for enhanced financial flows to the community as a whole. These community level investments were typically cultivated through a personal, trusted relationship with an individual within the project planning process and the immigrant. These personal relationships created a reliable liaison between immigrant and community projects and portrayed a sense of dependability and accountability that was lacking within the local government. The immigrants spoke about many community issues that they believed should be addressed within Villa Sandino but they believed the community should be the backbone of identifying these needs and organizing the subsequent projects. The immigrants focused on developing the autonomy and independence of community members and felt that they needed to be empowered and individual agency fostered in order for community level issues to be fully addressed. This demonstrates that the immigrants approached 'transnationalism from below' by focusing on 'development from below', investing in the individuals rather than the whole.

Return trips and personal investments were also a significant source of economic transnational engagement by this group. A common theme with the immigrant group was 
a concentration on returning to their home community at least once a year. The immigrants made more frequent and longer trips back to Villa Sandino once they started their own business and could enjoy a heightened sense of flexibility with their schedule. These return trips established an atmosphere where exchanges of knowledge and ideas were transferred between entrepreneur and town members directly. The trips also allowed the immigrants to stay connected to Villa Sandino and observe the needs of the community. Lastly, by physically returning to Villa Sandino the entrepreneurs were spending money in the community on basic daily purchases, as well as larger services and goods for family and friends. They were injecting financial capital directly into the community.

Personal investments were less frequently cited by this group but were specified as a long-term goal by many of the individuals. These investments were manifested in land and home purchases. A few of the immigrants purchased houses for the purpose of vacation and potential return migration and one had purchased several farms to build a local business and create an opportunity to actively engage in transnational entrepreneurship and eventually retire in Villa Sandino. The home and land purchases were typically linked to a desire for return migration, typically at the time of retirement from their positions in the United States. The goal to return to Nicaragua for their senior years was common, and this mentality encouraged specific investment strategies that were centered around self-interest.

Financial capital and economic ideas were commonly transferred through the production of knowledge bridges. They had a wealth of information and expertise that they collected through their distinct journeys because these immigrants were able to 
develop an entrepreneurial identity and successfully start a small business. Once they were able to feel confident in their business acumen and position as entrepreneurs they tended to see opportunity gaps along with skills and information that would be useful to their counterparts in Villa Sandino. The immigrants shared their know-how through informal as well as formal ways. Informally, immigrants imparted advice and guidance during return trips as well as through technologically aided communications. The entrepreneurs also created more formalized bridges by providing mini workshops through Skype and through guest speaking engagements at local schools and community events. Political: The political transnational field is often operationalized by implementing strategies that incentivize engagement in both the sending and receiving communities. These strategies include allowing immigrants to maintain voting rights while living abroad to encourage individuals to maintain an interest in their country of origin (Nyblade \& O’Mahony, 2014). Sending governments are also realizing that other synergistic opportunities exist. Governments are identifying diaspora groups abroad as potential liaisons that can be leveraged to lobby in the receiving countries political arena and create diplomatic and development bridges (Clemens, Özden \& Rapoport, 2014). Incentivizing emigrant membership in home-society through political incorporation and other rights transfers, generates goodwill and entices steady flows of investments and remittances from the diaspora (Itzigsohn, 2000; Goldring, 1998).

The political transnational field was not found to be a primary component of the engagement avenues undertaken by this group of immigrant entrepreneurs. The immigrants did not vote in local elections and none held office within their home countries. They also did not actively engage in political campaigning within Villa 
Sandino or serve as political liaisons, promoting Nicaraguan interests, within the United States. The political sector actually appeared to serve as a hindrance to the transnational interests of the immigrants. They cited a polarizing political atmosphere as an obstacle to community development within Villa Sandino and as a deterrent to actively engage in community projects.

The immigrant entrepreneurs revealed that living outside of their community allowed them to observe how political ideologies and deep rooted party alignments within families created rifts in the community and generated disruptive divides. Research has shown, by maintaining transnational relationships, especially with disadvantaged groups, transnational connections can weaken state control because these marginalized factions have new channels of association and are not as dependent on state controls and mandates (Spoonley, Bedford, \& Macpherson, 2003). This reality can weaken political culture. These immigrants approached their community contacts in a manner that bypassed political control and subverted traditional power structures. This may be indicative of transnational engagement weakening political party lines and challenging the mindset of a community with deeply engrained political turmoil. Although, political engagement was not a primary transnational activity discussed by the immigrant entrepreneur group, their actions and neutralizing perspectives may have larger political ramifications. Conversely, the absence of political engagement may ultimately limit the impact of their transnational engagement within their community and may fail to address some of the most pressing issues facing their home community.

Sociocultural: The last transnational field that will be discussed within the realm of this study are the socio-cultural connections. This transnational field is often 
intangible and is composed of ideas, values, and knowledge that is shared through the perspectives of immigrants to residents of their communities of origin. One major concept that is transferred in both informal and formal manners relates to the area of gender equity. It is significant that four of the entrepreneurs in this study are female. Their business success alone makes them forceful role models for young women in the community of Villa Sandino. Gender issues were discussed in the realm of domestic violence, household inequalities, and differences in opportunities and expectations for female youth. Local mentalities can shift and community expectations can expand to allow for a more equitable atmosphere by understanding that women have the capacity and potential to create their own livelihoods. Specific incidents of immigrant entrepreneurs serving as a business mentor for female start-ups in the community of origin were shared and investments into trainings and workshops for the local women's cooperatives and high schools were also highlighted. A complementary, and important, dynamic to this gendered transnational behavior was shaping the perspectives of male community members alongside the investments into female residents. Both the female and male entrepreneurs were able to exhibit an equitable outlook on gender and this attitude was observed by local members of the town. Gender norms and roles could be addressed through the transnational space by sharing ideas and attitudes about positive integration and equal rights of males and females.

An emergent characteristic in the conversations was how the immigration and entrepreneurial journeys supported the development of a strong sense of self of the immigrant. They described moving from a communal society into a situation that required a higher level of independence and self-reliance. This transition fostered the 
production of individuality within the immigrants and allowed them to explore their unique interests and passions. This sense of self also manifested a high degree of determination and resilience, where they were able to place self-interest above family or communal needs. This individualistic capacity generated an enhanced sense of esteem and confidence and led to a propensity towards self-advocacy and advocacy for others. The relationship between the immigrants shift to an autonomous entity along with their continued relationship transnational relationships is significant. The connection to community may feel threatened as one becomes more individualistic and independent. The interviews demonstrated an underlying sense of responsibility and connectedness that created a lasting relationship between immigrant and community members. However, a clear focus on individual to individual, or household, relationship was evident. The newfound individuality of the immigrants may influence their transnationality by focusing on the importance of investing their time, money and energy into the development of individual community members rather than the community as a whole. This produces a situation where the community leaders will need to establish a platform to capitalize on the increased human capital on an individual level in order to organize the efforts in a way that will reap benefits at the communal level. The immigrants focus on developing a sense of individuality and self-reliance is an important concept that they are in effect transferring through their actions. In this manner, the community members are able to develop individual agency and become empowered change agents.

The immigrants also noted an increased awareness of the importance of creativity and innovation in their journey and cited a lack of these attributes within the community 
of Villa Sandino. Creativity manifested itself in the form of resourceful problem solving, innovative idea generation, and the ability to imagine a prosperous future and set goals to reach specific, envisioned objectives. This lack of imagination and resourcefulness was referred to as a detrimental reality of the mentality of members of the Villa Sandino community. This characteristic was essential to the ability of the immigrants to imagine, plan, and establish their own business. Creativity and innovative thought are traits that could be transferred through idea sharing, continued communication, and modelling on the part of the immigrant upon return trips or through technological connectivity. Imparting an inventive perspective will support short-term resiliency while building an atmosphere of productive, long-term visioning.

\subsection{Conclusions}

This study explored how transnationalism was operationalized by a group of individuals from Villa Sandino, Nicaragua that have immigrated to the United States and subsequently started entrepreneurial ventures. The purpose of investigating this phenomenon through this specific group was to explore the journey these immigrants took through immigration, integration, and entrepreneurial start-up and examine the transnational engagement undertaken by this group to provide a deeper understanding that can influence programs and policies in both the business and migration fields. Recognizing the nature of transnational engagement of these individuals can also guide both the receiving and sending communities to develop more supportive and beneficial migrant engagement strategies.

The transmigrant holds a valuable position as an individual that understands and has ties to two cultures. This group of Nicaraguan immigrant entrepreneurs demonstrated 
this duality by describing their ability to successfully integrate into their receiving communities while maintaining cultural traditions and relationships with their sending communities. This group navigated the spectrum of informal and formal through their transnational activities. A large percentage of the local workforce in Villa Sandino is integrated into an informal economy and social networks. When the individuals immigrated to the United States they began to integrate into a more structured and organized social and economic framework. They cited this structure as a unifying force that allowed them to understand their new communities in an expedient way and gave them a sense of equity with other community members. They also noted that this structure was lacking in their home communities and led to biased and discriminatory practices and weakened community solidarity. On the other hand, their ability to navigate an informal setting helped them be flexible and adaptable within their pursuits. The informal nature of their community of origin also allowed for a comfortable and intimate social network and deconstructed the rigid expectations and bureaucracy that is faced with a regulated and controlled environment. Many times external interventions into developing, rural communities can be overly measured and structured, leading to inflexibility to incorporate the competing cultural norms. The immigrant entrepreneurs were able to introduce ideas and programs in a manner that paid tribute to the fluidness of local customs while slowly adding formal structure to generate a sustainable outcome.

Additionally, the immigrants played an important role in transforming pertinent knowledge, ideas, and resources into information that was easily digested by the community of origin. It is clear that there is valuable material and knowledge that is available within an advanced economy such as the United States. The immigrants come 
in contact with different concepts and instruments through their experiences integrating into a new culture and subsequently starting a business. These skills, perspectives, and expertise are valuable tools that could be operationalized within developing communities, however they are often targeted towards ecosystems with drastically different community capitals. The immigrants are able to translate these materials and ideas into usable and practical resources at a local level because of their duality of awareness and understanding. It is important to incorporate these diasporas into beneficial engagement strategies in both sending and receiving countries to expand the power of this distinct transnational space because of the unique position the immigrants hold as liaisons between two diverse cultures.

In general, when viewing this cycle of integration and transnational engagement, one of the predominant observations at the receiving country level is the how immigration policy has affected this group. A significant commonality within this group was the focus on family-based adjustment of status as the primary immigration strategy. Although these individuals became entrepreneurs and are recognized as business entities, they did not establish their legal status within the United States based on employment or labor visas. These individuals relied on connections with family members that had already become Permanent Residents or United States Citizens in order to obtain appropriate documentation. It is relevant to understand the reliance on family-based immigration accessibility for individuals living in countries and communities with limited ability to migrate based on technical or professional skills. Remittances and transnational engagement between immigrants and their home communities establishes a linkage that transfers financial and social capital from an advanced economy to developing nations 
and is substantial when discussing impacts and development goals. These activities surpass the foreign aid contributed by the United States to Nicaragua. If family-based immigration is reduced, this transnational bridge will constrict and development needs may increase. The United States can directly impact development goals within Nicaragua without expanding foreign aid levels by understanding how to harness and expand the influence of these transnational actors. It will be imperative to consider this relationship when considering the reduction or obstruction of the ability of individuals to immigrate based on familial relationships and realize how immigration patterns will transform within distinct countries and specifically rural communities.

Appropriate engagement strategies are essential to optimize the ability of the immigrants to self-actualize and become powerful transnational figures at a community level. It was found that investments in expanding the connectivity and availability of trusted institutions that can serve to support newly arriving immigrants is essential within the receiving community. The immigrants described finding initial connections and a sustained connection with their cultural values through attending local churches. Further, services provided through their affiliations with religious institutions helped the immigrants connect with jobs and expand their local social network. The Nicaraguan entrepreneurs commonly sought out institutions that provided English language training as an initial approach to building an essential skill that allowed them to integrate more quickly into their local community. They found language training through immigrant focused NGOs as well as community colleges. The English courses connected the immigrants to other non-native individuals, allowing them to associate with others going through similar integration journeys and creating an empathetic support system. These 
institutions were valued and trusted amongst the group and may serve as a valuable connector point to other local services. Connecting community services through religious and language based organizations can give the immigrant group access to a more diverse support network and direct them to training opportunities to promote meaningful incorporation into the local workforce and society.

Another constructive engagement strategy that emerged from this study was the importance of acknowledgement and recognition by the local business community for the budding entrepreneurs. The immigrants shared that they entered into their business ventures out of a mix of necessity and opportunity driven motivations. A common sentiment was the lack of an entrepreneurial identity when they started their businesses. However, as they became more successful and were incorporated into the local business ecosystem, their confidence grew and they began to recognize their own abilities and value. Creating acknowledgement practices for immigrant entrepreneurs will aid in developing their self-esteem and conviction as entrepreneurs, strengthening their contribution at a local level and allowing them to intervene in a transnational space with a clear identity. This recognition can take the form of invitations to local business luncheons or workshops, invitations to speak at local events or school business classes, incorporation into the chamber of commerce and local awards. It is beneficial for these events to be immigrant focused, but is more valuable for the recognition and events to integrate both immigrant and non-immigrant entrepreneurs. This will create business networks that are diversified and varied and demonstrate that the immigrant entrepreneurs are as influential as their non-immigrant counterparts. 
It was also found that acknowledgement and recognition motivate an entrepreneur to engage in the community in a manner that expands beyond their focus on the household within the sending community. It was also evident that the immigrant entrepreneurs preferred to invest in individuals rather than the community as a whole. They felt a stronger connection and sense of purpose when working on the individual level and also were able to avoid engaging with leadership that they mistrusted and believed were ineffective program administrators. The focus on the individual also emerged from their newfound sense of independence and autonomy and allowed them to affect the human capital of their home community directly. The importance of this personal connection was a shared perspective and injected knowledge and resources directly into the community but lacked a concentration on supporting the "community as a whole'. The community of Villa Sandino would benefit from creating a strategic and persistent emigrant engagement plan because of this reality. One prong of this plan should focus on organizing the individuals that are benefiting from these immigrant transactions to become active in community development initiatives and to provide opportunities for development and trainings for these individuals within the community. Secondly, the community should create an interface that actively engages with its emigrant population and incorporates them into community discussions and strategic planning. One of the pitfalls of the transnational environment within this group is the focus on individual connections but a lack of engagement at the community level. By creating community driven relationship building, the immigrants will feel acknowledged and included and will be able to voice their opinions and insights. This could happen through live streaming of community meetings, creating an immigrant-based committee 
that would consistently engage in dialogue with leaders, inviting the immigrants to interact with the community through speaking engagements or specialized trainings, and other communal associations.

The sending region would also benefit from encouraging the establishment of transnational businesses as well as local entrepreneurial endeavors by this group on a community and country level. Incentivizing local investments through optimizing the local regulatory environment and providing unique opportunities and tax benefits for transnational investment could promote an expansion of the local economy and workforce. The local leaders believed Villa Sandino could benefit from a replication of the entrepreneurs creating similar businesses within the local community. However, the immigrants did not show a propensity towards this activity. The entrepreneurs could impart their specialized knowledge and skill at a local level while reaping benefits as a business owner by actively promoting this type of transnational engagement. This activity could have a ripple effect by motivating the local residents and stimulating employment opportunities while inspiring the local youth to pursue their future with an entrepreneurial mindset.

Finally, and possibly most significantly, the advancement of and access to technology appears to be the cornerstone for enhanced and meaningful transnationalism within this group. The immigrants shared how the maintenance of connections with their hometown was drastically different years ago because of the comparative lack of technology. Immigrants shared that they typically could only speak to a select few family members on a prearranged basis. This communication took place over phone calls with limited service and expensive calling cards. Immigrants are now able to utilize various 
technological applications to stay connected with a diverse range of individuals from their community. They are able to make free phone calls and video chat on a consistent basis and with a wide range of individuals. This advancement of technology has allowed the immigrants to maintain an expanded social network and stay apprised of community happenings. It is clear that further advancement in technology will be even more beneficial for creating a dynamic transnational space. In fact, establishing platforms and applications with the specific motives of engaging immigrant populations in their home community and creating more effective technological bridges where knowledge and ideas can easily be transferred should be a focus for fostering transnationalism and promoting community involvement by immigrant populations. This may have the most dramatic effects on cultivating effective and active transmigrants and creating empowering cycles of engagement that allow for bidirectional flows between sending and receiving communities.

\subsection{Future Research}

The purpose of this study was to understand transnationalism from the perspective of immigrant entrepreneurs with the intention of enhancing development opportunities for sending communities. A focus was placed on collecting interviews from immigrant entrepreneurs from the community of Villa Sandino via skype conversations. Because of the limited time and financial resources associated with this research, only limited community level research could be undertaken. Three community leaders were chosen to discuss the effects of migration and transnationalism on the community of Villa Sandino. Future research would benefit from concentrating on a community level analysis to further complement the immigrant focused research. This approach would produce a 
parallel exploration of immigrant and community of origin experiences and would generate a more comprehensive understanding on community level impacts, needs, and perspectives. It would be effective to incorporate individual, household, and community level entities in this analysis and to ensure the inclusion of typically marginalized and vulnerable groups. This approach should embrace a thorough exploration of the unique community capitals that exist in Villa Sandino and how the development and interactions of these capitals can be enhanced through targeted emigrant engagement.

Additionally, an exploration of the transmigrant network and the interaction patterns of immigrants within the receiving country would add insight into how diaspora groups that are less saturated and more geographically dispersed engage with each other. Fostering ties within the immigrant populations from similar regions will generate a multiplier effect with their transnational activities and can encourage larger and more directed involvement. It would also be beneficial to investigate the transnational engagement of second and third generation immigrants. This study focused on first generation immigrants from Villa Sandino and this influenced their level of integration and transnational engagement. However, it is important to understand how subsequent generations relate back to the sending communities. Do their relationships remain strong or weaken with time and distance? Understanding this pattern will create insights into the potential for fostering transnational communities and strengthening the overall transnational space. 


\section{References}

Ambrosius, C., \& Cuecuecha, A. (2016). Remittances and the use of formal and informal financial services. World Development, 77, 80-98. doi:10.1016/j.worlddev.2015.08.01

Al-Ali, Nadje and Koser, Khalid, eds. (2002) New Approaches to Migration:

Transnationalism and Transformations of Home. London; New York: Routledge. (Routledge Research in Transnationalism)

Audretsch, D. B. (2004). Sustaining Innovation and Growth: Public Policy Support for Entrepreneurship. Industry \& Innovation,11(3), 167-191. doi:10.1080/1366271042000265366

Barajas, M. (2009). The Xaripu community across borders: Labor, migration, community, and family. Notre Dame, IN: University of Notre Dame Press.

Bauböck, R., \& Faist, T. (2010). Diaspora and Transnationalism Concepts, Theories and Methods. Amsterdam University Press.

Basch, Linda; Glick Schiller, Nina \& Szanton Blanc, Cristina (1994) Nations unbound: transnational projects, postcolonial predicaments and deterritorialized nation-states, Amsterdam: Gordon and Breach.

Beard, V., \& Sarmiento, C. (2010). Ties that bind: Transnational community-based planning in southern California and Oaxaca. International Development Planning Review, 32(3-4), 207-224. DOI: 10.3828/idpr.2010.06

Bisin, A and Verdier, T. (2000): "Beyond the Melting Pot: Cultural Transmission, Marriage and the Evolution of Ethnic and Religious Traits," Quarterly Journal of Economics, 115, 955ñ88.

Bonacich, E. (1973). A Theory of Middleman Minorities. American Sociological Review,38(5), 583. doi:10.2307/2094409

Borjas G.J. 1990, Friends and Starnrers: The Impact of Immigration on the Economy. Bourdieu, P. (1986). The forms of capital. S.l. Handbook of Theory and Research for the Sociology of Education. P. 241-258.

Bowling, B. (2009). Transnational Policing: The Globalization Thesis, a Typology and a Research Agenda. Policing,3(2), 149-160. doi:10.1093/police/pap001

Braziel, J. E., \& Mannur, A. (2008). Theorizing diaspora: a reader. Malden, MA,: Blackwell Pub. 
Bridger, J. C., \& Luloff, A. (1999). Toward an interactional approach to sustainable community development. Journal of Rural Studies, 15(4), 377-387.DOI: 10.1016/s0743-0167(98)00076-

Brinkerhoff, J. M. (2008). Diasporas and development: Exploring the potential. Boulder, CO: Lynne Rienner.

Burck, C. (2005). Positioning the Researcher. Multilingual Living, 158-168. doi:10.1057/9780230508675_8

Boyer, J. (2010). Food security, food sovereignty, and local challenges for transnational agrarian movements: The Honduras case. Journal of Peasant Studies, 37(2), 319-351. DOI: $10.1080 / 03066151003594997$

Brown, S., \& Bean, F. (2006). Assimilation Models, Old and New: Explaining a LongTerm Process. Retrieved April 12, 2017, from http://www.migrationpolicy.org/article/assimilation-models-old-and-new-explaininglong-term-process

Carling, J., \& Pettersen, S. V. (2014). Return Migration Intentions in the IntegrationTransnationalism Matrix. International Migration,52(6), 13-30. doi:10.1111/imig.12161

Carlino, Gerald A. (2001) Business Review Knowledge Spillovers: Cities' Role in the New Economy. Q4 2001.

Castles, S., \& Ranis, G. (2008, March). Migration and Development: Future Directions for Research and Policy. Presented at Social Science Research Council Conference. Retrieved February 19, 2017, from http://essays.ssrc.org/developmentpapers/wpcontent/uploads/MigrationDevelopmentSSRCConferencePapers.pdf

Center, A. I. (n.d.). American Immigration Center. Retrieved December 31, 2017, from https://www.us-immigration.com/blog/trumps-raise-act-proposes-merit-basedimmigration-system

Chambers, R. \& Conway, GR. (1991) Sustainable Rural Livelihoods: Practical Concepts for the 21st Century. IDS Discussion Paper 296, IDS (Institute of Development Studies), UK. 33 pp. 
Clemens, M. A., Özden, Ç, \& Rapoport, H. (2014). Migration and Development Research is Moving Far Beyond Remittances. World Development, 64, 121-124. DOI:10.1016/j.worlddev.2014.05.018

Collyer, M., \& King, R. (2015). Producing transnational space. Progress in Human Geography,39(2), 185-204. doi:10.1177/0309132514521479

Compete Caribbean. (n.d.). Retrieved April 18, 2017, from http://competecaribbean.org/

Conradson, D., \& Latham, A. (2005). Friendship, networks and transnationality in a world city: Antipodean transmigrants in London. Journal of Ethnic and Migration Studies,31(2), 287-305. doi:10.1080/1369183042000339936

Creswell, J. W. (2014). Research design: qualitative, quantitative, and mixed methods approaches. Thousand Oaks: SAGE Publications.

Creswell, J. W. (1998) and (2013). Qualitative inquiry and research design: choosing among five traditions. Thousand Oaks, Calif.: Sage.

Davila, A. E., \& Mora, M. T. (2013). Hispanic entrepreneurs in the 2000s: an economic profile and policy implications. Stanford, CA: Stanford University Press.

De Haan, Leo J. (2000). Globalization, Localization and Sustainable Livelihood. Sociologia Ruralis. 40(3): 339-365.

Délano, A. (2014). The diffusion of diaspora engagement policies: A Latin American agenda. Political Geography, 41, 90-100. DOI: 10.1016/j.polgeo.2013.11.007

Delanty, Gerard. (2003). Community, Routledge, New York.

Durkheim, É. (1964). The division of labor in society. New York: Free Press of Glencoe.

Ellis, F. (1998). Household strategies and rural livelihood diversification. Journal of Development Studies,35(1), 1-38. doi:10.1080/00220389808422553

Erdal, M. B., \& Oeppen, C. (2013). Migrant Balancing Acts: Understanding the Interactions Between Integration and Transnationalism. Journal of Ethnic and Migration Studies,39(6), 867-884. doi:10.1080/1369183x.2013.765647

Fairlie, R. W. (n.d.). Minority and immigrant entrepreneurs: access to financial capital. International Handbook on the Economics of Migration,153-175. doi:10.4337/9781782546078.00016 
Faist, T. (2012). Toward a Transnational Methodology: Methods to Address Methodological Nationalism, Essentialism, and Positionality. Revue européenne des migrations internationales,28(1), 51-70. doi:10.4000/remi.5761

Faist, T. (2007). Migrants as transnational development agents: an inquiry into the newest round of the migration-development nexus. Population, Space and Place,14(1), 21 42. doi:10.1002/psp.471

Faist, Thomas (2004a) The border-crossing expansion of social space: concepts, questions and topics, in Thomas Faist and Eyüp Özveren Eds., Transnational Social Spaces: Agents, Networks and Institutions, Aldershot, UK, Ashgate, pp. 1-36.

Faist, Thomas (2004b) Towards a political sociology of transnationalism, European Journal of Sociology, 45 (2), pp. 331-366.

Faist T. (2004). The Volume and Dynamics of International Migration and Transnational Social Spaces. Oxford: Oxford University Press.

Faist, T. (2000). The Bridging Function of Social Capital: Transnational Social Spaces. The Volume and Dynamics of International Migration and Transnational Social Spaces,195-241. doi:10.1093/acprof:oso/9780198293910.003.0007

Faist, Thomas. (n.d.). Transnationalism: Migrant Incorporation beyond Methodological Nationalism. Retrieved January 16, 2017, from https://heimatkunde.boell.de/2011/05/18/transnationalism-migrant-incorporationbeyond-methodological-nationalism

Fetsch, E. (2015). Left Behind? The New Generation of Latino Entrepreneurs. Retrieved April 12, 2017, from http://www.kauffman.org/blogs/growthology/2015/04/the-newgeneration-of-latino-entrepreneurs

Filipovic, J., Devjak, S., \& Ferfila, B. (n.d.). Diaspora Engagement Strategies and Policies. doi:UDK: 314.151.1(045)

Flora, J. L. (1998). Social Capital and Communities of Place1. Rural Sociology, 63(4), 481-506.

Flora, C. B. 2004. "Social Aspects of Small Water Systems." Journal of Contemporary Water Research and Education 128: 6-12.

Flora, C. B., \& Flora, J. L., (2008). Rural communities: legacy and change. Boulder, CO: Westview Press. 
Flores-Yeffal, N. Y., \& Aysa-Lastra, M. (2011). Place of Origin, Types of Ties, and Support Networks in Mexico-U.S. Migration*. Rural Sociology, 76(4), 481-510.

Foucault, M. (1982). The Subject and Power. Critical Inquiry,8(4), 777-795. doi:10.1086/448181

Fouron, G. E., \& Glick-Schiller, N. (2001). The generation of identity: Redefining the second generation within a transnational social field. In H. Cordero-Guzman, R. C. Smith, \& R.

Gadamer GH (1989) Truth and Method. Second edition (translation revised by Weinsheimer J, Marshall DG). London, Sheed and Ward.

Garrett, Natasha. (2011). Transnationalism, Home and Identitiy: Personal Essays. (Doctoral dissertation).

Gamlen, A. (2008). The emigration state and the modern geopolitical imagination. Political Geography, 27(8), 840-856. DOI:10.1016/j.polgeo.2008.10.004

Gamlen, A. (2006). Diaspora Engagement Policies: What are they, and what kinds of states use them? Centre on Migration, Policy and Society: Working Paper No. 32.

Garip, F. (2012). Repeat Migration and Remittances as Mechanisms for Wealth Inequality in 119 Communities From the Mexican Migration Project Data. Demography, 49(4), 1335-1360.

DOI: $10.1007 / \mathrm{s} 13524-012-0128-6$

Glick Schiller N., Basch L. and Blanc-Szanton C. 1991. Towards a Transnational Perspective on Migration. New York: New York Academy of Sciences.

Global Diaspora Week. (n.d.). Retrieved April 18, 2017, from http://www.diasporaalliance.org/global-diaspora-week/

Goldring, L. (1998), 'The power of status in transnational social fields', in M.P. Smith \& L. E. Guarnizo (eds.), Transnationlism from Below, 165-195. New Brunswick Grosfoguel (Eds.), Migration, transnationalization \& race in a changing New York (pp. 58-86). Philadelphia, PA: Temple University Press.

Guarnizo L., Portes A. and Haller W. (2003). Assimilation and Transnationalism: Determinants of Transnational Political Action Among Contemporary Migrants. American Journal of Sociology108(6):1211-1248. 
Guarnizo, Luis E. (2017) The migration-development nexus and the changing role of transnational immigrant organizations, Ethnic and Racial Studies, 40:3, 457-465, DOI: $10.1080 / 01419870.2017 .1249496$

Guba, E., \& Lincoln, Y. (1981). Effective evaluation. San Francisco: Jossey-Bass.

Hall, Stuart (1990) 'Cultural identity and diaspora' in Jonathan Rutherford (ed.) Identity: community, culture, difference, London: Lawrence \& Wishart

Haas, H. D. (2010). Migration and Development: A Theoretical Perspective 1. International Migration Review,44(1), 227-264. Doi:10.1111/j.17477379.2009.00804.x

Harris J.R., Todaro M. P., 1970, Migration Unemployment and Development: a twosector analysis. American Economic Association, 60(1), 126-142.

Harvey, D. (1990). The condition of postmodernity an enquiry into the origins of cultural change. Oxford: Blackwell.

Hertel, S. (2006). New moves in transnational advocacy: Getting labor and economic rights on the agenda in unexpected ways. Global Governance, 12, 263-281.

Hobbs, A. W., \& Jameson, K. P. (2011). Measuring the effect of bi-directional migration remittances on poverty and inequality in Nicaragua. Applied Economics, 44(19), 2451-2460. DOI: 10.1080/00036846.2011.564153

Ite, U. E. (2002). Turning Brain Drain into Brain Gain: Personal Reflections on Using the Diaspora Option. African Issues, 30(1), 76. DOI: 10.2307/1167096

Itzigsohn, J. (2000). Immigration and the Boundaries of Citizenship: The Institutions of Immigrants' Political Transnationalism. International Migration Review,34(4), 1126. doi: $10.2307 / 2675977$

Immigration. (n.d.). Retrieved April 10, 2017, from http://www.kauffman.org/microsites/state-of-the-field/topics/background-ofentrepreneurs/demographics/immigration

International diaspora Engagement Alliance. (n.d.). Retrieved April 18, 2017, from https://www.state.gov/s/partnerships/diaspora

Jackson, P., Craig, P., \& Dwyer, C. (2004). Transnational spaces. London: Routledge. 
Katigbak, E. O. (2015). Moralizing emotional remittances: Transnational familyhood and translocal moral economy in the Philippines 'Little Italy'. Global Networks, 15(4), 519-535. doi:10.1111/glob.12092

Kennedy, P. and Roudometof, V., 2002. 'Transnationalism in a Global Age' in Kennedy, P. and Roudometof, V. (eds.), Communities Across Borders: New Immigrants and Transnational Cultures, London: Routledge, pp. 1-26.

Kivisto, P., \& Faist, T. (2008). Citizenship: discourse, theory and transnational prospects. Malden, MA: Blackwell Publishing.

Krogstad, J. M. (2016, September 08). Key facts about how the U.S. Hispanic population is changing. Retrieved June 04, 2017, from http://www.pewresearch.org/facttank/2016/09/08/key-facts-about-how-the-u-s-hispanic-population-is-changing/

Kushnirovich, N. (2015). Economic Integration of Immigrant Entrepreneurs. Entrepreneurial Business and Economics Review,3(3), 9-27. doi:10.15678/eber.2015.030302

Lafleur, J. (2015). The enfranchisement of citizens abroad: Variations and explanations. Democratization, 22(5), 840-860. DOI: 10.1080/13510347.2014.979163

Lefebvre, Henri. (1991). The Production of Space. Malden: Blackwell Ltd. Translated by Donald Nicholson-Smith.

Levitt, P., \& Lamba-Nieves, D. (2010, May 21). "It's Not Just About the Economy, Stupid" - Social Remittances Revisited. Retrieved April 10, 2017, from http://www.migrationpolicy.org/article/its-not-just-about-economy-stupid-socialremittances-revisited

Levitt P, Nyberg Sørensen N. 2004. The transnational turn in migration studies, Global Commission on International Migration, Geneva

Light, I. H. (1973). Ethnic enterprise in America: business and welfare among Chinese, Japanese, and Blacks. Berkeley: University of California Press.

Light, I., \& Bonacich, E. (1991). Immigrant entrepreneurs: Koreans in Los Angeles 1965 - 1982. Berkeley: Univ. of California Press.

Lin, N. (1999). Institutions, Networks, and Capital Building. A Theory of Social Structure and Action Social Capital, 184-209. DOI: 10.1017/cbo9780511815447.01 
López, G., \& Stepler, R. (2016, January 19). Latinos in the 2016 Election: Missouri.

Retrieved June 04, 2017, from http://www.pewhispanic.org/fact-sheet/latinos-in-the2016-election-missouri/

Macbeth, Douglas. (2001). On "Reflexivity" in Qualitative Research: Two Readings, and a Third. Qualitative Inquiry, Volume 7. Number, 2001. P 35-68.

Massey, D. (2005) For Space, London; Thousand Oaks, Calif.: Sage.

Massey, D. S., Arango, J., Hugo, G., Kouaouci, A., Pellegrino, A., \& Taylor, J. E. (1993).

Theories of International Migration: A Review and Appraisal. Population and Development Review,19(3), 431. Doi:10.2307/2938462

Maxwell, J. A. (2013). Qualitative research design: an interactive approach. Thousand Oaks, CA: SAGE Publications.

Mercado, A. (2013). El Tequio: Social capital, civic advocacy journalism and the construction of a transnational public sphere by Mexican indigenous migrants in the US. Journalism, 16(2), 238-256. DOI: 10.1177/1464884913509782

MERIC (2005). Latino Entrepreneurs in Missouri: Policy Implications for Small Business Development Programs. Missouri Economic Research and Information Center Missouri Department of Economic Development. Retrieved from https://www.missourieconomy.org/pdfs/latino_entrepreneurs.pdf.

Merriam, S. (2009). Qualitative research: A guide to design and implementation. San Francisco, CA: Jossey-Bass.

Meyer, J. (2001). Network Approach versus Brain Drain: Lessons from the Diaspora. Int Migration International Migration, 39(5), 91-110. DOI: 10.1111/1468-2435.00173

Migration and Development. (2015, April 08). Retrieved January 17, 2017, from http://www.iom.int/migration-and-development.

Miraftab, F. (2011). Faraway Intimate Development: Global Restructuring of Social Reproduction. Journal of Planning Education and Research, 31(4), 392-405. DOI: $10.1177 / 0739456 \times 11420573$

Moran-Taylor, M. (2008). Guatemala's Ladino and Maya Migra Landscapes: The Tangible and Intangible Outcomes of Migration. Human Organization, 67(2), 111124. DOI: 10.17730/humo.67.2.718p7k3p312m66u5 
Meyer, J. (2001). Network Approach versus Brain Drain: Lessons from the Diaspora. Int Migration International Migration, 39(5), 91-110. DOI: 10.1111/1468-2435.00173

Mountz, A., \& Wright, R. A. (1996). Daily Life in the Transnational Migrant Community of San Agustín, Oaxaca, and Poughkeepsie, New York. Diaspora: A Journal of Transnational Studies,5(3), 403-428. doi:10.1353/dsp.1996.0017

Naude, W., Siegel, M., \& Marchand, K. (2015). Migration, entrepreneurship and development: A critical review. Maastricht Economic and social Research institute on Innovation and Technology (UNU-MERIT), 1-23.

Newland, K., \& Patrick, E. (2004). Beyond Remittances: The Role of Diaspora in Poverty Reduction in their Countries of Origin. Migration Policy Institut. Retrieved March 2, 2016, from http://www.migrationpolicy.org/research/beyond-remittancesrole-diaspora-poverty-reduction-their-countries-origin

Nicaragua profile - Timeline. (2017, July 05). Retrieved March 28, 2018, from http://www.bbc.com/news/world-latin-america-19909695

Nicaragua Demographics Profile 2014. (n.d.) Retrieved May 6, 2015, from http://www.indexmundi.com/Nicaragua/demographics_profile.html

Nichols, C. M. (2009). Rethinking Randolph Bourne's Trans-National America: How World War I Created an Isolationist Antiwar Pluralism. The Journal of the Gilded Age and Progressive Era,8(02), 217-257. doi:10.1017/s1537781400001158

Noorloos, F. V. (2011). A transnational networked space: Tracing residential tourism and its multi-local implications in Costa Rica. International Development Planning Review, 33(4), 429-444. DOI: 10.3828/idpr.2011.22

Nyblade, B., \& O’Mahony, A. (2014). Migrants’ Remittances and Home Country Elections: Cross-National and Subnational Evidence. Studies in Comparative International Development St Comp Int Dev, 49(1), 44-66. DOI: 10.2307/3088896

Nye, J., \& Keohane, R. O. (1971). Transnational Relations and World Politics: An Introduction. International Organization,3(25), 329-349. doi:10.4159/harvard.9780674593152.intro

O'brien, C. (2015). Transnational issue-specific expert networking: A pathway to local policy change. .Social Science \& Medicine, 146, 285-291. DOI: 10.1016/j.socscimed.2015.10.017 
O’Neil, Kevin. (2003). Remittances from the United States in Context. Retrieved March 19, 2016, from http://www.migrationpolicy.org/article/remittances-united-statescontext

Orozco, M., Porras, L., \& Yansura, J. (2016). The Continued Growth of Family Remittances to Latin America and the Caribbean in 2015. Inter-American Dialogue. Retrieved March 3, 2016, from http://www.thedialogue.org/wpcontent/uploads/2016/02/2015-Remittances-to-LAC-2122016.pdf

Orozco, M. (2009). Migration and remittances in times of recession: Effects on Latin American economies. Inter-American Dialogue. Retrieved from https://www.oecd.org/dev/americas/42753222.pdf.

Patton, M. Q. (2015). Qualitative research and evaluation methods integrating theory and practice. Los Angeles, CA: Sage.

Phillips, N. (2009). Migration as development strategy? The new political economy of dispossession and inequality in the Americas. Review of International Political Economy, 16(2), 231-259. DOI: 10.1080/09692290802402744

Pillow, W. (2003). Confession, catharsis, or cure? Rethinking the uses of reflexivity as methodological power in qualitative research. International Journal of Qualitative Studies in Education,16(2), 175-196. doi:10.1080/0951839032000060635

Piore, M. J. (1980). Birds of passage: migrant labor and industrial societies. Cambridge: Cambridge University Press.

Portes, A., \& Rumbaut, R. G. (2014). Immigrant America: a portrait. Berkeley, CA: Univ. of Calif. Press.

Portes, A., Escobar, C., \& Radford, A. W. (2002). Immigrant Transnational Organizations And Development: A Comparative Study. Transnationalism: Diasporas and the Advent of a New (dis)order Transnationalism, 559-594. DOI: 10.1163/ej.9789004174702.i-788.195

Portes, A., Guarnizo, L. E., \& Haller, W. J. (2002). Transnational Entrepreneurs: An Alternative Form of Immigrant Economic Adaptation. American Sociological Review, 67(2), 278. DOI: $10.2307 / 3088896$ 
Portes, A., Guarnizo, L. E., \& Landolt, P. (1999). The study of transnationalism: pitfalls and promise of an emergent research field. Ethnic and Racial Studies,22(2), 217-237. doi:10.1080/014198799329468

Portes, A. (1999). Conclusion: Towards a new world - the origins and effects of transnational activities. Ethnic and Racial Studies,22(2), 463-477. doi:10.1080/014198799329567

Portes, A. (1998). The economic sociology of immigration: essays on networks, ethnicity, and entrepreneurship. New York: Russell Sage Foundation.

Portes, A., \& Macleod, D. (1996). Educational Progress of Children of Immigrants: The Roles of Class, Ethnicity, and School Context. Sociology of Education,69(4), 255. doi:10.2307/2112714

Portes, Alejandro and Min Zhou. 1993. "The New Second Generation: Segmented Assimilation and Its Variants." Annals of the American Academy of Political and Social

Portes, A., \& Bach, R. L. (1985). Latin journey: Cuban and Mexican immigrants in the United States. Berkeley: University of California Press.

Pries, L. 2001. The approach of transnational social spaces: responding to new configurations of the social and the spatial. In Pries, L. editor, New Transnational Social Spaces: International Migration and Transnational Communities in the Early Twenty-First Century. London: Routledge, 3-33.

Qin, H., \& Flint, C. (2012). The Impacts of Rural Labor Out-Migration on Community Interaction and Implications for Rural Community-Based Environmental Conservation in Southwest China. Human Organization, 71(2), 135-148. doi:10.17730/humo.71.2.2864132502219150

Reisenauer, E., \& Gerdes, J. (2012). From Return-Oriented to Integration-Related Transnationalisation: Turkish Migrants in Germany. Revue européenne des migrations internationales,28(1), 107-128. doi:10.4000/remi.5797

Remittance Data. (2014, March 28). Retrieved January 16, 2017, from http://www.migrationpolicy.org/article/remittance-data 
Rudel, T. K. (2006). After the labor migrants leave: The search for sustainable development in a sending region of the Ecuadorian Amazon. World Development, 34(5), 838-851.

Sagynbekova, L. (2016). The impact of international migration: process and contemporary trends in Kyrgyzstan. Switzerland: Springer.

Sandoval, G. F. (2013). Shadow Transnationalism: Cross-Border Networks and Planning Challenges of Transnational Unauthorized Immigrant Communities. Journal of Planning Education and Research, 33(2), 176-193. DOI:

$10.1177 / 0739456 \times 12469881$

Schiller, N. G., Basch, L., \& Blanc, C. S. (1995). From Immigrant to Transmigrant: Theorizing Transnational Migration. Anthropological Quarterly,68(1), 48. doi: $10.2307 / 3317464$

Schiller, N. G., Basch, L., \& Blanc-Szanton, C. (1992a). Transnationalism: A New Analytic Framework for Understanding Migration. Annals of the New York Academy of Sciences,645(1 Towards a Tra), 1-24. doi:10.1111/j.1749-6632.1992.tb33484.x

Schiller, N. G., Basch, L., \& Blanc-Szanton, C. (1992b) Towards a Definition of Transnationalism. Annals of the New York Academy of Sciences, 645(1 Towards a Tra), Ix-Xiv. doi:10.1111/j.1749-6632.1992.tb33482.x

Schiller, N. G., \& Çağlar, A. (2009). Towards a Comparative Theory of Locality in Migration Studies: Migrant Incorporation and City Scale. Journal of Ethnic and Migration Studies,35(2), 177-202. doi:10.1080/13691830802586179

Schiller, N. G., \& Faist, T. (2012). Migration, development, and transnationalization: $a$ critical stance. New York: Berghahn Books.

Schmook, B., \& Radel, C. (2008). International Labor Migration from a Tropical Development Frontier: Globalizing Households and an Incipient Forest Transition. Hum Ecol Human Ecology, 36(6), 891-908. DOI: 10.1007/s10745-008-9207-0 Sequeira, J. M., Carr, J. C., \& Rasheed, A. A. (2009). Transnational Entrepreneurship: Determinants of Firm Type and Owner Attributions of Success. Entrepreneurship Theory and Practice,33(5), 1023-1044. doi:10.1111/j.1540-6520.2009.00333.x Smith, M.P., \& Guarnizo, L.E. (2003). Transnationalism from below (Vol. 6). New Brunswick: Transaction. 
Spoonley, P., Bedford, R., \& Macpherson, C. (2003). Divided loyalties and fractured sovereignty: Transnationalism and the nation-state in Aotearoa/New Zealand. Journal of Ethnic and Migration Studies,29(1), 27-46. doi:10.1080/1369183032000076704

Stewart, J. (2012). A Tale of Two Communities: Divergent Development and Embedded Brokerage in Postwar Guatemala. Journal of Contemporary Ethnography, 41(4), 402431. DOI: $10.1177 / 0891241612442215$

Streeck, Wolfgang, Schmitter, Philippe C. (1985), Community, Market, State - and Associations? The Prospective Contribution of Interest Governance to Social Order, in : European Sociological Review 1, no. 2 pp. 119-138.

Taylor, M. J., Moran-Taylor, M. J., Castellanos, E. J., \& Elías, S. (2011). Burning for Sustainability: Biomass Energy, International Migration, and the Move to Cleaner Fuels and Cookstoves in Guatemala. Annals of the Association of American Geographers, 101(4), 918-928. DOI: 10.1080/00045608.2011.568881

Tesch, R. (1990). Qualitative research: analysis types and software tools. New York: Falmer Press.

The Comparative Immigrant Entrepreneurship Project (CIEP). (n.d.). Retrieved April 10, 2017, from https://cmd.princeton.edu/publications/data-archives/ciep

The World Factbook: NICARAGUA. (2018, March 16). Retrieved March 28, 2018, from https://www.cia.gov/library/publications/the-world-factbook/geos/nu.html

U.S. Census Bureau (2000). 2000 Census Data. Retrieved from https://www.census.gov/2000census/data/.

U.S. Census Bureau (2010). 2010 Census Data. Retrieved from https://www.census.gov/2010census/data/.

U.S. Census Bureau (2012). Survey of Business Owners. Retrieved from https://www.census.gov/library/publications/2012/econ/2012-sbo.html

USCIS: Adjustment of Status. (n.d.). Retrieved April 04, 2018, from https://www.uscis.gov/greencard/adjustment-of-status

Üçok, M. (2011). Consumption practices of transmigrants: a multi-sited ethnographic study of Turkish immigrants in Denmark. Odense: University Press of Southern Denmark. 
Ujimoto, K. V., Bonacich, E., \& Modell, J. (1982). The Economic Basis of Ethnic Solidarity. Pacific Affairs,55(1), 169. doi:10.2307/2756952.

Verdaguer, M. E. (2009). Class, ethnicity, gender and Latino entrepreneurship. New York: Routledge.

Vertovec, S. (1999). Conceiving and researching transnationalism. Ethnic and Racial Studies, 22(2), 447-462. doi:10.1080/014198799329558

Visa Bulletin for December 2017. Retrieved December 02, 2017, from https://travel.state.gov/content/travel/en/legal/visa-law0/visa-bulletin/2018/visabulletin-for-december-2017.html

Waldinger, R. (2014). The politics of cross-border engagement: Mexican emigrants and the Mexican state. Theory and Society Theor Soc, 43(5), 483-511.1 DOI: 0.1007/s11186-014-9229-0

Waldinger, R. (1986). Through the Eye of the Needle: Immigrants and Enterprise in New York's Garments Trades. New York; New York . Press.

Walker, T. W., Nietschmann, B., Arguello, R., Parker, F. D., \& Orozco, M. S. (2017, November 23). Nicaragua. Retrieved March 28, 2018, from https://www.britannica.com /place/Nicaragua

Waters, M. C., \& Jiménez, T. R. (2005). Assessing Immigrant Assimilation: New Empirical and Theoretical Challenges. Annual Review of Sociology,31(1), 105-125. doi:10.1146/annurev.soc.29.010202.100026

Weeks, G., \& Weeks, J. (2013). Immigration and Transnationalism: Rethinking the Role of the State in Latin America. International Migration,53(5), 122-134. doi:10.1111/imig.12054

Weiss, R. S. (1994). Learning from strangers: the art and method of qualitative interview studies. New York: The Free Press.

Wilkinson, K. (1991). The community in rural America. New York: Greenwood Press.

Willson, M. A. (2006). Technically together: rethinking community within technosociety. New York: P. Lang.

Woldetensae, Y. (2007). Optimizing the African Brain Drain: Strategies for Mobilizing the Intellectual Diaspora towards Brain-Gain. Paper presented at the Conference of 
Rectors, Vice Chancellors and Presidents of African Universities (COREVIP) in Tripoli, Libya.

Wood, C. H. (1982). Equilibrium and Historical-Structural Perspectives on Migration. International Migration Review, 16(2), 298. Doi:10.2307/2545100

World Bank. Systems \& Remittances. (2016). Retrieved March 19, 2016, from http://www.worldbank.org/en/topic/paymentsystemsremittances

Xie, Y., \& Greenman, E. (n.d.). Segmented Assimilation Theory: A Reformulation and Empirical Test. Opulation Studies Center Research Report 05-581. Retrieved August, 2005.

Yin, R. K. (2009). Case study research: design and methods. Los Angeles: SAGE

Publications.

Zamora, R. G. (2005). Mexico: International Migration, Remittances and Development. The Development Dimension Migration, Remittances and Development, 81-87. 


\section{Appendix A}

\section{INTERVIEW GUIDE (Immigrant Entrepreneurs)}

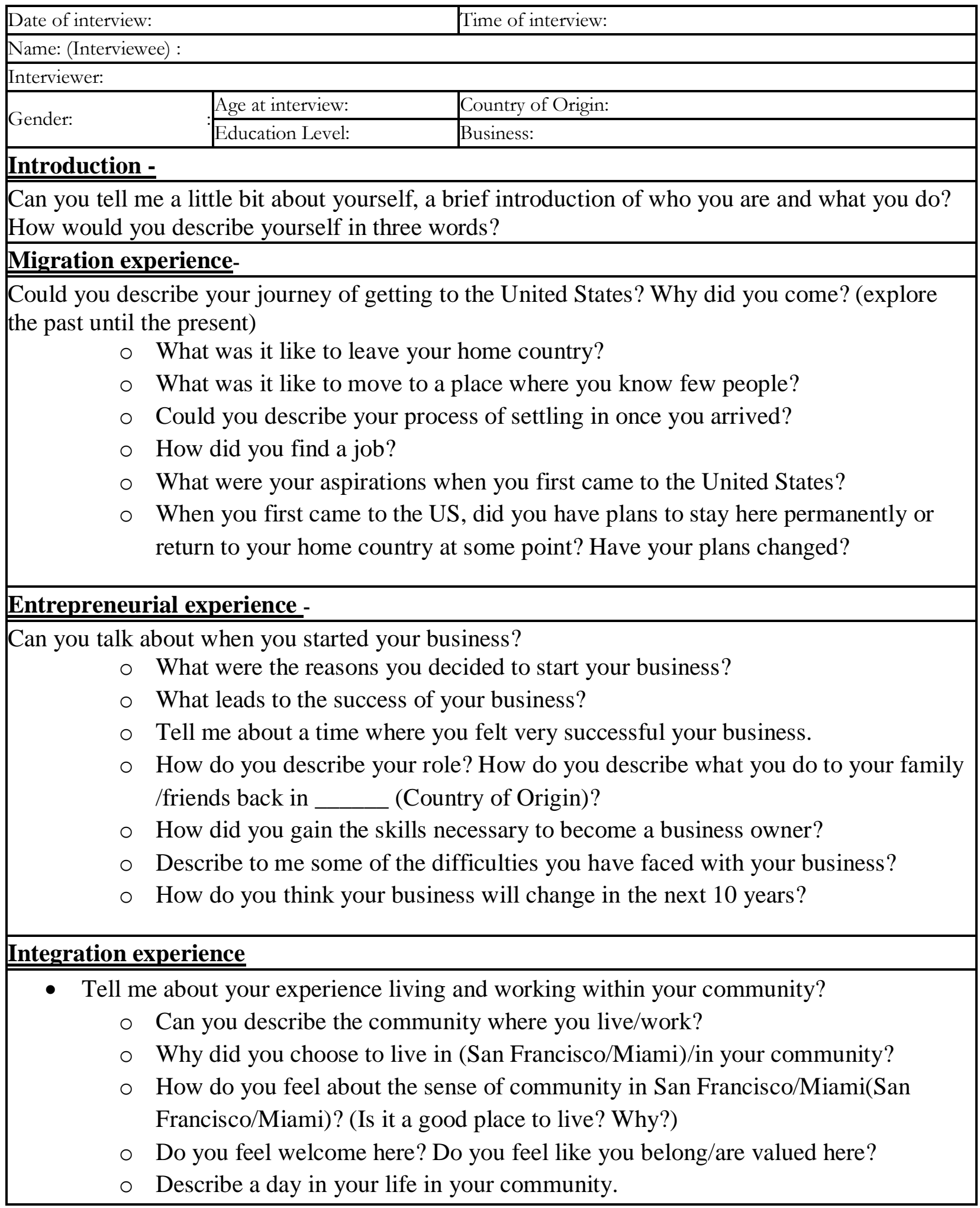




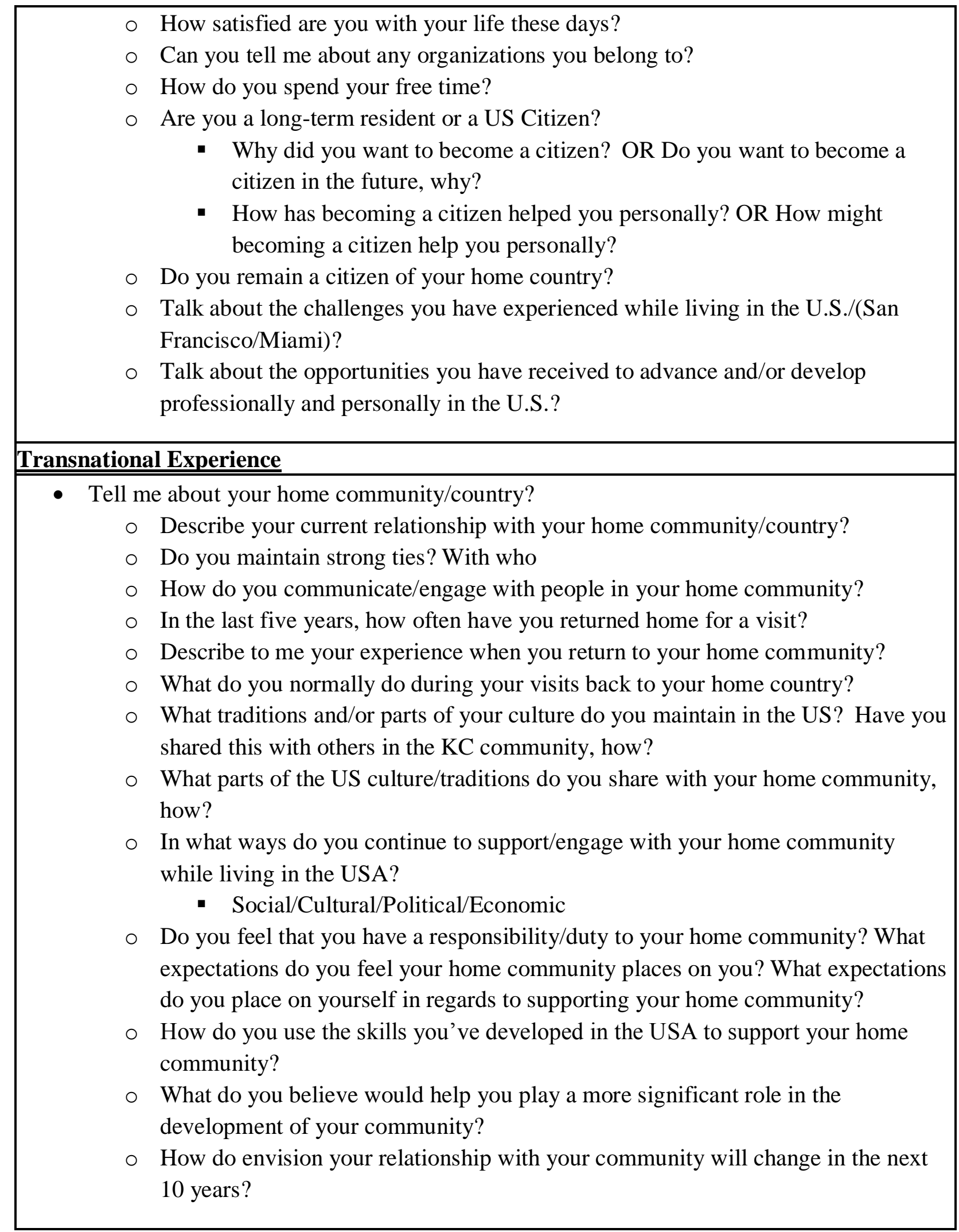




\section{Appendix B}

\section{INTERVIEW GUIDE (Community Leaders - Villa Sandino)}

\section{General Questions - Community Leaders}

- Tell me a little about Villa Sandino

- How would you describe your town to someone who has never been there?

- Tell me about a time you were proud of your community?

- What are the biggest opportunities/successes of this community?

- Tell me about a time you were disappointed in your community?

- What are some of the major struggles/challenges that your community faces?

- Tell me about the people in your community, what do they typically do for a living, why do they chose to stay in Villa Sandino?

- Tell me about yourself and your position within your community.

$\circ$ What type of community projects has your organization worked with in the years since you have been a part of it?

- In your memory, tell me about a couple of the most successful projects that have been initiated in Villa Sandino.

- Why do you think these projects were successful?

- Tell me about some of the project that have been less successful?

- Why do you think they were unsuccessful?

- What could have supported these projects to have been more successful?

- Tell me about the people that leave Villa Sandino.

$\circ$ Why do they leave?

- Where do they go?

- Do they maintain contact, how?

- Do they come back for visits or to live after they have left?

- How do people immigrating to the United States negatively affect Villa Sandino?

- How do people immigrating to the United States negatively affect Villa Sandino?

- Tell me specifically about the people that have immigrated to the United States.

- What is the perception of community members of individuals that have moved to the United States?

- Do they have maintained contact with their family members/friends

- Do they have maintained contact with the community (outside of their family)

- Do you know of any strategies or tactics that are used by community organizations to connect with residents living abroad?

- In what ways do you think people living in the United States could better support or contribute to the development of Villa Sandino? 


\section{Appendix C}

\section{Consent Form}

\section{CONSENT TO SERVE AS A SUBJECT IN RESEARCH}

Transnationalism and Latino Immigrant Entrepreneurs

\section{INTERVIEWS}

1. I agree to be a part of a research project directed by Andrea Tappmeyer, University of Missouri-Columbia.

2. I understand that:

a. I must be at least 18 years of age to participate.

b. My participation in this project is voluntary. I may withdraw from the process at any time without penalty and I do not have to answer any questions I don't want to.

c. The project is interested in knowing about my experience settling into my community, starting a business, and maintaining a relationship with my community and country of origin.

d. This will be my part in the research: I will participate in an interview with the project director, Andrea Tappmeyer. This interview will last around 60 minutes. If necessary, I may be asked to participate in a short follow-up interview at a later date.

e. These are the good things that I can get out of being a part of the study: My answers may help to identify things that can be done to improve the entrepreneurship skills of Latino business owners, their networks of support, and their ability to transfer positive resources back to their country/community of origin while also providing benefits to their receiving community.

f. My participation in this interview is subject to low risk of harm.

g. I understand that the interview will be tape recorded and transcribed, and that the following steps will be taken to protect my identity: (1) My name will not be mentioned on the tapes, nor will it appear in any of the transcriptions; (2) The tapes will be destroyed after transcription and analysis has been completed. Tapes and transcriptions will be kept in a locked file and no one except Andrea Tappmeyer will see them.

h. The results of this research may be published, but I will not be personally identified.

3. I have had a chance to ask any questions I have about the project. If I have any other questions, I can contact Andrea Tappmeyer (573/529-1859).

4. It is okay for Andrea Tappmeyer to tell others what they learned from this project but I will not be mentioned by name. The information will be presented in an anonymous manner.

You may contact the MU campus Institutional Review Board (IRB) office at 483 McReynolds Hall, Columbia, MO 65211, telephone: (573)882-9585. Project IRB \# is 2009113 


\section{Appendix E}

\section{Participant Themes}

\section{WALTER}

Lack of cultural connections leads to expanded social network Leveraging stability to create opportunity

Supporting individuals to foster financial sustainability

Focusing on interests,

Transition from informal to formal

\section{PATRICIA}

Integration into parallel culture

Familiarity as security

Familiarity as incubation

Cultural translation of resources and ideas.

\section{RACHEL}

Becoming engaged and finding community

Navigating two worlds

Problem-solving and development of an entrepreneurial spirit

Partnership to overcome weaknesses

'Out-of-the-box thinking'

\section{ROGELIO}

Delayed gratification and resilience

Ability to 'pivot' and adopt changes

Connecting through religion

Self-reliance above trust in others

Establishing relationships built on respect and quality

\section{ELIAS}

Change as growth

Legacy and family tradition

Connecting struggle with success

The importance of mentorship and guidance

Information as power

\section{CAMDEN}

Exploring individuality

Systematic evolution

Transparency and equity

Power and control

Diversity as an attribute 


\section{KRISTEN}

The role of structure and organization

Finding voice and communication

Creating value through personalization and differentiation

Establishing connections and strengthening linkages

\section{MOSES}

Managing expectations

Determination, perseverance and self-reliance

Expanding influence through relationship building

Functional capacity building through hands-on experience

Self-advocacy

\section{FABRICIO}

Gaining exposure through diverse connections

Focus on opportunity identification

Collaborative approach

Sustainable and diversified investing practices

Vision and foresight as strategies for personal realization

\section{ROSA}

Building on cultural capital

Faith and preparedness as complementary qualities

Shifting perspectives

Progress through a participatory and forward-looking approach Authenticity and value-based decision making 


\section{Appendix E}

\section{Grouped Themes Determinants/Strategies/Motivations/Conditions}

\begin{tabular}{|c|c|c|}
\hline & THEME & $\begin{array}{l}\text { SUB-THEMES FROM WITH-IN AND } \\
\text { CROSS CASE ANALSYES }\end{array}$ \\
\hline \multicolumn{3}{|l|}{ DETERMINANTS } \\
\hline \multirow[t]{2}{*}{ DEMOGRAPHIC } & AGE & $\begin{array}{l}\text { Agerange at time of immigration }-14-30 \\
\text { Age range at time of entrepreneurial } \\
\text { pursuit }-23-54 \\
\text { Age range at time of study }-27-62\end{array}$ \\
\hline & GENDER & $\begin{array}{l}4 \text { Female (all married) } \\
6 \text { Male (5 married, } 1 \text { single) }\end{array}$ \\
\hline \multirow[t]{4}{*}{ HUMAN CAPITAL } & EDUCATION & $\begin{array}{l}1 \text { - partial high-school } \\
3 \text { - high school diploma Nicaragua } \\
1 \text { - high school diploma U.S. } \\
3 \text { - College diploma - Nicaragua } \\
2 \text { - College diploma - United States }\end{array}$ \\
\hline & $\begin{array}{l}\text { TECHNICAL } \\
\text { ABILITY/PROFESSIONAL } \\
\text { ACUMEN }\end{array}$ & $\begin{array}{l}\text { Problem-solving and development of an } \\
\text { entrepreneurial spirit }\end{array}$ \\
\hline & & $\begin{array}{l}\text { Functional capacity building through } \\
\text { hands-on experience }\end{array}$ \\
\hline & & $\begin{array}{l}\text { Progress through a participatory and } \\
\text { forward-looking approach }\end{array}$ \\
\hline \multirow[t]{12}{*}{ ASSIMILATION } & IMMIGRATION STATUS & $\begin{array}{l}\text { At time of study - } 10 \text { had legal status } \\
\text { At time of initial immigration - } \\
\text { 1- refugee } \\
6 \text { - family based adjustment of status } \\
3 \text { - overstayed tourist visa } \\
\quad \text { (undocumented, no legal status) }\end{array}$ \\
\hline & & Leveraging stability to create opportunity \\
\hline & & Family based immigration \\
\hline & & $\begin{array}{l}\text { Diverse range of age and travel history at } \\
\text { time of migration }\end{array}$ \\
\hline & $\begin{array}{l}\text { LENGTH OF STAY IN THE } \\
\text { US }\end{array}$ & Leveraging stability to create opportunity \\
\hline & & Becoming engaged and finding community \\
\hline & & Secondary Migration \\
\hline & $\begin{array}{l}\text { CONTEXT OF } \\
\text { INCORPORATION }\end{array}$ & $\begin{array}{l}\text { Lack of cultural connections leads to } \\
\text { expanded social network }\end{array}$ \\
\hline & & Integration into parallel culture \\
\hline & & Becoming engaged and finding community \\
\hline & & Navigating two worlds \\
\hline & & Establishing relationships built on respect \\
\hline
\end{tabular}




\begin{tabular}{|c|c|c|}
\hline & & and quality \\
\hline & & Diversity as an attribute \\
\hline & & $\begin{array}{l}\text { Diverse range of age and travel history at } \\
\text { time of migration }\end{array}$ \\
\hline & & $\begin{array}{l}\text { Reliance on family and religion for initial } \\
\text { integration }\end{array}$ \\
\hline & & Secondary Migration \\
\hline & & $\begin{array}{l}\text { Perceptions of Discrimination and } \\
\text { Community Inclusion }\end{array}$ \\
\hline & & Space (Physical and Personal) \\
\hline & $\begin{array}{l}\text { SOCIAL CAPITAL } \\
\text { (size and scope) }\end{array}$ & $\begin{array}{l}\text { Expanding influence through relationship } \\
\text { building }\end{array}$ \\
\hline & & Building on cultural capital \\
\hline & & $\begin{array}{l}\text { Gaining exposure through diverse } \\
\text { connections }\end{array}$ \\
\hline & & Diversity as an attribute \\
\hline \multicolumn{3}{|l|}{ MOTIVATIONS } \\
\hline & $\begin{array}{l}\text { RESPECT \& } \\
\text { RESPONSIBILITY }\end{array}$ & $\begin{array}{l}\text { Establishing relationships built on respect } \\
\text { and quality }\end{array}$ \\
\hline & & $\begin{array}{l}\text { Authenticity and value-based decision } \\
\text { making }\end{array}$ \\
\hline & & Household Remittances \\
\hline & & $\begin{array}{l}\text { Community needs and individual } \\
\text { investments }\end{array}$ \\
\hline & $\begin{array}{l}\text { APPRECIATION \& } \\
\text { GRATITUDE }\end{array}$ & Legacy and family tradition \\
\hline & & Frequent Communication \\
\hline & & Household Remittances \\
\hline & PRIDE & $\begin{array}{l}\text { Establishing relationships built on respect } \\
\text { and quality }\end{array}$ \\
\hline & & Legacy and family tradition \\
\hline & & $\begin{array}{l}\text { Expanding influence through relationship } \\
\text { building }\end{array}$ \\
\hline & $\begin{array}{l}\text { BELONGING \& } \\
\text { CONNECTEDNESS }\end{array}$ & Navigating two worlds \\
\hline & & Legacy and family tradition \\
\hline & & Connecting through religion \\
\hline & & Finding voice and communication \\
\hline & & $\begin{array}{l}\text { Establishing connections and } \\
\text { strengthening linkages }\end{array}$ \\
\hline
\end{tabular}




\begin{tabular}{|c|c|c|}
\hline & & Collaborative approach \\
\hline & & Frequent Communication \\
\hline & & Return Trips \\
\hline & FREEDOM \& FLEXIBILITY & Emergent Independence and Autonomy \\
\hline & & Return Trips \\
\hline & & Exploring individuality \\
\hline & $\begin{array}{l}\text { RETURN MIGRATION } \\
\text { ASPIRATIONS }\end{array}$ & $\begin{array}{l}\text { Sustainable and diversified investing } \\
\text { practices }\end{array}$ \\
\hline & & Return Trips \\
\hline & & $\begin{array}{l}\text { Vision and foresight as strategies for } \\
\text { personal realization }\end{array}$ \\
\hline & $\begin{array}{l}\text { IDENTIFICATION OF } \\
\text { OPPORTUNITY GAPS }\end{array}$ & Focusing on interests \\
\hline & & Systematic evolution \\
\hline & & 'Out-of-the-box thinking' \\
\hline & & Familiarity as incubation \\
\hline & $\begin{array}{l}\text { OPPORTUNITY VS. } \\
\text { NECESSITY DRIVEN }\end{array}$ & Change as growth \\
\hline & & $\begin{array}{l}\text { Creating value through personalization } \\
\text { and differentiation }\end{array}$ \\
\hline & & Focus on opportunity identification \\
\hline & & $\begin{array}{l}\text { Vision and foresight as strategies for } \\
\text { personal realization }\end{array}$ \\
\hline & & $\begin{array}{l}\text { Complex Blend of Opportunity and } \\
\text { Necessity Driven Motives }\end{array}$ \\
\hline \multirow[t]{13}{*}{ STRATEGIES } & $\begin{array}{l}\text { INVESTMENT IN } \\
\text { INDIVIDUALS }\end{array}$ & $\begin{array}{l}\text { Supporting individuals to foster financial } \\
\text { sustainability }\end{array}$ \\
\hline & & $\begin{array}{l}\text { Establishing relationships built on respect } \\
\text { and quality }\end{array}$ \\
\hline & & Transparency and equity \\
\hline & & Power and control \\
\hline & & $\begin{array}{l}\text { Creating value through personalization } \\
\text { and differentiation }\end{array}$ \\
\hline & & $\begin{array}{l}\text { Functional capacity building through } \\
\text { hands-on experience }\end{array}$ \\
\hline & & Self-advocacy \\
\hline & & $\begin{array}{l}\text { Vision and foresight as strategies for } \\
\text { personal realization }\end{array}$ \\
\hline & & $\begin{array}{l}\text { Community needs and individual } \\
\text { investments }\end{array}$ \\
\hline & KNOWLEDGE TRANSFERS & $\begin{array}{l}\text { Cultural translation of resources and } \\
\text { ideas }\end{array}$ \\
\hline & & Change as growth \\
\hline & & $\begin{array}{l}\text { The importance of mentorship and } \\
\text { guidance }\end{array}$ \\
\hline & & Information as power \\
\hline
\end{tabular}




\begin{tabular}{|c|c|c|}
\hline & & Power and control \\
\hline & & $\begin{array}{l}\text { Creating value through personalization } \\
\text { and differentiation }\end{array}$ \\
\hline & & $\begin{array}{l}\text { Functional capacity building through } \\
\text { hands-on experience }\end{array}$ \\
\hline & & Shifting perspectives \\
\hline & & Knowledge Bridges \\
\hline & $\begin{array}{l}\text { RELIGIOUS BASED } \\
\text { INVOLVEMENT }\end{array}$ & Connecting through religion \\
\hline & & $\begin{array}{l}\text { Faith and preparedness as complementary } \\
\text { qualities }\end{array}$ \\
\hline & & $\begin{array}{l}\text { Reliance on family and religion for initial } \\
\text { integration }\end{array}$ \\
\hline & & $\begin{array}{l}\text { Community needs and individual } \\
\text { investments }\end{array}$ \\
\hline & & $\begin{array}{l}\text { Connecting Resources at the Community } \\
\text { Level }\end{array}$ \\
\hline & LINKING INSTITUTIONS & $\begin{array}{l}\text { Establishing connections and } \\
\text { strengthening linkages }\end{array}$ \\
\hline & & $\begin{array}{l}\text { Progress through a participatory and } \\
\text { forward-looking approach }\end{array}$ \\
\hline & & $\begin{array}{l}\text { Connecting Resources at the Community } \\
\text { Level }\end{array}$ \\
\hline & RETURN TRIPS & Shifting perspectives \\
\hline & & Return Trips \\
\hline & & Partnership to overcome weaknesses \\
\hline & $\begin{array}{l}\text { CONNECTING THROUGH } \\
\text { TECHNOLOGY }\end{array}$ & Information as power \\
\hline & & Finding voice and communication \\
\hline & & Shifting perspectives \\
\hline & & Household Remittances \\
\hline & & Frequent Communication \\
\hline & ADAPTABLE PLANNING & Transition from informal to formal \\
\hline & & $\begin{array}{l}\text { Problem-solving and development of an } \\
\text { entrepreneurial spirit }\end{array}$ \\
\hline & & Ability to 'pivot' and adopt changes \\
\hline & & Systematic evolution \\
\hline & & $\begin{array}{l}\text { Vision and foresight as strategies for } \\
\text { personal realization }\end{array}$ \\
\hline & & $\begin{array}{l}\text { Faith and preparedness as complementary } \\
\text { qualities }\end{array}$ \\
\hline & & Shifting perspectives \\
\hline & & $\begin{array}{l}\text { Progress through a participatory and } \\
\text { forward-looking approach }\end{array}$ \\
\hline & & $\begin{array}{l}\text { Vision and foresight as strategies for } \\
\text { personal realization }\end{array}$ \\
\hline
\end{tabular}




\begin{tabular}{|c|c|c|}
\hline & & Delayed gratification and resilience \\
\hline & & Slow Growth \\
\hline & $\begin{array}{l}\text { REPLICATION/CULTURAL } \\
\text { TRANSLATION }\end{array}$ & $\begin{array}{l}\text { Cultural translation of resources and } \\
\text { ideas. }\end{array}$ \\
\hline & & Information as power \\
\hline & & $\begin{array}{l}\text { Functional capacity building through } \\
\text { hands-on experience }\end{array}$ \\
\hline & & Focus on Informal Training and Guidance \\
\hline \multicolumn{3}{|l|}{ CONDITIONS } \\
\hline & TRUSTED INSTITUTIONS & Language Acquisition \\
\hline & & Focus on Informal Training and Guidance \\
\hline & & Familiarity as security \\
\hline & & Familiarity as incubation \\
\hline & & Partnership to overcome weaknesses \\
\hline & & Focus on employment \\
\hline & & Technical Skill Development \\
\hline & IMMIGRATION CLIMATE & Family based immigration \\
\hline & & Familiarity as security \\
\hline & & The role of structure and organization \\
\hline & $\begin{array}{l}\text { ADVANCEMENT AND } \\
\text { ACCESS TO TECHNOLOGY }\end{array}$ & Information as power \\
\hline & & Finding voice and communication \\
\hline & & Shifting perspectives \\
\hline & & Frequent Communication \\
\hline & & Household Remittances \\
\hline & $\begin{array}{l}\text { STRUCTURES OF } \\
\text { ACKNOWLEDGEMENT }\end{array}$ & Connecting struggle with success \\
\hline & & The role of structure and organization \\
\hline & & Self-advocacy \\
\hline & & $\begin{array}{l}\text { Vision and foresight as strategies for } \\
\text { personal realization }\end{array}$ \\
\hline & $\begin{array}{l}\text { ACCESS TO FINANCIAL } \\
\text { CAPITAL }\end{array}$ & $\begin{array}{l}\text { Sustainable and diversified investing } \\
\text { practices }\end{array}$ \\
\hline & & Reliance on Personal Financial Capital \\
\hline & & Slow Growth \\
\hline & & Managing expectations \\
\hline & & Partnership to overcome weaknesses \\
\hline
\end{tabular}




\section{VITA}

Andrea Marie Tappmeyer was born December 26, 1981, in Maryville, MO, to Steve and Lynette Tappmeyer. She received a Bachelor of Science in Business Administration from the University of Missouri in 2004. Andrea served as a Small Business Development Peace Corps Volunteer in Villa, Sandino, Nicaragua from 20082010. In 2010, she married Yasser Talavera Silwany. She continued with a career in public service as a member of AmeriCorps at the International Institute of St. Louis, where she assisted with refugee resettlement and immigrant integration from 2010-2011. Andrea obtained a Master's of Public Administration from the Monterey Institute of International Studies (MIIS) in August of 2013. While attending MIIS, she was awarded a Boren Fellowship, allowing her to study Bahasa Indonesia and work with Mercy Corps on entrepreneurial development projects in Ambon, Indonesia. Andrea began a career with the United States Citizenship and Immigration Services (USCIS) in 2014. While working full-time, she began part-time doctoral studies in Rural Sociology, with an emphasis in Sustainable Development, at the University of Missouri-Columbia. Her daughter, Sasha Talavera was born in January of 2018. She completed her Ph.D. in Rural Sociology in 2018. Her research emphasis has focused on the nexus of immigration and development. Andrea continues to work as an Immigration Services Officer with USCIS in Lee's Summit, MO. 